University of Louisville

ThinkIR: The University of Louisville's Institutional Repository

$12-2011$

\title{
An exploration of factors affecting participation in U.S. health information exchange networks : a dual network participation theory based case study.
}

Judah Thornewill 1961-

University of Louisville

Follow this and additional works at: https://ir.library.louisville.edu/etd

\section{Recommended Citation}

Thornewill, Judah 1961-, "An exploration of factors affecting participation in U.S. health information exchange networks : a dual network participation theory based case study." (2011). Electronic Theses and Dissertations. Paper 1441.

https://doi.org/10.18297/etd/1441

This Doctoral Dissertation is brought to you for free and open access by ThinkIR: The University of Louisville's Institutional Repository. It has been accepted for inclusion in Electronic Theses and Dissertations by an authorized administrator of ThinkIR: The University of Louisville's Institutional Repository. This title appears here courtesy of the author, who has retained all other copyrights. For more information, please contact thinkir@louisville.edu. 


\title{
AN EXPLORATION OF FACTORS AFFECTING PARTICIPATION IN \\ U.S. HEALTH INFORMATION EXCHANGE NETWORKS \\ A DUAL NETWORK PARTICIPATION THEORY BASED CASE STUDY
}

\author{
By
}

Judah Thornewill

\begin{abstract}
A Dissertation
Submitted to the Faculty of the

School of Interdisciplinary and Graduate Studies of the University of Louisville In Partial Fulfillment of the Requirements

For the Degree of
\end{abstract}

Doctor of Philosophy

College of Arts and Sciences

Department of Sociology

College of Business Administration

Department of Computer Information Systems

School of Public Health and Information Sciences

Department of Health Management and Systems Sciences

Louisville, Kentucky

December 2011 
(C) 2011 by Judah Thornewill

All rights reserved 
AN EXPLORATION OF FACTORS AFFECTING PARTICIPATION IN U.S. HEALTH INFORMATION EXCHANGE NETWORKS

A DUAL NETWORK PARTICIPATION THEORY BASED CASE STUDY

By

Judah Thornewill

A Dissertation Approved on

December 5, 2011

By the following Dissertation Committee:

\begin{tabular}{|c|}
\hline $\begin{array}{l}\text { Brian Dos Santos, } \mathrm{PhD} \\
\text { Dissertation Director }\end{array}$ \\
\hline John yers, $\mathrm{PhD}$ \\
\hline James Taylor, DMan \\
\hline
\end{tabular}

Allen Whitt, PhD

Richard Wilson, DHSc 


\section{DEDICATION}

This dissertation is dedicated to my wife Araby and our children Ben and Alice 


\section{ACKNOWLEDGEMENTS}

I would like to thank my committee chair Dr. Brian Dos Santos, PhD and my committee members, Allen Whitt, PhD, James Taylor, DMan, Richard Wilson, DHSc and John Myers, PhD for invaluable guidance and support throughout the dissertation process. In addition, special thanks to Jeff Potash, $\mathrm{PhD}$ for important pre-dissertation support and to Robert Esterhay, MD for his many hours of work reviewing and interpreting the data with me in the Spring and Summer 2011. Last, but certainly not least, thanks to my family and friends for ongoing support and enthusiasm during the research and writing process. 


\begin{abstract}
An Exploration of Factors Affecting Participation in

U.S. Health Information Exchange Networks
\end{abstract}

Judah Thornewill

December 16, 2011

Background: Failure to achieve their goals of over 200 U.S. Health Information Exchange Networks (HIENs) which formed or operated in the U.S. from 2004 to 2010, lost time, capital and opportunity at individual, organizational and societal levels, and a lack of theory driven research on HIENs underscores a need for research to better understand factors affecting development of these kinds of large, complex collaborations.

Purpose: A new dual network participation theory is developed by combining three source theories. The new theory supports integrated consideration of organizational and technological factors which affect participation by individuals and their affiliated organizations in complex collaborations like HIENs. Research questions are formulated focused on advancing knowledge about: types of participation in HIENs; validity of variables used to operationalize the theory; barriers and enablers to participation in HIENs; and implications for theory and research.

Method: A retrospective, theory-driven, multi-level, multi-case, mixed methods case study is done using a convenience sample of 6 HIEN sites (network level), 109 individuals (individual level) and 125 organizations (organizational level). Qualitative data is analyzed to develop valid ordinal variables and test hypotheses for each case. Valid ordinal variables are entered into SPSS. A principle component analysis is done to create combined predictor variables. An OLS regression analysis supports identification 
of predictor effects on intent to participate. Network level analyses identify key influences on the predictors.

Findings: Network level barriers to participation include heterogeneity of participants, lack of HIEN resources, lack of qualified leadership, lack of training and education and lack of stable Network IT. Individual/organizational level barriers include lack of support from influential others, low benefit expectancy, lack of knowledge, and high cost expectancy. Recommendations are made for future research studies with enough statistical power for hypothesis testing across larger populations of sites/participants (e.g., 100-300 sites; 1,000 - 3,000 participants).

Conclusions: While the use of a small, non-random sample of sites/subjects implies caution regarding generalization, the research yields new insights with implications for both practice and theory. These include preliminary recommendations for improving the success of HIENs and new opportunities for research on barriers and enablers of participation in large scale collaborations. 


\section{TABLE OF CONTENTS}

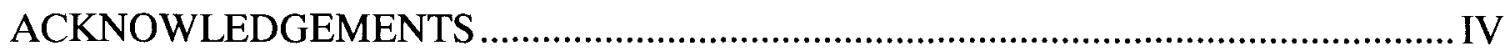

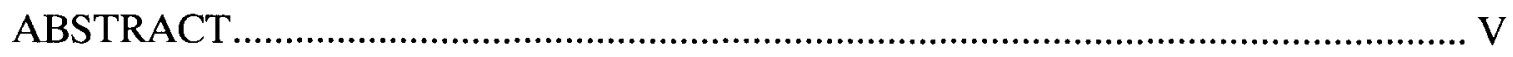

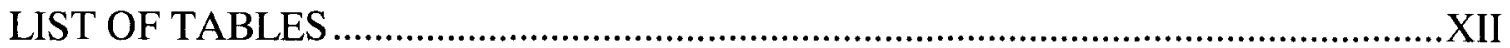

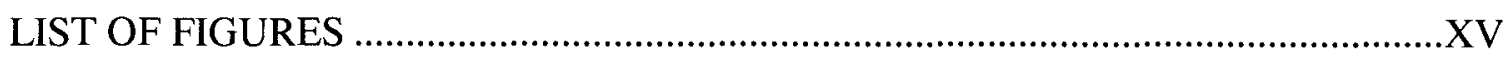

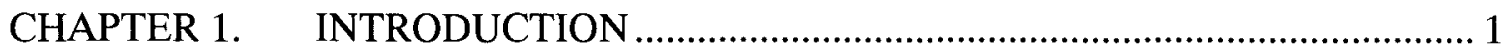

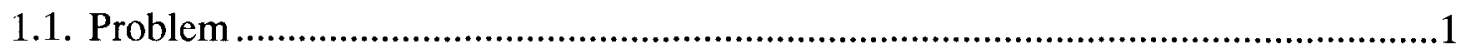

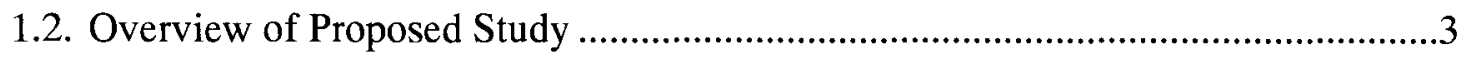

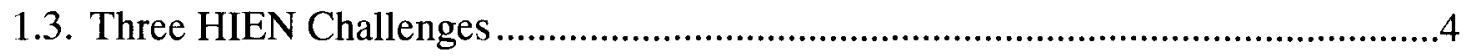

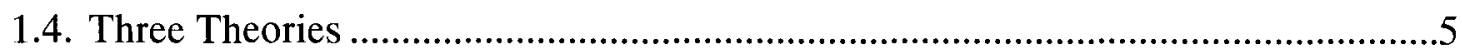

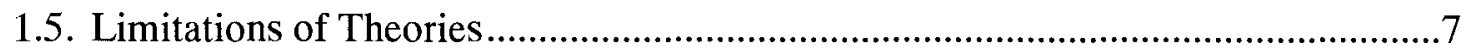

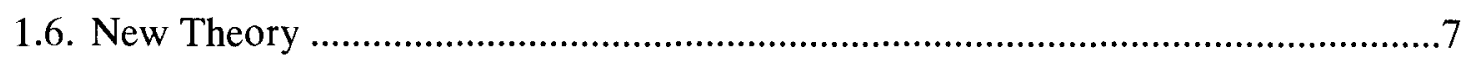

1.6.1. Operationalizing the DNTP: Variables and Hypotheses ..................................9

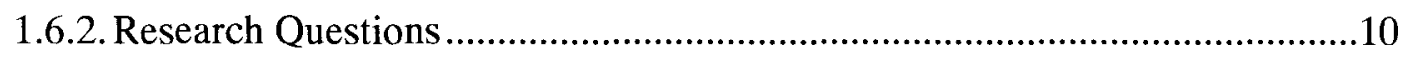

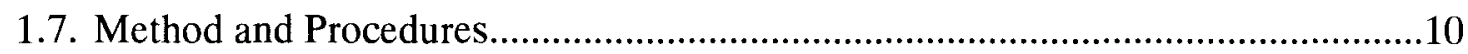

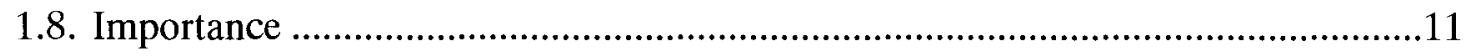

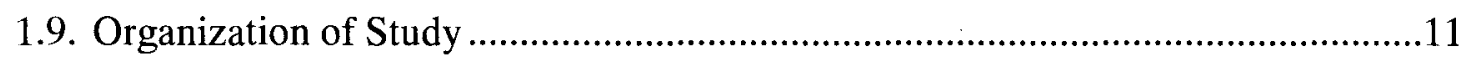

CHAPTER 2. LITERATURE REVIEW …………….......................................... 13

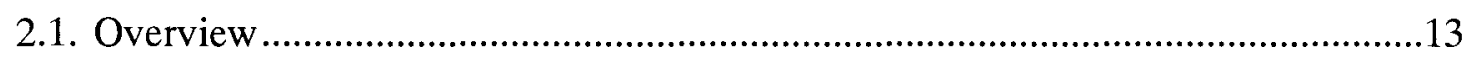

2.2. HIEN Characteristics and Challenges...............................................................13

2.2.1. Definitions of HIENs .................................................................................13 


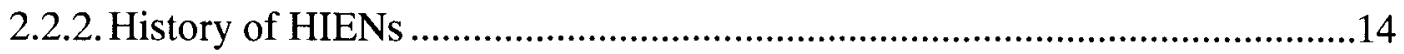

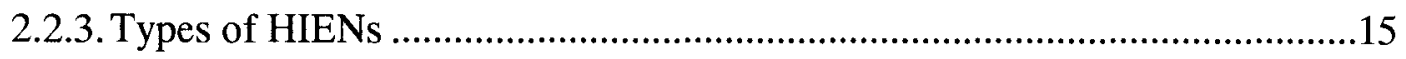

2.2.4. HIEN Ubiquity Requirement ......................................................................17

2.2.5. HIEN Innovation Efforts.............................................................................17

2.2.6. Three HIEN Challenges ........................................................................18

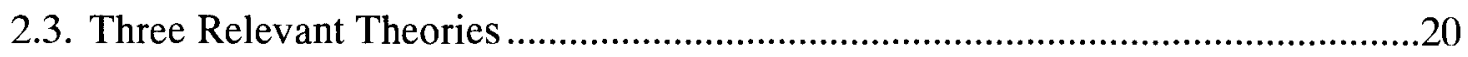

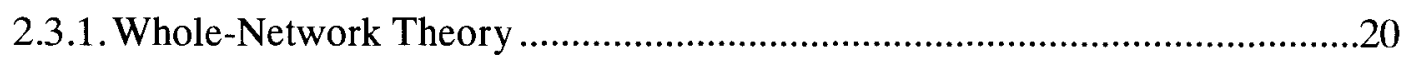

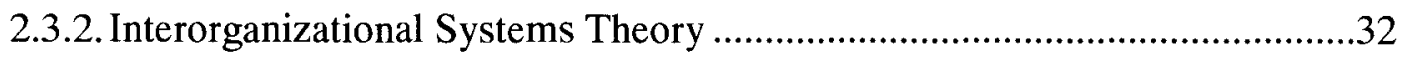

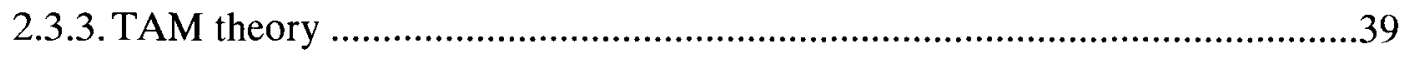

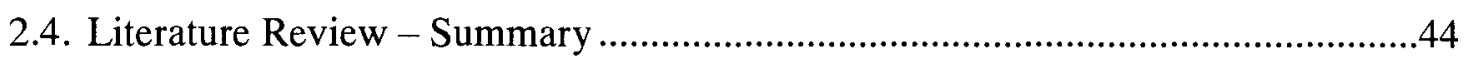

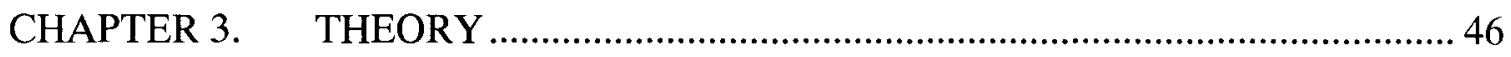

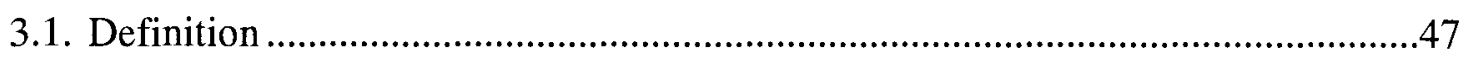

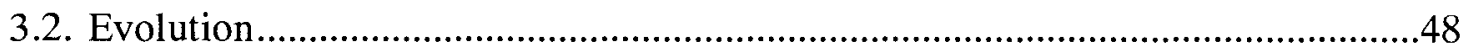

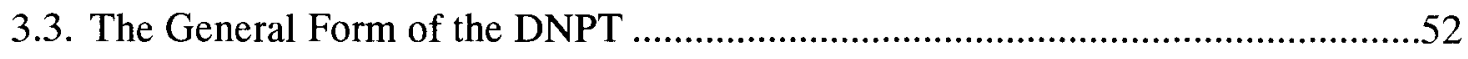

3.4. Operationalizing the Theory (Elements, Interactions and Hypotheses) ……........55

3.4.1. Set 1. Actual Participation ...........................................................................56

3.4.2. Set 2. Intent to Participate ..........................................................................5

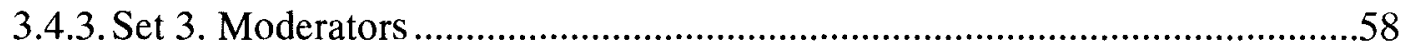

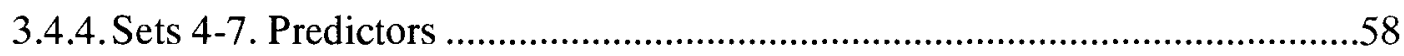

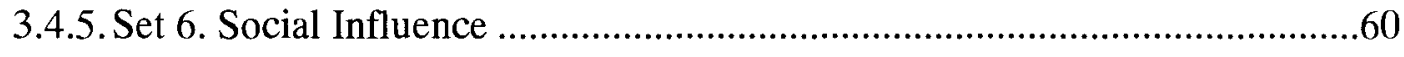

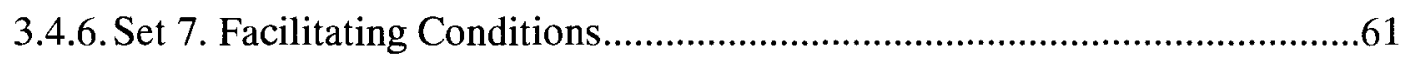

3.4.7. Sets 8-9. Dual Network Attributes................................................................61

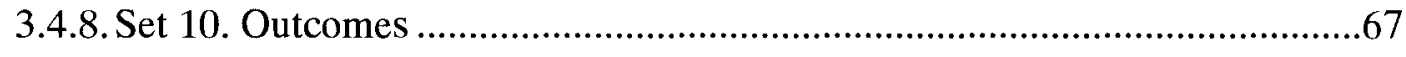




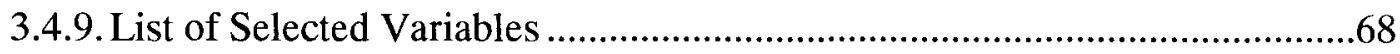

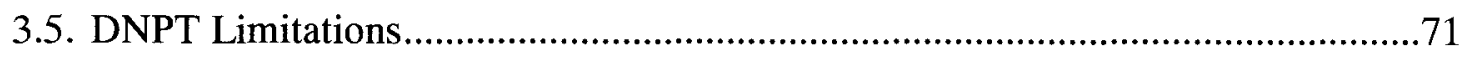

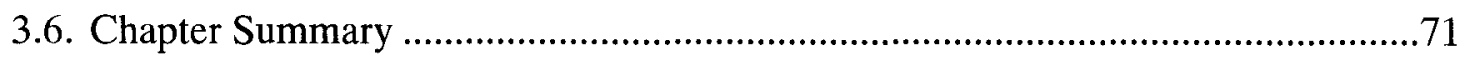

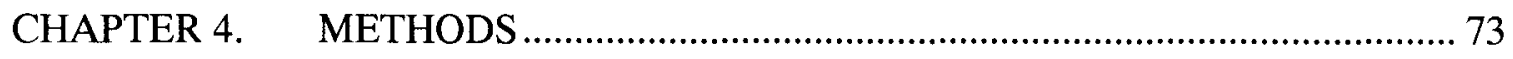

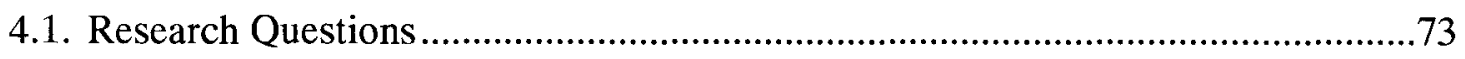

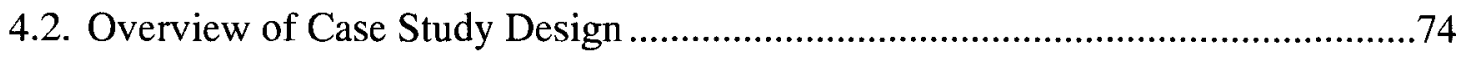

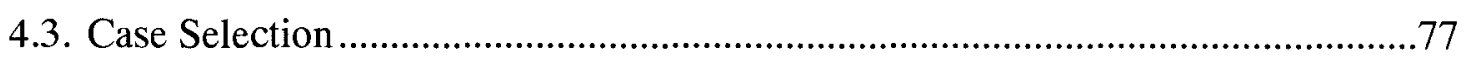

4.4. Document Selection, Assembly and Review ........................................................78

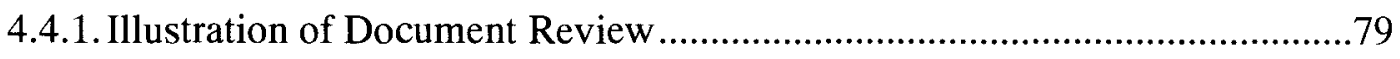

4.5. Use of Theory to Develop Variables and Hypotheses .............................................80

4.6. Instrument Development and Completion ...........................................................

4.6.1. Instrument 1: Participation Opportunity Types ...............................................85

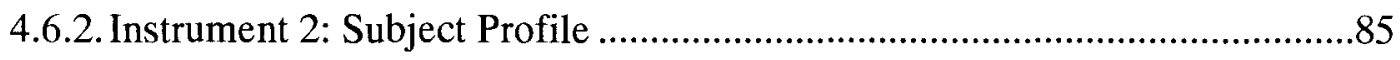

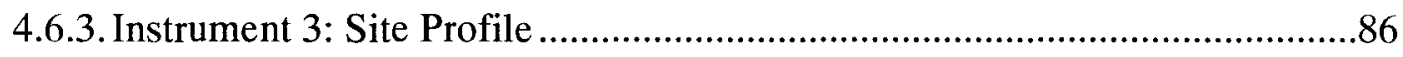

4.7. Assembling Supporting and Refuting Evidence and Alternate Explanations .......86

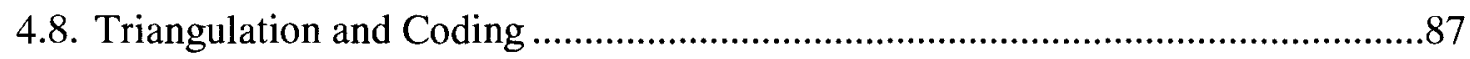

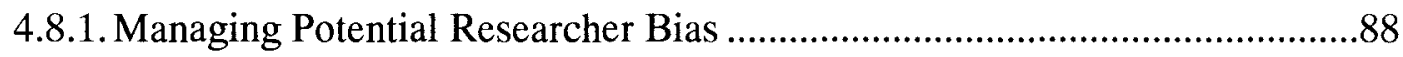

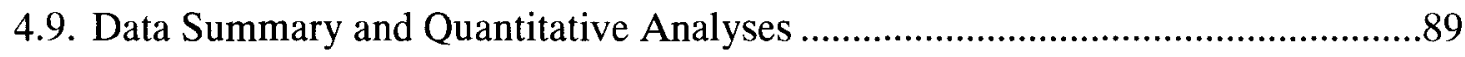

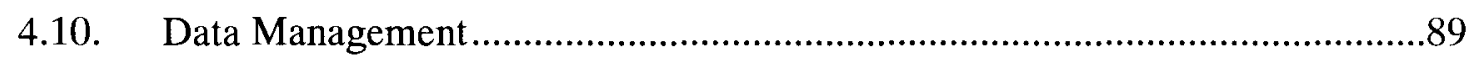

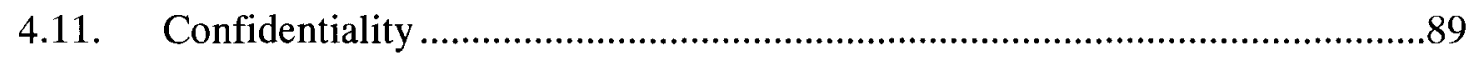

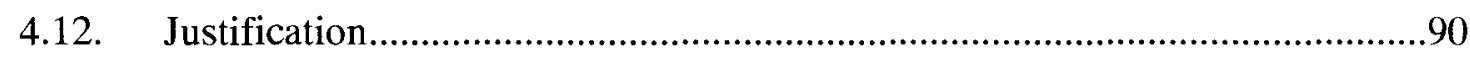

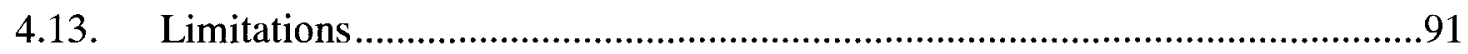

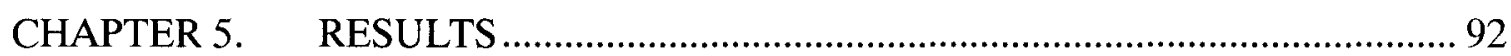




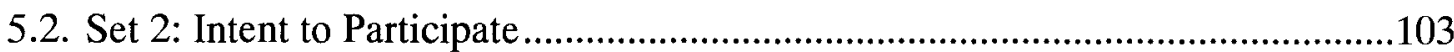

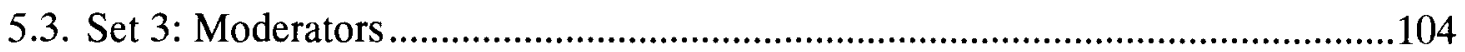

5.4. Set 4: Predictor Variables - Benefit Expectancy .............................................113

5.5. Set 5: Predictor Variables -Cost Expectancy ...............................................117

5.6. Set 6: Predictor Variables - Social Influence ................................................122

5.7. Set 7: Predictor Variables - Facilitating Conditions.......................................123

5.8. Principal Component Analysis of Predictors ..............................................128

5.9. OLS Regression of Predictors on Intent to Participate ...................................131

5.10. Set 8: Whole-Network Attributes ...................................................132

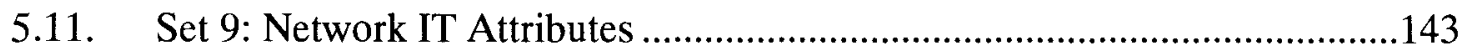

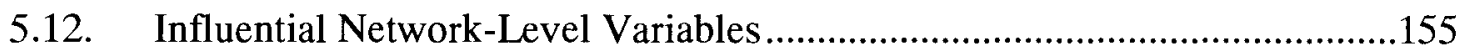

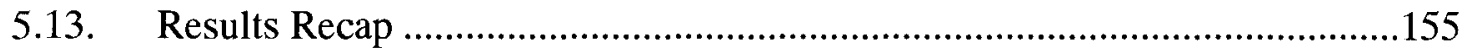

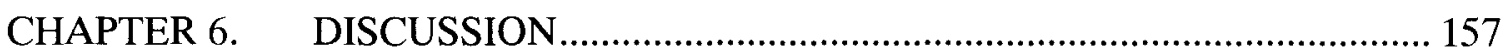

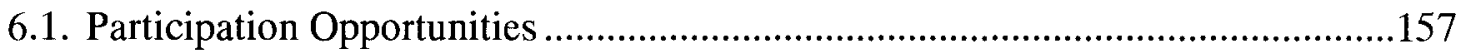

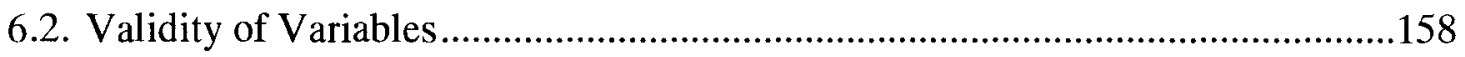

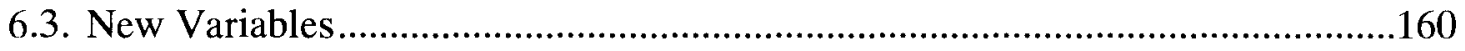

6.4. Barriers and Enablers of Participation in HIENs ..............................................160

6.4.1. How Do Moderators Influence Intent to Participate? ................................160

6.4.2. How Do Predictors Affect Intent to Participate in the HIENs? ...................163

6.4.3. How Do Dual Network Attributes Affect Predictors?................................164

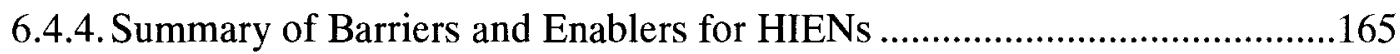

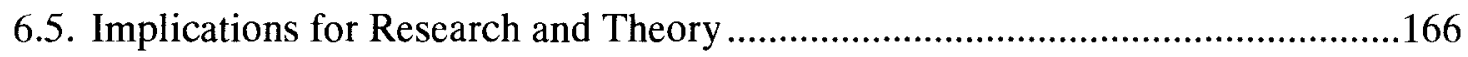


6.5.1. Revised Terminology and Concepts .............................................................167

6.5.2. Research Participation Opportunity Typology …………………..................169

6.5.3. Refine and Validate Variables .................................................................170

6.5.4. Test the Theory Using Larger Sample Sizes................................................170

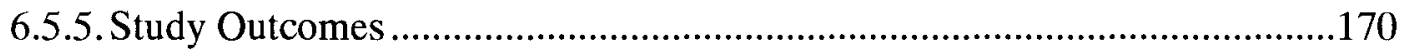

6.5.6. Summary of Implications for Theory and Research ....................................171

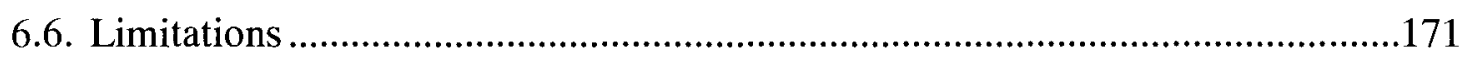

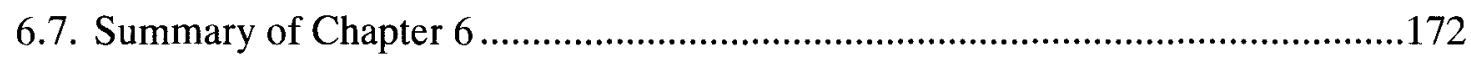

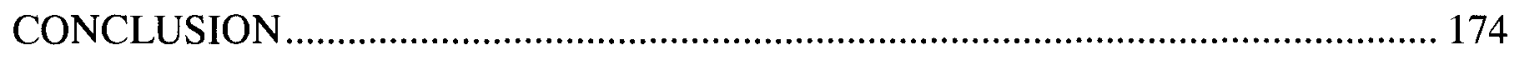

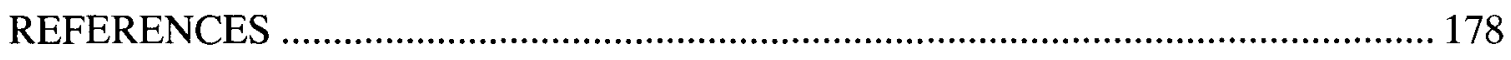

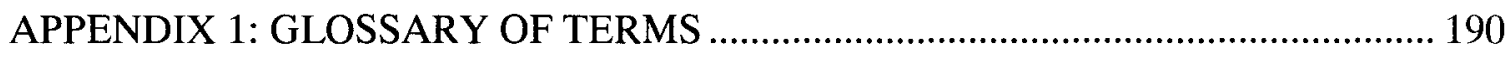

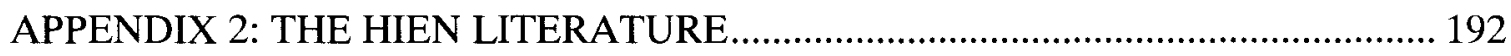

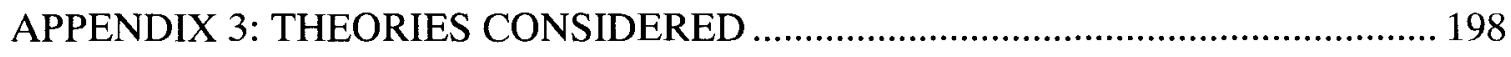

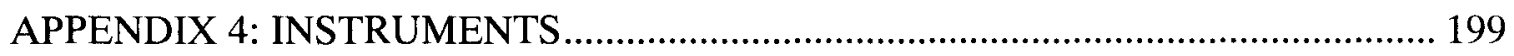

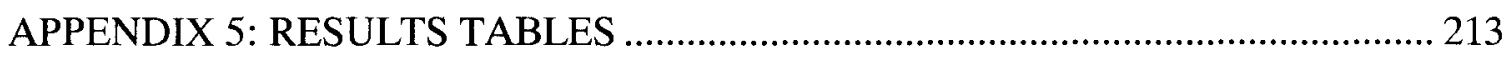

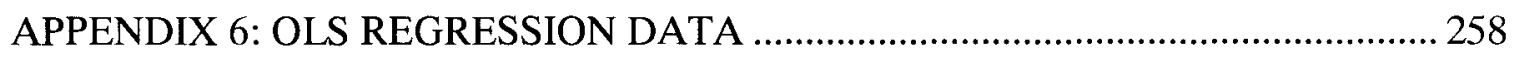

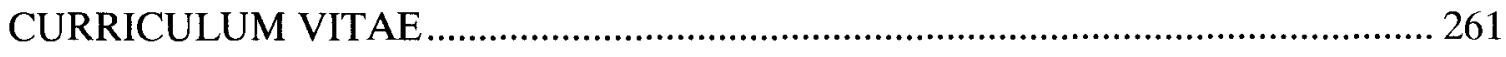




\section{LIST OF TABLES}

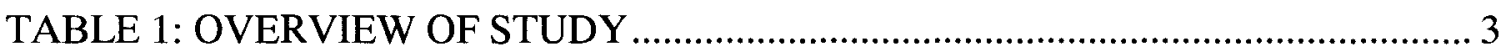

TABLE 2: WHOLE-NETWORK THEORY STRENGTHS AND LIMITATIONS ....... 31

TABLE 3: IOS THEORY STRENGTHS AND LIMITATIONS …............................. 38

TABLE 4: IOS THEORY STRENGTHS AND LIMITATIONS ............................... 44

TABLE 5. SUMMARY OF LITERATURE REVIEW FINDINGS .......................... 45

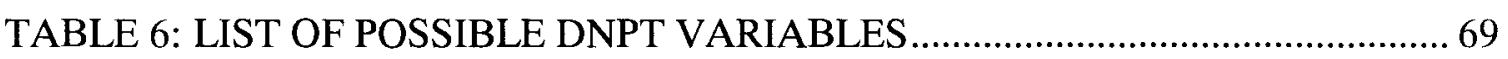

TABLE 7. SITES, INDIVIDUALS, ORGANIZATIONS AND DATA INCLUDED IN

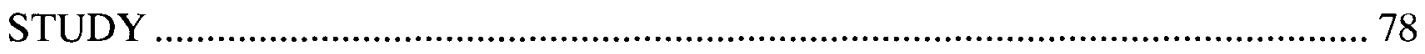

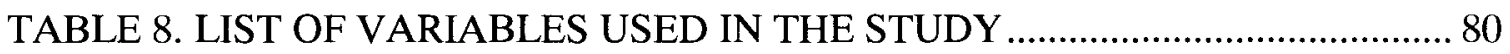

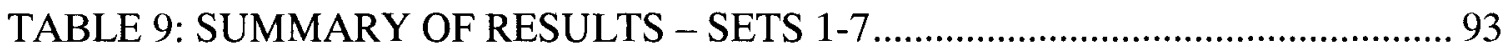

TABLE 10: SUMMARY OF RESULTS - SETS 8-9 ........................................... 96

TABLE 11: SET 1: ACTUAL PARTICIPATION OPPORTUNITY TYPES - NON-

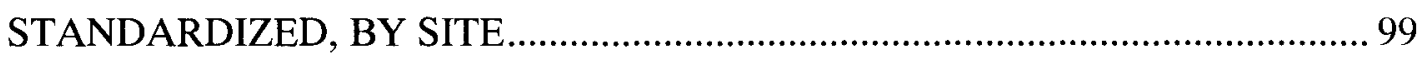

TABLE 12: SET 1: ACTUAL PARTICIPATION OPPORTUNITY TYPES -

STANDARDIZED AND RANKED ….................................................. 102

TABLE 13: ROTATED COMPONENT SCORES: BENEFIT EXPECTANCY .......... 129

TABLE 14: ROTATED COMPONENT SCORES: LOW COST EXPECTANCY ...... 129

TABLE 15: ROTATED COMPONENT SCORES: FACILITATING CONDITIONS 130

TABLE 16: SUMMARY OF REGRESSION OF COMBINED PREDICTORS ON

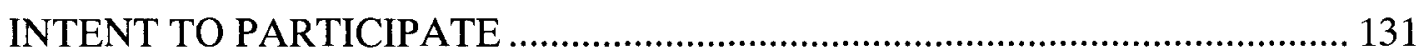


TABLE 17: BARRIERS AND ENABLERS OF PARTICIPATION IN HIENS

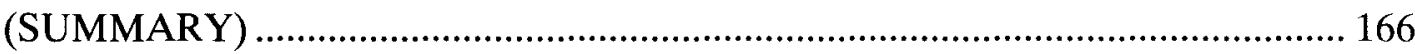

TABLE 18: SUMMARY OF IMPLICATIONS FOR THEORY AND RESEARCH ... 171

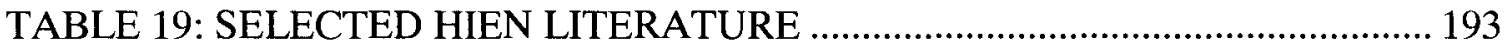

TABLE 20: PARTIAL LIST OF THEORIES CONSIDERED FOR HIEN RESEARCH

TABLE 21: INSTRUMENT 2: SUBJECT PROFILE................................................. 203

TABLE 22: SET 1: ACTUAL PARTICIPATION OPPORTUNITY TYPES - NON-

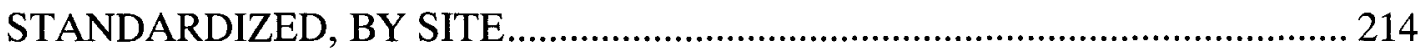

TABLE 23: SET 1: ACTUAL PARTICIPATION OPPORTUNITY TYPES -

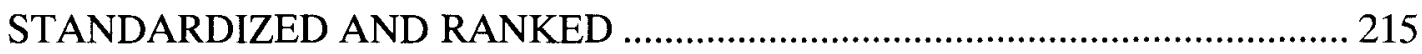

TABLE 24: SET 1: ACTUAL PARTICIPATION OPPORTUNITY TYPES -

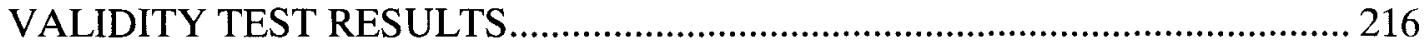

TABLE 25: SET 2: INTENT TO PARTICIPATE VARIABLES - VALIDITY TEST

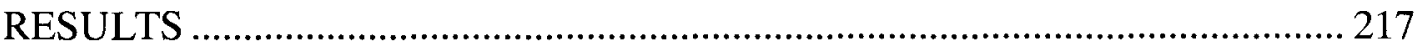

TABLE 26: SET 3: MODERATOR VARIABLES - TEST RESULTS FOR VALIDITY

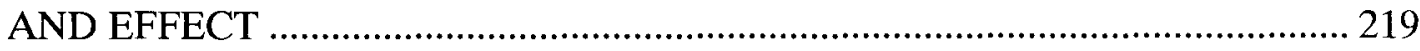

TABLE 27: SET 4: BENEFIT EXPECTANCY - TEST RESULTS FOR VALIDITY

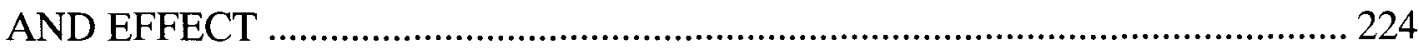

TABLE 28: SET 5: COST EXPECTANCY - TEST RESULTS FOR VALIDITY AND

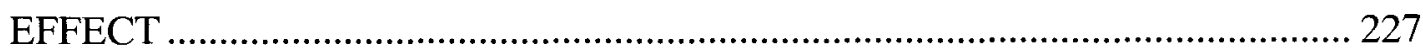

TABLE 29: SET 6: SOCIAL INFLUENCE - TEST RESULTS FOR VALIDITY AND

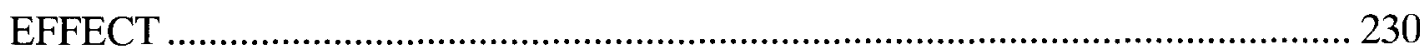

xiii 
TABLE 30: SET 7: FACILITATING CONDITIONS - TEST RESULTS FOR VALIDITY AND EFFECT 232

TABLE 31: PREDICTORS - PRINCIPLE COMPONENT ANALYSIS ....................... 241

TABLE 32: SET 8: WHOLE-NETWORK ATTRIBUTES .......................................... 243

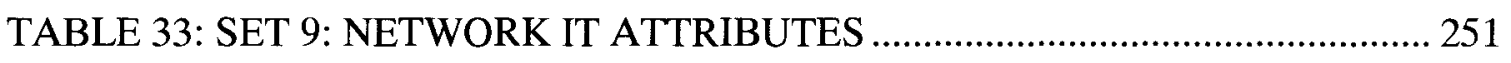




\section{LIST OF FIGURES}

FIGURE 1: WHOLE-NETWORK FORMATION (DEVELOPED BY AUTHOR) ......... 6

FIGURE 2: OVERVIEW OF DUAL NETWORK PARTICIPATION THEORY ........... 9

FIGURE 3: HEALTH INFORMATION EXCHANGE STAKEHOLDERS, LEVELS

AND USE CASES (COPIED FROM THORNEWILL ET AL., 2011) .................. 16

FIGURE 4: WHOLE-NETWORK THEORY (NOMOLOGICAL MODEL) ................. 24

FIGURE 5: THREE TYPES OF GOVERNANCE (COPIED FROM RAAB ET AL, 2009) 28

FIGURE 6: INTERORGANIZATIONAL SYSTEMS THEORY (NOMOLOGICAL

MODEL) 35

FIGURE 7: TECHNOLOGY ACCEPTANCE MODEL

FIGURE 8: THE EMERGENCE OF DUAL NETWORKS (ILLUSTRATION BY

THORNEWILL) 49

FIGURE 9: DUAL NETWORK PARTICIPATION THEORY .................................. 54

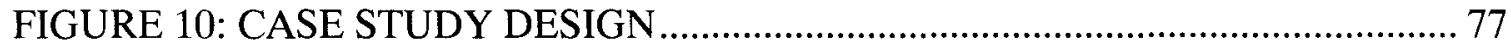

FIGURE 11: FOUR TYPES OF NETWORK LEVEL COLLABORATIVES ............. 167 


\section{CHAPTER 1. INTRODUCTION}

\subsection{Problem}

From 2004 to 2010, as part of a U.S. Federal Government effort to 'automate' its $\$ 2$ trillion healthcare system (Thompson et al. 2004), over 200 health information organizations (HIOs) ${ }^{1}$ were established (eHealth Initiative 2009). The mission of these HIOs was to develop and provide health information exchange (HIE) services to organizations and individuals in citywide or statewide geographical areas. HIE services are a kind of interorganizational information technology service connecting the information systems of local healthcare organizations and supporting electronic exchange of patient healthcare information among them.

During the time-period of interest, HIOs and HIE were viewed as an essential part of a 10 year strategy to provide an electronic health record for every American (Bush 2005). HIE offered potential to reduce healthcare costs by up to $\$ 78$ billion per year while improving quality of care (Walker et al. 2005). Yet, in spite of a sustained nationwide effort, most HIOs were unable to secure participation from a critical mass of organizations and individuals they sought to engage during this time, and as a result most foundered or failed (Adler-Milstein et al. 2009; eHealth Initiative 2009; Grossman et al. 2008; Health Data Management 2007). Consequently, the achievement of the Federal

\footnotetext{
${ }^{\prime}$ See Appendix 1: Glossary of Terms for definitions of this and other acronyms and technical or industryspecific terms used in this study.
} 
government's goal of nationwide HIE by 2014 seems improbable. As an expert in the field stated: "comprehensive, nationwide electronic patient data exchange will be more difficult than anyone imagined" (Plas 2007).

Surprisingly, considering the importance to the U.S. healthcare sector of HIOs and HIE (hereinafter collectively referred to as health information exchange networks or HIENs), little theory-driven research has been done on factors affecting their development and success. A review in leading academic journals in the fields of information systems, organizational sciences, health informatics and health policy identified no theory driven academic research on U.S. HIENs, and just a few studies of HIENs in other countries (Ammenwerth et al. 2004; Kuhn et al. 2007; Mantzana et al. 2007; Sahay et al. 2009; Sprivulis et al. 2007; Ure et al. 2009).

The lack of research has important implications. Organizationally, it means that leaders seeking to develop HIENs or similar collaboratives may lack guidance that can help them effectively manage development of such collaboratives. This may lead to additional failures, or failure to achieve the full potential, of these new collaboratives. Technologically, it means that government or private firms may invest in technologies which subsequently aren't adopted and used by those for whom they are developed, thereby reducing returns on investments. Societally, it means increased potential for systemic failures - like those seen with the U.S. HIENs from 2004 to 2010 - which limit the ability for entire industries or economies to progress as quickly as they could.

The goal of this research is to help address this important gap in knowledge. 


\subsection{Overview of Proposed Study}

What factors affect the development and success of collaboratives like HIENs?

The study explores this general question by focusing on three key challenges which limit HIEN success (Table 1). Three theories are identified relevant to studying these challenges. However, critical limitations found with each points to the need for new theory. To meet this need, a dual network participation theory (DNPT) is developed designed to study factors which affect participation in dual networks like HIENs. A set of variables are selected (drawn from the three existing theories) and testable hypotheses are generated. To validate these variables and test the hypotheses data from 6 HIEN sites (network level), 109 individuals (individual level) and their affiliated organizations (organizational level) are compiled and analyzed.

Table 1: Overview of Study

\begin{tabular}{|l|l|l|l|l|l|}
\hline \multicolumn{1}{|c|}{ Literature review } & \multicolumn{1}{|c|}{ Theory development } & Case study \\
\hline \multicolumn{1}{|c|}{$\begin{array}{c}\text { Three HIEN } \\
\text { challenges } \\
\text { theories }\end{array}$} & $\begin{array}{l}\text { Limitation } \\
\text { (doesn't } \\
\text { consider) }\end{array}$ & $\begin{array}{c}\text { New dual } \\
\text { network } \\
\text { participation } \\
\text { theory } \\
\text { (includes) }\end{array}$ & $\begin{array}{c}\text { Proposed } \\
\text { variables and } \\
\text { testable } \\
\text { hypotheses }\end{array}$ & $\begin{array}{c}\text { (6 sites, } \\
\text { 109 } \\
\text { individuals, } \\
\mathbf{1 2 5} \\
\text { organizations) }\end{array}$ \\
\hline $\begin{array}{l}\text { Whole-network } \\
\text { participation }\end{array}$ & $\begin{array}{l}\text { Whole- } \\
\text { network } \\
\text { theory }\end{array}$ & $\begin{array}{l}\text { Information } \\
\text { technology }\end{array}$ & $\begin{array}{l}\text { Whole-network } \\
\text { attributes }\end{array}$ & $\begin{array}{l}\text { How do whole- } \\
\text { network attributes } \\
\text { affect intent to } \\
\text { participate by } \\
\text { organizational } \\
\text { leaders? }\end{array}$ & $\begin{array}{l}\text { Are variables } \\
\text { valid? If so, } \\
\text { what are } \\
\text { affects? }\end{array}$ \\
\hline $\begin{array}{l}\text { Inter- } \\
\text { organizational } \\
\text { system (IOS) } \\
\text { participation }\end{array}$ & IOS theory & $\begin{array}{l}\text { Whole- } \\
\text { networks }\end{array}$ & IOS attributes & $\begin{array}{l}\text { How do IOS } \\
\text { attributes affect } \\
\text { intent to } \\
\text { participate by } \\
\text { organizational } \\
\text { leaders? }\end{array}$ & $\begin{array}{l}\text { Are variables } \\
\text { valid? If so, } \\
\text { what are } \\
\text { affects? }\end{array}$ \\
\hline $\begin{array}{l}\text { Individual } \\
\text { participation }\end{array}$ & $\begin{array}{l}\text { Technology } \\
\text { acceptance } \\
\text { model (TAM } \\
\text { theory) }\end{array}$ & $\begin{array}{l}\text { Whole- } \\
\text { networks }\end{array}$ & TAM attributes & $\begin{array}{l}\text { How do TAM } \\
\text { attributes affect } \\
\text { intent to } \\
\text { participate by } \\
\text { organizational } \\
\text { leaders }\end{array}$ & $\begin{array}{l}\text { Are variables } \\
\text { valid? If so, } \\
\text { what are } \\
\text { affects? }\end{array}$ \\
\hline
\end{tabular}




\subsection{Three HIEN Challenges}

Virtually all of 200 or so community and state HIENs which operated in the U.S. from $2004-2010$ spent significant time and effort trying to address three $H I E N$ challenges. I refer to these as the whole-network participation challenge, the interorganizational system (IOS) participation challenge and the individual participation challenge.

The whole-network participation challenge, an organizational one, revolves around questions of how to organize the HIEN in order to foster participation by desired organizations in planning, organizing and funding the service. HIENs experiment with various collaborative governance structures and processes in efforts to secure input and support from the desired organizations. However, achieving desired levels of participation proves to be more difficult than anticipated, causing ongoing delays and problems, especially in the domain of governance (eHealth Initiative 2009; Foundation of Research and Education of AHIMA 2009; University of Massachusetts Medical School 2008).

The IOS participation challenge revolves around questions of how to develop and deliver HIEN information technology (IT) that organizations will accept and use. HIEN technologies are complex, expensive and risky to implement, and can have disruptive effects on the organizational IS with which they seek to connect (Dimitropoulos 2007; Dolin et al. 2006; eHealth Initiative 2007). In addition, an approach favorable to some organizations may cause other organizations to not participate (Vest et al. 2010a). Even after extensive discussions, debates and negotiations with potential organizational 
participants, IOS participation agreements prove difficult to secure (Adler-Milstein et al. 2009; Rudin et al. 2009).

The individual participation challenge revolves around questions of how to secure participation in HIEN services of individual users such as physicians, nurses and patients. Many factors, such as privacy and security challenges, diversity of user types and characteristics, need for physicians and nurses to access data through multiple organizational systems, and lack of ability to 'compel' users to use the systems, limit individuals' willingness to support or use the technology (Anderson 2007; Grossman et al. 2008; Tripathi et al. 2009).

\subsection{Three Theories}

Three theories are then identified which are particularly relevant to the study of the three challenges. These are whole-network theory, interorganizational system (IOS) theory and technology acceptance models (TAM theory).

Whole-network theory is an emerging area of study in the organizational sciences literature (Provan et al. 2007; Raab et al. 2009). A whole-network is a group of three or more organizations connected in ways - usually formal - that facilitate achievement of a common goal (Provan et al. 2007). Whole-networks are theorized as ontologically distinguishable from traditional organizations (Raab et al. 2009). Figure 1 illustrates Raab et al.'s supposition that just as individuals learned to combine to form organizations as distinct entities beginning in the $16^{\text {th }}$ century, so organizations begin learning how to combine to form whole-networks as distinct entities starting around the year 1970 . Whole-network researchers identify a range of factors such as network trust, governance 
structure and stakeholder size and quantity which affect how collaboratives develop, and who 'joins' them (Kenis et al. 2009; Provan et al. 2008).

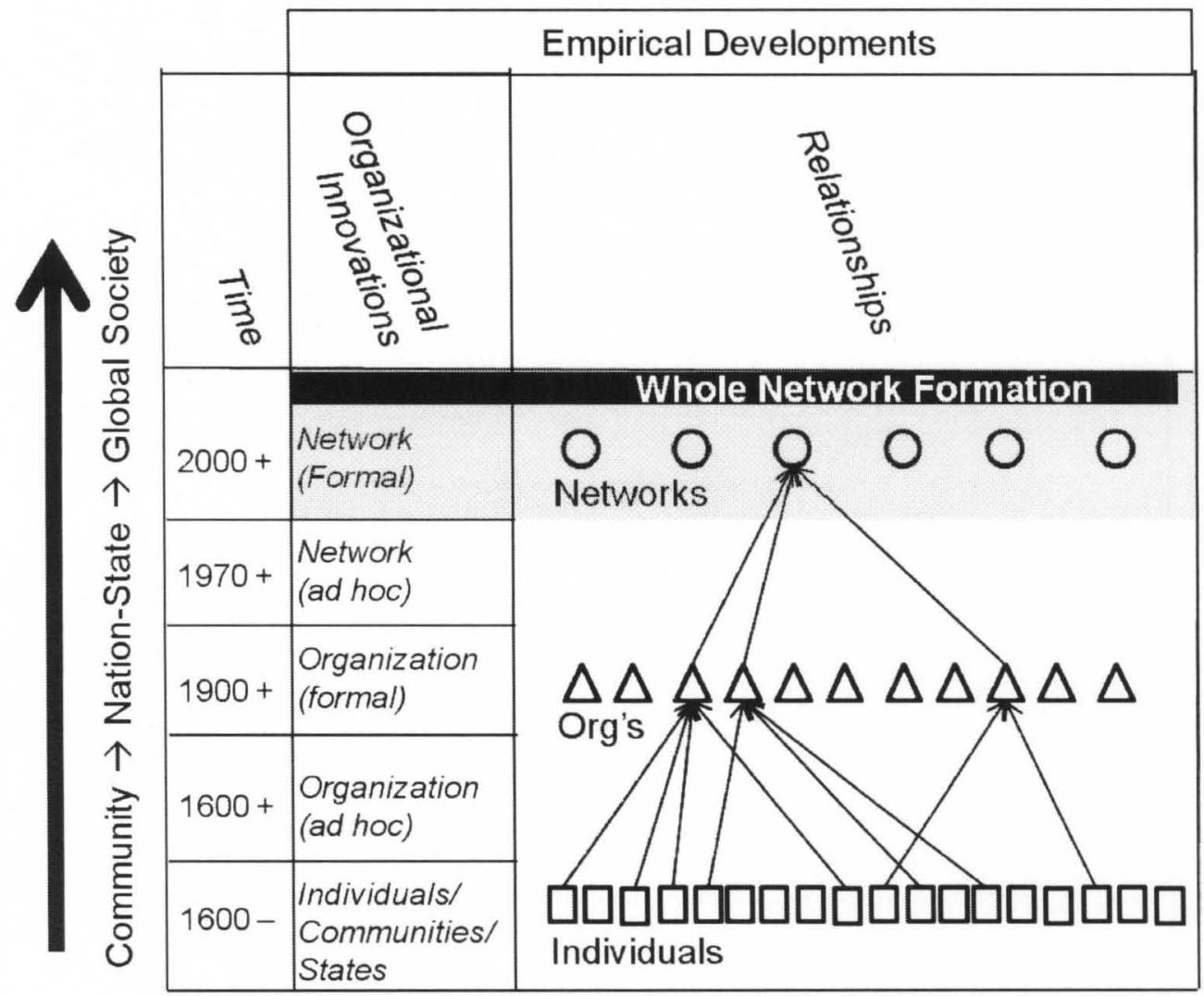

Figure 1: Whole-network Formation (Developed by Author)

IOS theory, developed in the information systems (IS) field, comes from the study of "automated information systems shared by two or more organizations and designed to link business processes" (Robey et al. 2008). Researchers use IOS theory to study the effects of factors such as technological instability, technological complexity and participant heterogeneity on adoption of IOS by organizations (Robey et al. 2008).

TAM theory (Venkatesh et al. 2003), also developed in the IS field, studies the adoption of IT by individuals in organizational settings. TAM theory is seen as one of the 
most significant accomplishments in the IS field because of its robust ability to predict individual acceptance of IT in organizations (Benbasat et al. 2007).

\subsection{Limitations of Theories}

However, analysis of each theory finds significant limitations for research on HIEN participation challenges. Whole-network theory is limited by its early stage of development and by the lack of models which consider the effects of information systems on whole-networks. IOS theory is limited by a lack of ability to consider the effects of whole-networks on IOS development and adoption (Robey et al. 2008). TAM theory is limited by its focus on participation by individual employees in organizational contexts, and its inability to consider the effects of whole-networks on individuals or organizations. The limitations identified point to the need for new theory to support research on barriers to participation in HIENs.

\subsection{New Theory}

To be useful for such research, a new theory will need to consider network forms of organization and network forms of IT within an integrated context. Without such integration, the research could fail to consider potentially influential interactions between new network organization forms and new type of enabling network IT. To meet this need, elements of whole-network, IOS and TAM theories are combined to form a dual network participation theory (DNPT). The DNPT focuses on a hitherto undefined phenomenon: network information-technology dependent whole-networks ("dual-networks"). 
Figure 2 illustrates how the DNPT works. Each dual network has attributes which exist at the network level (the level of a dual network such as a HIEN). These include whole-network attributes and network IT attributes. For a given participation opportunity, these network level attributes will influence four predictors found at the individual level (the level of individuals who are participating in the network level site). These predictors, developed based on the theory of planned behavior (TPB) (Ajzen 1991), will reflect an individual's beliefs about costs, benefits, social influence and facilitating conditions associated with the participation opportunity for the individual (at the individual level) and his/her affiliated organization(s) (at the organizational level). Changes in these predictors (the independent variables) are hypothesized to affect intent to participate (the dependent variable) (Ajzen 1991). Intent to participate will correlate with actual participation. Actual participation will generate outcomes. Outcomes will influence attributes. Thus, the DNPT offers potential for development of parsimonious theory similar to that developed in the TAM literature (the area inside the dotted lines). 
Given a qualified dual network participation opportunity...

\section{Dual Network Attributes Predictors (IV) Participation (DV)}

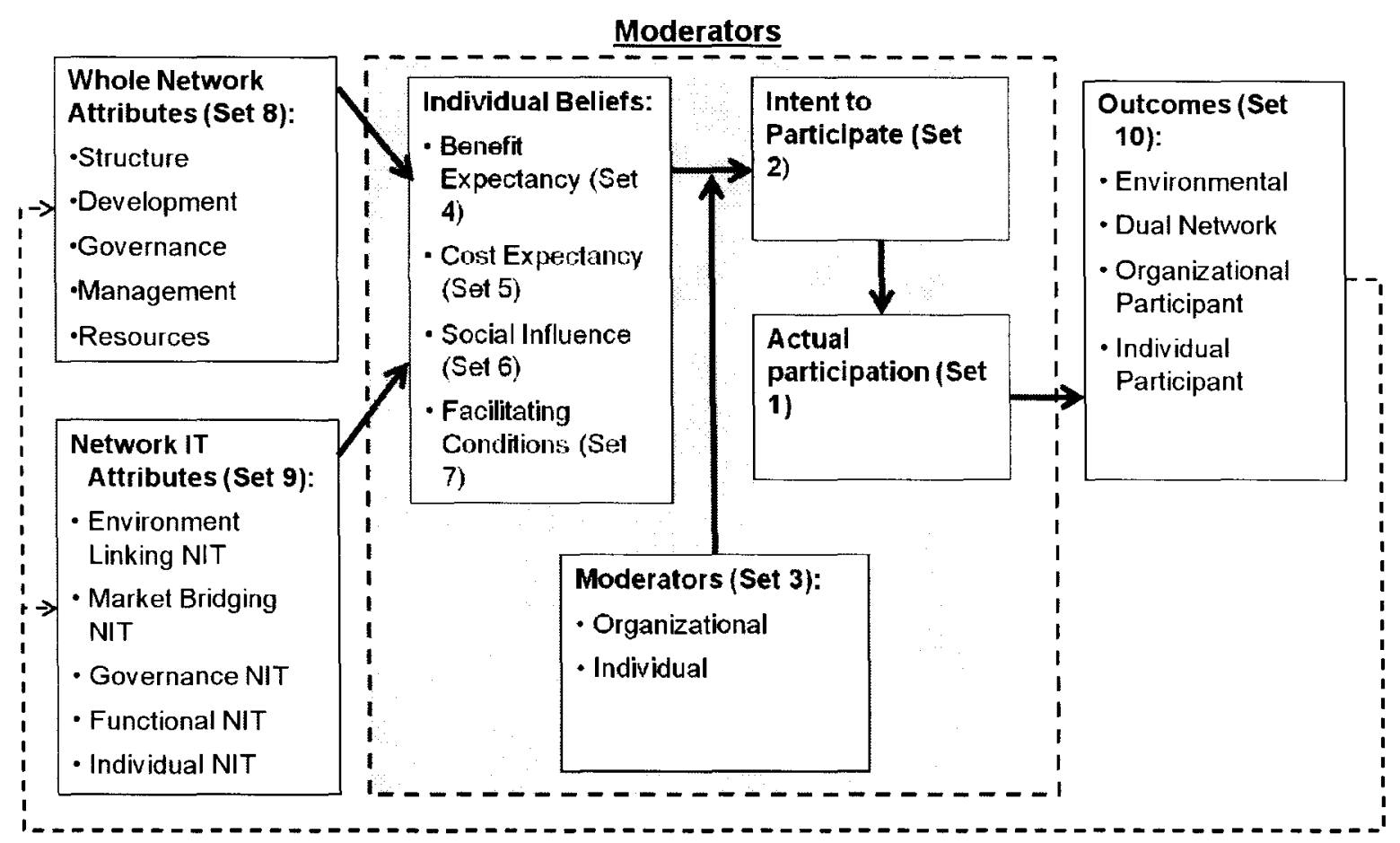

Figure 2: Overview of Dual Network Participation Theory

\subsubsection{Operationalizing the DNTP: Variables and Hypotheses}

Variables used in the DNPT are drawn from the three source theories. As

recommended for new theory development, more rather than fewer variables are included (Whetten 1989). The first formulation of the theory contains 10 sets of variables. These include dual network variables, predictor variables, moderator variables, intent to participate variables and actual participation variables. A validity question for each variable and hypotheses for each variable in sets 3-9 are developed (e.g., $\mathrm{H}_{\mathrm{n}}$ : increase in $X$ (predictor variable) will increase $Y$ (intent to participate). 


\subsubsection{Research Questions}

The formulation raises a number of questions. Are the selected variables valid for dual networks? What additional variables might be missing? Do proposed effects occur? Answers to these general questions are, of course, not available in the literature due to the newness of the theory and the lack of research on dual networks. This leads to five exploratory questions to be addressed in this study:

1. What kinds of participation opportunities do HIENs offer?

2. Which of the proposed DNPT variables appear to be valid for the study of participation in HIENs?

3. What new variables should be considered and do they appear to be valid?

4. Once valid variables are selected, what does the data say about barriers and enablers to participation in HIENs? Specifically:

a. How do moderators (organizational leader gender, age; organization size, type) moderate intent to participate?

b. How do predictors affect intent to participate?

c. How do dual network attributes affect predictors?

5. What are the implications of the study for theory and research?

\subsection{Method and Procedures}

To answer these questions, a theory driven, retrospective, multi-level, multi-case, mixed methods case study design appropriate for exploratory theory-development is conducted (Eisenhardt 1989; Yin 2008). A convenience sample of six HIEN sites (network level cases) with 109 associated individuals (individual level cases) and 125 
organizations (organizational level cases) is used. The HIENs are appropriate for study because: 1 .) they started in 2004-2005 or thereafter under fairly typical circumstances; 2 .) they experienced some exceptional challenges in obtaining participation; and 3.) a rich set of qualitative data is available about them. Data is used to complete three instruments: 1.) Types of Participation; 2.) Site Attributes; and 3.) Subject Attributes. Each instrument is designed to capture information which can be used to determine: 1 .) the validity of each variable (current and new); and 2.) evidence supporting, refuting or providing alternative explanations for each hypothesis. Data from the instruments is then summarized, analyzed qualitatively and statistically, and then interpreted.

\subsection{Importance}

The study makes important contributions to research and practice. On the research side, it advances development of a new theory with potential to support new avenues of research on participation in dual networks. Practically, it identifies factors which affect participation in HIEN collaboratives. Such findings may be helpful to leaders of HIENs and other dual networks seeking to better understand barriers and enablers of success.

\subsection{Organization of Study}

The remainder of this study proceeds as follows: Chapter 2 reviews the literature on HIENs and relevant theories for the study of HIENs found in information systems and organizational science literatures. Chapter 3 presents the new dual network participation theory and its elements drawn from the three source theories. Chapter 4 describes the methods used to validate the theory and answer the research questions posed. Chapter 5 
reviews results of tests of the validity and effects of each of approximately 65 variables.

Chapter 6 provides a general discussion including answers to each of the 5 questions posed for the study. 


\section{CHAPTER 2. LITERATURE REVIEW}

\subsection{Overview}

The literature review begins with a review of HIEN definitions, types, success requirements, innovation efforts and challenges (Section 2.2). This leads to a focus on three key participation challenges which HIENs face (Section 2.3). Next, three theories whole-network, IOS and TAM theories - are reviewed, and their applicability to the study of the HIEN challenges are considered. Important limitations are found with each theory, leading to the conclusion that new theory is needed to support the research (Section 2.3).

The review draws from multiple disciplines. It considers academic studies in the fields of organizational sciences, information systems, health informatics, and health policy. In addition, it considers non-academic papers published in professional healthcare journals and reports by U.S. federal and state government organizations. Details about the literatures considered are provided in Appendices 2 and 3.

\subsection{HIEN Characteristics and Challenges}

\subsubsection{Definitions of HIENS}

A number of terms appear in the literature to describe the phenomena of interest. These include health information exchange (HIE), regional health information organization (RHIO), state level health information exchange (SL-HIE), health record 
bank (HRB), payer based health record (PBHR), electronic health record (EHR) and community health information network (CHIN) (e.g., ONC-HIT 2008). The use of these terms is sometimes imprecise. For example, the term health information exchange (HIE) is used in at least four ways: as a verb (the act of HIE), a type of organization (a HIE), a type of government initiative (a state HIE), and a type of technology (a HIE system, platform or network). In this study, the term health information exchange network (HIEN) is coined to refer to a collaborative activity organized to provide electronic information exchange services related to health or healthcare. The term HIE is used as a verb to refer to the act of health information exchange.

\subsubsection{History of HIENs}

The idea of health information exchange (HIE) is not new in U.S. healthcare. The need for HIE in occupational health was recognized as early as the 1950s (Byers 1957). In the early 1980 's, electronic data interchange (EDI) systems for processing financial transactions first appeared in the U.S. healthcare industry (Chester 1986; Ramamurthy et al. 1995). In the 1990s, the first nationwide effort to form HIENs for the exchange of clinical patient information appeared in the form of community health information networks (CHINs) organized to share hospital data in communities (Dowling 1997; Lorenzi 2003). However, in the 1990s virtually all the CHINs shut down because of factors including privacy and data ownership concerns, difficulty defining value and lack of governance structures to support collaborative decision-making (Dowling 1997; Lorenzi 2003). 
In 2004, the HIENs considered in this study begin forming with President George

W. Bush's executive order calling for the creation of an electronic health record for every American by 2014 (Bush 2005). They offer potential to reduce healthcare costs by up to $\$ 78$ billion per year while improving quality of care (Walker et al. 2005). However, HIEN collaboratives starting in 2004 experienced limited progress even after several years of development (Adler-Milstein et al. 2008; Health Data Management 2007). This situation led one expert to comment: "comprehensive, nationwide electronic patient data exchange will be more difficult than anyone imagined" (Plas 2007).

\subsubsection{Types of HIENs}

There are many possible types of HIEN. As shown in Figure 3 (copied from Thornewill et al. 2011), HIENs can, in principle, exchange health information among or between different stakeholder types (hospitals, physicians, pharmacies, health plans, Medicaid), at different geographical scales (organizational, communitywide, statewide, nationwide, international), and for different use cases (individual health, chronic diseases like diabetes, or heart disease, medication management, population health and so on). In general, successful development of HIENs involves striking a balance between breadth (handling more types, scales and use cases) and feasibility (effectively handling one or a few types, scales and use cases) (e-Health Initiatives 2007b).

Two types of HIEN formed and predominated in the U.S. from 2004 to 2010 . The first of these were community HIENs, reflecting a mission of providing HIE services for healthcare organizations and patients within a geographical region such as a regional metropolitan area. Over 150 community HIENs formed and/or operated during this time 
(eHealth Initiative 2008; eHealth Initiative 2009). The second type formed were state HIENs, reflecting a mission to foster statewide HIEN. Over 50 of these formed during the period of interest through executive orders and/or passage of legislation in virtually every state and U.S. territory (eHealth Initiative 2008; Foundation of Research and Education of AHIMA 2009). Both community and state HIENs engaged multiple stakeholder types, while focusing on few key use cases.

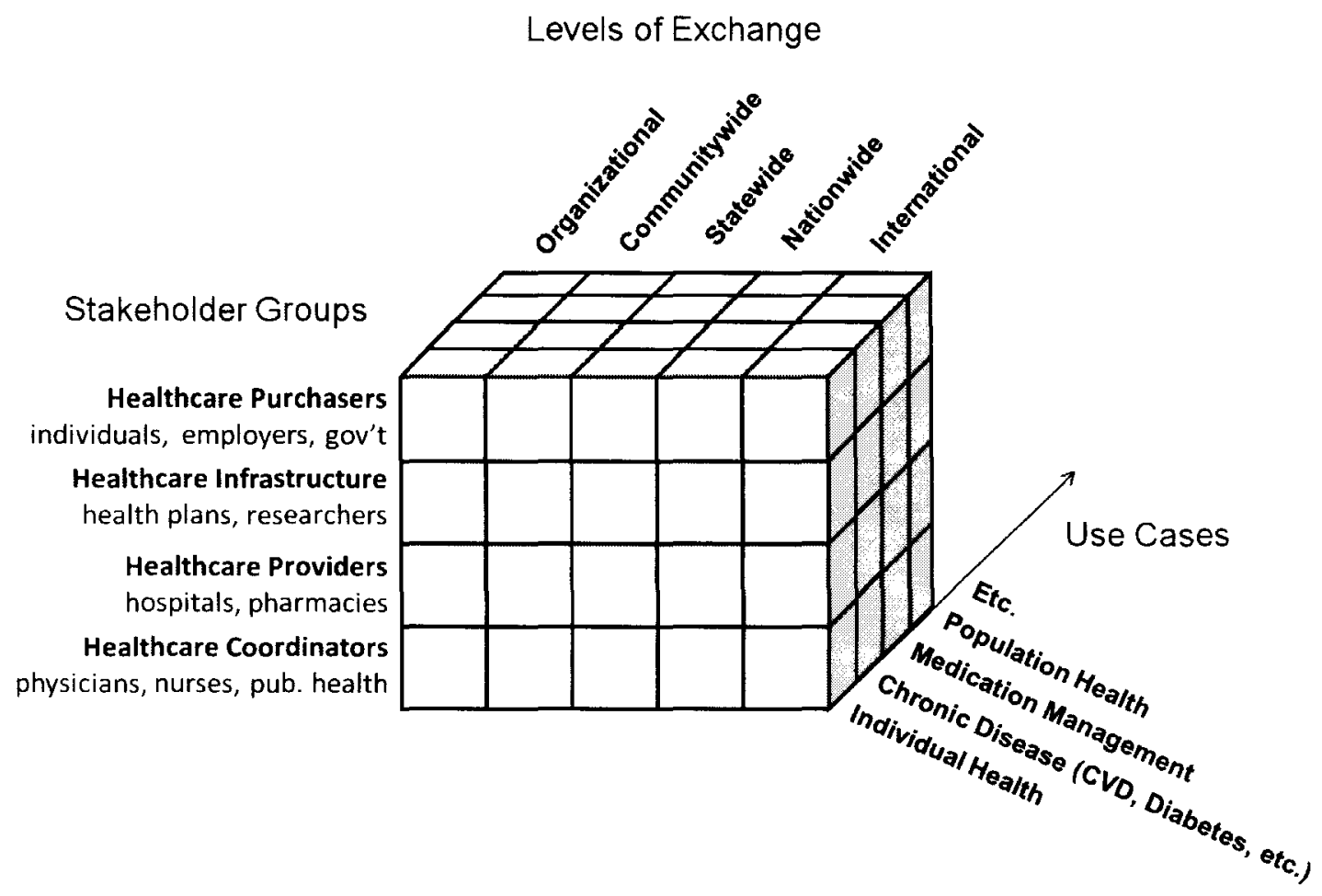

Figure 3: Health Information Exchange Stakeholders, Levels and Use Cases (copied from Thornewill et al., 2011) 


\subsubsection{HIEN Ubiquity Requirement}

A key concern of community and state HIENs was obtaining a critical mass of key providers and patients (eHealth Initiative 2008; eHealth Initiative 2009) (hereafter called the Ubiquity Requirement). If only partial patient information is available to the provider, it can increase rather than decrease overall administrative costs for the provider (Middleton 2005). Patients are unlikely to support a HIEN unless it works at a majority of the provider settings where patients visit (Thornewill et al. 2011).

Furthermore, stakeholder intent to invest to become HIEN compatible is affected by participation level (e-Health Initiatives 2007b). To connect to a HIEN service, providers have to make significant investments in both technology (such as a compatible electronic health record) and organizational redesign (including redesign of patient record keeping, data entry and disclosure processes) (Kaushal et al. 2005). Such investments are difficult to justify unless the provider is assured that data on a majority of their patients can be made available through the HIEN, and, that the HIEN is likely to persist over time (Dowling et al. 2010; Walker et al. 2005).

\subsubsection{HIEN Innovation Efforts}

In efforts to satisfy the ubiquity requirement, and obtain investment, HIENs engaged in two types of innovation: 1.) organizational innovation - the development and use of organizational structures which can support collaborative decision-making by multiple healthcare organizations interested in the HIEN services; and, 2.) technological innovation - the development of information technology based services which support 
patient health information exchange (HIE) among these healthcare organizations (e.g., eHealth Initiative 2008; eHealth Initiative 2009; NORC 2009).

Organizationally, three broad types of organizational structures were attempted in order to support collaborative development and support of HIENs: government controlled, private sector controlled, and hybrid (University of Massachusetts Medical School 2009).

Technologically, three broad types of technology architecture were attempted: centralized information repositories, distributed peer to peer architectures, and hybrids (e.g., Ball et al. 2007). None of these approaches proved to be evidently superior during the time period of interest (SLHIE 2009; University of Massachusetts Medical School 2009).

In practice, finding the right combinations of governance and technology presented a series of difficult challenge for HIENs.

\subsubsection{Three HIEN Challenges}

For purposes of this study, these challenges are viewed as the whole-network participation challenge, the interorganizational system (IOS) participation challenge, and the individual technology participation challenge.

The whole-network challenge, an organizational one, emerges as HIENs seek to secure the participation of a critical mass of organizations and their leaders in the process of planning the HIEN and governing its operations. To address this challenge, HIENs focus extensive effort on governance and management mechanisms which can assure participating organizations that HIEN services will be developed and delivered in a way 
which is fair and reasonable for all parties (eHealth Initiative 2007). In addition, HIENs seek to develop services which can provide tangible value to organizational and individual participants - such as improved quality and efficiency of care and reduced workload (e-Health Initiatives 2007b; NORC 2009). Furthermore, in attempts to maintain the trust and support of government based organizations such as state Medicaid or Medicare, HIENs seek to understand and/or shape regulatory, legislative and political factors affecting ability of government organizations to participate in HIEN (Foundation of Research and Education of AHIMA 2009). However, in spite of their efforts, most HIENs are unable to obtain the critical mass of support and participation they need to move forward (eHealth Initiative 2009).

The IOS challenge, a technological one, relates to the design of interorganizational systems (IOS) (Robey et al. 2008) used by HIENs to link to multiple information systems (IS) at organizational levels. HIEN IOS must link to multiple, often non-standardized IS of diverse organizations operating in the healthcare sector. This makes HIEN systems complex, expensive, and risky to implement. In addition, for many organizations, the HIENs have potential to have disruptive effects on the organizational IS with which they seek to connect (Dimitropoulos 2007; Dolin et al. 2006; eHealth Initiative 2007). The technical challenges of developing and deploying HIEN IOS meant that even after extensive discussions, debates and negotiations with potential organizational participants, adoption agreements proved difficult to secure (AdlerMilstein et al. 2009; Brailer 2007; Rudin et al. 2009).

The individual challenge, also technological, involves securing acceptance and use of HIEN services by individuals affiliated with organizational adopters. At times, 
physicians, nurses and patients may all be invited to access and use HIEN services. However, physicians and nurses may not support or use HIEN services even if their organizations adopt it, and patients may resist having their data electronically shared even if their provider recommends it (Anderson 2007; Grossman et al. 2008; Tripathi et al. 2009). At a certain point, even if an organization wants to support an HIEN service, it cannot do so if individual users don't use it. Efforts to understand and address requirements to encourage individuals to participate were a third key challenge HIENs sought to address.

\subsection{Three Relevant Theories}

Three theories are identified as particularly relevant for study of the three challenges. These are: interorganizational networks at the network level (whole-network theory), interorganizational systems theory (IOS theory) and technology acceptance models (TAM theory). Each theory is reviewed in turn. Each theory review begins with a justification for the selection of the theory. This is followed by a discussion of the history of the theory, its empirical and theoretical contexts, a nomological model, methods used, and challenges faced. As each theory review progresses, key strengths and limitations of the theory for the study of HIENs are highlighted. Each review concludes with identification of an overarching strength and limitation of the theory for the study of HIENs.

\subsubsection{Whole-Network Theory}

\subsubsection{1. $\quad$ Reason for Selection}


Whole-network theory is selected for its relevance to the study of the HIEN whole-network participation challenge. Its selection is justified by the fit between wholenetwork and HIEN characteristics. Whole-networks are defined as groups of three or more organizations connected in ways - usually formal - that facilitate achievement of a common goal (Provan et al. 2007; Raab et al. 2009; Zaheer et al. 2010). HIENs fit this definition; they all have governance structures with representation from three or more organizations (eHealth Initiative 2008).

\subsubsection{2. $\quad \underline{\text { History }}$}

The term whole-network first appears in the literature in 2003 (Kilduff et al.), reflecting the $21^{\text {st }}$ century emergence of a new kind of networked collaborative (Raab et al. 2009). Whole-network studies are a subset of a broad category of organizational network studies which begin in the 1970's and 1980s (Benson 1975; Cook 1977; Powell 1990). A seminal whole-network theory published in 1995 (Provan et al.) provides a foundation for subsequent work. Whole-network research has grown steadily since then, with approximately 70 empirical and 10 theoretical papers published by 2010 (Provan et al. 2007; Zaheer et al. 2010). For purposes of studying HIENs, whole-network theory offers a new and distinctive approach. However, the newness of the field, and limited number of studies done to date, may also limit its value.

Strength: potential for new insights into HIEN challenges

Limitation: newness of field; small set of studies 


\subsubsection{Empirical Contexts}

The whole-network field is grounded in empirical studies of whole-network phenomena in public and non-profit sectors, the private sector and temporary networks. Types of whole-networks studied include mental health services networks, healthcare networks, school district networks, job and training networks, community development networks, college athletics networks, construction industry networks, biotechnology networks, banking networks, technology development networks and construction networks (Huang et al. 2007a; Milward et al. 2010; Provan et al. 2004; Provan et al. 1995; Turrini et al. 2010). New areas which have had less study to date, but are of interest include public-private and temporary whole-networks (Raab et al. 2009). Many new opportunities for empirical study of whole-networks are emerging, as the numbers and types of whole-networks increase, and more researchers begin studying them (Provan et al. 2007). The ability to draw upon these related empirical contexts is certainly a strength of the whole-network context. However, the literature does not contain any direct studies of HIENs; nor are studies found on the effects of IT on whole-network development.

Strength: study of other complex public-private networks - including ones in healthcare

Limitation: lack of study of HIENs

Limitation: lack of studies of influence of IT on whole-networks

\subsubsection{Theoretical Contexts}


Whole-network research has been described as a multi-level, multi-theoretic discipline (Provan et al. 2007). Study of whole-networks involves consideration of phenomena at individual, organizational and whole-network levels (Brass et al. 2004). Different theories may be relevant at different levels of analysis - such as cognitive theories at the individual level (e.g., Ajzen 1991), neo-classical theories of markets and hierarchy at the organizational level (e.g., Williamson 1981), and network theories at the network level (e.g., Borgatti et al. 2003). In addition, positivist, interpretive and critical theoretical stances may be used in whole-network research, although most research to date has been positivist in nature (Provan et al. 2007). The multi-level theoretical stance is clearly a strength of whole-network theory, since so many factors have potential to effect HIEN development and success.

Strength: multi-level, multi-theoretic perspective

Limitation: none

\subsubsection{Nomological Model}

The term nomological model refers to a formalized view of scientific explanation which supports development of refutable hypotheses (Railton 1978). Much wholenetwork research is guided by a nomological model which considers the effects of wholenetwork properties and processes on organizational decisions to join a whole-network (Figure 4) (Provan et al. 2007). Decisions to join influence whole-network outcomes such as capacity for a whole-network to achieve its stated goals (Kenis et al. 2009; Provan et al. 2007). Elements from each part of the model are considered in turn. 


$\begin{array}{lll}\text { Whole Network Properties } & \begin{array}{l}\text { Dependent } \\ \text { Variable (DV) }\end{array} & \begin{array}{l}\text { Whole Network } \\ \text { Outcomes }\end{array}\end{array}$

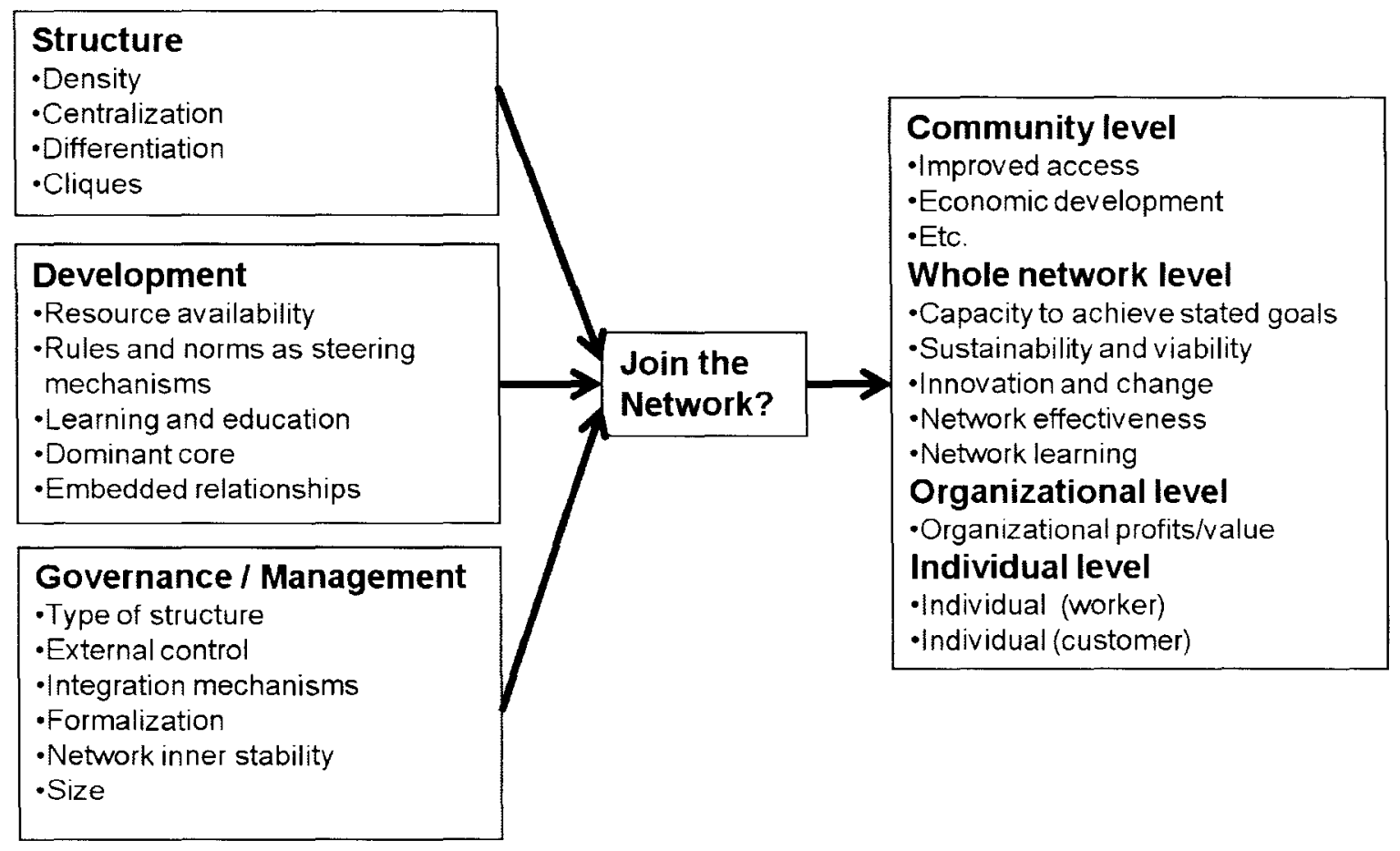

Figure 4: Whole-Network Theory (Nomological Model)

\subsection{Whole-Network Properties and Processes}

Properties and processes of whole-networks are categorized in three broad areas: structure, development and governance (Provan et al. 2007).

Structure has been shown to influence the information that flows through a network (Provan et al. 2007). Structural attributes, measured using network analysis techniques (Wasserman et al. 1994), include density, centralization, differentiation and cliques. Density, the number of network ties, tends to increase over time in wholenetworks (Venkatraman et al. 2004). However, there is a tradeoff between density and centralization. Increased centralization, that is centralized coordination of networks, 
facilitates coordination and integration, but lessens as density increases (Morrissey et al. 1994; Provan et al. 1995). There is also a tradeoff between centralization and differentiation (Bazzoli et al. 1999): more differentiated networks have reduced centralization. However, cliques (tightly linked sub-networks) operating within a larger network are associated with positive outcomes for the whole-network (Provan et al. 1998). For purposes of studying factors affecting participation in HIENs, ability to study structural attributes seems to be a valuable contribution of whole-network theory. However, there is an associated limitation: the potential difficulty in obtaining accurate social network measures because of the network bounding problem (Laumann et al. 1989; Provan et al. 2007).

\section{Strength: use of structural attributes}

Limitation: challenges obtaining accurate network measurement

Development - how whole-networks develop over time - is the focus of about half of the studies in the whole-network literature (Provan et al. 2007). Not surprisingly, resource availability strongly affects the ability of whole-networks to develop and achieve participation goals over time (Provan et al. 2007; Provan et al. 1995). However, rules and norms as steering mechanisms also strongly affect network development (Sydow et al. 1998). Furthermore, the processes by which participating organizations develop and learn about these rules and norms are also influential, as is education of participants about the network's and participating organizations' meanings, goals and values (van Raak et al. 2001). A dominant core of organizational and individual leaders 
strengthens development of networks (Owen-Smith et al. 2004), as do embedded relationships, particularly those based on shared successes in the past (Gulati et al. 1999). In addition, leadership attributes positively affect whole-network development and success (Provan et al. 2007; Provan et al. 1995). These include:

- Stability Management (degree to which leadership buffers instability/nurtures stability in the network)

- Accountability Management (assignation of accountability of managers for performance and results for the whole-network and community)

- Steering Network Processes (processes to support ethical decision-making, and facilitate centralization of control)

- Generic Networking (time spent interacting with network constituencies to identify tensions, and blend participant interests to achieve whole-network goals)

- Management Tenure (tenure of whole-network management team)

- Staff Coherence (competitiveness vs. coherence of staff)

- Services Capability (capability to provide services desired to participants). In addition, formalization, such as formalized rules, written agendas and decision-making procedures, and network inner stability (levels of trust, reciprocity and norms of cooperation) can have positive effects on network development (Provan et al. 2008). Thus, whole-network theory supports consideration of a number of attributes which may affect HIEN participation. 
Strength: development attributes

Limitation: none

Governance - structures by which participants provide input and exercise oversight and control - is a third important dimension of whole-network theory (Provan et al. 2007). Three broad types of whole-network governance structure have been identified (see Figure 5) (Provan et al. 2008). Self-governed network governance (when participants share leadership responsibilities) are hypothesized as beneficial for highly cohesive whole-networks with less than 6-8 participants (Provan et al. 2008). Lead organization network governance (in which one organizational participant leads and administers the network) is hypothesized as effective for moderate number of organizational participants in a whole-network of moderate complexity. Network administrative organization (NAO) governance (in which an independent NAO supports the whole-network) is hypothesized as effective for networks including large numbers of participants and more complex network processes. For the purpose of studying HIENs, the ability to consider effects of these different types of governance on whole-networks seems to be a particularly important strength.

Strength: governance typology

Limitation: none 


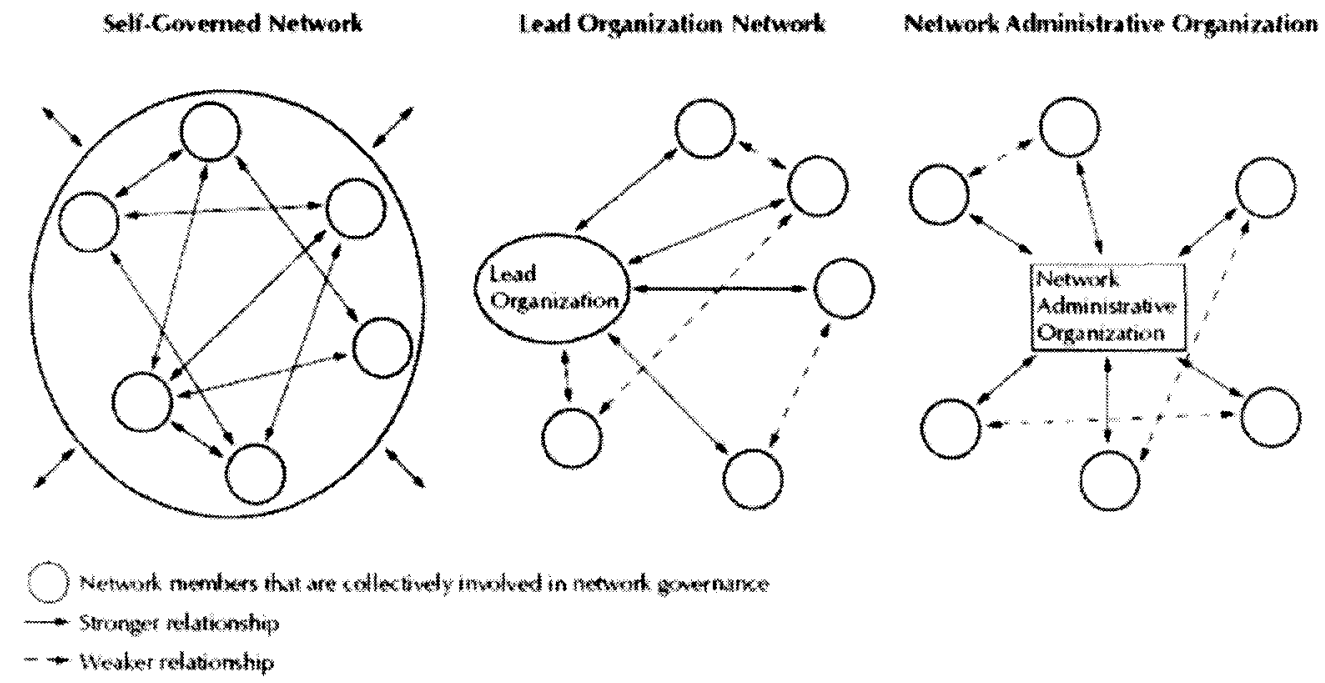

Figure 5: Three Types of Governance (copied from Raab et al, 2009)

\subsubsection{Whole-Network Outcomes}

Outcomes - consequences of whole-networks - are another set of attributes which appear in the whole-network literature. In general, outcomes are considered at the levels of community, whole-network, organization and individual (Provan et al. 2008; Provan et al. 2001; Turrini et al. 2010). At the community level, outcome measures consider overall effects of the network on a community of interest. Measures may include factors such as improved access to healthcare services, improved community innovation rates, economic development contributions, or other community level values (Kenis et al. 2009; Provan et al. 2008; Provan et al. 1995). At the network level, outcome measures may include the capacity of the whole-network to achieve its stated goals, the sustainability and viability of the whole-network, and levels of innovation and change achieved by the wholenetwork (Kenis et al. 2009; Provan et al. 2008; Provan et al. 1995). At the organizational level, organizations may experience outcomes such as increased profits, revenues or other 
business value, an area about which an extensive literature already exists (Zaheer et al. 2010). Finally, outcomes may occur at the individual level, such as increased individual efficiency or satisfaction with service (Provan et al. 1995). The ability to consider outcomes at multiple levels is another notable strength of whole-network theory, although a limitation may be the many different variables involved.

Strength: outcomes measurement at multiple levels

Limitation: multiple attributes and relationships to consider

\subsubsection{Methods}

A variety of methods are used to study whole-networks. As is typical in studies of emerging social phenomena (e.g., Johnson et al. 2004), these may include qualitative methods (such as case studies and action research), quantitative methods (based on surveys or other observational methods), and mixed methods approaches (combining the above). Network analysis, which gathers data using surveys and observation, is also used in some studies, but is not necessary to use for the study of whole-networks. Provan's (2007) review of the literature provides examples of the use of each type of method. For purposes of the study of HIENs, openness to multiple methods, and support for mixed methods approaches, are strengths of whole-network theory. However, a limitation is the lack of parsimonious methods for measurement of key variables.

Strength: openness of methods - supports mixed methods approaches

Limitation: lack of parsimonious methods for measurement 


\subsubsection{Challenges in the Field of Whole-Network Research}

As of 2010, whole-network research is still at an exploratory stage of development (Provan et al. 2007; Raab et al. 2009). Noted challenges in the field include long time frames and costly observation methods for longitudinal comparative studies (Provan et al. 2007); idiosyncratic whole-network structures and processes which limit ability to use cross-sectional research designs (e.g., network bounding challenges (Laumann et al. 1989)); rapid evolution and transitory characteristics of whole-network phenomena (Raab et al. 2009); challenges posed by multiple levels of analysis (Brass et al. 2004); and, the organizational focus of researchers and their funders (Zaheer et al. 2010). For purposes of the study of HIENs, the exploratory stage of development and the many variables and relationships represent limitations of whole-network theory.

Limitation: exploratory stage of development of the theory

Limitation: many variables and relationships

Limitation: cost and extended time to do longitudinal case studies

\subsubsection{Summary of Strengths and Limitations}

The review of the whole-network literature has led to the identification of a number of strengths and limitations of whole-network theory for research on HIENs (Table 2). 
Table 2: Whole-Network Theory Strengths and Limitations

\begin{tabular}{|l|l|}
\hline Strengths & Limitations \\
\hline \hline $\begin{array}{l}\text { Emerging theory offering new insights into HIEN } \\
\text { challenges }\end{array}$ & Newness of field; small set of studies \\
\hline $\begin{array}{l}\text { Grounded in study of other complex public-private } \\
\text { networks, including in healthcare }\end{array}$ & Lack of study of HIENs \\
\hline Multi-level, multi-theoretic perspective & $\begin{array}{l}\text { Lack of studies of influence of IT on whole- } \\
\text { networks }\end{array}$ \\
\hline Nomological model with 'join' as key variable & Positive bias (networks are good) \\
\hline Structural attributes & $\begin{array}{l}\text { Lack of knowledge about validity of attributes for } \\
\text { HIENs }\end{array}$ \\
\hline Development attributes & Large number of factors and relationships \\
\hline Outcomes measures at multiple levels & Lack of parsimonious methods for measurement \\
\hline Governance typology & Cost and time to do longitudinal case studies \\
\hline Support for mixed methods approaches & $\begin{array}{l}\text { Challenges obtaining accurate network } \\
\text { measurement }\end{array}$ \\
\hline $\begin{array}{l}\text { Openness of methods - supports mixed methods } \\
\text { approaches }\end{array}$ & $\begin{array}{l}\text { Challenges of defining network boundaries for } \\
\text { study }\end{array}$ \\
\hline
\end{tabular}

On the strengths side, whole-network theory is an emerging theory offering valuable new insights. Grounded in study of other complex public-private networks, some in healthcare, it supports analysis at multiple levels, using multiple theories. Driven by a nomological model with 'join' as a key variable, it supports consideration of the effects of a variety of attributes, including structures, development factors, and type of governance, on decisions to join a whole-network. In addition it supports consideration of outcomes at multiple levels. Methodologically, it supports use of multiple methods for research.

On the limitations side, the newness of the field, the small set of studies, the lack of study of HIENs, and the lack of studies of how IT influences whole-networks raise questions about the validity of the theory for study of HIENs. In addition, methodological concerns appear related to the lack of parsimonious methods for measurement, the cost and extended time to do longitudinal case studies, and challenges of defining network boundaries for study. The lack of ability to address relationships between whole-networks 
and network IT seems critical. No whole-network research has been published looking specifically at whole-networks whose purpose is the development of information

technology based interorganizational systems (Provan et al. 2007); nor have empirical studies been published looking at the effects of IT on whole-networks (Raab et al. 2009). Yet, as the case of HIENs shows, network forms of IT can be highly influential on the formation of whole-networks, and, conversely, whole-network structures can be highly influential on how IT develops.

In summary, a key strength of whole-network theory is its focus on emerging network forms of organization like that used by HIENs. A key limitation is that wholenetwork theory does not consider the influence of information technology factors on whole-network development and success.

\subsubsection{Interorganizational Systems Theory}

\subsubsection{Reason for Selection}

IOS theory is selected for its potential to support research on the HIEN IOS participation challenge (IOS challenge). Specifically, the theory is expected to be useful for answering questions about why sought after organizations do or don't participate in using the HIEN technologies which are developed. Use of IOS theory is justified by the fit between IOS and HIENs. IOS are "automated information systems shared by two or more organizations and designed to link business processes" (Robey et al. 2008). HIENs fit this definition; they all seek to develop HIE (IOS) which link to the IS of two or more participating organizations in order to gather and exchange information among them. 


\subsubsection{2. $\quad$ History}

IOS research is a sub-discipline of the IS research field (Association of Information Systems 2010b). It originates in the 1980s as organizations begin adopting systems like electronic data interchange (EDI) to transmit data between organizations by electronic means. Its original (axiological) focus is helping organizations better understand how and why to adopt EDI. This leads to studies of factors affecting organizational adoption, and, studies of the effects of adoption on organizational outcomes (Barrett et al. 1982; Chester 1986). By 2008, IOS is a well established, growing field of study, with hundreds of studies published, and many new questions arising as new IOS applications develop using new technologies like wireless or extensible markup language (XML) (Robey et al. 2008). Academic problems of interest relate to "ownership and governance of business processes that span multiple organizations" in increasingly decentralized networks and across multiple jurisdictions (Robey et al. 2008).

Strength: established field for study of IOS adoption by organizations

Limitation: none

\subsubsection{Empirical Context}

Empirical studies in the IOS field focus on organizations, with an emphasis on larger, for-profit firms likely to invest in and adopt IOS like EDI (Robey et al. 2008). Types of IOS studied include EDI, supply chain management, and other pooled information resources such as airline reservation systems, common databases, communication networks or collaboration networks (Robey et al. 2008). Less research 
has been done in governmental and non-profit contexts, or on new kinds of IOS such as social network services.

Strength: study of transactional-oriented IOS like EDI

Limitation: lack of study of emerging forms of IOS

Limitation: lack of study of IOS use in non-corporate settings

\subsubsection{Theoretical Context}

IOS research is recognized as a multi-theoretic discipline for which a single overarching theory is unlikely to develop (Robey et al. 2008). Historically, much IOS research has relied on diffusion of innovations theory (Rogers 1995), while IOS research in the governance domain has relied mainly on transaction cost economics theory (Williamson 1981). However, theories including information processing theory, agency theory and game theory have also been used (Robey et al. 2008). There is growing interest in increasing the theoretical diversity in IOS studies, by, for example, extending discussions about IOS identity and legitimacy from more critical perspectives (King et al. 2006; Robey et al. 2008).

Strength: use of diffusion of innovations theory and transaction cost economics theory

Limitation: lack of theoretical diversity (e.g., critical theory perspectives) 


\subsubsection{Nomological Model}

The most common nomological model used in IOS research is shown in Figure 6. This involves consideration of various antecedents which affect organizational adoption of IOS. In this general model, governance related transaction cost factors can also serve as predictors of adoption. In addition, the model supports consideration of effects of IOS adoption on various outcome measures.

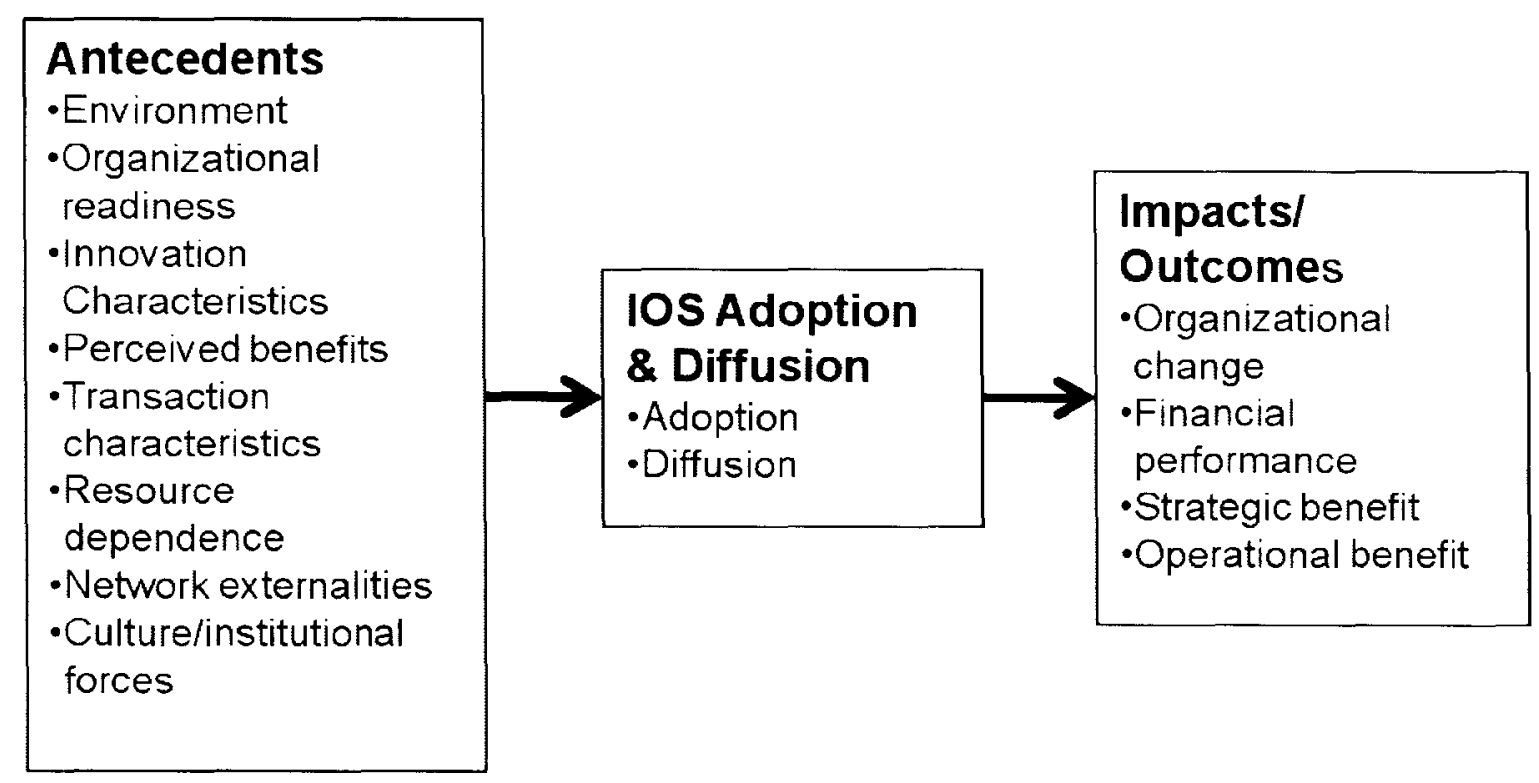

Figure 6: Interorganizational Systems Theory (Nomological Model)

It is important to note that most of these variables are at the organizational level. Environmental antecedents, for example, refer to the organization's environment - not a whole-network environment. Similarly, outcomes such as financial performance, organizational change or strategic benefit, refers to organizational outcomes. 
Strength: well developed model predicting organizational adoption of IOS based on organizational attributes and outcomes

Limitation: doesn't consider attributes at the whole-network level

\subsubsection{Methods}

Several methods are used in IOS research. Much of the research involves tests of hypotheses generated by diffusion of innovation theory or transaction cost economic theory. For these, quantitative data are generated from surveys or organizational data and analyzed using standard statistical techniques. However, qualitative methods such as case studies, action research, and textual analysis are also used, though less frequently, either alone or in mixed method studies (Robey et al. 2008).

Strength: established methods for hypothesis testing using data generated from surveys and organizational records 


\subsubsection{Challenges}

IOS researchers are facing a number of new challenges caused by the growth in diversity and scale of IOS under conditions of globalization (Robey et al. 2008). Challenges include addition of new theories, consideration of individual cognitive factors, participation in more critical discourse, and studies of IOS for new types of organizational forms (Robey et al. 2008). In addition, the field may benefit from consideration of the "impacts of interorganizational contexts on IOS capabilities and, conversely, the capacity of IOS capabilities to shape interorganizational contexts" (Robey et al. 2008).

Strength: None

Limitation: lack of research on impact of interorganizational contexts on IOS adoption and outcomes

\subsubsection{Summary of Strengths and Limitations}

The review of IOS theory has identified strengths and limitations for research on the HIEN IOS participation challenge (Table 3). 
Table 3: IOS Theory Strengths and Limitations

\begin{tabular}{|l|l|}
\hline Strengths & Limitations \\
\hline $\begin{array}{l}\text { Established field for study of IOS adoption by } \\
\text { organizations }\end{array}$ & Lack of study of emerging forms of IOS \\
\hline Study of transactional-oriented IOS like EDI & Lack of study of IOS use in non-corporate settings \\
\hline Use of diffusion of innovations theory & $\begin{array}{l}\text { lack of theoretical diversity (e.g., critical theory } \\
\text { perspectives) }\end{array}$ \\
\hline Use of transaction cost economics theory & $\begin{array}{l}\text { Doesn't consider attributes at the whole-network } \\
\text { level }\end{array}$ \\
\hline $\begin{array}{l}\text { Well developed model predicting organizational } \\
\text { adoption of IOS based on organizational attributes } \\
\text { and outcomes }\end{array}$ & $\begin{array}{l}\text { Lack of research on impact of interorganizational } \\
\text { contexts on IOS adoption and outcomes }\end{array}$ \\
\hline $\begin{array}{l}\text { Established methods for hypothesis testing using } \\
\text { data from surveys and organizational records }\end{array}$ & \\
\hline
\end{tabular}

On the strengths side, IOS research is an established field for understanding IOS adoption by organizations, with an emphasis on study of transactional-oriented IOS like EDI. As a multi-theoretic discipline, its workhorse theories are diffusion of innovations theory and transaction cost economics theory. These have led to well developed models for predicting organizational adoption of IOS based on organizational attributes and outcomes. Well established methods are found for hypothesis testing using data generated from surveys and organizational records. It appears reasonable to think that the IOS body of knowledge could be used to predict barriers to adoption of HIEN systems by some organizations - especially when HIEN services are transactional in nature.

On the limitations side, the IOS research field is constrained by a lack of study of emerging forms of IOS, lack of study of IOS use in non-corporate settings, lack of theoretical diversity (e.g., critical theory perspectives, lack of consideration of attributes at the whole-network level, and lack of research on impact of interorganizational contexts on IOS adoption and outcomes. These limitations seem significant within a HIEN context. HIEN technologies, are, in general far more complex than typical EDI systems; HIENs must connect with systems used by a broader range of organizations, typically 
including government, non-profits, and small-businesses like physicians' offices; decisions to adopt may not be driven just by economic benefit, but may also be influenced by concepts like social justice which require different theories to model; and, finally, HIEN characteristics at the whole-network level clearly have a significant effect on technology design and subsequent adoption.

In summary, a key strength of IOS theory is its ability to predict adoption of transactional types of IOS in large profit-driven organizations. A key limitation is lack of ability to consider effects of whole-network level factors on participation by an organization.

\subsubsection{TAM theory}

\subsubsection{1. $\quad$ Reason for Selection}

Technology acceptance model (TAM theory) is selected for its potential to support research on the HIEN individual technology participation challenge (individual challenge). Specifically, TAM theory promises to be useful to help answer questions about why individuals like physicians, nurses or patients do or don't adopt and use HIEN technologies. The selection is justified by the fit between TAM theory and HIEN characteristics. The so called technology acceptance models (TAM) (Venkatesh et al. 2003; Venkatesh et al. 2010), developed in the IS field, focus on factors affecting individual adoption of IT in organizational contexts. They are highly effective at predicting such adoption in a broad range of contexts. This fits with HIENs' need to better understand factors affecting individual participation in HIEN technologies, 
particularly when such acceptance by individuals is a requirement in order for HIENs to satisfy the ubiquity requirement.

\subsubsection{History of TAM theory}

TAM research emerges in the 1980s out of early efforts to understand how and why individuals adopt information technology in organizational settings (Davis et al. 1989). As organizations increase investments in IT, the question of whether individuals will use it becomes increasingly important to answer before investing. Delone and Mcleans synthesize a decade of research to provide a seminal model of antecedents which predict individual acceptance and use of information technology (1992). A steadily increasing volume of studies and refinements of theory ensue (Bagozzi 2007; Benbasat et al. 2007; Davis et al. 1989; Delone et al. 2003; Straub et al. 1995; Venkatesh et al. 2000). Current versions demonstrate strong predictive validity in multiple organizational and cultural contexts, and can explain up to $70 \%$ of variance in individual technology use in organizations (Venkatesh et al. 2008; Venkatesh et al. 2010).

Strength: mature, robust theory for predicting individual adoption of IT in organizational contexts

Limitation: none

\subsubsection{Theoretical Foundations}

The theory of planned behavior (TPB) (Ajzen 1991) provides theoretical underpinnings for TAM theory. Developed in the field of social psychology, TPB 
proposes that individual behavior is determined by three factors: individual attitudes towards the behavior, subjective norms shaping the behavior, and perceived ability to control the behavior. TPB efficacy in predicting behavior is supported by numerous empirical studies (Ajzen 1991; Armitage et al. 2001). TAM theory reflects successful adaptation of TBP for predicting individual adoption of IT. TAM theory has also evolved to include elements from other theories such as innovation diffusion theory and social cognition theory. For example, the unified theory of acceptance and use of technology (UTAUT) is a TAM based model with eight constructs, some of which are drawn from other areas (Venkatesh et al. 2003; Venkatesh et al. 2010). However, TAM-based approaches all focus on an individual's planned behavior - in this case their plan to use (or not use) IT - as a key dependent variable.

Strength: use of highly validated theory of planned behavior (TPB)

Limitation: only applies to individuals

\subsubsection{4. $\quad$ Nomological Model}

The nomological model used in TAM studies (Figure 7) looks at factors affecting acceptance, and subsequent outcomes. Antecedents (independent variables or IVs) include effort expectancy, performance expectancy, facilitating conditions, and social influence. Individual acceptance (dependent variable or DV) is measured either through intention to use (a factor which can be included in the questionnaire) or actual IT use (a factor which requires subsequent measurement of actual use of IT). Actual IT use is 
difficult to measure reliably (Straub et al. 1995; Venkatesh et al. 2003), and studies show that intention to use correlates with actual IT use at acceptable levels. Hence, studies tend to use intention to use as the DV (Venkatesh et al. 2003). The third part of the model focuses on outcomes. Here, acceptance and use of technology by individuals is treated as an IV, and effects of use on individuals and organizations are treated as the DV.

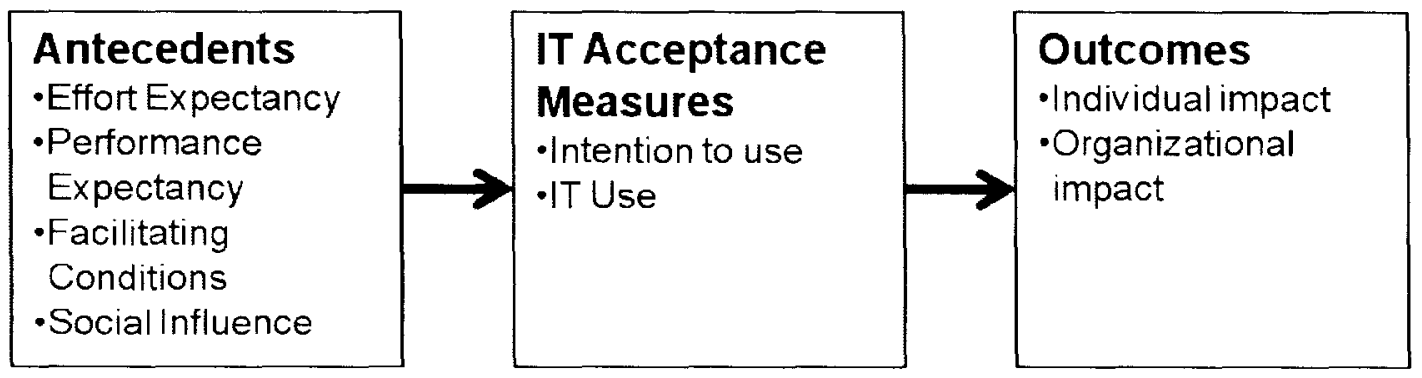

Figure 7: Technology Acceptance Model

Strength: TAM provides a well defined, validated set of variables for study of IT adoption.

Limitation: none found

\subsubsection{5. $\quad \underline{\text { Methods }}$}

TAM studies rely predominantly on the use of structured questionnaires. TAM questionnaires have been refined to include as few as 16 questions suitable for statistical analysis and are administered to a sample of individuals who are considering adoption of a new information technology (Venkatesh et al. 2003). 
Strength: simple and easy to administer questionnaires

Strength: analysis using established statistical methods like OLS regression

Limitation: none

\subsubsection{Challenges}

Current challenges on which TAM researchers are focused include efforts to adapt TAM theory for use across cultures (Venkatesh et al. 2010), a proposal for a paradigm shift to add additional variables and concepts (Bagozzi 2007), extensions of the approach to include effects of social networks (Sykes et al. 2009), integration with the five factor personality model (Devaraj et al. 2008), a focus on individual interactions with technology at a micro level (Al-Natour et al. 2009) and adaptation to consumer contexts (Pavlou 2003). An overarching challenge relates to the proliferation of TAM-like models, and lack of standardized TAM approaches (Benbasat et al. 2007). However, no work appears in the literature looking at applying TAM, or similar models, to predict individual participation in whole-networks.

Strength: none

Limitation: lack of application to individual participation in whole-networks

\subsubsection{Summary of Strengths and Limitations}

TAM theory has obvious strengths for research on factors affecting individual acceptance of technology in organizational settings. It is a mature, robustly predictive 
theory; it features a well defined, validated set of variables; it has simple, easy to administer questionnaires; and responses can be analyzed using established statistical methods. These strengths are illustrated by the success of recent TAM studies of EMR adoption in hospitals and physician practices (Bhattacherjee et al. 2007; Boonstra et al. 2009; Davidson et al. 2005; Klein 2007). However, TAM theory also has important limitations for the study of whole-networks, including its focus on the individual, and lack of application in whole-network contexts.

Table 4: IOS Theory Strengths and Limitations

\begin{tabular}{|l|l|}
\hline Strengths & Limitations \\
\hline $\begin{array}{l}\text { Mature, robust theory for predicting individual } \\
\text { adoption of IT in organizational contexts }\end{array}$ & Only applies to individuals \\
\hline $\begin{array}{l}\text { Use of widely validated theory of planned behavior } \\
\text { (TPB) }\end{array}$ & $\begin{array}{l}\text { Lack of application to individual participation in } \\
\text { whole-networks. }\end{array}$ \\
\hline $\begin{array}{l}\text { Provides a well defined, validated set of variables } \\
\text { for study of IT adoption: }\end{array}$ & \\
\hline Simple easy to administer questionnaires & \\
\hline Analysis using established statistical methods & \\
\hline
\end{tabular}

In summary, a key strength of TAM theory is its ability to predict adoption of IT by individuals in organizational contexts. A key limitation is lack of application of TAM to individual decisions to participate in whole-network contexts.

\subsection{Literature Review - Summary}

Table 5 summarizes main points established in the literature review. From $2004-$ 2010, community and state HIENs in the U.S. experience three challenges which limit their ability to achieve their stated goals. These are the challenges of whole-network participation, IOS participation and individual participation. Three theories are selected 
with potential to support research on those challenges. However, critical limitations exist with each. Whole-network theory, while useful for study of the whole-network challenge, is limited by lack of ability to consider IT factors. Conversely, IOS and TAM theories, while useful for the study of the IOS and individual challenges, are limited by lack of consideration for whole-network factors. Thus, the literature review points to the need for new theory which can incorporate the strengths of each theory while addressing its limitations.

Table 5. Summary of Literature Review Findings

\begin{tabular}{|l|l|l|l|}
\hline Challenge & Theoretical approach & Strengths & Limitations \\
\hline $\begin{array}{l}\text { Whole-network } \\
\text { participation }\end{array}$ & $\begin{array}{l}\text { Whole-network theory } \\
\text { (Provan et al. 2007) }\end{array}$ & $\begin{array}{l}\text { Studies new whole- } \\
\text { network forms of which } \\
\text { HIENs are emerging } \\
\text { examples } \\
\text { Multi-theoretic }\end{array}$ & $\begin{array}{l}\text { Early stage of } \\
\text { development } \\
\text { Doesn't consider IT }\end{array}$ \\
\hline $\begin{array}{l}\text { Interorganizational } \\
\text { system participation }\end{array}$ & $\begin{array}{l}\text { Interorganizational system } \\
\text { adoption research (Robey et } \\
\text { al. 2008) }\end{array}$ & $\begin{array}{l}\text { Identifies various factors } \\
\text { affecting organizational } \\
\text { adoption of IOS }\end{array}$ & $\begin{array}{l}\text { Organizational focus } \\
\text { Doesn't consider } \\
\text { whole-networks }\end{array}$ \\
\hline $\begin{array}{l}\text { Individual technology } \\
\text { participation }\end{array}$ & $\begin{array}{l}\text { Technology acceptance } \\
\text { models (Venkatesh et al. } \\
\text { 2003) }\end{array}$ & $\begin{array}{l}\text { Identifies various factors } \\
\text { affecting individual } \\
\text { acceptance of IT }\end{array}$ & $\begin{array}{l}\text { Focus on individuals } \\
\text { in organizational } \\
\text { contexts } \\
\text { Doesn't consider } \\
\text { whole-networks }\end{array}$ \\
\hline
\end{tabular}




\section{CHAPTER 3. THEORY}

In the preceding literature review, three theories of potential value for research on barriers affecting HIEN participation were reviewed. None of the theories, alone, was found to be sufficient for the study of whole-networks, like HIENs, which are significantly influenced by information technology. Thus, a need to develop new theory was identified. To meet this need, a network information technology dependent wholenetwork (dual network) participation theory (DNPT) is proposed to support the study of factors affecting participation in dual networks like HIENs. Development of new crossdisciplinary theory has been recognized as important for advancing knowledge in both organizational and technological contexts (Christens et al. 2008; Grover et al. 2008; Orlikowski et al. 2001; Whetten et al. 2009).

With respect to Reynolds three forms of theory (set-of-laws, axiomatic or causal) (2007) The DNPT is developed as a causal theory, mirroring the form used by the three source theories. The theoretical form satisfies Reynolds's criteria for abstractness (independence from time and space), empirical relevance (falsifiability based on observations), and intersubjectivity (draws upon existing concepts and understandings agreed upon by a community of scholars).

Theory development involves at least four types of research: development of terminology (descriptions of a phenomena), gaining understanding (generating better ideas about how and why a phenomena occurs), explanation (generating falsifiable 
statements about why past events occurred); and prediction (generating falsifiable predictions about future events) (Babbie 2007; Reynolds 2007). This study focuses on advancing knowledge in the first three areas: terminology, understanding and explanation.

Theories develop through iterative processes involving focus on a real-world problem, development of a tentative theory and eliminating errors in the theory through hypothesis testing which leads to a new set of problems (Popper 1972). This study is presented as an iteration in a Popperian process of falsification.

The DNPT is presented in 5 sections: 1.) definitions (what are dual networks); 2.) evolution (where do dual networks come from); 3.) The general form of the theory (the "why" of the theory); 4.) DNPT elements, interactions and hypotheses (the "what and "how" of the theory); and 5.) DNPT limitations (the "who, where and when" of the theory). By the chapter's end, four dimensions of a theoretical contribution (Whetten 1989) are addressed: what key concepts define the phenomena of interest? why do they emerge? how are they related? and for whom, when, and where are they valid?

\subsection{Definition}

In the DNPT, dual networks are defined as network information technology (network IT) dependent whole-networks. In this definition, network IT refers to properties of electronic communications network connected electronic information systems (Orlikowski 1992); whole-networks refers to properties of a consciously created group of three or more autonomous but interdependent organizations striving to achieve a 
common goal and jointly produce an output (Provan et al. 2007); dependent means that the whole-network could not plausibly achieve its goals without the use of network IT. In addition, as used in the theory, the term individual refers to an individual person (a human agent) involved in a dual network as a designer, participant, funder, decision-maker or user. The term organization refers to a goal directed group with a formal charter, with organizational dimensions such as "structural arrangements, business strategies, ideology, culture, control mechanisms, standard operating procedures, division of labor, expertise and communication patterns, as well as environmental pressures such as government regulation, competitive forces, vendor strategies, professional norms, state of knowledge about technology and socio-economic conditions" (Orlikowski 1992).

\subsection{Evolution}

Where do dual networks come from and how and why do they develop? Raab et al. (2009) provide a useful perspective in Heading Toward a Society of Networks. They postulate that a new form of human collective - whole-networks - are "about to become the new dominant form in the future replacing the formal hierarchical organization that has dominated the $20^{\text {th }}$ century". They support this claim by observing four stages of development of human collectives through history. These stages, illustrated in Figure 8 , develop as a result of streams of innovation in the areas of organization, technology, organizational research, and information systems research. 


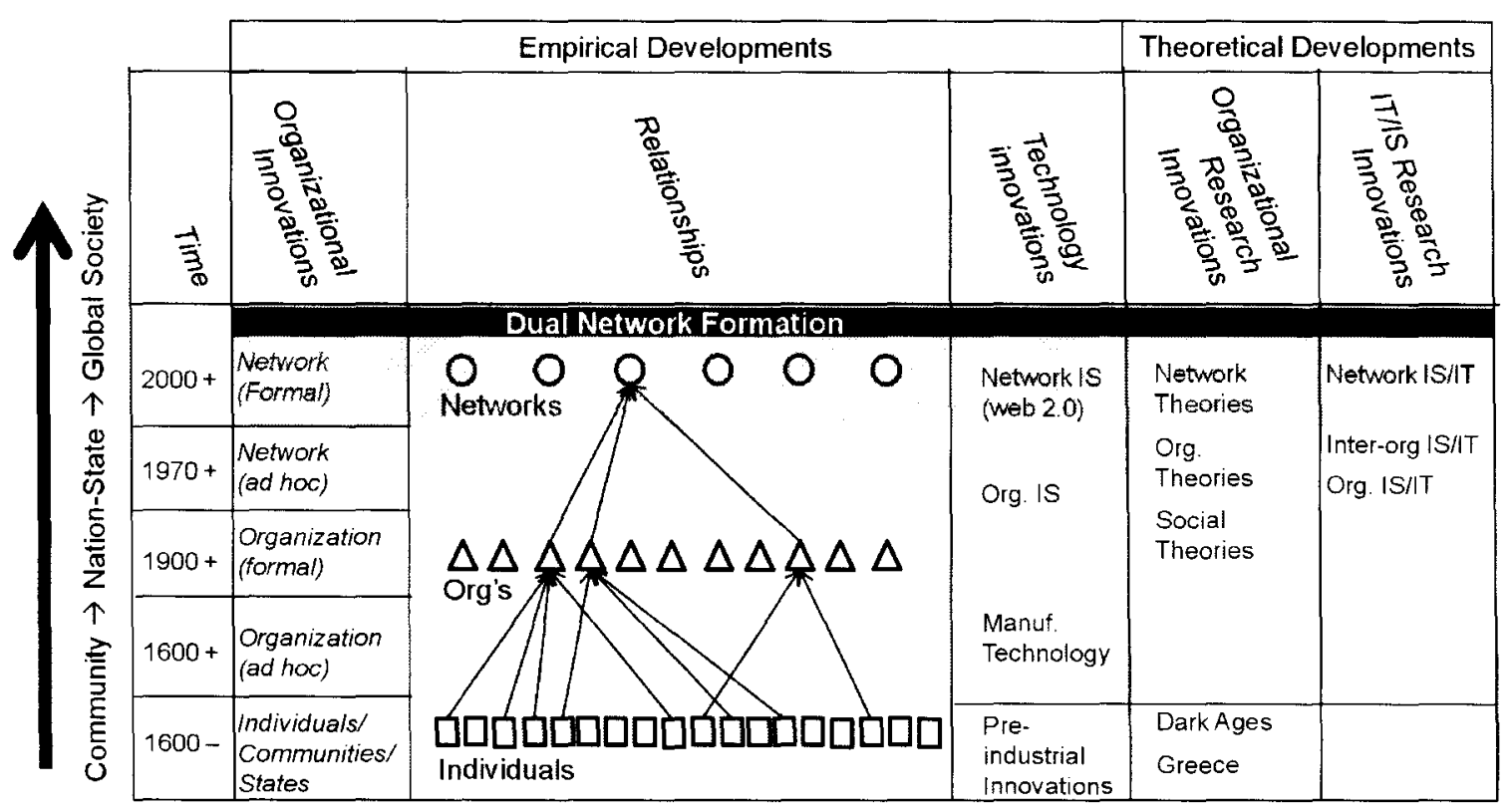

Figure 8: The Emergence of Dual Networks (Illustration by Thornewill)

The first stage, beginning around 1600, involves emergence of informal organizations. People in this stage do not conceive of organizations as entities separate from their owners and operators. However, over time, organizational innovations (laws, regulations, methods, institutions) develop, until, around 1900, an age of formal organizations begins. In this stage, people begin to conceive of organizations as formally separate and distinct from individuals. Theoretical innovations in organizational research, such as organizational theories, support this process of formalization.

The evolution of networks recapitulates that of organizations. Driven by information technology, informal networks of organizations begin emerging around 1970 (Castells 2000). Around 2000, formal networks - whole-networks - begin to be recognized as distinct and separate from organizations. Theoretical innovations in science, such as network analysis, also support this process of formalization. 
While Raab et al.'s paper presents a useful perspective on the evolution of organizations and networks, it does not substantively address the role of information technology (IT) and IT theory in the development of network forms of organization. To complement their work, I include in Figure 8 two columns representing the empirical development of technology and development of new theories of technology.

As has been broadly discussed (e.g., Eischen 2000; Leiner et al. 2009; Wikipedia 2010; Williams 1997), development of technology can be seen occurring in four broad historical phases. The first phase, that of pre-industrial innovations, involves development of technologies such as tools and methods for agriculture, building, and record-keeping like those used in city-states up to the 1600s. The second phase, that of manufacturing technology innovations, involves development of mass production innovations starting in the $17^{\text {th }}$ century in areas like textiles and mining, and progressing to areas like transportation (trains and ships), household goods, and so on. The third phase, that of organizational information systems (IS) innovations beginning in the mid$20^{\text {th }}$ century, involves development of information technology to automate organizational processes. This phase includes inventions of computing technologies (mainframes microcomputers and personal computers) and software (accounting, inventory management, contact management, document production and so on) to automate labor-intensive organizational functions. The fourth phase, that of network IT innovations, begins to emerge in the 1970s with the invention of networking technologies. These evolve at every scale from local (local area networks) to global (worldwide satellite communication networks). Network IT begins to be used outside the organization to support inter-organizational exchange of information (electronic data interchange, VISA) 
and new kinds of network-level exchange between individuals and organizations (the internet, the World Wide Web, peer production networks like Wikipedia, value networks, and so on). New forms of network IT based work appear (global outsourcing, homebased work, mobile work using hand-held devices, and etc.). Many experts believe that the pace of network IT innovation is likely to increase in the future.

Clearly, given its impact, developing scientific knowledge about the nature and effect of IS/IT on individuals, organizations and society is important. To this end, IS/IT research begins developing in the 1960's. It initially focuses on management information systems (MIS), drawing attention to the use of information technology to improve organizational production processes (Mason et al. 1973). At the time, the field is characterized by largely positivistic research methods, corresponding to the prevailing theories of the firm as mechanical systems supported by controlled technologies. From the 1970's through the 1990s, IS/IT research grows rapidly (Association of Information Systems 2010b). Methodologically, research expands from a largely positivist, quantitative focus, to embrace qualitative methods (Baskerville et al. 1998; Benbasat et al. 1987; Walsham 1995), more complex theories of causality such as structuration theory (Desanctis et al. 1994; Orlikowski 1992), critical theory perspectives (e.g., Hart et al. 1997), and design science based approaches (Hevner et al. 2004). Research in technology acceptance models (TAM) focuses on predicting individual acceptance and use of IT in organizational settings. In the 2000 s, a growing body of research on network perspectives (as they relate to organizations) begins to appear in top IS journals (see discussion in Chapter 2 for details). However, no formal research or theories of network IT related to whole-network theories appear in the IT literature. 
In summary, the evolution of network IT enabled whole-networks, or dual networks, occurs as a result of field observations (organizational innovations and network innovations) and theoretical developments (organizational research innovations and IS/IT research innovations). Thus, dual networks can be seen as a new, emerging form of human collective, whose development and success is shaped by a complex set of factors.

\subsection{The General Form of the DNPT}

The brief history of innovations in the prior section introduces a broad array of factors with potential to affect development of dual networks. Given this complexity, can a parsimonious theory be developed to predict dual network development and success?

The DNPT is developed based on the idea that the theory of planned behavior (TPB) (Ajzen 1991) which underlies TAM theory can be used to reduce the complexity of variables to a manageable level for the study of dual network participation.

TPB focuses on an individual's planned behavior as a dependent variable in research (Ajzen 1991). A highly cited theory, TPB's popularity derives from at least three benefits it offers to researchers.

First, TPB is based on findings in psychology that individual planned behavior is influenced by a few consistent factors related to an individual's core beliefs. These include individual attitudes towards the behavior based on beliefs about the effects of the behavior, subjective norms shaping the behavior based on beliefs about how other 
important people will perceive the behavior, and perceived ability to control the behavior based on beliefs about ability to control the outcomes of the behavior.

Second, planned behavior correlates strongly with actual behavior in many contexts (Venkatesh et al. 2003). This is important because the gathering of actual data about use or participation can be expensive, time-consuming and subject to measurement error (Devaraj et al. 2003; Straub et al. 1995).

Third, data about planned behavior can often be captured simply and reliably using survey instruments. For example, TAM related instruments can reliably capture factors affecting individual employees' planned behavior with respect to use of information technology. UTAUT, for example, uses 16 questions to predict $70 \%$ of the variance in planned behavior to use IT in a wide range of settings (Venkatesh et al. 2003).

As shown in Figure 9, below, the DNPT draws on these concepts to theorize that dual network attributes (whole-network and network IT attributes) will influence four predictors, which are beliefs of organization-affiliated individuals about participation benefits (benefit expectancy), costs (low cost expectancy), norms (social influence) and ability-to-control outcomes (facilitating conditions). These predictors will, in turn, influence intent to have organization participate. Intent to participate may also be influenced by moderators - organizational moderators like size or age, or, individual moderators like gender or education level. Intent to participate will lead to actual participation which creates outcomes. Outcomes will influence dual network attributes and predictors. The area inside the gray box is where potential exists for successful development of predictive theory along the lines of TAM. 
Given a qualified dual network participation opportunity...

\section{Dual Network Attributes Predictors (IV) Participation (DV) Outcomes}

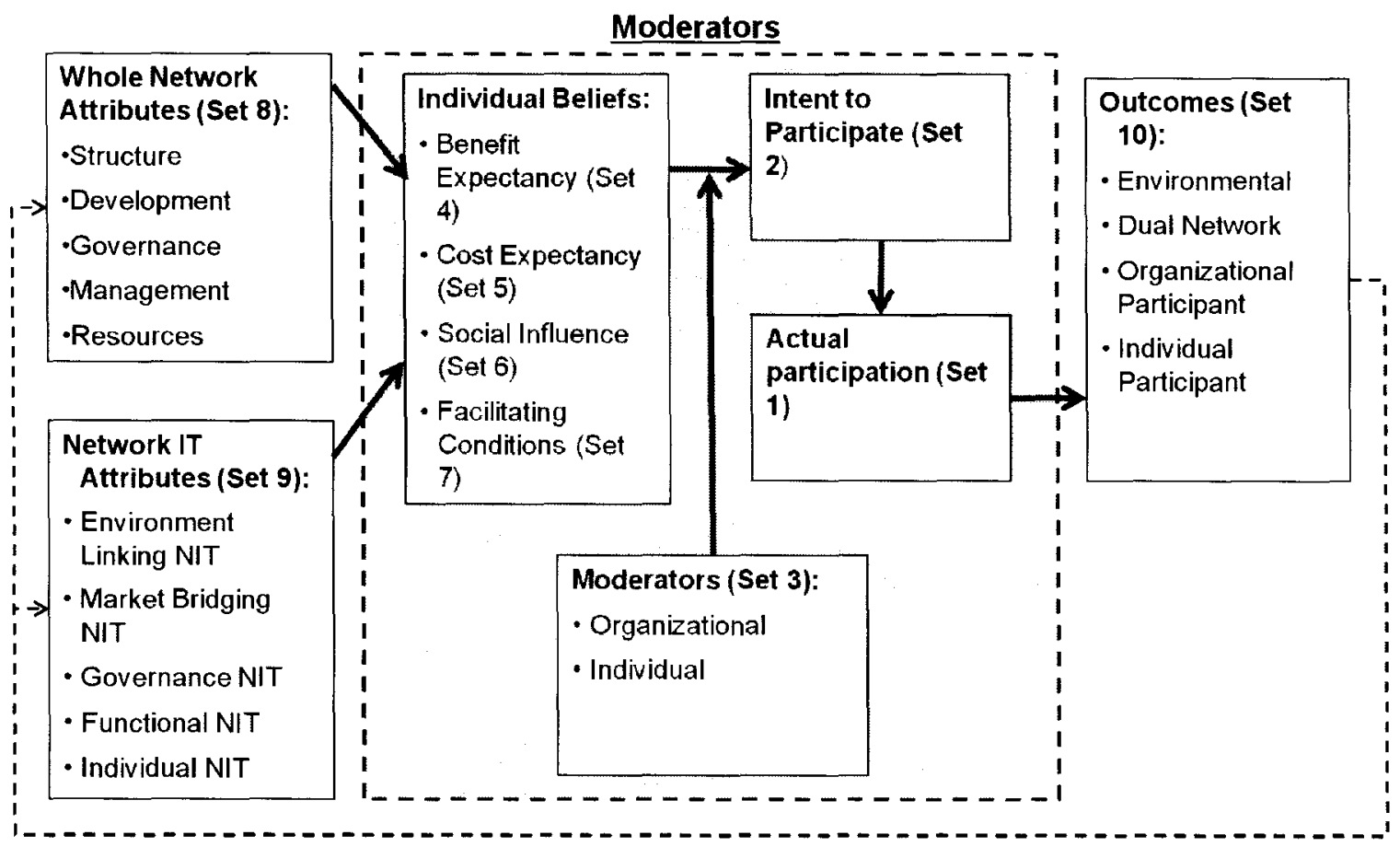

Figure 9: Dual Network Participation Theory

A hypothetical scenario illustrates the basic idea. A CEO may spend several months developing plans to participate in a dual network (formation of intention to participate). She also 'socializes' the idea with other senior managers and board members who form their own opinions (formation of intent to participate). This process culminates in a proposal to a board of directors to authorize the organization to participate (decision to participate). Upon approval, the CEO signs a formal participation agreement with the dual network (actual participation starts). After a year of participation the participation agreement is evaluated (dotted line showing feedback). Feedback is received from employees about unanticipated problems caused by the participation, and from a key board member regarding a potential competitive risk associated with participation 
(individual reactions to participation). This feedback causes the CEO to rethink her interest in having the organization participate (intent to participate). The CEO reduces the level of participation of the organization for year 2 (actual participation). Can such behaviors be predicted?

In its general form, the DNPT generates three falsifiable propositions:

- $P_{1}$ : increase in $X_{D N}$ attribute will increase $Y_{\text {predictor }}$

- $P_{2}$ : increase in $X_{\text {predictor }}$ will increase $Y_{\text {intent to participate }}$

- $P_{3}$ : increase in $X_{\text {participation will increase }} Y_{\text {outcome }}$

\subsection{Operationalizing the Theory (Elements, Interactions and Hypotheses)}

To operationalize the DNPT, variables relevant to HIENs are drawn from the three source theories and used to generate falsifiable hypotheses. Ten sets of variables, $(\sim 85$ in all) are developed. These are:

- Set 1: Actual Participation (how do individuals actually participate)

- Set 2: Intent to Participate (individual intent to have organization participate)

- Set 3: Moderators

- Set 4: Predictors - Benefit Expectancy

- Set 5: Predictors - Cost Expectancy

- Set 6: Predictors - Social Influence

- Set 7: Predictors - Facilitating Conditions

- Set 8: Whole-network Attributes

- Set 9: Network IT Attributes

- Set 10: Outcomes

Details about each proposed set of variables and their theorized relationships and effects follow. Consistent with recommendations for new theory development, the DNPT errs on the side of including more variables, rather than less, to reduce risk that potentially important concepts aren't excluded too early (Whetten 1989). Particular attention is paid 
to the area within the dotted lines because of the potential this area offers for parsimonious theory similar to TAM.

\subsubsection{Set 1. Actual Participation}

The literature suggests potential for a number of different measures of actual participation in dual networks. For example, in TAM research, actual participation by individuals is measured by factors such as minutes of time logged in to a particular software system (Straub et al. 1995; Venkatesh et al. 2003). In the IOS literature, organizational adoption of electronic data interchange (EDI) is often measured binarily (does the organization use EDI?) (Reimers et al. 2010; Robey et al. 2008). In the wholenetwork literature, little research has been done on participation measures. However, the literature suggests that a range of types of participation may occur from participation in informal planning networks to participation in formal joint-venture arrangements (Provan et al. 2007). How should actual participation be measured?

The DNPT proposes to measure actual participation in the context of a qualified dual network participation opportunity. A qualified participation opportunity is defined as an opportunity for a participant to obtain meaningful benefits by participating in a dual network. Based on this definition, a dual network participation opportunity could include an opportunity to participate in a dual network exploratory meeting, engage in a dual network planning process, sit on a board, capitalize a project or sign a multi-year services contract.

This discussion opens new questions about actual participation. What different types of participation opportunities are made by dual networks? Are relationships 
between intent to participate and actual participation consistent across these different types of participation opportunities?

\subsubsection{Set 2. Intent to Participate}

Actual participation can only be measured after the fact, and thus has limited value to researchers seeking to predict participation. However, intent to participate can serve as a useful proxy for actual participation. Having a way to measure intent to participate is essential to the DNPT. Variables to measure intent to participate are developed by modifying the approach used by Venkatesh (2003) for TAM, based on TPB guidelines for development of TPB theory and questionnaires (Ajzen 2011b). Three variables are proposed, designed to capture intent to participate (IP1), likelihood to participate (IP2), and plans to participate (IP3).

Two rationales support this selection. First, these questions have been well validated for employees in organizational settings who must make decisions about whether a behavior (using IT) is in the interest of themselves and their organization (Venkatesh et al. 2003). Since organizational leaders must make a similar set of calculations when considering a decision to participate in something like a dual network, modifications of the question seem reasonable to make.

Second, the decision to participate is, ultimately, made by an individual. Albeit influenced by others (such as other organizational leaders), an organizational leader at a certain point makes an individual decision about whether or not to commit his/her organization to a course of action. This claim is confirmed by the use of 'intention to 
adopt" in surveys completed by organizational leaders in studies of EDI adoption by organizations.

Nevertheless, there are clearly differences between an individual decision to use IT (the TAM focus) and an organizational leader's decision to commit an organization to participate (the DNPT focus). As formulated, are these variables valid for measuring intent to participate by both individuals and organizations? Are other variables needed to capture intent to participate in a dual network context?

\subsubsection{Set 3. Moderators}

The DNPT also proposes that moderators related to characteristics of individuals and organizations will moderate intent to participate. Drawing from Venkatesh (2003), proposed individual moderators are age (M1), gender (M2), and DN experience (M3). Proposed organizational moderators are organization size (M4), and organization experience with DN (M5). Are these proposed moderators valid in a dual network context? What other individual and organizational moderators moderate participation in dual networks?

\subsubsection{Sets 4-7. Predictors}

Having discussed intent to participate as the key dependent variable for the research and moderators which may affect this participation, the discussion now turns to predictors which may affect it. Four predictors, adapted from Venkatesh (2003), are proposed: benefit expectancy, low cost expectancy, social influence and facilitating conditions. 


\subsubsection{Set 4. Benefit Expectancy}

Benefit expectancy is derived from Venkatesh's concept of performance expectancy (2003). It encompasses attitudes towards a behavior based on behavioral beliefs about the likely benefits of the behavior (Ajzen 1991). The behavior of interest is an organizational leader's decision to sign a contract or otherwise commit the organization to participate in a dual network. Presumably, the leader's decision will be influenced by expectations that the participation will benefit the organization and the leader in some manner. These benefits may include improved ability for the organization to do its work (BE1), provide ability to accomplish tasks more quickly (BE2), increase the organization's productivity (BE3) or improve financial performance (BE4). In addition, the leader is likely to support participation that delivers personal benefits (BE5). Finally, the IOS literature finds that IOS adoption may be influenced by strategic factors such as interest in increasing innovation, influencing business process change, improving trading partner relationships and other factors (Robey et al. 2008). Thus, other factors may also affect benefit expectancy (BE6).

While these benefit expectancy factors seem reasonable to consider, they have not been evaluated in a dual network context. Are these factors valid in a dual network context? Are they the most relevant factors influencing organizational leaders' determination of benefit expectancy? What other benefit expectancy factors influence participation in dual networks? 


\subsubsection{Set 5. Cost Expectancy}

Cost expectancy is derived from Venkatesh's concept of effort expectancy (2003). It encompasses attitudes towards a behavior based on behavioral beliefs about the likely costs of the behavior (Ajzen 1991). Again, the behavior of interest is an organizational leader's decision to sign a contract or otherwise commit the organization to participate in a dual network. Presumably, the leader will make the decision based on a belief that there will be costs involved in participation. These costs may include individual leader time and effort (CE1), organizational time and effort (CE2), financial commitment (relative to overall resources) (CE3), social capital investment by the leader (CE4) and organization (CE5).

Are these cost expectancy factors valid in a dual network context? Are they the most influential factors organizational leaders consider in determining cost expectancy? What other cost expectancy factors influence participation in a dual network?

\subsubsection{Set 6. Social Influence}

Social influence is derived from Venkatesh's concept of the same name (2003). It encompasses subjective norms influencing a behavior based on normative beliefs about the behavior (Ajzen 1991). Social influence may be affected by whether other influential people think the organization should participate (SI1), people important to the leader think the organization should participate (SI2), and people to whom the leader reports think the organization should participate (SI3).

Are these social influence factors valid in a dual network context? Are they the most relevant factors in determining social influence? Are there other factors which influence social influence in a dual network context? 


\subsubsection{Set 7. Facilitating Conditions}

Facilitating conditions is derived from Venkatesh's concept of the same name (2003). It encompasses beliefs about the "presence of factors that may facilitate or impede ability to control the performance of the behavior and the perceived power of these factors" (Ajzen 2011a (italics added)). These control beliefs give rise to perceived behavioral control. In general, perceived behavioral control is hypothesized to increase intention to perform a given behavior (Ajzen 1991). Facilitating conditions may exist at the level of the individual, organization, dual network and environment. They may include access to resources (FCI, FC2, FC3), knowledge (FC4, FC5, FC6), tools and technologies (FC7, FC8, FC9), and support personnel (FC10, FC11, FC12) (Venkatesh et al. 2003). Environmental conditions may include environmental stability (FC13) and resource munificence (FC14) ( (Provan et al. 2007).

Are these proposed factors for measuring facilitating conditions valid in a dual network context? Is there overlap between individual and organizational factors? Are there other factors not included here which contribute to facilitating conditions in dual network context?

\subsubsection{Sets 8-9. Dual Network Attributes}

Having completed a review of proposed DNPT predictors and moderators, the discussion now turns to an analysis of dual network attributes which may affect the predictors (which in turn affect intent to participate and actual participation). Selected attributes from the whole-network and network IT literatures are considered. A subset which appears most likely to influence predictors is highlighted. 


\subsubsection{Set 8. Whole-Network Attributes}

As discussed in the literature review, attributes of whole-networks which influence whole-network outcomes are identified in the areas of structure, development and governance (Provan et al. 2007).

Network measures including density, centralization, differentiation and cliques can have both positive and negative influences on whole-network development (Provan et al. 2007). In the DNPT, they are hypothesized to affect social influence (SI). However, they can also have confounding effects on one another, have positive or negative effects on a whole-network's success depending on the situation, and require use of specialized social network survey instruments which can be challenging to administer and interpret in early stage or rapidly growing networks (Laumann et al. 1989; Provan et al. 2007).

Resource availability (WN1) strongly affects the ability of whole-networks to develop and achieve participation goals over time (Provan et al. 2007; Provan et al. 1995). This attribute is hypothesized to positively affect facilitating conditions (FC). Rules and norms as steering mechanisms (WN1a) can positively affect wholenetwork development, as can processes by which participating organizations develop and learn about these rules and norms (WN2) (Sydow et al. 1998; van Raak et al. 2001). These attributes are hypothesized to affect Social Influence (SI).

In addition, a number of dual network variables are hypothesized to have potential to positively affect all four attributes.

A dominant core (WN3) of organizational and individual leaders strengthens development of networks (Owen-Smith et al. 2004), as do embedded relationships (WN4), particularly those based on shared successes in the past (Gulati et al. 1999). 
Different types of whole-network governance (WN5) are hypothesized as effective for dual networks of different sizes (Provan et al. 2008). Shared governance (where participants share leadership responsibilities) is beneficial for highly cohesive whole-networks with less than 6-8 participants. Lead organization governance (in which one organizational participant leads and administers the network) is effective for moderate number of organizational participants in a whole-network of moderate complexity. Network administrative organization (NAO) governance (in which an independent NAO supports the whole-network) is effective for networks including large numbers of participants and more complex network processes).

Formalization, such as formalized rules, written agendas and decision-making procedures (WN6), and network inner stability (levels of trust, reciprocity and norms of cooperation) (WN7) have positive effects on whole-network success, as do network inner stability (levels of trust, reciprocity and norms of cooperation) have positive effects (Provan et al. 2008).

Leadership related attributes can positively affect whole-networks (Provan et al. 2007). These include stability management (degree to which leadership buffers instability and/or nurtures stability in the network) (WN8), accountability management (assignation of accountability of managers for performance and results for the whole-network and community) (WN9), steering network processes (processes to support ethical decisionmaking, and facilitate centralization of control) (WN10), generic networking (time spent interacting with network constituencies to identify tensions, and blend participant interests to achieve whole-network goals) (WN11), management tenure (tenure of wholenetwork management team) (WN12), staff coherence (competitiveness vs. coherence of 
staff) (WN13) and services capability (capability to provide services desired to participants) (WN14).

A number of whole-network variables have been identified. Are they valid for dual networks? Are important factors being omitted? What other whole-network variables influence intent to participate in a dual network?

\subsubsection{2. $\quad$ Set 9. Network IT Attributes}

As the history of its development suggests, network information technology (network IT) is a broad category, encompassing innovations ranging from mobile phones used by individuals to communications network technology, and from supply chain management solutions to global search engine services and electronic financial clearinghouses. For purposes of the DNPT research, 5 categories of network IT are proposed, referencing their potential use in a dual network context. Environmental linking network IT refers to network IT which automates processes of connecting individuals involved in whole-network governance or management with the environment. Market bridging network IT refers to network IT which automates processes of connecting individuals involved in whole-network governance or management with the whole-network's market. Governance network IT refers to network IT which automates processes of governing the whole-network, such as formation of governance structures like a board of directors, or authorization of expenditures, contracts or plans. Functional network IT refers to network IT which automates processes of operating the wholenetwork, including, if applicable, delivery of IT services to organizational users. Individual network IT refers to network IT such as cell phones, computers, email service 
and so on which are purchased by individuals or their organizations for other purposes and available to support activities related to the whole-network.

Use of environmental linking network IT (such as belonging to an online community of interest) (NIT1) is hypothesized to increase benefits expectancy (by improving understanding of changes in the environment) and increase social influence (by facilitating stronger linkages with influential people in the environment such as political leaders).

Use of market bridging network IT (such as online market information services) (NIT2) is hypothesized to increase benefits expectancy (by improving understanding of current market dynamics and needs), and increase social influence (by facilitating stronger understanding and connections with influential people in the marketplace such as key suppliers, customers, distributors or regulators).

Use of governance network IT (such as virtual board meeting services) (NIT3) is hypothesized to increase social influence (by saving time or facilitating involvement by geographically distant participants) and increase facilitating conditions (by supporting more rapid decision-making by board in response to problems).

Use of functional network IT (e.g., network linked systems for planning, accounting, procurement, distribution, customer relationship management and billing) (NIT4) is hypothesized to have a positive effect on low cost expectancy (by supporting more efficient, effective and integrated dual network operations) and increase facilitating conditions (by providing for more efficient, effective and integrated participant service and support). 
Use of individual network IT (e.g., home based computers, laptops, wireless mobile devices) (NIT5) is hypothesized to increase facilitating conditions (by providing participants easier access to service and support).

Network IT compatibility (such as ability for an organization system to connect with a dual network system) (NIT 6) is hypothesized to increase facilitating conditions. This is a well known factor affecting IOS adoption (e.g., Teo et al. 2003).

Reduced network IT cost (NIT7) is hypothesized to increase low cost expectancy. Network IT openness (ability to access, link to and/or modify network IT source code or standards) (NIT8) is hypothesized to increase low cost expectancy.

Network IT innovativeness (the newness or cachet of the network IT) (NIT9) is hypothesized to increase social influence. However, there is potential that use of innovative network IT in early stages of the adoption curve may be perceived as time consuming (increasing effort expectancy).

Network IT environmental stability (the stability of technological infrastructure such as operating system, communications systems and standards) (NIT11) is hypothesized to increase social influence (influencers will be more confident that environmental change won't obsolete the network IT being used), and increase facilitating conditions (tools and technologies can be counted on).

Network IT outsourcing (purchasing network IT from a vendor) (NIT12) is hypothesized to have a positive effect on benefits expectancy, low cost expectancy and facilitating conditions. The argument is that the growing speed and complexity of network IT development lifecycles, and ability to access network IT services through the 
web, favor outsourcing, especially as openness and software as a service becomes more available and loss costly.

Network IT ownership symmetry (when a participant's ownership or control of network IT is equal in proportion to that of other participants) (NIT13) is hypothesized to increase social influence (influential people associated with participants in a less than equal ownership position will be less likely to support participation).

Network IT abundance (the relative abundance of network IT available or in use by people and organizations in the environment) (NIT 14) is hypothesized to increase facilitating conditions (people will have access to or know how to use network IT to facilitate the service being received). This concept is adapted from the concept of resource munificence in the whole-network literature (when an environment is more rich, more funding is likely to be available for a given collaborative) (Provan, 2007).

Are these proposed network IT variables valid for dual networks? Are there other network IT variables not included here which influence intent to participation in dual networks? What are the effects on participation of the network IT variables proposed?

\subsubsection{Set 10. Outcomes}

The last area of the DNPT is outcomes. A number of outcomes at different levels are identified in both the whole-network and IOS literatures (Herranz 2010; Provan et al. 2007; Provan et al. 1995; Robey et al. 2008).

At the environmental level, such as a city, state or country, these include changes in environmental stability (OC1), environmental competitiveness (OC2) or environmental growth (OC3). 
At the market level they include increased innovations in the marketplace (OC4), improved market access to products/services (OC5), and increased market efficiency (OC6).

At the dual network level, they include ability to achieve stated goals (OC7), sustainability and viability (OC8) or capacity to innovate and change as environment and market change (OC9).

At the organizational level they include financial impact (e.g., new revenues/profits) (OC10), strategic impact (improved competitive position in marketplace) (OC11), and increased operational efficiency (OC12).

At the individual level (e.g., participant employee), they include increased work productivity (OC13), increased financial status (raises or bonuses from employer) (OC14), and increased social status (such as prestige from being a participant) (OC15).

Are these outcome factors valid? What other kinds of outcomes are generated by dual network? What are the effects of outcomes on future dual network development and participation?

\subsubsection{List of Selected Variables}

The discussion of the 10 sets points to a list of around 85 possible DNPT variables which could be used in an actual study. These are summarized in Table 6 . 
Table 6: List of Possible DNPT Variables

\begin{tabular}{|l|l|}
\hline $\begin{array}{l}\text { Variables } \\
\text { Code }\end{array}$ \\
\hline Short Name \\
\hline Set 1. & Actual Participation \\
\hline AP1 & Actual Participation Variables \\
\hline Set 2. Intent to Participate \\
\hline IP1 & Intent to Participate \\
\hline IP2 & Likelihood to Participate \\
\hline IP3 & Plan to Participate \\
\hline IP4 & Other? \\
\hline Set 3. Moderators \\
\hline M1 & Subject Age \\
\hline M2 & Subject Gender \\
\hline M3 & Subject Dual Network Experience \\
\hline M4 & Organization size \\
\hline M5 & Organization Dual Network (DN) experience \\
\hline M6 & Other individual moderators? \\
\hline M7 & Other organizational moderators? \\
\hline Set 4. Benefit Expectancy \\
\hline BE1 & Ability to do Job \\
\hline BE2 & Task Completion \\
\hline BE3 & Productivity \\
\hline BE4 & Financial Performance \\
\hline BE5 & Value of Decision \\
\hline BE6 & Other Value \\
\hline Set 5. Cost Expectancy \\
\hline CE1 & Leader Time and Effort \\
\hline CE2 & Organization Time and Effort \\
\hline CE3 & Financial Commitment \\
\hline CE4 & Leader Reputation Risk \\
\hline CE5 & Organizational Reputation Risk \\
\hline CE6 & Other? \\
\hline Set 6. Social Influence \\
\hline SI1 & Support by Influential People \\
\hline SI2 & Support by Important People \\
\hline SI3 & Support by Superiors \\
\hline S14 & Other? \\
\hline Set 7. Facilitating Conditions \\
\hline FC1 & Subject Resources \\
\hline FC2 & Organizational Resources \\
\hline FC3 & Dual Network Resources \\
\hline FC4 & Subject Knowledge \\
\hline FC5 & Organizational Knowledge \\
\hline FC6 & Dual Network Knowledge \\
\hline FC7 & Subject Tools and Technologies \\
\hline FC8 & Organizational Tools and Technologies \\
\hline FC9 & Dual Network Tools and Technologies \\
\hline FC10 & Subject Staff Support \\
\hline FC11 & Organizational Staff Support \\
\hline FC13 & Dual Network Staff Support \\
\hline
\end{tabular}




\begin{tabular}{|c|c|}
\hline \multicolumn{2}{|c|}{ Variables } \\
\hline Code & Short Name \\
\hline FC14 & Resource Munificence \\
\hline$\overline{\mathrm{FC} 15}$ & Other? \\
\hline \multicolumn{2}{|c|}{ Set 8. Whole-network Attributes } \\
\hline WN1 & Resource Availability \\
\hline WN1a & Rules and norms (as steering mechanisms) \\
\hline WN2 & Learning and Education \\
\hline WN3 & Dominant Core \\
\hline WN4 & Embedded Relationships \\
\hline WN5 & Right Type of Governance? \\
\hline WN6 & Formalization \\
\hline WN7 & Network Inner Stability \\
\hline WN8 & $\begin{array}{l}\text { Stability Management (degree to which subject buffers instability /nurtures } \\
\text { stability in the network) }\end{array}$ \\
\hline WN9 & $\begin{array}{l}\text { Accountability Management (assignation of accountability of managers for } \\
\text { performance and results for the whole-network and community) }\end{array}$ \\
\hline WN10 & $\begin{array}{l}\text { Steering Network Processes } \\
\text { (processes to support ethical decision-making, and facilitate centralization } \\
\text { of control) }\end{array}$ \\
\hline WN11 & $\begin{array}{l}\text { Generic Networking } \\
\text { (time spent interacting with network constituencies to identify tensions, } \\
\text { and blend participant interests to achieve whole-network goals) }\end{array}$ \\
\hline WN12 & Management Tenure (tenure of whole-network management team) \\
\hline WN13 & Staff Coherence (competitiveness vs. coherence of staff) \\
\hline WN14 & Services Capability (capability to provide services desired to participants) \\
\hline WN15 & Other \\
\hline \multicolumn{2}{|c|}{ Set 9. Network IT Attributes } \\
\hline NIT1 & Environmental Linking Network IT \\
\hline NIT2 & Market Bridging Network IT \\
\hline NIT3 & Governance Network IT \\
\hline NIT4 & Functional Network IT \\
\hline NIT5 & Individual Network IT \\
\hline NIT6 & Network IT Compatibility \\
\hline NIT7 & Network IT Cost \\
\hline NIT8 & Network IT Openness \\
\hline NIT9 & Network IT Innovativeness \\
\hline NIT11 & Network IT Environmental Stability \\
\hline NIT12 & Network IT Outsourcing \\
\hline NIT13 & Network IT Ownership Symmetry \\
\hline NIT14 & Network IT Abundance \\
\hline NIT15 & Other \\
\hline \multicolumn{2}{|c|}{ Set 10. Outcomes } \\
\hline $\mathrm{OC} 1$ & Environmental Stability \\
\hline $\mathrm{OC2}$ & Environmental Competitiveness \\
\hline OC3 & Environmental Growth \\
\hline $\mathrm{OC} 4$ & Market Innovation \\
\hline OC5 & Market Access \\
\hline OC6 & Market Efficiency \\
\hline OC7 & Goal Capacity \\
\hline OC8 & Sustainability and Viability \\
\hline
\end{tabular}




\begin{tabular}{|l|l|}
\hline \multicolumn{2}{|l|}{ Variables } \\
Code & Short Name \\
\hline \hline OC9 & Innovation/Change \\
\hline OC10 & Organizational Finances \\
\hline OC11 & Organizational Strategy \\
\hline OC12 & Organizational Operations \\
\hline OC13 & Individual Productivity \\
\hline OC14 & Individual Finances \\
\hline OC15 & Individual Social Status \\
\hline
\end{tabular}

\subsection{DNPT Limitations}

As defined, the DNPT should apply to any individual with an organizational affiliation considering participation in a network level collaboration involving two or more individual or organizational participants. The theory could apply to collaborations not dependent on network IT, since those factors could simply be excluded from consideration. In principle, much like TAM, it should apply globally, across multiple languages, cultures and jurisdictions. However, the theory has never been operationalized, and may, in practice, have many limitations which are not evident in this initial formulation. Additional research needs to be done to validate the theory for use in different contexts. As is typical in new theory development, the theory can be expected to undergo significant evolution as more experience is gained in its formulation and use.

\subsection{Chapter Summary}

In summary, Chapter 3 has presented a new theory of potential value for the study of dual networks like HIEN. Four dimensions of a theoretical contribution (Whetten 1989) were addressed. Dual networks are "network IT dependent whole-networks" involving individual agents, organizations, whole-networks and network information 
technologies and their attributes (\#1: what). Dual networks are a new phenomena emerging around the turn of the $21^{\text {st }}$ century under the influence of empirical and theoretical innovations in areas of human organization and IT. Organizational leaders (subjects) decide to participate in dual networks because of their beliefs about expected benefits, expected costs, social influence and facilitating conditions (Ajzen 1991) (\#2: why). Intent to participate, a proxy for actual participation is affected by predictors, which are, in turn, affected by dual network attributes. Intent to participate leads to actual participation which creates outcomes. Outcomes influence dual network attributes, which, in turn, influence the predictors (\#3. how). The DNPT is designed to predict participation by organizationally affiliated individuals in a qualified dual network participation opportunity (\#4. who, when, where). 


\section{CHAPTER 4. METHODS}

In Chapter 3, a new dual network participation theory was developed designed to study barriers and enablers to participation in complex collaborations such as HIENs. In this chapter, a DNPT driven case study research method is presented designed to answer the five research questions in this study.

The methods section is presented in the following sections: research questions; overview of case study design; case selection; document selection, assembly and review; use of theory to develop variables and hypotheses; instrument development and completion; triangulation and coding; data management; confidentiality; justification; and limitations.

\subsection{Research Questions}

The case study was designed to develop answers to five questions:

1) What kinds of participation opportunities do the 6 HIENs offer?

2) Which of the proposed DNPT variables are valid for the study of participation in dual networks like the 6 HIENs?

3) What new variables should be considered and are they valid?

4) Once valid variables are selected, what does the data say about barriers and enablers to participation in the 6 HIENs? Specifically:

a.) how do moderators (organizational leader gender, age; organization size, type) moderate intent to participate?

b.) how do predictors affect intent to participate?

c.) how do dual network attributes affect predictors? 
5) What are the implications of the findings for theory and research?

\subsection{Overview of Case Study Design}

A theory driven, retrospective, multi-level, multi-case, mixed methods case study design with triangulation by two researchers was developed to answer these questions. Each element of the design was developed considering established best-practice guidelines for case study research (see Yin 2008).

The term theory-driven refers to a case study in which researchers do the research in order to answer questions already generated by a theory. A risk of theory-driven research is that researchers will be blinded to seeing new or novel patterns shaping the phenomena of interest because of their preconceptions related to the theory being used. However, theory-driven research has also been shown to strengthen validity and reliability of case-study research, especially when theoretical assumptions and approaches are explicitly stated, limitations of the theory are considered, and researchers are open to re-evaluating the theory based on what is learned is (Yin 2008).

The term retrospective refers to a study of phenomena which have already occurred. Retrospective cases studies are often used to develop knowledge about complex social and organizational phenomena in which researchers cannot actually 'be there' in the present. Typically, they involve review of documents and records. Retrospective studies are limited by the fact that sometimes researchers will see things differently when observing or participating in the present than they do when looking at historical documents and records separate from the social context in which they were produced. Conversely, researchers engaged in the 'heat of the moment' can often fail to see different patterns which can become visible through analysis of records developed over a 
period of time. Validity and reliability of retrospective studies is strengthened when researchers consider multiple types of information (e.g. formal documents, meeting notes, conversational notes, etc), and triangulate to find common themes which appear in multiple sources (Yin 2008).

The term multi-level refers to analysis of multiple levels of phenomena (e.g. individual-level, organizational-level, network-level, societal level, etc.). Multi-level analysis is technically difficult. It often requires consideration of many more variables, and increases risk of confounding variables and researcher confusion. For example, how can a researcher distinguish an individual's idea about an organization for which $\mathrm{s} / \mathrm{he}$ works from consideration of an organization as such? How might researcher or subject preconceptions about what is an organization influence the objectivity of the study? However, single-level models which do not consider multiple levels of influence also pose risk to validity in the studies of complex social phenomena: they can lead to a reductionist approach in which complex phenomena are oversimplified thereby reducing ability to develop new insights. Multi-level analysis is often used in case studies to strengthen knowledge of complex phenomena, and has been recommended for study of whole-networks (Brass et al. 2004) and organizationally enmeshed information systems (Orlikowski 2010; Orlikowski et al. 2001).

The term multi-case refers to the use of multiple cases in the study. This study includes 6 site level cases, 109 individual level cases, and 125 organizational level cases. Analysis of multiple cases in a case study can take more time and resources. However, use of multiple cases in a case study can strengthen validity through replication logic. 
Replication logic increases case study validity by identifying common themes which appear in multiple cases (Yin 2008).

The term mixed methods refers to the use of both qualitative and quantitative research methods to approach understanding of a phenomenon of interest. In the study of complex social phenomena, the use of qualitative methods, alone, has been shown to increase risk of findings being influenced by subjective biases by researchers, while the use of quantitative methods alone has been show to increase risk of being influenced by methodological biases of researchers (Creswell 2003). Studies of complex social phenomena using mixed methods supported by triangulation of findings from both types of research can generate more valid, reliable results than either type alone (Creswell 2003).

Triangulation by two or more researchers reviewing the same data can strengthen validity of findings in case study research (Yin 2008). In reviewing complex data, researcher familiarity with the context in which data was generated can be helpful. A risk to validity can occur when two researchers are considering information for one research purpose which was generated in another research context. This risk to validity can be reduced when two researchers discuss, debate and disclose potential biases caused by prior relationships to the phenomena of interest (Yin 2008).

With these various considerations and risks to validity in mind, a six step case study design was developed, as shown in Figure 10. At each step, the design was developed to maximize potential to achieve valid and reliable results given the type of methods being used and given the limitations and risks of bias associated with those methods. 
The case study began with step 1 , case selection. This was followed by step 2, document selection, assembly and review. Step 3 involved: a.) use of theory to develop variables and hypotheses, and b.) development of instruments to validate variables and code results for sites and subjects. Step 4 involved identification of data which a.) supports, b.) refutes and/or c.) provides alternate interpretations for observations about variable validity and hypotheses. Step 5 involved triangulation and coding of data by two researchers. Step 6 involved summarizing data, excluding invalid variables, running statistical analyses and interpreting results.

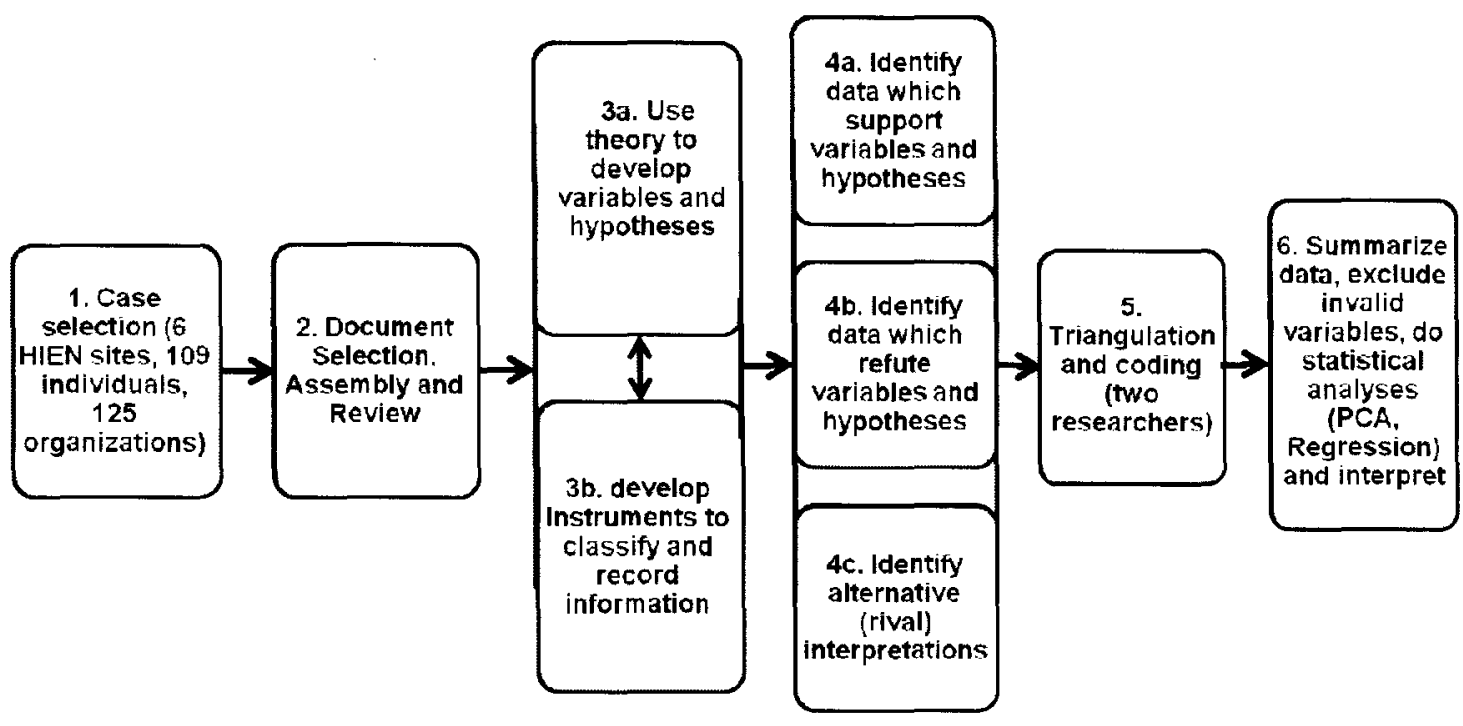

Figure 10: Case Study Design

\subsection{Case Selection}

A convenience sample of 6 HIENs (network level cases), 109 associated individuals (individual level cases) and 125 affiliated organizations (organizational level cases) were selected for the study. A set of documents generated from prior research by 
the two researchers was available about their development from 2004 to 2010 . The six HIENs had operated between 2004 and 2010 in two mid-sized U.S. states and their development had started in reasonably typical ways when compared to HIENs across the U.S. Importantly, each of the selected HIENs experienced significant participation challenges between 2004 and 2010. Individuals and their affiliated organizations were selected for inclusion in the study if they were on a HIEN board or were identified in board records as influential HIEN participants. There were more organizations than individuals because some individuals were affiliated with two or more organizations.

Table 7. Sites, Individuals, Organizations and Data Included in Study

\begin{tabular}{|l|l|l|l|l|}
\hline Site & Type & $\begin{array}{l}\text { Number of } \\
\text { Individuals/Organizations } \\
\text { considered }\end{array}$ & Data Sources & Dates \\
\hline 1 & Regional & 21 & $\begin{array}{l}\text { Public records; Survey(s); Focus } \\
\text { Groups }\end{array}$ & $2005-2009$ \\
\hline 2 & State 1a & 26 & $\begin{array}{l}\text { Public records; Survey(s); Focus } \\
\text { Groups }\end{array}$ & $2004-2009$ \\
\hline 3 & State 2a & 15 & Public records; Survey(s); Interviews & 2010 \\
\hline 4 & State 2b & 23 & Public records; Survey(s); Interviews & 2010 \\
\hline 5 & State 2c & 17 & Public records; Survey(s); Interviews & 2010 \\
\hline 6 & Regional & 7 & Public records; Survey(s);Interviews & 2010 \\
\hline \begin{tabular}{l} 
Total \\
\hline
\end{tabular} & $109 / 125^{1}$ & & & \\
\hline
\end{tabular}

\subsection{Document Selection, Assembly and Review}

Documents used for the study included documents gathered from websites and historical published records compiled by the two researchers from $2004-2010$. Records 
were assembled in an electronic file cabinet created for each site. Records included board meetings, reports and web-site pages, results of interviews and surveys, and results of focus group meetings. Once documents were assembled, they were reviewed by researcher 1 . Then, a summary of the documents and their contents was provided to researcher 2 , who was also already familiar with most of the documents. The two researchers then met together multiple times, with a computer screen on front of each researcher, to review data and develop and complete instruments. Using this procedure the two researchers were able to quickly and easily access relevant source documents and review information they contained as a basis for completing the instruments in the study.

\subsubsection{Illustration of Document Review}

To illustrate how the document review worked in practice, documents gathered for site 1 included board meeting minutes, committee meeting minutes, lists of board and committee members and their organizational affiliations, business plans, results of research including focus groups and web surveys, bylaws, ethics policy, vendor selection and bid information, and news and public relations announcements. In addition, for most of the individuals listed as board or committee members in the site 1 website, detailed information about them and their organization(s) was available through their affiliated organization's website. For example, one individual's organizational vision, mission, size, board of directors, organizational chart, annual report, and policy positions related to HIE were posted on the organization's web site. In addition, the individual's title, tenure, level of authority, and other biographical information was available. These documents were stored in a folder on the computer of researcher 1 , and contents were reviewed with 
researcher 2. Researchers 1 and 2 often referred to these documents, or opened and reviewed documents, as needed, during the process of completing instruments for site 1.

\subsection{Use of Theory to Develop Variables and Hypotheses}

Variables from 9 of the 10 sets of variables identified in the DNPT were selected for use in the case study. Set 10 was excluded because no outcomes data was available for the HIENS of interest. Thus, the variable sets considered were:

- Set 1: Actual Participation (how do subjects actually participate)

- Set 2: Intent to Participate (subject intent to have organization participate)

- Set 3: Moderators

- Set 4: Predictors - Benefit Expectancy

- Set 5: Predictors - Cost Expectancy

- Set 6: Predictors - Social Influence

- Set 7: Predictors - Facilitating Conditions

- Set 8: Whole-network Attributes

- Set 9: Network IT Attributes

For each variable in each set, queries and hypotheses were formulated to consider the nature and effect of the variable. Variables, queries and hypotheses used are summarized in Table 8.

Table 8. List of Variables Used in the Study

\begin{tabular}{|l|l|l|l|}
\hline \multicolumn{2}{|l|}{ Cariables } & Query & $\begin{array}{l}\text { Hypothesis } \\
\text { (if } \\
\text { applicable) }\end{array}$ \\
\hline \hline Set 1. Actual Participation & & \\
\hline AP1 & Actual Participation Variables & $\begin{array}{l}\text { What types of 'participation opportunities' } \\
\text { appear in dual networks? }\end{array}$ & \\
\hline Set 2. Intent to Participate & & $\begin{array}{l}\text { Is 'intent to participate' valid for dual network } \\
\text { participants? }\end{array}$ & \\
\hline IP1 & Intent to Participate & $\begin{array}{l}\text { Is 'likelihood to participate' valid for dual } \\
\text { network participants? }\end{array}$ & \\
\hline IP2 & Likelihood to Participate & $\begin{array}{l}\text { Is 'plan to participate' valid for dual network } \\
\text { participants? }\end{array}$ & \\
\hline IP3 & Plan to Participate & \multicolumn{2}{l}{} \\
\hline
\end{tabular}




\begin{tabular}{|c|c|c|c|}
\hline \multicolumn{2}{|c|}{$\begin{array}{l}\text { Variables } \\
\text { Code Short Name }\end{array}$} & Query & $\begin{array}{l}\text { Hypothesis } \\
\text { (if } \\
\text { applicable) }\end{array}$ \\
\hline IP4 & Other? & $\begin{array}{l}\text { Are other variables needed to capture 'intent to } \\
\text { participate'? }\end{array}$ & \\
\hline \multicolumn{4}{|c|}{ Set 3. Moderators } \\
\hline M1 & Subject Age & Does age moderate effect? & Yes \\
\hline $\mathrm{M} 2$ & Subject Gender & Does gender moderate effect? & No \\
\hline M3 & $\begin{array}{l}\text { Subject Dual Network } \\
\text { Experience }\end{array}$ & $\begin{array}{l}\text { Does leader collaboration experience moderate } \\
\text { effect? }\end{array}$ & Yes \\
\hline M4 & Organization size & Does organization size moderate effect? & Yes \\
\hline M5 & $\begin{array}{l}\text { Organization Dual Network } \\
\text { (DN) experience }\end{array}$ & $\begin{array}{l}\text { Does organization collaboration experience } \\
\text { moderate effect? }\end{array}$ & Yes \\
\hline M6 & Other individual moderators? & $\begin{array}{l}\text { Are other individual moderators needed? If so, } \\
\text { what? }\end{array}$ & Yes \\
\hline M7 & $\begin{array}{l}\text { Other organizational } \\
\text { moderators? }\end{array}$ & $\begin{array}{l}\text { Are other organizational moderators needed? If } \\
\text { so, what? }\end{array}$ & Yes \\
\hline \multicolumn{4}{|c|}{ Set 4. Benefit Expectancy } \\
\hline BE1 & Ability to do Job & $\begin{array}{l}\text { Does dual network potential to be 'useful to } \\
\text { participants in doing their jobs' increase 'intent } \\
\text { to have organization participate?' }\end{array}$ & Yes \\
\hline BE2 & Task Completion & $\begin{array}{l}\text { Does dual network potential to 'enable an } \\
\text { organization to accomplish tasks more quickly' } \\
\text { increase 'intent to have organization } \\
\text { participate?' }\end{array}$ & Yes \\
\hline BE3 & Productivity & $\begin{array}{l}\text { Does dual network potential to 'increase } \\
\text { organizational productivity' increase 'intent to } \\
\text { have organization participate?' }\end{array}$ & Yes \\
\hline $\mathrm{BE} 4$ & Financial Performance & $\begin{array}{l}\text { Does dual network potential to 'improve } \\
\text { financial performance' increase 'intent to have } \\
\text { organization participate?' }\end{array}$ & Yes \\
\hline BE5 & Value of Decision & $\begin{array}{l}\text { BE6. Does belief that decision 'will be seen as } \\
\text { positive contribution to the organization by my } \\
\text { superiors and peers' increase 'intent to have } \\
\text { organization participate?' }\end{array}$ & Yes \\
\hline BE6 & Other Value & $\begin{array}{l}\text { Are other variables needed to measure benefit } \\
\text { expectancy? If so, what? }\end{array}$ & Yes \\
\hline \multicolumn{4}{|c|}{ Set 5. Cost Expectancy } \\
\hline CE1 & Leader Time and Effort & $\begin{array}{l}\text { Does decreased expectation of 'time and effort' } \\
\text { by leaders increase 'intent to have } \\
\text { organization participate?' }\end{array}$ & Yes \\
\hline CE2 & Organization Time and Effort & $\begin{array}{l}\text { Does decreased expectation of 'time and effort' } \\
\text { by the organization increase 'intent to have } \\
\text { organization participate?' }\end{array}$ & Yes \\
\hline $\mathrm{CE} 3$ & Financial Commitment & $\begin{array}{l}\text { Does decreased relative financial commitment } \\
\text { expectation of 'time and effort' by the } \\
\text { organization increase 'intent to have } \\
\text { organization participate?' }\end{array}$ & Yes \\
\hline CE4 & Leader Reputation Risk & $\begin{array}{l}\text { Does decreased perceived risk to leader's social } \\
\text { capital decrease 'intent to have organization } \\
\text { participate?' }\end{array}$ & Yes \\
\hline CE5 & Organizational Reputation Risk & $\begin{array}{l}\text { Does decreased perceived risk to organization's } \\
\text { social capital increase 'intent to have } \\
\text { organization participate?' }\end{array}$ & Yes \\
\hline CE6 & Other? & Are other variables needed to measure cost & No \\
\hline
\end{tabular}




\begin{tabular}{|c|c|c|c|}
\hline $\begin{array}{l}\text { Variab } \\
\text { Code }\end{array}$ & Short Name & Query & $\begin{array}{l}\text { Hypothesis } \\
\text { (if } \\
\text { applicable) }\end{array}$ \\
\hline & & expectancy? If so, what? & \\
\hline \multicolumn{4}{|c|}{ Set 6. Social Influence } \\
\hline SI1 & Support by Influential People & $\begin{array}{l}\text { Does 'intent to have organization participate' } \\
\text { increase when people who influence a leader's } \\
\text { decisions think that the organization should } \\
\text { participate? }\end{array}$ & Yes \\
\hline SI2 & Support by Important People & $\begin{array}{l}\text { Does 'intent to have organization participate' } \\
\text { increase when people who are important to } \\
\text { leader think that the organization should } \\
\text { participate? }\end{array}$ & Yes \\
\hline SI3 & Support by Superiors & $\begin{array}{l}\text { Does 'intent to have organization participate' } \\
\text { increase when people to whom a leader reports } \\
\text { thinks that the organization should participate? }\end{array}$ & Yes \\
\hline S14 & & $\begin{array}{l}\text { Are other variables needed to measure social } \\
\text { influence? If so, what? }\end{array}$ & No \\
\hline \multicolumn{4}{|c|}{ Set 7. Facilitating Conditions } \\
\hline $\mathrm{FC} 1$ & Subject Resources & $\begin{array}{l}\text { Does increase in 'subject resources necessary to } \\
\text { participate' increase intent to participate? }\end{array}$ & Yes \\
\hline $\mathrm{FC} 2$ & Organizational Resources & $\begin{array}{l}\text { Does increase in 'organizational resources } \\
\text { necessary to participate' increase intent to } \\
\text { participate? }\end{array}$ & Yes \\
\hline $\mathrm{FC} 3$ & Dual Network Resources & $\begin{array}{l}\text { Does increase in 'DN resources necessary to } \\
\text { support intent to participate' increase intent to } \\
\text { participate? }\end{array}$ & Yes \\
\hline FC4 & Subject Knowledge & $\begin{array}{l}\text { Does increase of 'subject knowledge necessary } \\
\text { to participate' increase intent to participate? }\end{array}$ & Yes \\
\hline FC5 & Organizational Knowledge & $\begin{array}{l}\text { Does increase of 'organizational knowledge } \\
\text { necessary to participate' increase intent to } \\
\text { participate? }\end{array}$ & Yes \\
\hline FC6 & Dual Network Knowledge & $\begin{array}{l}\text { Does increase of 'DN knowledge necessary to } \\
\text { support intent to participate' increase intent to } \\
\text { participate? }\end{array}$ & Yes \\
\hline $\mathrm{FC7}$ & Subject Tools and Technologies & $\begin{array}{l}\text { Does increase in 'subject tools and technologies } \\
\text { necessary to participate' increase intent to } \\
\text { participate? }\end{array}$ & Yes \\
\hline $\mathrm{FC} 8$ & $\begin{array}{l}\text { Organizational Tools and } \\
\text { Technologies }\end{array}$ & $\begin{array}{l}\text { Does increase in 'organizational tools and } \\
\text { technologies necessary to participate' increase } \\
\text { intent to participate? }\end{array}$ & Yes \\
\hline FC9 & $\begin{array}{l}\text { Dual Network Tools and } \\
\text { Technologies }\end{array}$ & $\begin{array}{l}\text { Does increase in 'DN tools and technologies } \\
\text { necessary to support intent to participate' } \\
\text { increase intent to participate? }\end{array}$ & Yes \\
\hline $\mathrm{FC} 10$ & Subject Staff Support & $\begin{array}{l}\text { Does increase of 'subject staff support needed to } \\
\text { participate' increase intent to participate? }\end{array}$ & Yes \\
\hline FC11 & Organizational Staff Support & $\begin{array}{l}\text { Does increase of 'organizational staff support } \\
\text { needed to participate' increase intent to } \\
\text { participate? }\end{array}$ & Yes \\
\hline FC12 & Dual Network Staff Support & $\begin{array}{l}\text { Does increase of 'DN staff support needed to } \\
\text { support participation' increase intent to } \\
\text { participate? }\end{array}$ & Yes \\
\hline $\mathrm{FC} 13$ & Environmental Stability & $\begin{array}{l}\text { Does increase in environmental stability increase } \\
\text { intent to participate? }\end{array}$ & Yes \\
\hline $\mathrm{FC} 14$ & Resource Munificence & Does increase in financial munificence in the & Yes \\
\hline
\end{tabular}




\begin{tabular}{|c|c|c|c|}
\hline \multicolumn{2}{|c|}{ Variables } & \multirow[t]{2}{*}{ Query } & \multirow{2}{*}{$\begin{array}{l}\text { Hypothesis } \\
\text { (if } \\
\text { applicable) }\end{array}$} \\
\hline Code & Short Name & & \\
\hline & & environment increase intent to participate? & \\
\hline FC15 & Other? & $\begin{array}{l}\text { Are other variables needed to measure } \\
\text { facilitating conditions? If so, what? }\end{array}$ & Yes \\
\hline $\mathrm{N} / \mathrm{A}$ & & Is there duplication or overlay of factors? & Yes \\
\hline \multicolumn{4}{|c|}{ Set 8. Whole-network Attributes } \\
\hline WN1 & $\begin{array}{l}\text { Rules and norms } \\
\text { (as steering mechanisms) }\end{array}$ & Does increased Rules and Norms increase SI? & Yes \\
\hline WN2 & Learning and Education & $\begin{array}{l}\text { Does increased Learning and Education increase } \\
\text { SI? }\end{array}$ & Yes \\
\hline WN3 & Dominant Core & $\begin{array}{l}\text { Does increased Dominant Core increase BE, } \\
\text { LCE, SI, FC? }\end{array}$ & Yes \\
\hline WN4 & Embedded Relationships & $\begin{array}{l}\text { Does increased Embedded Relationships } \\
\text { increase BE, LCE, SI, FC? }\end{array}$ & Yes \\
\hline WN5 & Right Type of Governance? & $\begin{array}{l}\text { Does Right Type of Governance increase BE, } \\
\text { LCE, SI, FC? }\end{array}$ & Yes \\
\hline WN6 & Formalization & $\begin{array}{l}\text { Does increased Formalization increase BE, LCE, } \\
\text { SI, FC? }\end{array}$ & Yes \\
\hline WN7 & Network Inner Stability & $\begin{array}{l}\text { Does increased Network Inner Stability increase } \\
\text { BE, LCE, SI, FC? }\end{array}$ & Yes \\
\hline WN8 & $\begin{array}{l}\text { Stability Management } \\
\text { (degree to which subject buffers } \\
\text { instability /nurtures stability in } \\
\text { the network) }\end{array}$ & $\begin{array}{l}\text { Does increase in Stability Management increase } \\
\text { BE, LCE, SI, FC? }\end{array}$ & Yes \\
\hline WN9 & $\begin{array}{l}\text { Accountability Management } \\
\text { (assignation of accountability } \\
\text { of managers for performance } \\
\text { and results for the whole- } \\
\text { network and community) }\end{array}$ & $\begin{array}{l}\text { Does increase in Accountability Management } \\
\text { increase BE, LCE, SI, FC? }\end{array}$ & Yes \\
\hline WN10 & $\begin{array}{l}\text { Steering Network Processes } \\
\text { (processes to support ethical } \\
\text { decision-making, and facilitate } \\
\text { centralization of control) } \\
\end{array}$ & $\begin{array}{l}\text { Does increase in Steering Network Processes } \\
\text { increase BE, LCE, SI, FC? }\end{array}$ & Yes \\
\hline WN11 & $\begin{array}{l}\text { Generic Networking } \\
\text { (time spent interacting with } \\
\text { network constituencies to } \\
\text { identify tensions, and blend } \\
\text { participant interests to achieve } \\
\text { whole-network goals) }\end{array}$ & $\begin{array}{l}\text { Does increase in Generic Networking increase } \\
\text { BE, LCE, SI, FC? }\end{array}$ & Yes \\
\hline WN12 & $\begin{array}{l}\text { Management Tenure } \\
\text { (tenure of whole-network } \\
\text { management team) }\end{array}$ & $\begin{array}{l}\text { Does increase in Management Tenure increase } \\
\text { BE, LCE, SI, FC? }\end{array}$ & Yes \\
\hline WN13 & $\begin{array}{l}\text { Staff Coherence } \\
\text { (competitiveness vs. coherence } \\
\text { of staff) }\end{array}$ & $\begin{array}{l}\text { Does increase in Staff Coherence increase BE, } \\
\text { LCE, SI, FC? }\end{array}$ & Yes \\
\hline WN14 & $\begin{array}{l}\text { Services Capability } \\
\text { (capability to provide services } \\
\text { desired to participants) }\end{array}$ & $\begin{array}{l}\text { Does increase in Services Capability increase } \\
\text { BE, LCE, SI, FC? }\end{array}$ & Yes \\
\hline WN15 & Other & $\begin{array}{l}\text { Do other whole-network attribute variables } \\
\text { significantly affect BE, LCE, SI, FC? If so, } \\
\text { what? }\end{array}$ & Unsure \\
\hline \multicolumn{4}{|c|}{ Set 9. Network IT Attributes } \\
\hline NIT1 & Environmental Linking & Does increased Environmental Linking Network & Yes \\
\hline
\end{tabular}




\begin{tabular}{|c|c|c|c|}
\hline $\begin{array}{l}\text { Variab } \\
\text { Code }\end{array}$ & $\begin{array}{l}\text { les } \\
\text { Short Name }\end{array}$ & Query & $\begin{array}{l}\text { Hypothesis } \\
\text { (if } \\
\text { applicable) }\end{array}$ \\
\hline & Network IT & IT improve BE, SI? & \\
\hline NIT2 & Market Bridging Network IT & $\begin{array}{l}\text { Does increased Market Bridging Network IT } \\
\text { improve BE, SI? }\end{array}$ & Yes \\
\hline NIT3 & Governance Network IT & $\begin{array}{l}\text { Does increased Governance Network IT improve } \\
\text { SI, FC? }\end{array}$ & Yes \\
\hline NIT4 & Functional Network IT & $\begin{array}{l}\text { Does increased Functional Network IT improve } \\
\text { LCE, FC? }\end{array}$ & Yes \\
\hline NIT5 & Individual Network IT & $\begin{array}{l}\text { Does increased Individual Network IT improve } \\
\text { FC? }\end{array}$ & Yes \\
\hline NIT8 & Network IT Openness & $\begin{array}{l}\text { Does increased Network IT Openness improve } \\
\text { LCE? }\end{array}$ & Yes \\
\hline NIT9 & Network IT Innovativeness & $\begin{array}{l}\text { Does increased Network IT Innovativeness } \\
\text { improve SI, LCE? }\end{array}$ & Yes \\
\hline NIT11 & $\begin{array}{l}\text { Network IT Environmental } \\
\text { Stability }\end{array}$ & $\begin{array}{l}\text { Does increased Network IT Environmental } \\
\text { Stability improve SI, FC? }\end{array}$ & Yes \\
\hline NIT12 & Network IT Outsourcing & $\begin{array}{l}\text { Does increased Network IT Outsourcing } \\
\text { improve BE, LCE, FC? }\end{array}$ & Yes \\
\hline NIT13 & $\begin{array}{l}\text { Network IT Ownership } \\
\text { Symmetry }\end{array}$ & $\begin{array}{l}\text { Does increased Network IT Ownership } \\
\text { Symmetry improve SI? }\end{array}$ & Yes \\
\hline \multirow[t]{2}{*}{ NIT14 } & Network IT Abundance & $\begin{array}{l}\text { Does increased Network IT Abundance improve } \\
\text { FC? }\end{array}$ & Yes \\
\hline & Other & $\begin{array}{l}\text { Do other Network IT variables significantly } \\
\text { affect BE, LCE, SI, FC? If so, what? }\end{array}$ & Unsure \\
\hline
\end{tabular}

DN, Dual Network (a network IT dependent whole-network); IT, Information Technology; Network IT, Network Information Technology

\subsection{Instrument Development and Completion}

Three instruments were developed and used for the study. The instruments were designed to support triangulation of data for each site (network level) and the selected individuals (individual level) and their affiliated organization(s) (organizational level) with respect to each variable and hypothesis. Instrument design allowed evidence from multiple sources to be recorded in a tabular form, with columns for evidence which supported, refuted or provided alternate explanations for the phenomena. This format was designed to support systematic review of the data by the researchers as a basis for making determinations about variable validity and effects. Actual instruments used are shown in 
Appendix 4. In practice, the instruments evolved and were refined as the researchers worked through the subjects and documents.

\subsubsection{Instrument 1: Participation Opportunity Types}

Instrument 1 had two parts, 1a and 1b. Instrument 1a: participation opportunity types - non-standardized was designed to capture site (network level) information about the types of participation opportunity each site presented to participants. Records from each site were analyzed beginning in their pre-start up period. A text description of each opportunity was recorded, along with the month numbers from the start in which the opportunity appeared.

Instrument 1b: participation opportunity types - standardized and ranked, supported conversion of opportunities listed in instrument 1a into a standardized format. Each opportunity type was listed next to columns which described whether and how intent to participate and actual participation could be measured for that opportunity. If the actual participation opportunity could be measured, it was considered valid.

\subsubsection{Instrument 2: Subject Profile}

Instrument 2: subject profile was designed to capture individual level and organizational level information about individual participants and their affiliated organization(s) at a given point in time with respect to a given participation opportunity. An example of this instrument is contained in the Appendix 4. Instrument 2 included sections for answers to various queries related to variable sets 1-7. The instrument included places to enter answers to queries about what type of participation opportunity 
the subject participated in, what moderator attributes were associated with the subject and his/her affiliated organization, and the subject's level of intent to participate. In addition, for sets 4-7 (the predictors), the instrument provided places for entry of data in answer to queries about each predictor variable, including: 1.) whether the variable as defined was valid for that individual; 2.) if the variable was valid, data which supported, refuted, or provided rival explanations for the proposed effect of the factor on participation; and 3.) whether the proposed effect was supported.

\subsubsection{Instrument 3: Site Profile}

Instrument 3: site profile was designed to capture network level information about the HIEN of interest. Instrument 3 contains sections for variable sets $8-9$. For each site, the instrument provided places for entry of data in answer to queries about each site variable and hypothesis, including: 1.) whether the site variable as defined was valid for that site; 2.) if the variable was valid, data which supported, refuted, or provided rival explanations for the proposed effect of the factor on the predictors influencing intent to participate; and 3.) whether the proposed effect was supported.

\subsection{Assembling Supporting and Refuting Evidence and Alternate Explanations}

Instruments 2 and 3 were developed using a tabular format with columns for entry of qualitative evidence related to variable validity, evidence which supported hypotheses, evidence which refuted hypotheses, and evidence pointing to alternative explanations for the phenomenon being observed. An iterative process was used. Researcher 1 would complete part of an instrument for a few cases, and then researchers 1 and 2 would meet 
to review and discuss what had been done. Over approximately 4 months of meetings, multiple changes were made to the instrument designs, wording of the prompting questions used to elicit answers to questions, the wording of answers to the questions (e.g. the wording of the ordinal variable choices) and the descriptions of different types of qualitative evidence being considered. Each instrument evolved significantly over time through this process.

\subsection{Triangulation and Coding}

Consistent with established practices for strengthening validity and reliability of analysis of qualitative data (Creswell 2003; Marshall et al. 2006; Yin 2008), two types of triangulation were used in completing each of the instruments for each case. First, multiple sources of information about the same phenomena were evaluated. Second, two researchers reviewed the data in each of the instruments. In situations where the two researchers disagreed on an interpretation, discussion, debate and review of source information occurred until a consensus was reached on the interpretation. Final decisions about the validity and effects of each variable for each case were made by the two researchers, sitting together and discussing and debating until both agreed on the interpretation. Final interpretations were then used to add codes to each variable for each case regarding validity and effect of the variable in that case. With respect to validity, each variable was coded as valid, valid with questions, or not valid. With respect to affects on participation of variables in sets 3-9, variables for each subject were coded based on whether the hypothesis was supported, supported with questions, or not supported. 


\subsubsection{Managing Potential Researcher Bias}

Familiarity with the social and organizational context in which documents and records are produced can increase validity of retrospective case study research, provided potential biases associated with prior interactions are considered and methods to reduce influence of those biases are used (Yin 2008). Either one or both of the two researchers had met personally all of the 109 individuals included in the study between 2005 and 2010 in the HIEN settings of interest. These meetings occurred in the context of several action research initiatives (Davison et al. 2004; Minkler 2000; Whyte 1989) in which the researchers were providing support and guidance to the HIENs. These prior meetings ranged from a single 1 hour meeting with some participants to many hours of interaction with others in board meetings, focus groups, and other contexts. Thus, the researchers had some familiarity with social contexts in which documents and records were produced.

The potential for these prior interactions to influence observations in ways which could reduce objectivity for this study was considered and discussed. Processes of reflection to consider how to reduce bias related to prior relationships and connections can reduce risks to validity in qualitative research (Cargo et al. 2008; Marshall et al. 2006; Yin 2008). The researchers took time to reflect on their potential biases related to their prior work, and to discuss and debate how they were interpreting information to reduce potential for biased interpretation of the data. In addition, the researchers took care to answer questions with the context of the theory (DNPT) being used in this study. In general, given the complexity of the phenomena being considered, the researchers believe that their interpretations of the data were strengthened by their familiarity with 
the individuals, organizations and sites involved. During the process, new insights and perspectives were gained, and the researchers were at times surprised by what was being learned.

\subsection{Data Summary and Quantitative Analyses}

After the instruments were completed for each subject and site, data was summarized and invalid variables excluded. Data from sets 4-7 (the predictor variables) were entered into SPSS. A principle component analysis was done to identify common components, or factors, in the predictor data. New variables were created by combining similar variables. A regression analysis was done to analyze effect on intent to participate across the six sites. Quantitative and qualitative data were then both considered in the interpretation of the data.

\subsection{Data Management}

All instruments were developed and data stored using Microsoft Excel and Word software. SPSS version 17 was used for the statistical analyses.

\subsection{Confidentiality}

The research was determined to be IRB exempt by the University of Louisville IRB review board. The data used was organizational and commercial in nature, was either drawn from websites and public records or used by permission and will be published only in non-identifiable form. 


\subsection{Justification}

The study design is consistent with established best practices criteria for conducting exploratory case studies. Case study methods are appropriate to use in exploratory theory building research (Yin 2008). Case study methods are recommended for studies of whole-networks (Provan et al. 2007) and information systems (Benbasat et al. 1987). Use of theory to generate variables and hypotheses can strengthen case studies by helping focus attention (Eisenhardt 1989; Yin 2008). While not a representative sample, the selection of 6 sites (network level cases) 109 associated individuals (individual level cases) and 125 affiliated organizations (organizational level cases) strengthened the ability to identify themes which are consistent across multiple levels and across multiple cases within each level. Methods used to strengthen validity and reliability of findings included: identification of the risks to validity and reliability posed by the type of research being conducted (Yin 2008); use of theory to focus the investigation (Yin 2008); development of instruments which present information in tabular form (Yin 2008); assembly of data which supports, refutes or provides alternative or 'rival' explanations (Eisenhardt 1989; Yin 2008); triangulation of data from multiple sources (Jick 1979); review of data by two researchers (Yin 2008); use of mixed methods (Creswell 2003); and ongoing discussion and reflection by the researchers to identify and manage risks to validity associated with researchers' unexamined theoretical beliefs and/or prior relationships with the sites and subjects (Yin 2008). 


\subsection{Limitations}

Despite the use of best-practice methods to maximize validity and reliability of the study, the findings are only applicable to the six HIEN sites (network level) and the associated individuals (individual level) and organizations (organizational level) in this study. The cases are not a random sample, and the findings are not generalizable to all sites, individuals or organizations. 


\section{CHAPTER 5. RESULTS}

Results of the research are summarized in Table 9 and 10. Table 9 shows results for variable sets 1-7 and reflects analysis of two participation opportunities (POs), a less challenging and more challenging one. Table 10 shows results for sets $8-9$. Source data supporting the findings for each set appear in tables in Appendix 5.

In some cases in sets $3-7$, some invalid data scores changed somewhat for individuals with respect to different predictor variables. For example, for variables BE1, $\mathrm{BE} 2$ and $\mathrm{BE} 3,11 \%$ of individuals were coded as invalid because they did not have a job "as such" with an organization they represented. In BE4 and CE2 invalid subjects dropped to $7 \%$ and $4 \%$ respectively, because the question became relevant to selfemployed individuals or individuals serving on boards of organizations (but not employed by them). In addition, in some instances, the invalid \% changed for the same individual depending on the participation opportunity being considered. These differences occurred because the answers changed based on nuances of the questions asked in the context of different POs, or because a different time-period was being considered for the subject (e.g. the individual changed employers but stayed on the board). 
Table 9: Summary of Results - Sets 1-7

\begin{tabular}{|c|c|c|c|c|c|c|c|}
\hline \multicolumn{2}{|c|}{ Variable } & \multirow[t]{2}{*}{ Question(s) } & \multirow[t]{2}{*}{ Valid? } & \multirow{2}{*}{$\begin{array}{l}\text { Alt. } \\
\text { Exp? }\end{array}$} & \multirow[t]{2}{*}{ Answer } & \multirow{2}{*}{\begin{tabular}{r|} 
PO1 \\
Mean \\
SD \\
\end{tabular}} & \multirow{2}{*}{$\begin{array}{r}\text { PO2 } \\
\text { Mean } \\
\text { SD } \\
\end{array}$} \\
\hline Code & Name & & & & & & \\
\hline \multicolumn{8}{|c|}{ Set 1. Actual Participation } \\
\hline$\overline{\mathrm{AP} 1}$ & $\begin{array}{l}\text { Actual Participation } \\
\text { Variables }\end{array}$ & $\begin{array}{l}\text { What types of 'participation } \\
\text { opportunities' appear in dual } \\
\text { networks? }\end{array}$ & Yes* & N/A & \begin{tabular}{|l|} 
See \\
Table \\
12 \\
\end{tabular} & & \\
\hline \multicolumn{8}{|c|}{ Set 2. Intent to Participate } \\
\hline IP1 & Intent to Participate & $\begin{array}{l}\text { Is 'intent to participate' valid } \\
\text { for dual network participants? }\end{array}$ & Yes & No & Yes & $\begin{array}{r}4.6 \\
.9\end{array}$ & $\begin{array}{r}2.6 \\
1.09\end{array}$ \\
\hline IP2 & $\begin{array}{l}\text { Likelihood to } \\
\text { Participate }\end{array}$ & $\begin{array}{l}\text { Is 'likelihood to participate' } \\
\text { valid for dual network } \\
\text { participants? }\end{array}$ & Yes & No & Yes & $\begin{array}{r}4.6 \\
.9\end{array}$ & $\begin{array}{r}2.6 \\
1.09\end{array}$ \\
\hline IP3 & Plan to Participate & $\begin{array}{l}\text { Is 'plan to participate' valid for } \\
\text { dual network participants? }\end{array}$ & Yes & No & Yes & $\begin{array}{r}4.6 \\
.9 \\
\end{array}$ & $\begin{array}{r}2.6 \\
1.09 \\
\end{array}$ \\
\hline IP4 & Other? & $\begin{array}{l}\text { Are other variables needed to } \\
\text { capture 'intent to participate'? }\end{array}$ & $\mathrm{N} / \mathrm{A}$ & N/A & No & & \\
\hline \multicolumn{8}{|c|}{ Set 3. Moderators } \\
\hline M1 & Subject Age & Does age moderate effect? & Yes & No & Yes** & & \\
\hline M2 & Subject Gender & Does gender moderate effect? & Yes & Yes & $\mathrm{No}^{* *}$ & & \\
\hline M3 & $\begin{array}{l}\text { Subject Dual } \\
\text { Network } \\
\text { Experience }\end{array}$ & $\begin{array}{l}\text { Does leader collaboration } \\
\text { experience moderate effect? }\end{array}$ & Yes & No & Yes & & \\
\hline M4 & Organization size & $\begin{array}{l}\text { Does organization size } \\
\text { moderate effect? }\end{array}$ & Unsure* & Yes & Unsure** & & \\
\hline M5 & $\begin{array}{l}\text { Organization Dual } \\
\text { Network (DN) } \\
\text { experience }\end{array}$ & $\begin{array}{l}\text { Does organization collaboration } \\
\text { experience moderate effect? }\end{array}$ & Yes* & Yes & Yes** & & \\
\hline M6 & $\begin{array}{l}\text { Other individual } \\
\text { moderators? }\end{array}$ & $\begin{array}{l}\text { Are other individual moderators } \\
\text { needed? If so, what? }\end{array}$ & & & Yes & & \\
\hline M6a & $\begin{array}{l}\text { Subject Level of } \\
\text { Authority }\end{array}$ & $\begin{array}{l}\text { What was the level in the } \\
\text { organization/ group of this } \\
\text { subject? }\end{array}$ & Yes & Yes & No** & & \\
\hline M6b & $\begin{array}{l}\text { Professional } \\
\text { Membership }\end{array}$ & $\begin{array}{l}\text { What, if any, professional } \\
\text { membership, license to } \\
\text { practice or other legally } \\
\text { recognized authority to } \\
\text { practice in their profession did } \\
\text { this individual have? (If more } \\
\text { than one, select most } \\
\text { influential one) }\end{array}$ & Yes & Yes & Yes** & & \\
\hline M7 & $\begin{array}{l}\text { Other organizational } \\
\text { moderators? }\end{array}$ & $\begin{array}{l}\text { Are other organizational } \\
\text { moderators needed? If so, } \\
\text { what? }\end{array}$ & N/A & $\mathrm{N} / \mathrm{A}$ & Yes & & \\
\hline$\overline{\mathrm{M}} 7 \mathrm{a}$ & $\begin{array}{l}\text { Organizational } \\
\text { Level }\end{array}$ & $\begin{array}{l}\text { At what level in the network } \\
\text { did this organization/group } \\
\text { operate? }\end{array}$ & Yes* & Yes & Yes* & & \\
\hline M7b & $\begin{array}{l}\text { Product/Service of } \\
\text { Organization/ Group }\end{array}$ & $\begin{array}{l}\text { What was the primary product } \\
\text { or service which this } \\
\text { organization/group produced } \\
\text { or supported in this network? }\end{array}$ & Yes & Yes & Yes** & & \\
\hline
\end{tabular}




\begin{tabular}{|c|c|c|c|c|c|c|c|}
\hline \multicolumn{2}{|c|}{ Variable } & \multirow[t]{2}{*}{ Question(s) } & \multirow[t]{2}{*}{ Valid? } & \multirow{2}{*}{$\begin{array}{l}\text { Alt. } \\
\text { Exp? }\end{array}$} & \multirow[t]{2}{*}{ Answer } & \multirow{2}{*}{\begin{tabular}{r|} 
PO1 \\
Mean \\
SD \\
\end{tabular}} & \multirow{2}{*}{$\begin{array}{r}\text { PO2 } \\
\text { Mean } \\
\text { SD } \\
\end{array}$} \\
\hline Code & Name & & & & & & \\
\hline \multicolumn{8}{|c|}{ Set 4. Benefit Expectancy } \\
\hline BE1 & Ability to do Job & $\begin{array}{l}\text { Does dual network potential to } \\
\text { be 'useful to participants in } \\
\text { doing their jobs' increase } \\
\text { 'intent to have organization } \\
\text { participate?' }\end{array}$ & Yes* & Yes & Yes** & $\begin{array}{l}2.7 \\
.69\end{array}$ & $\begin{array}{l}2.4 \\
.62\end{array}$ \\
\hline $\mathrm{BE} 2$ & Task Completion & $\begin{array}{l}\text { Does dual network potential to } \\
\text { 'enable an organization to } \\
\text { accomplish tasks more } \\
\text { quickly' increase 'intent to } \\
\text { have organization participate?' }\end{array}$ & Yes* & Yes & Yes** $^{* *}$ & $\begin{array}{l}2.7 \\
.61\end{array}$ & $\begin{array}{l}2.3 \\
.56\end{array}$ \\
\hline$\overline{\mathrm{BE} 3}$ & Productivity & $\begin{array}{l}\text { Does dual network potential to } \\
\text { 'increase organizational } \\
\text { productivity' increase 'intent } \\
\text { to have organization } \\
\text { participate?' }\end{array}$ & Yes* & Yes & Yes** & $\begin{array}{l}2.6 \\
.62\end{array}$ & $\begin{array}{l}2.3 \\
.58\end{array}$ \\
\hline BE4 & $\begin{array}{l}\text { Financial } \\
\text { Performance }\end{array}$ & $\begin{array}{l}\text { Does dual network potential to } \\
\text { 'improve financial } \\
\text { performance' increase 'intent } \\
\text { to have organization } \\
\text { participate?' }\end{array}$ & Yes & Yes & Yes & $\begin{array}{l}2.6 \\
.89\end{array}$ & $\begin{array}{l}2.4 \\
.76\end{array}$ \\
\hline BE5 & Value of Decision & $\begin{array}{l}\text { BE6. Does belief that decision } \\
\text { 'will be seen as positive } \\
\text { contribution to the } \\
\text { organization by my superiors } \\
\text { and peers' increase 'intent to } \\
\text { have organization participate?' }\end{array}$ & Yes & Yes & Yes** $^{* *}$ & $\begin{array}{l}3.5 \\
.65\end{array}$ & $\begin{array}{l}2.7 \\
.70\end{array}$ \\
\hline BE6 & Other Value & $\begin{array}{l}\text { Are other variables needed to } \\
\text { measure benefit expectancy? If } \\
\text { so, what? }\end{array}$ & N/A & $\mathrm{N} / \mathrm{A}$ & No & & \\
\hline \multicolumn{8}{|c|}{ Set 5. Cost Expectancy } \\
\hline CE1 & $\begin{array}{l}\text { Subject Time and } \\
\text { Effort }\end{array}$ & $\begin{array}{l}\text { Does decreased expectation of } \\
\text { 'time and effort' by leaders } \\
\text { increase 'intent to have } \\
\text { organization participate?' }\end{array}$ & Yes & Yes & Yes & $\begin{array}{l}3.4 \\
.63\end{array}$ & $\begin{array}{l}3.2 \\
.53\end{array}$ \\
\hline CE2 & $\begin{array}{l}\text { Organization Time } \\
\text { and Effort }\end{array}$ & $\begin{array}{l}\text { Does decreased expectation of } \\
\text { 'time and effort' by the } \\
\text { organization increase 'intent } \\
\text { to have organization } \\
\text { participate?' }\end{array}$ & Yes & Yes & Yes & $\begin{array}{l}3.5 \\
.52\end{array}$ & $\begin{array}{l}3.2 \\
.45\end{array}$ \\
\hline CE3 & $\begin{array}{l}\text { Financial } \\
\text { Commitment }\end{array}$ & $\begin{array}{l}\text { Does decreased relative } \\
\text { financial commitment } \\
\text { expectation of 'time and } \\
\text { effort' by the organization } \\
\text { increase 'intent to have } \\
\text { organization participate?' }\end{array}$ & Yes & Yes & Yes & $\begin{array}{l}3.8 \\
.71\end{array}$ & $\begin{array}{l}2.9 \\
.62\end{array}$ \\
\hline CE4 & Individual social & Does decreased perceived risk & Yes* & Yes & Yes** & 3.7 & 3.1 \\
\hline
\end{tabular}




\begin{tabular}{|c|c|c|c|c|c|c|c|}
\hline \multicolumn{2}{|c|}{ Variable } & \multirow[t]{2}{*}{ Question(s) } & \multirow[t]{2}{*}{ Valid? } & \multirow{2}{*}{$\begin{array}{l}\text { Alt. } \\
\text { Exp? }\end{array}$} & \multirow[t]{2}{*}{ Answer } & \multirow{2}{*}{\begin{tabular}{r|} 
PO1 \\
Mean \\
SD
\end{tabular}} & \multirow{2}{*}{\begin{tabular}{|r|} 
PO2 \\
Mean \\
SD \\
\end{tabular}} \\
\hline Code & Name & & & & & & \\
\hline & capital risk & $\begin{array}{l}\text { to leader's social capital } \\
\text { 'increase 'intent to have } \\
\text { organization participate?' }\end{array}$ & & & & .73 & .42 \\
\hline CE5 & $\begin{array}{l}\text { Organization/Group } \\
\text { Reputation Risk }\end{array}$ & $\begin{array}{l}\text { Does decreased perceived risk } \\
\text { to organization/group's } \\
\text { social capital increase 'intent } \\
\text { to have organization } \\
\text { participate?' }\end{array}$ & Yes* & Yes & Yes & $\begin{array}{l}3.9 \\
.81\end{array}$ & $\begin{array}{l}3.2 \\
.52\end{array}$ \\
\hline CE6 & Other? & $\begin{array}{l}\text { Are other variables needed to } \\
\text { measure cost expectancy? If } \\
\text { so, what? }\end{array}$ & N/A & N/A & Yes & & \\
\hline CE6a & \begin{tabular}{|l} 
Regulatory \\
Compliance Cost
\end{tabular} & $\begin{array}{l}\text { Does decreased cost of } \\
\text { regulatory compliance increase } \\
\text { 'intent to have organization } \\
\text { participate?' }\end{array}$ & TBD & TBD & TBD & & \\
\hline \multicolumn{8}{|c|}{ Set 6. Social Influence } \\
\hline SI1 & $\begin{array}{l}\text { Support by } \\
\text { Influential People }\end{array}$ & $\begin{array}{l}\text { Does 'intent to have } \\
\text { organization participate' } \\
\text { increase when people who } \\
\text { influence a leader's decisions } \\
\text { think that the organization } \\
\text { should participate? }\end{array}$ & Yes & Yes & Yes & $\begin{array}{l}3.8 \\
.56\end{array}$ & $\begin{array}{l}2.9 \\
.71\end{array}$ \\
\hline SI2 & $\begin{array}{l}\text { Support by Important } \\
\text { People }\end{array}$ & $\begin{array}{l}\text { Does 'intent to have } \\
\text { organization participate' } \\
\text { increase when people who are } \\
\text { important to leader think that } \\
\text { the organization should } \\
\text { participate? }\end{array}$ & Yes & Yes & Yes & $\begin{array}{l}3.8 \\
.56\end{array}$ & $\begin{array}{l}2.9 \\
.71\end{array}$ \\
\hline $\mathrm{SI3}$ & Support by Superiors & $\begin{array}{l}\text { Does 'intent to have } \\
\text { organization participate' } \\
\text { increase when people to whom } \\
\text { a leader reports thinks that the } \\
\text { organization should } \\
\text { participate? }\end{array}$ & Yes* & Yes & Yes** & $\begin{array}{l}3.8 \\
.56\end{array}$ & $\begin{array}{l}2.9 \\
.69\end{array}$ \\
\hline S14 & & $\begin{array}{l}\text { Are other variables needed to } \\
\text { measure social influence? If } \\
\text { so, what? }\end{array}$ & $\mathrm{N} / \mathrm{A}$ & $\mathrm{N} / \mathrm{A}$ & No & & \\
\hline \multicolumn{8}{|c|}{ Set 7. Facilitating Conditions } \\
\hline FC1 & Subject Resources & $\begin{array}{l}\text { Does increase in 'subject } \\
\text { resources necessary to } \\
\text { participate' increase intent to } \\
\text { participate? }\end{array}$ & Yes & Yes & Yes & $\begin{array}{l}3.2 \\
.46\end{array}$ & $\begin{array}{l}3.2 \\
.46\end{array}$ \\
\hline $\mathrm{FC} 2$ & $\begin{array}{l}\text { Organizational } \\
\text { Resources }\end{array}$ & $\begin{array}{l}\text { Does increase in 'organizational } \\
\text { resources necessary to } \\
\text { participate' increase intent to } \\
\text { participate? }\end{array}$ & Yes* & Yes & Yes & $\begin{array}{l}3.2 \\
.44\end{array}$ & $\begin{array}{l}3.2 \\
.44\end{array}$ \\
\hline FC3 & $\begin{array}{l}\text { Dual Network } \\
\text { Resources }\end{array}$ & $\begin{array}{l}\text { Does increase in 'DN resources } \\
\text { necessary to support intent to } \\
\text { participate' increase intent to } \\
\text { participate? }\end{array}$ & Yes & Yes & Yes & $\begin{array}{l}3.1 \\
.30\end{array}$ & $\begin{array}{l}3.1 \\
.30\end{array}$ \\
\hline
\end{tabular}




\begin{tabular}{|c|c|c|c|c|c|c|c|}
\hline \multicolumn{2}{|c|}{ Variable } & \multirow[t]{2}{*}{ Question(s) } & \multirow[t]{2}{*}{ Valid? } & \multirow{2}{*}{$\begin{array}{l}\text { Alt. } \\
\text { Exp? }\end{array}$} & \multirow[t]{2}{*}{ Answer } & \multirow{2}{*}{\begin{tabular}{r|} 
PO1 \\
Mean \\
SD \\
\end{tabular}} & \multirow{2}{*}{$\begin{array}{r}\text { PO2 } \\
\text { Mean } \\
\text { SD } \\
\end{array}$} \\
\hline Code & Name & & & & & & \\
\hline$\overline{\mathrm{FC} 4}$ & Subject Knowledge & $\begin{array}{l}\text { Does increase of 'subject } \\
\text { knowledge necessary to } \\
\text { participate' increase intent to } \\
\text { participate? }\end{array}$ & Yes & Yes & Yes** & $\begin{array}{l}2.7 \\
.59\end{array}$ & $\begin{array}{l}2.7 \\
.59\end{array}$ \\
\hline FC5 & $\begin{array}{l}\text { Organizational } \\
\text { Knowledge }\end{array}$ & $\begin{array}{l}\text { Does increase of 'organizational } \\
\text { knowledge necessary to } \\
\text { participate' increase intent to } \\
\text { participate? }\end{array}$ & Yes* & Yes & Yes & $\begin{array}{l}.7 \\
.51\end{array}$ & $\begin{array}{l}2.7 \\
.51\end{array}$ \\
\hline FC6 & $\begin{array}{l}\text { Dual Network } \\
\text { Knowledge }\end{array}$ & $\begin{array}{l}\text { Does increase of 'DN } \\
\text { knowledge necessary to } \\
\text { support intent to participate' } \\
\text { increase intent to participate? }\end{array}$ & Yes & Yes & Yes & $\begin{array}{l}2.5 \\
.50\end{array}$ & $\begin{array}{l}2.5 \\
.50\end{array}$ \\
\hline FC7 & $\begin{array}{l}\text { Subject Tools and } \\
\text { Technologies }\end{array}$ & $\begin{array}{l}\text { Does increase in 'subject tools } \\
\text { and technologies necessary to } \\
\text { participate' increase intent to } \\
\text { participate? }\end{array}$ & Yes & Yes & Yes** & $\begin{array}{l}3.2 \\
.53\end{array}$ & $\begin{array}{l}3.2 \\
.53\end{array}$ \\
\hline FC8 & $\begin{array}{l}\text { Organizational Tools } \\
\text { and Technologies }\end{array}$ & $\begin{array}{l}\text { Does increase in 'organizational } \\
\text { tools and technologies } \\
\text { necessary to participate' } \\
\text { increase intent to participate? }\end{array}$ & Yes* & Yes & Yes** & $\begin{array}{l}3.2 \\
.48\end{array}$ & $\begin{array}{l}3.2 \\
.48\end{array}$ \\
\hline FC9 & $\begin{array}{l}\text { Dual Network Tools } \\
\text { and Technologies }\end{array}$ & $\begin{array}{l}\text { Does increase in 'DN tools and } \\
\text { technologies necessary to } \\
\text { support intent to participate' } \\
\text { increase intent to participate? }\end{array}$ & Yes & Yes & Yes* & $\begin{array}{l}2.9 \\
.28\end{array}$ & $\begin{array}{l}2.9 \\
.28\end{array}$ \\
\hline FC10 & Subject Staff Support & $\begin{array}{l}\text { Does increase of 'subject staff } \\
\text { support needed to participate' } \\
\text { increase intent to participate? }\end{array}$ & Yes & Yes & Yes** & $\begin{array}{l}3.2 \\
.49\end{array}$ & $\begin{array}{l}3.2 \\
.49\end{array}$ \\
\hline FC11 & $\begin{array}{l}\text { Organizational Staff } \\
\text { Support }\end{array}$ & $\begin{array}{l}\text { Does increase of 'organizational } \\
\text { staff support needed to } \\
\text { participate' increase intent to } \\
\text { participate? }\end{array}$ & Yes* & Yes & Yes** & $\begin{array}{l}3.1 \\
.36\end{array}$ & $\begin{array}{l}3.1 \\
.36\end{array}$ \\
\hline FC12 & $\begin{array}{l}\text { Dual Network Staff } \\
\text { Support }\end{array}$ & $\begin{array}{l}\text { Does increase of 'DN staff } \\
\text { support needed to support } \\
\text { participation' increase intent to } \\
\text { participate? }\end{array}$ & Yes & Yes & Yes & $\begin{array}{l}3.0 \\
.21\end{array}$ & $\begin{array}{l}3.0 \\
.21\end{array}$ \\
\hline FC13 & $\begin{array}{l}\text { Environmental } \\
\text { Stability }\end{array}$ & $\begin{array}{l}\text { Does increase in environmental } \\
\text { stability increase intent to } \\
\text { participate? }\end{array}$ & Yes & Yes & Yes & $\begin{array}{l}2.4 \\
.50\end{array}$ & $\begin{array}{l}2.4 \\
.50\end{array}$ \\
\hline FC14 & $\begin{array}{l}\text { Resource } \\
\text { Munificence }\end{array}$ & $\begin{array}{l}\text { Does increase in financial } \\
\text { munificence in the } \\
\text { environment increase intent to } \\
\text { participate? }\end{array}$ & Yes & Yes & Yes & $\begin{array}{l}3.0 \\
.23\end{array}$ & $\begin{array}{l}3.0 \\
.23\end{array}$ \\
\hline FC15 & Other? & $\begin{array}{l}\text { Are other variables needed to } \\
\text { measure facilitating } \\
\text { conditions? If so, what? }\end{array}$ & N/A & N/A & No & & \\
\hline
\end{tabular}

${ }^{*}$ Additional research recommended to further develop/validate this variable; ** Additional research recommended on effect of variable.

Table 10: Summary of Results - Sets 8-9 


\begin{tabular}{|c|c|c|c|c|c|c|}
\hline Code & Name & Questions & Valid & $\begin{array}{l}\text { Alt. } \\
\text { Exp? }\end{array}$ & \begin{tabular}{l|} 
For/ \\
Against
\end{tabular} & Answer \\
\hline \multicolumn{7}{|c|}{ Set 8. Whole-network Attributes } \\
\hline WN1 & $\begin{array}{l}\text { Rules and norms } \\
\text { (as steering mechanisms) }\end{array}$ & $\begin{array}{l}\text { Does increased Rules and } \\
\text { Norms increase SI? }\end{array}$ & Yes* & No & $6 / 2$ & Yes \\
\hline WN2 & Learning and Education & $\begin{array}{l}\text { Does increased Learning } \\
\text { and Education increase } \\
\text { SI? }\end{array}$ & Yes & No & $5 / 0$ & Yes \\
\hline WN3 & Dominant Core & $\begin{array}{l}\text { Does increased Dominant } \\
\text { Core increase BE, LCE, } \\
\text { SI, FC? }\end{array}$ & Yes* & No & $6 / 2$ & Yes** \\
\hline WN4 & Embedded Relationships & $\begin{array}{l}\text { Does increased Embedded } \\
\text { Relationships increase } \\
\text { BE, LCE, SI, FC? }\end{array}$ & Yes* & No & $6 / 2$ & Yes** \\
\hline WN5 & Right Type of Governance? & $\begin{array}{l}\text { Does Right Type of } \\
\text { Governance increase BE, } \\
\text { LCE, SI, FC? }\end{array}$ & Yes* & No & $6 / 0$ & Yes \\
\hline WN6 & Formalization & $\begin{array}{l}\text { Does increased } \\
\text { Formalization increase } \\
\text { BE, LCE, SI, FC? }\end{array}$ & Yes & No & $6 / 0$ & Yes \\
\hline WN7 & Network Inner Stability & $\begin{array}{l}\text { Does increased Network } \\
\text { Inner Stability increase } \\
\text { BE, LCE, SI, FC? }\end{array}$ & Yes* & No & $6 / 0$ & Yes \\
\hline WN8 & $\begin{array}{l}\text { Stability Management } \\
\text { (degree to which subject buffers } \\
\text { instability / nurtures stability in } \\
\text { the network) }\end{array}$ & $\begin{array}{l}\text { Does increase in Stability } \\
\text { Management increase BE, } \\
\text { LCE, SI, FC? }\end{array}$ & Yes* & Yes & $6 / 2$ & Yes** $^{* *}$ \\
\hline WN9 & $\begin{array}{l}\text { Accountability Management } \\
\text { (assignation of accountability } \\
\text { of managers for performance } \\
\text { and results for the whole- } \\
\text { network and community) }\end{array}$ & $\begin{array}{l}\text { Does increase in } \\
\text { Accountability } \\
\text { Management increase BE, } \\
\text { LCE, SI, FC? }\end{array}$ & Yes & No & $6 / 0$ & Yes \\
\hline WN10 & $\begin{array}{l}\text { Steering Network Processes } \\
\text { (processes to support ethical } \\
\text { decision-making, and facilitate } \\
\text { centralization of control) }\end{array}$ & $\begin{array}{l}\text { Does increase in Steering } \\
\text { Network Processes } \\
\text { increase BE, LCE, SI, } \\
\text { FC? }\end{array}$ & Yes* & No & $6 / 0$ & Yes \\
\hline WN11 & $\begin{array}{l}\text { Generic Networking } \\
\text { (time spent interacting with } \\
\text { network constituencies to } \\
\text { identify tensions, and blend } \\
\text { participant interests to achieve } \\
\text { whole-network goals) }\end{array}$ & $\begin{array}{l}\text { Does increase in Generic } \\
\text { Networking increase BE, } \\
\text { LCE, SI, FC? }\end{array}$ & Yes* & Yes & $6 / 0$ & Yes** \\
\hline WN12 & $\begin{array}{l}\text { Management Tenure } \\
\text { (tenure of whole-network } \\
\text { management team) }\end{array}$ & $\begin{array}{l}\text { Does increase in } \\
\text { Management Tenure } \\
\text { increase BE, LCE, SI, } \\
\text { FC? }\end{array}$ & Yes & No & $6 / 0$ & Yes \\
\hline WN13 & $\begin{array}{l}\text { Staff Coherence } \\
\text { (competitiveness vs. coherence } \\
\text { of staff) }\end{array}$ & $\begin{array}{l}\text { Does increase in Staff } \\
\text { Coherence increase BE, } \\
\text { LCE, SI, FC? }\end{array}$ & Yes* & No & $6 / 0$ & Yes \\
\hline WN14 & $\begin{array}{l}\text { Services Capability } \\
\text { (capability to provide services } \\
\text { desired to participants) }\end{array}$ & $\begin{array}{l}\text { Does increase in Services } \\
\text { Capability increase BE, } \\
\text { LCE, SI, FC? }\end{array}$ & Yes & No & $1 / 0$ & Unsure $^{* *}$ \\
\hline WN15 & Other & $\begin{array}{l}\text { Do other whole-network } \\
\text { attribute variables } \\
\text { significantly affect BE, }\end{array}$ & $\mathrm{N} / \mathrm{A}$ & N/A & & Yes \\
\hline
\end{tabular}




\begin{tabular}{|c|c|c|c|c|c|c|}
\hline & & LCE, SI, FC? If so, what? & & & & \\
\hline WN15a & Resource Availability & $\begin{array}{l}\text { To what degree does the } \\
\text { site have adequate } \\
\text { resources, such as } \\
\text { facilities, staff, and } \\
\text { funding, to achieve its } \\
\text { goals? }\end{array}$ & Yes* & No & $6 / 0$ & Yes \\
\hline \multicolumn{7}{|c|}{ Set 9. Network IT Attributes } \\
\hline$\overline{\text { NIT1 }}$ & $\begin{array}{l}\text { Environmental Linking Network } \\
\text { IT }\end{array}$ & $\begin{array}{l}\text { Does increased } \\
\text { Environmental Linking } \\
\text { Network IT improve BE, } \\
\text { SI? }\end{array}$ & Yes* & No & $6 / 2$ & Yes** \\
\hline NIT2 & Market Bridging Network IT & $\begin{array}{l}\text { Does increased Market } \\
\text { Bridging Network IT } \\
\text { improve BE, SI? }\end{array}$ & Yes* & No & $6 / 2$ & Yes \\
\hline NIT3 & Governance Network IT & $\begin{array}{l}\text { Does increased } \\
\text { Governance Network IT } \\
\text { improve SI, FC? }\end{array}$ & Yes* & No & $6 / 3$ & Yes** \\
\hline NIT4 & Functional Network IT & $\begin{array}{l}\text { Does increased Functional } \\
\text { Network IT improve } \\
\text { LCE, FC? }\end{array}$ & Yes* & No & $6 / 1$ & Yes** \\
\hline NIT5 & Individual Network IT & $\begin{array}{l}\text { Does increased Individual } \\
\text { Network IT improve FC? }\end{array}$ & Yes* & Yes & $6 / 0$ & Yes** \\
\hline NIT8 & Network IT Openness & $\begin{array}{l}\text { Does increased Network } \\
\text { IT Openness improve } \\
\text { LCE? }\end{array}$ & Yes* & Yes & $4 / 2$ & Unsure** \\
\hline NIT9 & Network IT Innovativeness & $\begin{array}{l}\text { Does increased Network } \\
\text { IT Innovativeness } \\
\text { improve SI, LCE? }\end{array}$ & Yes* & Yes & $6 / 1$ & Unsure** \\
\hline NIT11 & $\begin{array}{l}\text { Network IT Environmental } \\
\text { Stability }\end{array}$ & $\begin{array}{l}\text { Does increased Network } \\
\text { IT Environmental } \\
\text { Stability improve SI, FC? }\end{array}$ & Yes* & No & $6 / 0$ & Yes \\
\hline NIT12 & Network IT Outsourcing & $\begin{array}{l}\text { Does increased Network } \\
\text { IT Outsourcing improve } \\
\text { BE, LCE, FC? }\end{array}$ & Yes & No & $5 / 0$ & Yes** \\
\hline NIT13 & $\begin{array}{l}\text { Network IT Ownership } \\
\text { Symmetry }\end{array}$ & $\begin{array}{l}\text { Does increased Network } \\
\text { IT Ownership Symmetry } \\
\text { improve SI? }\end{array}$ & Yes* & No & $6 / 0$ & Yes \\
\hline \multirow[t]{2}{*}{ NIT14 } & Network IT Abundance & $\begin{array}{l}\text { Does increased Network } \\
\text { IT Abundance improve } \\
\text { FC? }\end{array}$ & Yes* & No & $6 / 0$ & Yes \\
\hline & Other & $\begin{array}{l}\text { Do other Network IT } \\
\text { variables significantly } \\
\text { affect BE, LCE, SI, FC? } \\
\text { If so, what? }\end{array}$ & & & & No \\
\hline
\end{tabular}

*Additional research recommended to further develop/validate this variable; ** Additional research recommended on effect of variable. 


\subsection{Set 1: Actual Participation}

Variable set 1 contained 1 question: what types of participation opportunities appear in dual networks? Study of the 6 sites found a diverse set of opportunities (shown in Table 11). For example, site 1 went through 7 identifiable stages of development in which opportunities to participate emerged. These included: pre-formation exploration (months 1-21); corporate formation, phase 1 (months 22-27); corporate formation, phase 2 (month 27); goal formation (vision, mission, values) (months 25-33); start-up planning and fundraising (months 40-46); research and planning meetings and interviews (months 40-47); business planning (develop, finalize and approve) (months 45-50); outsource health information exchange vendor selection (months 51-57). Other sites had different stages and timelines, such as conducting trade-shows and education events (site 4), or corporate formation earlier or later in the process (sites 3 and 5).

Table 11: Set 1: Actual Participation Opportunity Types - Non-Standardized, by Site

\begin{tabular}{|c|c|c|c|}
\hline Participation Opportunity & Months & Participation Opportunity & Months \\
\hline Site 1 & & Site 4 & \\
\hline Pre-formation exploration & $1-21$ & $\begin{array}{l}\text { Goal formation phase } 1 \text { (HIE } \\
\text { planning and education for state) }\end{array}$ & $17-27$ \\
\hline Corporate formation (phase 1) & $22-27$ & $\begin{array}{l}\text { Business Plan for planning and } \\
\text { education services (refined yearly) }\end{array}$ & $25-59$ \\
\hline Corporate formation (phase 2 - handover) & 27 & Fundraising & $25-59$ \\
\hline Goal formation (vision, mission, values) & $25-33$ & $\begin{array}{l}\text { Participate in educational } \\
\text { events/tradeshows }\end{array}$ & $25-59$ \\
\hline Start-up planning and fundraising & $40-46$ & $\begin{array}{l}\text { Planning phase } 2 \text { : planning for } \\
\text { growth opportunities (including } \\
\text { providing HIE services) }\end{array}$ & $47-59$ \\
\hline $\begin{array}{l}\text { Research and planning meetings and } \\
\text { interviews }\end{array}$ & $40-47$ & $\begin{array}{l}\text { Lobby state government for } \\
\text { recognition as state designated entity } \\
\text { for HIE }\end{array}$ & $47-59$ \\
\hline $\begin{array}{l}\text { Lobby state government for formal } \\
\text { recognition as 'exclusive' HIE for metro } \\
\text { area. }\end{array}$ & $35-60$ & $\begin{array}{l}\text { Operational funding and } \\
\text { implementation (phase } 2-\mathrm{EMR} \\
\text { education) }\end{array}$ & $55-65$ \\
\hline $\begin{array}{l}\text { Business plan (develop, finalize and } \\
\text { approve) }\end{array}$ & $45-50$ & Site 5 & \\
\hline Outsource HIE vendor selection & $51-57$ & Pre-formation exploration & $1-63$ \\
\hline
\end{tabular}




\begin{tabular}{|c|c|c|c|}
\hline Participation Opportunity & Months & Participation Opportunity & Months \\
\hline Operational funding and implementation & $58-76$ & Goal formation ( 4 organizations) & $11-19$ \\
\hline Site 2 & & Start-up planning, fundraising & $16-19$ \\
\hline Pre-formation exploration & $1-26$ & Select planning vendor & $20-25$ \\
\hline Legislative development & $27-46$ & $\begin{array}{l}\text { Participate in research and planning } \\
\text { process }\end{array}$ & $26-60$ \\
\hline $\begin{array}{l}\text { Identity formation (interpreting legislation } \\
\text { by board) }\end{array}$ & $47-57$ & $\begin{array}{l}\text { Business plan Version } 1 \text { (develop, } \\
\text { finalize and approve) }\end{array}$ & $46-54$ \\
\hline Action plan (develop, finalize, approve) & $54-64$ & Outsource HIE vendor selection & $55-64$ \\
\hline $\begin{array}{l}\text { Conduct annual trade-shows and } \\
\text { educational event }\end{array}$ & $56-71$ & Corporation formation & $64-66$ \\
\hline Form operating corporation & $65-70$ & $\begin{array}{l}\text { Business plan Version } 2 \text { (develop, } \\
\text { finalize and approve) }\end{array}$ & $65-75$ \\
\hline Operational funding and implementation & $68-\overline{71}$ & $\begin{array}{l}\text { Operational funding and } \\
\text { implementation }\end{array}$ & $69-76$ \\
\hline Site 3 & & Site 6 & \\
\hline Pre-formation exploration & $1-4$ & $\begin{array}{l}\text { Pre-formation exploration (each party } \\
\text { contributed staff) }\end{array}$ & $1-10$ \\
\hline Corporation formation & $5-8$ & Corporate formation & $9-11$ \\
\hline Goal formation & $6-8$ & Goal formation & $10-13$ \\
\hline Select/engage third party administrative org & 6-8 & Start-up planning and fundraising & $12-15$ \\
\hline Participate in research and planning & $6-8$ & $\begin{array}{l}\text { Business plan (develop, finalize and } \\
\text { approve) }\end{array}$ & $15-17$ \\
\hline $\begin{array}{l}\text { Business plan (develop, finalize and } \\
\text { approve) }\end{array}$ & $9-16$ & $\begin{array}{l}\text { Outsource HIE vendor selection } \\
\text { (from merger partner) }\end{array}$ & $16-20$ \\
\hline$\underline{\text { Site } 4}$ & & $\begin{array}{l}\text { Operational funding and } \\
\text { implementation }\end{array}$ & $21-$ \\
\hline $\begin{array}{l}\text { Pre-formation exploration (governor gives } \\
\text { executive order for call to action summit } \\
\text { with follow-up) }\end{array}$ & $1-15$ & & \\
\hline $\begin{array}{l}\text { Corporate formation (board and non-profit } \\
\text { form) }\end{array}$ & $15-18$ & & \\
\hline
\end{tabular}

Analysis of similarities among these opportunities led to development of the standardized typology shown in Table 12. Participation opportunities identified include opportunities to participate in idea generation, board/committees, public comment/input, investment in plan development, investment in start-up, use of services, use of educational services, lobbying for protected status from government, and providing services to the network. Each of these types of actual participation except idea generation were found to be measurable in principle, and had potential to correlate with intent to participate. However, a site (a dual network) would need to maintain formal records of invitations and actual participation to support measurement of these factors. 
After its formation, the standardized typology was tested for validity for the 109 subjects (individual and organizational levels) in the study. For each subject, questions about two participation opportunities, a 'less challenging' and a 'more challenging' one, were asked and answered. A participation opportunity was scored as valid if it could be answered, e.g., it 'fit', for all or virtually all of the subjects. The participation opportunities selected were found to be valid for $100 \%$ of the subjects in the study. However, some types of participation opportunity (such as the opportunity to use technology services) were not able to be evaluated because the opportunity was not offered by the sites in this study. 
Table 12: Set 1: Actual Participation Opportunity Types - Standardized and Ranked

\begin{tabular}{|c|c|c|c|c|}
\hline $\begin{array}{l}\text { Participation } \\
\text { opportunity }\end{array}$ & Prompt & $\begin{array}{l}\text { Is Intent to } \\
\text { participate } \\
\text { measurable? } \\
\text { If so, how? }\end{array}$ & Prompt & $\begin{array}{l}\text { Is actual } \\
\text { participation } \\
\text { measurable? } \\
\text { If so, how? }\end{array}$ \\
\hline 1. Generate idea & $\begin{array}{l}\text { Were one or more } \\
\text { people involved in } \\
\text { coming up with } \\
\text { ideas? }\end{array}$ & No & & No \\
\hline $\begin{array}{l}\text { 2. Provide } \\
\text { funding to } \\
\text { explore idea }\end{array}$ & $\begin{array}{l}\text { Were one or more } \\
\text { funders invited to } \\
\text { participate in pre- } \\
\text { formation funding? }\end{array}$ & $\begin{array}{l}\text { By network } \\
\text { entrepreneur(s) }\end{array}$ & $\begin{array}{l}\text { Did the subject } \\
\text { provide } \\
\text { funding? }\end{array}$ & $\begin{array}{l}\text { Yes } \\
\text { Based on funding } \\
\text { records }\end{array}$ \\
\hline $\begin{array}{l}\text { 3. Participate in } \\
\text { Meetings to } \\
\text { Explore Idea }\end{array}$ & $\begin{array}{l}\text { Was the subject } \\
\text { invited to participate } \\
\text { in pre-formation } \\
\text { exploration? }\end{array}$ & $\begin{array}{l}\text { By network } \\
\text { entrepreneur(s) }\end{array}$ & $\begin{array}{l}\text { Did the subject } \\
\text { attend } \\
\text { meetings? }\end{array}$ & $\begin{array}{l}\text { Yes } \\
\text { Based on attendance } \\
\text { at meetings }\end{array}$ \\
\hline $\begin{array}{l}\text { 4. Join board/ } \\
\text { committees }\end{array}$ & $\begin{array}{l}\text { Was the subject } \\
\text { invited to participate } \\
\text { as a member of a } \\
\text { board or committee? }\end{array}$ & $\begin{array}{l}\text { Yes } \\
\text { Based on response } \\
\text { to invitations to } \\
\text { attend or renew }\end{array}$ & $\begin{array}{l}\text { Did the subject } \\
\text { attend } \\
\text { meetings? How } \\
\text { did the subject } \\
\text { vote? }\end{array}$ & $\begin{array}{l}\text { Yes } \\
\text { Based on attendance } \\
\text { at meetings and } \\
\text { voting record. }\end{array}$ \\
\hline $\begin{array}{l}\text { 5. Invest in plan } \\
\text { development }\end{array}$ & $\begin{array}{l}\text { Was the subject } \\
\text { invited to invest in } \\
\text { plan development? }\end{array}$ & $\begin{array}{l}\text { Yes } \\
\text { Based on pre- } \\
\text { funding survey }\end{array}$ & & $\begin{array}{l}\text { Yes } \\
\text { Based on actual } \\
\text { investment made }\end{array}$ \\
\hline $\begin{array}{l}\text { 6. Provide } \\
\text { public } \\
\text { comment/ } \\
\text { input }\end{array}$ & $\begin{array}{l}\text { Was the subject } \\
\text { invited to provide } \\
\text { comment as a } \\
\text { potential member of } \\
\text { the network? }\end{array}$ & $\begin{array}{l}\text { Yes } \\
\text { Based on response } \\
\text { to invitations }\end{array}$ & $\begin{array}{l}\text { Did the subject } \\
\text { make comments } \\
\text { or attend } \\
\text { comment } \\
\text { meetings? }\end{array}$ & $\begin{array}{l}\text { Yes } \\
\text { Based on record of } \\
\text { comments or } \\
\text { attendance at } \\
\text { meetings. } \\
\end{array}$ \\
\hline $\begin{array}{l}\text { 7. Invest in } \\
\text { start-up of } \\
\text { operations }\end{array}$ & & $\begin{array}{l}\text { Yes } \\
\text { Based on pre- } \\
\text { funding survey }\end{array}$ & & $\begin{array}{l}\text { Yes } \\
\text { Based on actual } \\
\text { investment made }\end{array}$ \\
\hline 8. Use services & $\begin{array}{l}\text { Was the subject } \\
\text { invited to use } \\
\text { technology services } \\
\text { offered by network? }\end{array}$ & \begin{tabular}{|l|} 
Yes \\
$\begin{array}{l}\text { Based on records } \\
\text { of invitation }\end{array}$ \\
\end{tabular} & \begin{tabular}{|l} 
Did subject use \\
technology \\
services offered \\
by network? \\
\end{tabular} & $\begin{array}{l}\text { Yes } \\
\text { Based on actual use } \\
\text { of services } \\
\end{array}$ \\
\hline $\begin{array}{l}\text { 9. Lobby } \\
\text { government } \\
\text { for protected - } \\
\text { status }\end{array}$ & $\begin{array}{l}\text { Was the subject } \\
\text { invited to lobby } \\
\text { government for } \\
\text { protected status? }\end{array}$ & $\begin{array}{l}\text { Yes } \\
\text { Based on records } \\
\text { of request(s) }\end{array}$ & $\begin{array}{l}\text { Did subject } \\
\text { lobby for } \\
\text { protected } \\
\text { status? } \\
\end{array}$ & $\begin{array}{l}\text { Yes } \\
\text { Requires reporting } \\
\text { back by subject. }\end{array}$ \\
\hline $\begin{array}{l}\text { 10. Use of } \\
\text { educational - } \\
\text { services }\end{array}$ & $\begin{array}{l}\text { Was the subject } \\
\text { invited to use } \\
\text { educational services } \\
\text { offered by network? }\end{array}$ & $\begin{array}{l}\text { Yes } \\
\begin{array}{l}\text { Based on records } \\
\text { of invitation }\end{array} \\
\end{array}$ & $\begin{array}{l}\text { Did subject use } \\
\text { educational } \\
\text { services offered } \\
\text { by network? } \\
\end{array}$ & $\begin{array}{l}\text { Yes } \\
\begin{array}{l}\text { Based on actual use } \\
\text { of services }\end{array} \\
\end{array}$ \\
\hline $\begin{array}{l}\text { 11. Services } \\
\text { provider }\end{array}$ & $\begin{array}{l}\text { Was the subject } \\
\text { invited to provide } \\
\text { services to the } \\
\text { network? }\end{array}$ & $\begin{array}{l}\text { Yes } \\
\begin{array}{l}\text { Based on records } \\
\text { of invitation }\end{array}\end{array}$ & $\begin{array}{l}\text { Did subject } \\
\text { actually provide } \\
\text { services to the } \\
\text { network? }\end{array}$ & $\begin{array}{l}\text { Yes } \\
\text { Based on records of } \\
\text { actual provision of } \\
\text { services. }\end{array}$ \\
\hline
\end{tabular}




\subsection{Set 2: Intent to Participate}

Variable set 2 contained 3 variables designed to measure intent to participate. For variables 2-4, a 5 point Likert-type scale was developed and used to assess the validity of the proposed variables. Valid answers to these questions were generated for $100 \%$ of the subjects. The answers (means and standard deviations) for each of the 3 questions were almost identical for each subject, indicating likelihood that they are measuring the same construct.

No additional questions to measure intent to participate were believed to be needed. However, some questions were raised with respect to the meaning of the term 'intent to participate' as it relates to different types of participation opportunities. Some opportunities, such as participation in educational activities, posed little or no cost and risk to a group/organization represented by a subject. In such an instance, a subject's indication of being 'likely to participate' may imply participation in a one-time event by just herself or a few people from her organization. For other opportunities, such as organization-wide use of a costly technology service, a high intent to participate may imply organization-wide intent to participate in a high-risk endeavor. In this case, 'intent to participate' will have a quite different meaning and implication. Furthermore, some participants represented no organization or group. In this instance, participation referred only to the individual's participation, and did not imply participation or support by any group or organization. Thus, the concept of intent to participate must be carefully defined to reflect the kind of participation opportunity being considered. The questions for measuring intent to participate were rated as valid, with the caveat that questions should 
be tailored based on the type of participation opportunity being considered and who is being asked to participate.

\subsection{Set 3: Moderators}

Variable set 3 contained 7 questions about moderators - variables which may moderate the effect of predictors on intent to participate.

For variable M1, subject age, subjects were placed into one of 7 groups based on their age: 18-24 (0\%), 25-34 (0\%), 35-44 (21\%), 45-54 (53\%), 55-64 (23\%), 65-74 (3\%), $75+(0 \%)$. This attribute was measurable for all subjects. Ninety seven percent $(97 \%)$ of the subjects in this cohort were between 35 and 64 years of age. No subjects were younger; $3 \%$ were older. Variable M1 was assessed as valid.

Hypothesis M1 was that age will have a moderating affect. It was anticipated that people at the youngest and oldest ends of the scale would be less likely to participate, because they would be less likely to have the confidence and support of their organization or group. Evidence for hypothesis M1 was the lack of subjects in the young and old age ranges. Evidence against hypothesis M1 was that age was not observed as having an effect on participation for any of the subjects studied. However, this could be because no very young or very old were present. No alternate explanations for these phenomena were found. Hypothesis M1 was supported with recommendations for additional research to look at effects on participation of being very young or very old.

For variable M2, subject gender, selections were male (59\%) and female (41\%).

The attribute was measured for all subjects. It was assessed as valid. 
Hypothesis M2 was that gender will have a moderating affect. It was anticipated that being female would reduce intent to participate, because subjects would be less likely to have the confidence and support of their organization or group in U.S. culture. No evidence for hypothesis M2 was found in the qualitative review. Evidence against hypothesis M2 was that $41 \%$ (nearly half) of subjects were female. Females appeared to carry authority, were accorded respect, and participated in ways comparable to males in this cohort. No alternative explanations were found for these phenomena. Thus, hypothesis M2 was not supported. Gender did not appear to moderate participation. However, additional research is recommended for influence of gender in other contexts.

Variable M3, subject dual network experience, considered 'what level of experience with dual networks and collaboration did this subject have?' To measure this attribute, a 5 point scale was used: virtually no DN experience ( $0 \%)$, little DN experience $29 \%$ ), moderate DN experience (59\%), high level of DN experience (12\%), extremely high level of DN experience ( $0 \%)$. This attribute was found to be measurable for all subjects and assessed as valid.

Hypothesis M3 was that increase in subject experience with collaboration and dual networks will increase intent to participate. This is because dual network participation requires ability to work in a highly collaborative, networked environment in which decisions are made by consensus, rather than through hierarchy. Evidence for hypothesis M3 included: 1.) subjects with lower levels of experience in this area exhibited higher levels of impatience with the process, and were more likely to abandon it; 2.) some tried to manipulate or force the process, resulting in loss of goodwill from other participants; 3.) subjects with higher levels of experience appeared better able to 
navigate the process of decision-making and help the collaborative move forward. No evidence against hypothesis M3 was found. No alternate explanations for the phenomena were identified. Hypothesis M3 was supported.

Variable M4, organization size, considered the effects of organization or group size on willingness to participate in opportunities. To measure this attribute, a 5 point scale was used: small (0-10 employees) (11\%), somewhat small (11-499 employees) (24\%), medium (500-4999 employees) (16\%), large (5000 - 24999 employees) (22\%), very large (25000+ employees) (24\%). Several issues were identified which raised questions about the validity of this measure. First, while the attribute was measurable for $96 \%$ of subjects, it was not measureable for $4 \%$ who did not represent an employer and/or were not employed. In addition, questions emerged about the validity of using number of employees as a measure of size. A few organizations were found with few employees but very high revenues (one in the hundreds of millions). This led to questions about whether revenues might be a better measure of size, or whether employees of subcontracted vendors should be included. In addition, there were some associations, such as hospital associations, which, in themselves, had a low number of employees, but which represented organizations which collectively had hundreds of thousands of employees. Based on these considerations, the validity of variable M4 was rated as unsure, with recommendations for additional research to determine the best way to measure size of organizational/group participants.

Hypothesis M4 was that the number of employees would moderate participation. This moderation could occur in either direction. On the one hand, smaller organizations with less to lose might be more nimble and better able to participate and make decisions 
about participating. On the other hand, larger organizations could be more likely to make credible commitments and commit capital and resources to support participation in a network over time. Evidence for hypothesis M4 was that both these patterns were seen in some instances. However, uncertainly about the validity of the measure raised questions about these findings. No alternative explanations for these phenomena were found. Hypothesis M4 was rated as unsure, with recommendations for additional research on how to assess effects by size.

Variable M5, organization/group dual network experience, considered the level of experience with dual networks and collaboration of the organization or group represented by the subject. To measure this attribute, a 5 point scale was constructed: virtually no DN experience $(0 \%)$, a little DN experience $\quad(13 \%)$, moderate DN experience $(72 \%)$, high level of DN experience (12\%), extremely high level of DN experience $(0 \%)$. This attribute was measurable for $97 \%$ of the subjects. In $3 \%$ of the cases the subject did not work for or represent an organization or group and thus the attribute was not measurable. Variable M5 was rated as valid, with the caveat that it was only applicable to individuals who formally represent or work for an organization or group.

Hypothesis M5 was that an increase in organizational experience with collaboration and dual networks will increase subject's intent to participate. This is because dual network participation requires ability to work in a highly collaborative, networked environment in which decisions are made by consensus, rather than through hierarchy. Evidence for hypothesis M5 was that subjects whose organizations had higher experience with collaboration did seem to receive more support for their participation and operated more confidently. No evidence against hypothesis M5 was found. An alternate 
explanation for hypothesis M5 was that it may duplicate the social influence predictor, since it is driven by the level of support from others in the subject's group or organization. Hypothesis M5 was supported, with recommendations for additional research to assess overlap with social influence predictors.

Question M6 asked if additional individual moderators are needed for the model, and if so, what. Two additional variables, M6a and M6b, were added.

Variable M6a, subject level, was constructed to consider level of authority in the organization/group which the subject represented. Reasons for its addition were the diversity of levels represented in the cohort and possible affects of those levels on decisions to participate. Selections were added as encountered. Selections included member, board of directors ( $4 \%$ ), committee member, board of directors $(0 \%)$, chair, board of directors (3\%), member, dues paying (6\%), elected official or legislator (4\%), president/CEO/executive director (22\%), $\mathrm{CxO}$ (CFO, COO, $\mathrm{CMO}$, etc.) (15\%), vicepresident (23\%), director (13\%), manager (5\%), staff (4\%), and individual (4\%). If subjects fit more than one selection, the more influential level was chosen. This attribute was found to be measurable in all cases and was rated as valid.

Hypothesis M6a proposed that a higher subject level would increase intent to participate in some opportunities. Specifically, the hypothesis was that the higher the level of board or staff level authority, the more likely it is that the subject will intend to participate. Evidence for hypothesis M6a was that some higher level personnel did exhibit high levels of commitment in some cases. Evidence against hypothesis M6a was that some lower level personnel appeared more likely to participate in some opportunities such as planning and education which required low levels of organizational 
commitment. In addition, some higher level personnel did not participate in these, because they believed the opportunity was not important enough to justify their time. An alternate explanation for these phenomena was that people participate when there is a 'fit' between their roles and responsibilities, and the requirements presented by the opportunity to participate. Based on these results, hypothesis M6a was not supported, but recommendations were made for additional research to: 1.) look at effects of participation on level of 'fit' with authority and responsibility of the individual; and 2.) potential for fit to overlap with other predictors such as enabling conditions.

Variable M6b, professional membership, was constructed to consider effects of types of professional membership held by subjects. The reason for this addition was the observation that professional loyalties and obligations, especially for physicians, appeared to have strong influence on decisions about participation. Selections were added as encountered. Selections included: physician (M.D., D.O.) (16\%), nurse (RN or higher) $(3 \%)$, pharmacist (4\%), attorney (6\%), elected official (4\%), university professor (5\%), labor union member $(1 \%)$, certified public accountant $(1 \%)$, and none $(61 \%)$. If subjects fit more than one selection, the more influential one was chosen. This attribute was found to be measurable and assessed as valid.

Hypothesis M6b proposed that the more power and influence a subject's professional membership provides them, the more it will moderate their intent to participate in opportunities. Evidence for this hypothesis came from the examples of physicians, whose profession clearly gave them power and influence in this context. They exhibited high levels of power and influence over decision-making in 5 of the 6 sites. In addition, university professors, attorneys and pharmacists exhibited strong loyalty to their 
professions as well as to their employers, and also had comments which were accorded special respect in board meeting minutes based on their professional roles. No evidence against hypothesis M6b was found. An alternative explanation was that the influence of professional membership may be captured by the social influence predictors. Hypothesis M6b was supported, with recommendations for additional research to understand effects by type of professional affiliation, and potential overlap with social influence predictors. Question M7 asked if additional organizational moderators are needed for the model, and if so, what. In response to this question, variables M7a and M7b were added. Variable M7a, organizational level, was constructed to measure the level at which a group or organization operated in a network. The reason for this was the discovery that subjects representing all three ontological levels underpinning the model (individual, organizational and whole-network) were participating in the sites in this study. This discovery prompted construction of a hierarchy of entity levels to describe the type of entity represented by the subject. At the individual level, individuals were identified who participated as an individual (4\%), as a representative of an informal group of individuals (e.g., consumers in a state) $(1 \%)$, as a professional (e.g., as a physician) $(0 \%)$, and as a representative of a network of professionals (e.g., a physician association) (8\%). At an organizational level, individuals were identified representing traditional organizations (64\%). At a network level, participants were identified representing interorganizational networks such as a hospital association whose purpose is to benefit its member organizations (14\%).

Individuals were also identified who represented something new, which I called a mixed network (10\%). A mixed network is a network which includes participants from at 
least two of the three levels (individual, organization, and network). For example, a mixed network could include participants representing individuals and organizations, organizations and whole-networks, individuals and whole-networks, or individuals, organizations and whole-networks.

Three examples of mixed networks were found being represented in the HIENs in the study. A legislative network (4\%) is a network of individuals, organizations and networks represented by an elected legislator. Several legislators participated in the HIENs, and stated they were making decisions on behalf of their 'electorate'. A policy network $(3 \%)$ is a mixed network organized to recommend policy to government leaders or others. Policy networks identified were comprised of individual experts, representatives of organizations, and, in some cases, representatives of other networks. For example, a leader of a higher education policy network participated in one site. Participants representing policy networks stated they represented the interests of the policy network. A third type of mixed network (3\%) was HIENs. HIENs included leaders representing other HIENs as well as individuals not representing any organizations. Participants representing an HIEN while also on the board of another HIEN had unique challenges, because they were in the position of collaborating with a potential competitor.

Variable M7a was measurable as constructed. However, only one level was recorded per subject. It was listed as valid, with a caveat that some individuals may represent multiple levels or entities. Recommendations are made for additional research to develop a typology of mixed networks and to consider effects on participation as participant heterogeneity increases.

Hypothesis M7a proposed that type of entity would moderate intent to participate. 
Evidence for hypothesis M7a was that some mixed networks leaders were reluctant or unable to participate because of competitive issues (e.g., HIENs) or other institutional conflicts (e.g., state governmental procurement conflicts). No evidence against hypothesis M7a was found. An alternate explanation was that standard predictors related to benefit, cost, social influence and facilitating conditions may explain this variation. Hypothesis M7a was supported, with recommendations for additional research to explore potential overlap with the predictor variables.

Variable M7b, product/service of organization/group, was constructed to consider the primary product or service which an organization/group produced or supported in this network. The reason variable $\mathbf{M} 7 \mathrm{~b}$ was added was wide variation in the types of products and services offered by organizations and groups involved.

Product/service categories were added as they were encountered. They included: health information exchange network (HIEN) (1\%), consumer group advocate (e.g., AARP) $(2 \%)$, Medicaid program or safetynet funder $(4 \%)$, employer, union or Taft-Hartley fund (4\%), Medicare program, or related service (1\%), health plan, payor, or third party administrator $(15 \%)$, health information technology vendor $(2 \%)$, healthcare educator (college, university) (6\%), pharmaceutical or medical product manufacturer $(1 \%)$, hospital, skilled nursing facility, long term acute care or other in-patient facility (20\%), pharmacy, medical supply store or other healthcare retailer $(2 \%)$, public health department or group (2\%), physician or doctor of osteopathy office or other out-patient facility (14\%), nursing or allied health professional/facility (1\%), HIEN vendor (consulting / business services) (4\%), healthcare industry advocacy/network (3\%), and government oversight/regulation or support (16\%). If subjects fit more than one selection, 
the more influential one was chosen. This attribute was measurable for all subjects and assessed as valid.

Hypothesis M7b was that product/service of organization/group would moderate participation. The assumption was that HIENs would by necessity offer products and services which benefited one type of participant more than another, and thus, type of product or service would affect participation. There was strong support for hypothesis M7b: significant debates occurred in all sites regarding what types of health information exchange services should be developed and for whose benefit. As different participant types felt their interests were being addressed, they became more likely to participate and vice versa. No evidence against hypothesis M7b was found. However, an alternate explanation is that the predictor variables, such as cost and benefit, would correlate closely with this variable. Perhaps increased diversity of stakeholders, in and of itself, reduces benefit and increases cost because of the compromises involved in keeping diverse stakeholders at the table. Hypothesis M7b was supported, with recommendations for additional research to determine overlay with predictor variables such as cost and benefit.

\subsection{Set 4: Predictor Variables - Benefit Expectancy}

Set 4 contains questions related to benefit expectancy, the first of the four predictors proposed in the dual network participation theory model. Five variables were proposed to capture benefit expectancy: ability to do job, task completion, productivity, financial performance and value of decision. In addition, a question was asked about the 
need for other variables to measure benefit expectancy. Two participation opportunities (POs) were considered for each of these variables.

Variable BE1, ability to do job, considered the subject's perceptions regarding the ability of the site to increase his/her ability to do his/her job for the organization/group $\mathrm{s} / \mathrm{he}$ is representing. To measure this attribute, a 5 point scale was used: no potential increase $(1 \% / 4 \%)$, low potential increase $(30 \% / 52 \%)$, moderate potential increase $(46 \% / 30 \%)$, high potential increase $(12 \% / 3 \%)$, extremely high potential increase $(0 \% / 0 \%)$. This scale was valid for $89 \%$ of subjects who had jobs with an affiliated organization. However, it was not valid for $11 \%$ of subjects who did not work for an affiliated organization and thus, did not have a 'job' as such. For example, several individuals were self-employed; two were retired. The variable was assessed as valid, with the caveats that it would only apply to people affiliated with a group/organization for which they work. An alternative phrasing could be 'what is the ability of the site to help you do your work?' The term 'work' was found to be less restrictive than the term 'job'.

Hypothesis BE1 was that increase in ability to do job would positively influence intent to participate. Evidence for hypothesis BE1 was found in most valid cases. No evidence against hypothesis BE1 and no alternate explanations for this phenomenon were found. Hypothesis BE1 was supported, with recommendations for additional research on phrasing of the question.

Variable BE2, task completion, considers a subject's perceptions regarding the ability of the site to help the subject complete tasks for the organization/group s/he is representing. To measure this attribute, a 5 point scale was used: no potential increase 
$(1 \% / 3 \%)$, low potential increase $(30 \% / 54 \%)$, moderate potential increase $(51 \% / 31 \%)$, high potential increase $(6 \% / 1 \%)$, extremely high potential increase $(0 \% / 0 \%)$. This scale was also valid for $89 \%$ of subjects and invalid for $11 \%$ who did not work for an employer and thus did not have a 'job' as such. In addition, a question about the validity of the term 'tasks' came up, since the only assigned 'task' some subjects had was to participate in the HIEN. The variable was assessed as valid, with the caveats that it would only apply to tasks people were trying to accomplish on behalf of a group/organization. An alternative phrasing could be 'ability of the site to help you complete tasks related to your 'day-job'.

Hypothesis BE2 was that increase in ability to do tasks would positively influence intent to participate. Evidence for hypothesis BE2 was found in most valid cases. No evidence against hypothesis BE2 and no alternate explanations for this phenomenon were found. Hypothesis BE2 was supported, with recommendations for additional research on the phrasing of the question.

Variable BE3, productivity, considers a subject's perceptions regarding the ability of the site to increase productivity for the organization/group s/he is representing. To measure this attribute, a 5 point scale was used: no potential increase $(4 \% / 5 \%)$, low potential increase $(28 \% / 55 \%)$, moderate potential increase $(55 \% / 28 \%)$, high potential increase $(3 \% / 1 \%)$, extremely high potential increase $(0 \% / 0 \%)$. This scale was also valid for $89 \%$ of subjects, and invalid for the $11 \%$ who did not work for an employer and thus did not have a 'job' as such. The variable was assessed as valid.

Hypothesis BE3 was that increase in productivity would positively influence intent to participate. Evidence for hypothesis BE3 was found in most valid cases. No 
evidence against hypothesis BE3 and no alternate explanations were found. Hypothesis BE3 was supported.

Variables BE1, BE2 and BE3 had very similar responses. Thus these three appeared likely to be measuring the same construct. However, there are questions related to the meaning of 'job' and 'task' based on the position of the subject. For example, a CEO of a large organization may interpret the meaning of productivity or job very differently than a staff person.

Variable BE4, financial performance, considers a subject's perceptions regarding the potential for the HIEN to improve the financial performance of the organization/ group which the subject represents. To measure this attribute, a 5 point scale was used: no potential improvement $(9 \% / 6 \%)$, low potential improvement $(36 \% / 54 \%)$, moderate potential improvement $(32 \% / 23 \%)$, high potential improvement $(16 \% / 9 \%)$, extremely high potential improvement $(0 \% / 0 \%)$. This scale was valid for $93 \%$ of subjects, and invalid for $7 \%$ who did not represent a formal organization. The variable was assessed as valid with the caveat that it only applies to people who represent a formal organization.

Hypothesis BE4 was that increase in financial performance would positively influence intent to participate. Evidence for hypothesis BE2 was found in all valid cases. No evidence against hypothesis BE4 and no alternate explanations were found. Hypothesis BE was supported.

Variable BE5, value of decision, considers a subject's perceptions regarding the potential that her superiors and peers will view participation as a positive contribution to the organization/group. To measure this attribute, a 5 point scale was used ranging from no potential value $(0 \% / 0 \%)$, low potential value $(8 \% / 39 \%)$, moderate potential value 
$(35 \% / 42 \%)$, high potential value $(51 \% / 14 \%)$, extremely high potential value $(0 \% / 0 \%)$.

This scale was valid for $94 \%$ of subjects, and invalid for $6 \%$ who did not represent a formal organization or group. The variable was assessed as valid, with the caveat that it only applies to people who represent a formal organization.

Hypothesis BE5 was that increase in value of decision would positively influence intent to participate. Evidence for hypothesis BE5 was found in all valid cases. No evidence against hypothesis BE5 was found. However, an alternate explanation was found: BE5 also seemed to overlap with the social influence predictor. Hypothesis BE was supported, with recommendations for research to determine overlap with the social influence predictor.

In summary, benefit expectancy variables were found to be reasonably valid and predictive. However, additional research is recommended to refine questions based on type of participation opportunity and type of subject, as well as to identify overlap or redundancy in variables.

\subsection{Set 5: Predictor Variables -Cost Expectancy}

Set 5 contains questions related to cost expectancy, the second of the four predictors proposed in the dual network participation theory model. Five variables were proposed: ability to do job, task completion, productivity, financial performance and value of decision. In addition, a question was asked about the need for other variables to measure cost expectancy. Directions of these variables are reversed compared to the other predictors: the higher the choice number, the lower the cost. Two participation opportunities were considered for each of these variables. 
Variable CE1, subject time and effort, considers an individual's beliefs regarding his/her time and effort needed to participate. To measure this attribute, a 5 point scale was used: extremely high time and effort $(0 \% / 0 \%)$, high time and effort $(7 \% / 7 \%)$, moderate time and effort (45\%/70\%), low time and effort (48\%/23\%), no time and effort $(0 / 0 \%)$. This scale was valid for all subjects and assessed as valid.

Hypothesis CE1 was that decreased subject time and effort would positively influence intent to participate. Evidence supporting this hypothesis was found for most subjects. Evidence against the hypothesis was found in a few instances, where subjects saw increased time involvement as positive. However, this is because they saw value in their participation in board meetings, or educational activities. However, this argument did not seem compelling; these subjects too would still favor spending the least amount of time and effort needed to achieve the benefit they sought. No alternate explanation for the phenomena was found. Hypothesis CE1 was supported.

Variable CE2, organization/group time and effort, considers a subject's perceptions regarding his/her organization or group's time and effort needed to participate. To measure this attribute, a 5 point scale was used: extremely high $(0 \% / 0 \%)$, high $(0 \% / 4 \%)$, moderate $(47 \% / 73 \%)$, low $(49 \% / 17 \%)$, none $(1 \% / 0 \%)$. This scale was valid for $94 \% / 96 \%$ of subjects and invalid for $4 \% / 6 \%$ not affiliated with any group or organization. It was assessed as valid, with the caveat that it only applies to subjects affiliated with an organization or group.

Hypothesis CE2 was that decreased organization/group time and effort would increase intent to participate. Evidence for hypothesis CE2 was found for most subjects. 
No evidence against hypothesis CE2 and no alternate explanations were found. Hypothesis CE2 was supported.

Variable CE3, financial commitment, considers a subject's perceptions regarding the level of financial commitment required from an organization or group to participate. To measure this attribute, a 5 point scale was used: extremely high $(0 \% / 0 \%)$, high $(0 \% / 25 \%)$, moderate $(35 \% / 57 \%)$, low $(45 \% / 13 \%)$, none $(17 \% / 0 \%)$. This scale was valid for $96 \% / 94 \%$ of subjects and invalid for the $4 \% / 6 \%$ not affiliated with a group or organization. It was assessed as valid, with the caveat that it only applies to subjects affiliated with an organization or group.

Hypothesis CE3 was that decreased organization/group financial commitment would positively influence intent to participate. Evidence for the hypothesis was found for most subjects. Evidence against the hypothesis was found for a few subjects where increased financial commitment by their organization appeared to be associated with increased control over the direction of the service and therefore increased support for the service. However, on reflection this evidence appears weak. Increased control appears likely to be a construct related to the facilitating conditions predictor - increased control is a kind of facilitating condition. No alternate explanations were found. Hypothesis CE3 was supported.

Variable CE4, individual social capital risk, considers a subject's perceptions regarding the level of social capital the subject is putting at risk by participating. To measure this attribute, a 5 point scale was used: extremely high $(0 \% / 0 \%)$, high $(1 \% / 6 \%)$, moderate $(40 \% / 82 \%)$, low $(43 \% / 13 \%)$, virtually none $(0 \% / 0 \%)$. This scale was valid for all subjects. It was assessed as valid. 
Hypothesis CE4 was that decreased individual social capital risk would positively influence intent to participate. Evidence for the hypothesis was found for some subjects. For other subjects - those with low levels of social capital available to 'invest' in the HIEN - the relationship was harder to determine. No evidence against the hypothesis was found. An alternate explanation was found: social capital (as a kind of asset) appears similar to social influence (the predictor related to social connections). Is CE4 measuring the same construct as the social influence variables? Analysis does identify a possible difference between the two. A person can put their social capital at risk (CE4) and still be encouraged to participate by influential others (SI1). This distinction suggests that there may be two different constructs at work. Hypothesis CE4 was supported, with recommendations for research to consider overlap between subject's social capital risk and the social influence predictor.

Variable CE5, organization/group social capital risk, considers a subject's perceptions regarding the level of social capital his/her organization or group is putting at risk by participating. For example, an organization with a highly developed brand with positive attributes might put that the social capital connected with its reputation at risk if it participated in a network which generated a lot of negative publicity. To measure this attribute, a 5 point scale was used: extremely high $(0 \% / 0 \%)$, high (1\%/3\%), moderate (31\%/71\%), low (36\%/19\%), virtually none $(27 \% / 2 \%)$. This scale was valid for $96 \% / 94 \%$ of subjects, and invalid for the $4 \% / 6 \%$ not affiliated with a group or organization. It was assessed as valid, with the caveat that it only applies to subjects affiliated with a group or organization. 
Hypothesis CE5 was that decreased organizational social capital risk would positively influence intent to participate. Evidence for the hypothesis was found for some subject's organizations, but for other organizations - those with a low level of social capital to put at risk - the relationship was harder to determine. No evidence against the hypothesis was found. However, as with CE4 (individual social capital risk), an alternate explanation was found: organizational social capital (as a kind of asset) appears similar to social influence (the predictor related to social connections). Is CE5 measuring the same construct as the social influence variables? Again, analysis identifies a possible difference between the two. An organization can put its social capital at risk (CE4) and still be encouraged to participate by influential others (SI1). Hypothesis CE5 was supported, with recommendations for research to consider overlap between organization's social capital risk and the social influence predictor.

One additional cost factor, regulatory compliance cost, was identified as needed for some subjects. Development of this factor posed some challenges, so it was not included in this study. However, research in this area appears warranted. The questions to consider here is whether decreased cost of regulatory compliance increases intent to participate.

In summary, cost expectancy variables were found to be reasonably valid and predictive. However, additional research is recommended to refine questions based on type of participation opportunity and type of subject, to explore a variable related to regulatory compliance costs, and to identify redundancy in variables. 


\subsection{Set 6: Predictor Variables - Social Influence}

Set 6 contains questions related to social influence, the third of the four predictors proposed in the dual network participation theory model. Three variables were proposed to measure social influence: SI1 (support of influential people), SI2 (support by important people) and SI3 (support by superiors). In addition, a question was asked about the need for other variables to measure social influence. Two participation opportunities were considered for each of these variables.

Variables SI1 and SI2 consider a subject's perceptions regarding the support of important and influential people for participation in the HIEN. These variables were so similar that they are discussed together. To measure these two attributes, a 5 point scale was used: influential people strongly against participation $(0 \% / 3 \%)$, influential people somewhat against participation (6\%/23\%), influential people neutral about participation (8\%/60\%), influential people supportive about participation $(84 \% / 14 \%)$, influential people highly supportive about participation (1\%/1\%). The two attributes were valid for all subjects, and the distribution was identical for each. The variables were assessed as valid.

Hypotheses SI1 and SI2 were that increase in support would increase intent to participate. Evidence for both hypotheses was found in all cases. No evidence against the hypotheses and no alternate explanations for this phenomenon were found. Hypotheses SI1 and SI2 were supported.

Variable SI3, support from superiors, considers a subject's perceptions regarding the level of support superiors had for participation. To measure this attribute, a 5 point scale was used: superiors strongly against participation $(0 \% / 3 \%)$, superiors somewhat 
against participation $(6 \% / 22 \%)$, superiors neutral about participation $(7 \% / 57 \%)$, superiors supportive about participation ( $80 \% / 14 \%)$, superiors highly supportive about participation $(0 \% / 0 \%)$. This attribute was valid for $94 \% / 95 \%$ of subjects and invalid for $6 \% / 5 \%$ not employed or serving as a chair of a board. It was assessed as valid, with the caveat that it only applies to subjects who work in a hierarchy, and with a recommendation for additional research to see if it is redundant with the other variables.

Hypothesis SI3 was that increase in support would increase intent to participate. Evidence for this hypothesis was found in all valid cases. No evidence against the hypotheses and no alternate explanations for this phenomenon were found. Hypothesis SI3 was supported.

No additional variables were identified as needed in this category. The social influence variables appeared valid and predictive with the one validity exception noted.

\subsection{Set 7: Predictor Variables - Facilitating Conditions}

Set 7 contains variables related to facilitating conditions, the fourth of the four predictors. Fourteen variables were proposed to capture facilitating conditions. The first twelve are really four variables applied at three different levels. The four variables are resources, knowledge about HIE, network IT access and level of staff support. The three levels are individual, organization and network (HIEN). The last two variables are environmental stability and resource munificence. In addition, a question was asked about the need for other variables to measure facilitating conditions. Two participation opportunities were considered for each of these variables. 
Variables FC1, FC2 and FC3 considered a subject's perceptions regarding the general resources available, respectively, to the subject, organization and HIEN. General resources may include access to funding, transportation, facilities, and so on. To measure these attributes, a 5 point scale was used ranging from 'hardly any' to 'extremely high' (see Appendix 5 for details). These variables were valid for all subjects except for FC2, where $4 \%$ of subjects did not have an organizational affiliation. The variables were assessed as valid, with the caveat that FC2 only applies to people who work for a group/organization.

Hypotheses FC1, FC2 and FC3 were that an increase in resources at any level would positively influence intent to participate. Evidence for all three hypotheses was found for all valid subjects. No evidence against the hypotheses and no alternate explanations for this phenomenon were found. Hypotheses FC1, FC2 and FC3 were supported, with recommendations for research on whether a single question about resources could be developed.

Variables FC4, FC5 and FC6 considered a subject's perceptions regarding the level of knowledge about the HIEN possessed, respectively, by the subject, organization and HIEN. HIE is a complex, technically demanding field and wide variations in knowledge exist. To measure these attributes, a 5 point scale was used ranging from 'hardly any' to 'extremely high' (see Appendix 5 for details). These variables were valid for all valid subjects except for FC5, where $4 \%$ of subjects did not have an organizational affiliation. The variables were assessed as valid with the caveat about that FC5 only applies to people who work for a group/organization. 
Hypotheses FC4, FC5 and FC6 were that increase in knowledge at any level would positively influence intent to participate. Evidence for all three hypotheses was found for all valid subjects. For these subjects, increased knowledge by HIEs was associated with increased intent to participate. This makes sense in that it would result in increased HIE ability to deliver value to the subject and their organization. Evidence against the hypotheses was found for some of the subjects. Specifically, sometimes increased knowledge by subjects and their organizations/groups was associated with increased awareness about problems and challenges in this field, leading to reduced confidence about the potential to succeed. However, on further analysis, this seems to be a temporary issue related to developing knowledge. No alternate explanations for this phenomenon were found. Hypotheses FC4, FC5 and FC6 were supported, with recommendations for research on the issue of whether 'too much knowledge' may reduce intent to participate.

Variables FC7, FC8 and FC9 considered a subject's perceptions regarding access to network IT tools and technologies needed to interact with the HIEN which were available, respectively, to the subject, organization and HIEN. For example, access to email, teleconferencing services, web-based documents, and special technologies like electronic medical records all seemed relevant. To measure these attributes, a 5 point scale was used ranging from 'hardly any' to 'extremely high' (see Appendix 5 for details). These variables were valid for all subjects except for FC 8 , where $4 \%$ of subjects did not have an organizational affiliation. The variables were assessed as valid, with the caveat that FC8 only applies to people who work for a group/organization. 
Hypotheses FC7, FC8 and FC9 were that increase in access to network IT tools and technologies at any level would positively influence intent to participate. These questions were designed to explore the relationship between network IT, as such, and intent to participate. Evidence for all three hypotheses was found for all valid subjects for each question. No evidence against the hypotheses was found. Hypotheses FC7, FC8 and FC9 were supported.

Variables FC10, FC11 and FC12 considered a subject's perceptions regarding access to staff support needed to participate with the HIEN available, respectively, to the subject, organization and HIEN. Staff support was particularly relevant to subjects participating in boards and committee, but may also apply for participation in technical services. To measure these attributes, a 5 point scale was used ranging from 'hardly any' to 'extremely high' (see Appendix 5 for details). These variables were valid for all subjects except for FC10, where $4 \%$ of subjects did not have an organizational affiliation. The variables were assessed as valid, with the caveat about that FC10 only applies to people who work for a group/organization.

Hypotheses FC10, FC11 and FC12 were that increase in access to needed staff support would positively influence intent to participate. Limited evidence for all three hypotheses was found among some subjects. Specifically, where staff support was needed to participate, a lack of staff support reduced participation. However, some evidence against the hypotheses was found: staff support wasn't always needed to participate. In addition, an alternate explanation for this phenomenon was found: was access to staff support at the HIEN level a subset of the HIEN site level resources variable? Hypotheses FC10, FC11 and FC12 were supported, with recommendations for 
research on the issue of overlap between staff support and resource variables. Perhaps a more general 'resources' question could be constructed which could reduce the number of questions needed to assess facilitating conditions?

Variable FC13, environmental stability, considered a subject's perceptions regarding the relative level of stability in the environment within which the HIEN operated. Environment was defined to include the financial, regulatory and competitive environment as it applies to this participation opportunity. To measure this attribute, a 5 point scale was used ranging from highly unstable to highly stable (see Appendix 5 for details). This attribute was valid for all subjects. It was assessed as valid.

Hypothesis FC13 was that increase in environmental stability would increase intent to participate. Evidence for this hypothesis was found for all valid subjects. Many subjects saw regulatory instability - e.g., risks of changing state and national regulations regarding $\mathrm{HIE}$ - as a reason not to participate, or to be cautious about participating. No evidence against the hypotheses and no alternate explanations for this phenomenon were found. Hypothesis FC13 was supported.

Variable FC14, resource munificence, considers a subject's perceptions regarding the general availability of resources such as money, space, and equipment available to the organizations/groups which the HIEN seeks to serve. To measure this attribute, a 5 point scale was used ranging from few resources to extremely high level of resources (see Appendix 5 for details). This attribute was valid for all subjects. It was assessed as valid. Hypothesis FC14 was that increase in resource munificence would increase intent to participate. Evidence for this hypothesis was found for many subjects. Some subjects mentioned availability of potential funding sources (such as government grants) as a 
reason to participate, while others saw a lack of resources or capital to develop the HIE services as a reason not to participate. No evidence against the hypotheses and no alternate explanations for this phenomenon were found. Hypothesis FC13 was supported. No additional variables were identified as needed in this category. In general, the facilitating condition variables appeared valid and predictive. However, potentially significant overlaps among the variables were identified. Additional research is recommended to consider more parsimonious questions to assess facilitating conditions.

\subsection{Principal Component Analysis of Predictors}

A principal component analysis (PCA) of the four predictors was done, using SPSS, to better understand relationships among the variables. For this, 109 subject profiles from the less challenging and 109 from the more challenging participation opportunity were used. For each PCA a Kaiser-Meyer-Olkin (KMO) test of sampling adequacy and Bartlett test of sphericity (Norusis 2005) was run and evaluated. Matrix scores for each variable were considered. When more than one factor was identified, Varimax rotation with Kaiser normalization was used.

The benefit expectancy $(\mathrm{BE})$ predictor (variables BE1, BE2, BE3, BE4 and BE5) yielded a "meritorious" $\mathrm{KMO}$ of 0.84 , and significant correlation between the factors based on the Bartlett's test (.000). One (1) dominant factor was identified. BE1 (0.95) was the strongest contributor to the factor and BE5 (.68) the weakest. One combined factor (BECombined) was formed. 
Table 13: Rotated Component Scores: Benefit Expectancy

\begin{tabular}{|l|l|}
\hline & Component \\
\hline & 1 \\
\hline BE1 Ability to do job & .953 \\
\hline BE2 Task completion & .947 \\
\hline BE3 Productivity & .917 \\
\hline BE4 Financial performance & .747 \\
\hline BE5 Value of decision & .682 \\
\hline Extraction Method: Principal Component Analysis. \\
\hline 1 components extracted. \\
\hline
\end{tabular}

The PCA of the cost expectancy (CE) predictor (variables CE1, CE2, CE3, CE4 and CE5) yielded a "middling" KMO of 0.77 and significant correlation between the factors based on the Bartlett's test (.000). One (1) dominant factor was identified. CE5 (0.887) was the strongest contributor to the factor and CE1 (.68) the weakest. One combined factor (LCECombined) was formed.

Table 14: Rotated Component Scores: Low Cost Expectancy

\begin{tabular}{|l|r|}
\hline & Component \\
\hline & 1 \\
\hline CE1 Subject time and effort & .681 \\
\hline CE2 Organization time and effort & .854 \\
\hline CE3 Financial commitment & .822 \\
\hline CE4 Individual social capital risk & .852 \\
\hline CE5 Organization social capital risk & .887 \\
\hline \multicolumn{2}{|l|}{ Extraction Method: Principal Component Analysis. } \\
\hline 1 components extracted. \\
\hline
\end{tabular}

The PCA of the social influence (SI) predictor (variables SI1, SI2, and SI3) were so closely correlated that they generated 'not positive definite' errors in the correlation matrix. Consequently, KMO and Bartlett tests could not be run. However, based on the extremely close correlation of means and SDs of these variables, a combined factor (SICombined) was justified and formed. 
The PCA of the facilitating conditions (FC) predictor (variables FC1, FC2, FC3, FC4, FC5, FC6, FC7, FC8, FC9, FC10, FC11, FC12, FC13 and FC14), yielded a

"mediocre" KMO of .64, and significant correlation between the factors based on the Bartlett's test (.000). Five factors were identified and formed. FCResources was formed by combining FC1 (.860), FC2 (.898), FC3 (.645), and FC11 (.632). FCNetworkIT was formed by combining FC7 (.899) and FC8 (.883). FCKnowledge was formed by combining FC4 (.749), FC5 (.867) and FC6 (.810). FCSiteSupport was formed by combining FC9 (.798) and FC12 (.642). FCenvironment was formed by combining FC13 (.450) and FC14 (.776).

Table 15: Rotated Component Scores: Facilitating Conditions

\begin{tabular}{|l|c|c|c|c|c|}
\hline & \multicolumn{3}{|c|}{ Component } \\
\hline \hline FC1 Relevant Resources Available to Subject & 1 & 2 & 3 & 4 & 5 \\
\hline FC2 Relevant Resources Available to Organization & .860 & & & & \\
\hline FC3 Relevant Resources Available to the Site/HIE & .898 & & & & \\
\hline FC4 Relevant Knowledge of Subject & .645 & & & & \\
\hline FC5 Relevant Knowledge of Organization/ Group & & & .749 & & \\
\hline FC6 Relevant Knowledge of the Site/HIE & & & .867 & & \\
\hline FC7 Relevant Network IT tools and technologies Available to Subject & & & .810 & & \\
\hline $\begin{array}{l}\text { FC8 Relevant Network IT tools and technologies Available to } \\
\text { Organization/ Group }\end{array}$ & & .899 & & & \\
\hline FC9 Relevant Network IT tools and technologies Available to Site/HIE & & & & & \\
\hline FC10 Subject's Staff Support & .406 & .498 & & & \\
\hline FC11 Relevant Staff Support Available to Organization/ Group & .632 & .560 & & & \\
\hline FC12 Relevant Staff Support Available to Site/HIE & -.798 & & & .642 & \\
\hline FC13 Environmental Stability & .305 & & & & \\
\hline FC14 Resource Munificence & & & .315 & .450 \\
\hline $\begin{array}{l}\text { Extraction Method: Principal Component Analysis. } \\
\text { Rotation Method: Varimax with Kaiser Normalization. }\end{array}$ & & & & .776 \\
\hline Rotation converged in 6 iterations. & & & & \\
\hline
\end{tabular}




\subsection{OLS Regression of Predictors on Intent to Participate}

The factor variables developed were used for an OLS regression on intent to participate (IPCombined). Using SPSS, cases with missing data were excluded listwise, resulting in $\mathbf{N}$ of 97 . The null hypothesis (that the predictors have no effect on IP) was rejected: $\mathrm{F}=17.25 ; \mathrm{P}<.0005$. Over sixty one percent $(61.1 \%)$ of the variation in IPCombined was accounted for by the predictors $\left(\mathrm{R}^{2}=.611\right)$. T-tests of the coefficients for each of the factors supported exclusion of the null hypothesis of no influence for BECombined (.000), SI Combined (.000), LCECombined (.060), and FCKnowledge (.009). However, they did not support exclusion of FCResources (.788), FCNetworkIT (.955), FCSiteSupport (.344), or FCenvironment (.128). VIF analysis did not indicate problems with collinearity for any of the variables.

Table 16: Summary of Regression of Combined Predictors on Intent to Participate

\begin{tabular}{|c|c|c|c|c|}
\hline \multicolumn{2}{|c|}{ Model } & Beta & Sig & VIF \\
\hline \multirow[t]{9}{*}{1} & (Constant) & & .064 & \\
\hline & BECombined & .368 & .000 & 1.916 \\
\hline & SICombined & .412 & .000 & 1.683 \\
\hline & LCECombined & .130 & .060 & 1.057 \\
\hline & FCResources & -.021 & .788 & 1.383 \\
\hline & FCNetworkIT & .004 & .955 & 1.257 \\
\hline & FCKnowledge & .198 & .009 & 1.254 \\
\hline & FCSiteSupport & -.070 & .344 & 1.227 \\
\hline & FCenvironment & 114 & .128 & 1.246 \\
\hline
\end{tabular}

The results indicate that intent to participate in investing/lobbying by participants (in the six HIENs in the study) was most influenced by social influence (.412), followed by benefit expectancy (.368), knowledge about HIENs (.198), and low cost expectancy $(.130)$. 


\subsection{Set 8: Whole-Network Attributes}

Set 8 contains the site-level whole-network attributes in the DNPT. Fourteen whole-network variables (WN1 - WN14) were selected for consideration. Instrument 3 was used to study the validity of these variables and their potential effects on the four individual/organization level predictors, benefit expectancy $(\mathrm{BE})$, cost expectancy $(\mathrm{CE})$, social influence (SI) and facilitating conditions (FC). In addition, the need for additional variables was explored.

Validity of each variable was evaluated by considering whether, on its face, the variable appeared measurable, and if so, whether variation was visible in the HIENs. For each valid variable, a hypothesis about the effects of variations was then evaluated. This was done by looking at evidence for and evidence against the hypothesis and considering alternate explanations for the observations. Assessments about validity and effect are preliminary and qualitative. In each case, evaluation of larger sample sizes would be needed to develop operationally valid measures and evaluate effects across a population of sites. Recommendations for future research are also provided for each variable.

Variable WN1, rules and norms, considers the degree to which formalized rules and norms are in place and used to steer decision-making in a site. This attribute appeared to be measurable and variation across HIENs was found. For example, some HIENs had more written rules and norms in place than others with respect to managing conflicts of interest on their boards. It was assessed as valid.

Hypothesis WN1 was that increased rules and norms would increase social influence (SI). Evidence for this was found in all 6 HIENs. For example, all HIENs where rules and norms about ethics were lacking, encountered difficulties in this area. 
Evidence against it was found in 2 HIENs in which rules and norms imposed by state leaders created an excessive burden on the HIENs, creating new problems. No alternate explanations were found. The hypothesis was supported, with recommendations for additional research across a larger sample of sites to develop valid operational measures for this attribute.

Variable WN2, learning and education, considers the degree to which activities related to learning and education occur in a site (e.g., low, moderate, high). This variable appeared measurable and variation across HIENs was found. For example some HIENs hosted annual learning conferences while others did not. It was assessed as valid.

Hypothesis WN2 was that increased learning and education would increase social influence (SI). Evidence for this was found in 5 of the 6 HIENs. For example, participants in learning conferences developed increased social connections. No evidence against it was found. No alternate explanations were found. The hypothesis was supported.

Variable WN3, dominant core, considers the degree to which there is a dominant core of leaders driving development and making decisions for the network (e.g., no core, somewhat dominant core, highly dominant core). This variable appeared measurable and variation across HIENs was found. For example, HIENs had dominant cores of ranging from 2-7 people, with varying degrees of cohesion. It was assessed as valid.

Hypothesis WN3 was that increased dominant core would increase all four predictors, benefit expectancy (BE), low cost expectancy (LCE), social influence (SI) and facilitating conditions (FC). Evidence for this was found in all 6 HIENs. Those with more dominant cores were more successful at moving the HIEN forward through 
developmental stages. Evidence against it was found in 2 HIENs, when a dominant core of peoples disagreed about direction and reduced ability to move forward. However, this disagreement in a dominant core could also be characterized as a shift from a more dominant core to a less dominant core, since a core's dominance may be reduced if it is unable to make decisions. No alternate explanations were found. The hypothesis was supported, with recommendations to research how to more clearly define dominant core and its effects.

Variable WN4, embedded relationships, considers the degree to which there are embedded relationships - pre-existing social or organizational connections - among participants in a site (e.g., none, some, most, all). This variable appeared measurable and variation across HIENs was found. For example, some HIENs had participants with preexisting embedded relationships related to state Medicaid contracts, while others did not. It was assessed as valid.

Hypothesis WN4 was that increased embedded relationships would increase all four predictors, benefit expectancy (BE), low cost expectancy (LCE), social influence (SI) and facilitating conditions (FC). Evidence for this was found in all 6 HIENs. Embedded relationships facilitated decision-making and improved confidence in participating. Evidence against this was found in 2 HIENs. In these cases, embedded relationships between state Medicaid leaders and major hospitals and health plans appeared to reduce BE, LCE, SI and FC. State Medicaid was perceived as holding the HIENs hostage so they could control services to meet their needs. However, this embedded relationship was a positive in HIEN 6, which developed an approach which benefited Medicaid and major hospitals and plans. No alternate explanations were found. 
The hypothesis was supported, with recommendations for additional research to define measures for different types of embedded relationships and their effects.

Variable WN5, right type of governance, considers the degree to which right type of governance is in place in a site. This variable appeared measurable and variation across HIENs was found. Right type of governance was defined using the Provan et al. framework (2008). A site has the right type of governance if it satisfies one of the following three criteria:

a. Has less than 8 participants in a simple project and uses a shared governance model (the participants share in decision-making); or,

b. has 9-15 participants and simple to moderate complexity and uses a lead organization form of governance (one of the participating organizations provides the infrastructure, leadership and staff for the site); or,

c. has more than 15 participants or high complexity and uses a network administrative organization (where the participants agree to have an independent third party organization provide infrastructure, leadership and staff for the site).

The governance for each of the six HIENs was evaluated (e.g., wrong governance, mixture of right and wrong governance, right governance). All six HIENs were complex with more than 15 participating organizations. Two had wrong type of governance in place (they used a lead organization). Four had a mixture of right and wrong type of governance (they outsourced some work, such as strategic planning, to a third party, but did not outsource all work). The variable was assessed as valid. 
Hypothesis WN5 was that increased right governance would increase all four predictors, benefit expectancy (BE), low cost expectancy (LCE), social influence (SI) and facilitating conditions (FC). Evidence for this was found in all 6 HIENs. Governance posed major challenges for each HIEN. Conflicts of interests with lead organizations caused problems adversely affecting all 4 predictors. Sites which outsourced strategic planning and operations to a 'neutral' third party selected through an open process by all participants were able to progress more quickly, while increasing trust and confidence among their members. No evidence against the hypothesis and no alternate explanations were found. The hypothesis was supported, with recommendations for additional research to refine measures for assessing different types of mixed governance models.

Variable WN6, formalization, considers the degree to which the site uses formalized rules, written agendas and well defined decision-making procedures (e.g., low, moderate, high). This variable appeared measurable and variation across HIENs was found. For example, some HIENs published and used more detailed policies, procedures than others to guide decision-making. It was assessed as valid.

Hypothesis WN6 was that increased formalization would increase all four predictors, benefit expectancy (BE), low cost expectancy (LCE), social influence (SI) and facilitating conditions (FC). Evidence for this was found in all 6 HIENs. In all 6 HIENs, significant effort was made to formalize governance and management policies and procedures. Formalization was seen as a good and necessary activity. Sites which developed more formalization, especially around governance related activities, and communications with participants and the public, seemed to have increased success in developing and maintaining participation. Some HIENs lacked formalization in some 
areas, such as ways to handle conflicts of interest and experienced problems which reduced participation. This indicates a positive relationship between formalization and BE, LCE, SI and FC. No evidence against it and no alternate explanations were found. The hypothesis was supported.

Variable WN7, network inner stability, considers the degree to which trust, reciprocity and norms of cooperation exist among the participants in a site (e.g., very low, low, moderate, high, very high). This variable appeared measurable and variation across HIENs was found. For example, in 3 HIENs, a survey measuring social capital - trust among HIEN participants found variations in social capital by HIEN. In other HIENs, measures of collaborative capacity also showed variation. The variable was assessed as valid.

Hypothesis WN7 was that increased network inner stability would increase all four predictors, benefit expectancy (BE), low cost expectancy (LCE), social influence (SI) and facilitating conditions (FC). Evidence for this was found in all 6 HIENs. For all 6 HIENs, network inner stability was discussed at board meetings, and actively developed and described as a HIEN asset. Ability to make progress through steps of development appeared dependent on this factor, with participant trust being the most commonly discussed concept. BE, LCE, SI and FC all appeared to increase with increases in network inner stability. No opposing evidence and no alternate explanations were found. The hypothesis was supported, with recommendations for additional research on how to measure network inner stability.

Variable WN8, stability management, considers the degree to which leadership buffers instability or nurtures stability in the network (e.g., low, moderate, high). This 
variable appeared measurable and variation across HIENs was found. Leadership statements in board meetings for each HIEN touched on this issue. The records suggested that some HIEN leaders (HIENs 1, 4, 5) spent more time than others (HIEN 2) on stability management. It was assessed as valid.

Hypothesis WN8 was that increased stability management would increase all four predictors, benefit expectancy (BE), low cost expectancy (LCE), social influence (SI) and facilitating conditions (FC). Evidence for this was found in all 6 HIENs. All 6 HIENs engaged in some efforts to manage stability, and their records suggest that private meetings between leaders and participants usually resulted in increased BE, LCE, SI and FC. Evidence against it was found in 2 HIENs where HIEN leaders attempted to use power as a mechanism to achieve stability. For example, states (HIENs 2 and 4) attempted to leverage the state's regulatory or purchasing power to create stability by requiring major participants to adhere to an approach supported by the state. These approaches were less effective, in some cases backfiring to create loss of BE, LCE, SI and FC for a majority of participants. However, an alternate explanation for the evidence against the hypothesis was found: that the problem was a participant (the state) attempting to exert its interests against other interests. This may be better explained through looking at attributes related to collusion, conflict of interest management, and so on. The hypothesis was supported, with recommendations to research how to more clearly define stability management and its effects.

Variable WN9, accountability management, considers the degree to which site managers are assigned accountability for performance and results for network (e.g., low, moderate, high). This variable appeared measurable and variation across HIENs was 
found. Leadership accountability was assessed by considering factors such as type of contract, existence of written job contracts, performance goals, and power of a board to censure or remove managers for non-performance. The records showed that some HIENs had full time managers with stronger accountability while others had part time managers with less accountability. It was assessed as valid.

Hypothesis WN9 was that increased accountability management would increase all four predictors, benefit expectancy (BE), low cost expectancy (LCE), social influence (SI) and facilitating conditions (FC). Evidence for this was found in all 6 HIENs. For example, all 6 HIENs engaged in efforts to set goals and hold managers accountable for achieving those goals. Several HIENs encountered problems controlling managers who had first loyalties to a primary employer. This led to reductions in BE, LCE, SI, and FC. Other HIENs which held managers more accountable for performance achieved better results. No evidence against it and no alternate explanations were found. The hypothesis was supported.

Variable WN10, steering network processes, considers the degree to which there are processes in place to support ethical decision-making, and facilitate centralization of control (e.g., low, moderate, high). This variable appeared measurable and variation across HIENs was found. For example, all HIENs developed and used formal decisionmaking processes and had some kind of centralized controls. Most had some type of written conflict of interest policy. Some HIENs had more developed processes and controls than others. It was assessed as valid.

Hypothesis WN10 was that increased steering network processes would increase all four predictors, benefit expectancy (BE), low cost expectancy (LCE), social influence 
(SI) and facilitating conditions (FC). Evidence for this was found in all 6 HIENs. Efforts to develop and administer steering network processes occupied significant time and effort of all HIENs, suggesting this was seen as an important area to develop in order to progress. Sites with better developed processes seemed to engender more BE, LCE, SI and FC. Conversely, several HIENs experienced loss of BE, LCE, SI, FC as a result of conflict of interest problems caused by weak or non-existent policies, or as a result of divided control-mechanisms, such as state government officials attempting to control the network thereby creating conflict with board leadership. No evidence against the hypothesis and no alternate explanations were found. The hypothesis was supported, with recommendations to research different types of steering network processes and their effects.

Variable WN11, generic networking, considers how much time is spent interacting with network constituencies to identify tensions, and blend participant interests to achieve site level goals (e.g., little to none, some, a lot). This variable appeared measurable and variation across HIENs was found. For example, each HIEN involved leaders who spent significant time and effort doing generic networking. Some HIENs showed more time and effort than others in this area. It was assessed as valid.

Hypothesis WN11 was that increased generic networking would increase all four predictors, benefit expectancy (BE), low cost expectancy (LCE), social influence (SI) and facilitating conditions (FC). Evidence for this was found in all 6 HIENs. Generic networking appeared highly influential in developing BE, LCE, SI, and FC. Tensions and conflicting interests abounded in these HIENs. In some cases, leaders failed to put significant time and effort into talking to people about these conflicts, resulting in serious 
challenges and problems. Conversely, some of the greatest accomplishments for many of these HIENs - development and approval of consensus plans - occurred as a result of extensive time and effort in this area. No evidence against it was found. However, one alternate explanation was found: the variable seemed similar to WN8, stability management. The hypothesis was supported, with recommendations to research similarity with $\mathrm{WN} 8$, stability management.

Variable WN12, management tenure, considers tenure of a site's key management team members in months (e.g., 1-11, 12-35, 36-59, 60+). This variable was readily measurable and variation across HIENs was found. Different HIENs had leaders with different tenures, the longest being over 72 months. It was assessed as valid.

Hypothesis WN12 was that increased management tenure would increase all four predictors, benefit expectancy (BE), low cost expectancy (LCE), social influence (SI) and facilitating conditions (FC). Evidence for this was found in all 6 HIENs. Increased management tenure was associated with increased ability to manage complex leadership challenges in the HIENs, including challenges related to managing network stability, steering network processes, generic networking and so forth. Conversely, several HIENs lost leaders to turnover, which led to upheavals or delays which adversely affected BE, LCE, SI and FC. No evidence against it and no alternate explanations were found. The hypothesis was supported.

Variable WN13, staff coherence, considers the degree to which the site staff is highly competitive with one another, or more coherent and cooperative (e.g., highly competitive, somewhat competitive, in between, somewhat coherent, highly coherent). This variable appeared measurable and variation across HIENs was found. For example, 
HIEN 4 staff appeared highly coherent, while HIEN 2 staff was somewhat competitive. It was assessed as valid. However, it was recognized that in future studies of this type, the variable could pose some measurement difficulties. This is because actual records of internal dynamics like those available to this study may not be available. In these cases, confidential surveys by multiple staff could be needed to obtain accurate measures, since otherwise staff members might say things are coherent when they are not in order not to displease their boss.

Hypothesis WN13 was that increased staff coherence would increase all four predictors, benefit expectancy (BE), low cost expectancy (LCE), social influence (SI) and facilitating conditions (FC). Evidence for this was found in all 6 HIENs. For example, several HIENs had staff who did not behave coherently at certain times, leading to serious problems which reduced participant confidence and interest. No evidence against it and no alternate explanations were found. The hypothesis was supported, with recommendations for more research on how to measure staff coherence through a survey.

Variable WN14, services capability, considers the degree to which a site is capable of providing services desired to participants. In principle, this variable appeared measurable. However, in practice it was not able to be measured for 5 of the 6 HIENs because they were not offering services yet - only planning or developing them. It was assessed as valid because it seemed to be measurable where applicable.

Hypothesis WN14 was rated as unsure, because of a lack of data to evaluate it. No alternate explanations were identified.

Variable WN15a, resource availability, considers the degree to which a HIEN has adequate resources, such as facilities, staff, and funding, to achieve its goals (e.g., 
inadequate, somewhat inadequate, adequate). This variable appeared measurable and variation across HIENs was found. For example, board meeting minutes and HIEN records contained discussions about financial status and financial concerns. However, some questions emerged about how to measure the concept of adequate resources at given stages of development. It was assessed as valid, with recommendations for additional research on how to measure resource availability.

Hypothesis WN15a was that increased resource availability would increase all four predictors, benefit expectancy (BE), low cost expectancy (LCE), social influence (SI) and facilitating conditions (FC). Evidence for this straightforward hypothesis was found in all 6 HIENs. All HIENs had less than adequate resources, and participants saw it as a problem. Sites which obtained additional funding saw rapid increases in all four predictors as a result. No evidence against it and no alternate explanations were found. The hypothesis was supported.

To summarize, in general, the whole-network variables proposed in Set 8 appeared valid and likely to influence predictors as proposed. However, additional research is necessary to refine ways to measure some of the attributes and better understand their effects.

\subsection{Set 9: Network IT Attributes}

This section on Set 9 considers site-level network IT attributes, and their potential effects on the four predictors, benefit expectancy (BE), cost expectancy (CE), social influence (SI) and facilitating conditions (FC). Eleven network IT variables (NIT1-5, 
NIT8-9, NIT11-14) are considered. In addition, the need for additional variables is considered.

Validity and effect of each variable are evaluated. Validity is evaluated by considering whether, on its face, the variable appears measurable, and if so, whether variation is visible in the HIENs. For each valid variable, a hypothesis about the effects of variations is then evaluated. This is done by looking at evidence for and evidence against the hypothesis and considering alternate explanations for the observations. As with the Set 8 variables, assessments about validity and effect are preliminary and qualitative. Recommendations for future research are also provided for each variable.

Variable NIT1, environmental linking network IT, considers the degree to which network IT is used to connect site leaders with information about financial, regulatory, political and other changes occurring in the environment: for example, were e-newsletters or web-site subscriptions used (e.g., little or no use, some use, extensive use)? This variable appeared assessable through questions to HIEN leaders regarding how they gather information about changes in the environment. Some HIENs had different, or better, environmental linking IT tools than others. It was assessed as valid, with recommendations for further research on how to measure this attribute because of the rapid evolution of this kind of network IT.

Hypothesis NIT1 was that increased use of environmental linking network IT would increase benefit expectancy (BE) and social influence (SI). This is because site leaders would be able to offer increased benefits (timely information about changes) and communicate this information in way which positively influences influential people in the environment. Evidence for this was found in all 6 HIENs. Site leaders used online 
services such as the iHealthBeat service to maintain current intelligence about the environment. Information learned was communicated to participants and through websites and was seen as valuable. Conversely, HIEN leaders who at times did not access or use such tools seemed to have less ability to anticipate and manage changes in the environment. Evidence against it was found in 2 HIENs, when participants expressed concern about information overload. However, this did not seem to be strong counterevidence, because the information brought forward seemed important to consider. Suppressing it would only have slowed down decision-making. However, it does raise a question about whether network IT could cause information overload problems in some contexts. No alternate explanations were found. The hypothesis was supported, with recommendations for research to better define this attribute and understand its effects. Variable NIT2, market bridging network IT, considers the degree to which network IT is used to connect site leaders with current and potential participants in their markets - organizations and individuals who may participate or purchase services in the future. For example, were e-newsletters or web-site communications, or customer relationship management (CRM) software used (e.g., little or no use, some use, extensive use). This variable appeared assessable through questions to HIEN leaders regarding how they gather, manage and disseminate information to their markets. Some HIENs had different, or better, market bridging network IT tools than others. Tools included use of CRM tools, email, websites, online surveys, webinars and teleconferences to communicate with market actors. It was assessed as valid, with recommendations for further research on how to measure this attribute because of the rapid evolution of this kind of network IT. 
Hypothesis NIT2 was that increased use of market bridging network IT would increase benefit expectancy (BE) and social influence (SI). This is because site leaders would be able to offer increased benefits (timely information about changes) and communicate this information in way which positively influences influential people in their markets. Evidence for this was found in all 6 HIENs. Sites used network IT such as email, websites, and webinars to connect with their markets to positive affect. Some HIEN leaders who at times did not access or use such tools experienced problems with alienating markets by not fully understanding their wants and needs and not communicating effectively with them. Evidence against it was found in 3 HIENs, where information was posted on websites or sent via email which increased confusion or concerns in the markets, rather than helping. However, this may be attributable to problems with leadership decision-making, rather than the use of network IT as such. No alternate explanations were found. The hypothesis was supported, with recommendations for research to better define this attribute and understand its effects.

Variable NIT3, governance network IT, considers the degree to which network IT is used to automate processes of governance (e.g., little or no use, some use, extensive use). It appeared to be measurable through questions to HIEN leaders or review of board minutes. The most common types of governance network IT used were teleconferencing (to support remote attendance of meetings) and public and private websites for storing and disseminating governance documents such as minutes, procedures and bylaws. Some HIENs had different, or better, environmental linking IT tools than others. It was assessed as valid, with recommendations for further research on how to measure this attribute because of the rapid evolution of this kind of network IT. 
Hypothesis NIT3 was that increased use of governance network IT would increase social influence (SI) and facilitating conditions (FC). This is because site leaders would be able to reduce costs of administering governance processes for the site and participants and increase ability to support participation remotely. Evidence for this was found in all 6 HIENs. For example, teleconferencing for board meetings was widely used, and seen as valuable. Evidence against it was found in 3 HIENs, where participants at the board level expressed concerns about information overload and control at the board level. No alternate explanations were found. The hypothesis was supported, with recommendations for research to better define this attribute and understand its effects.

Variable NIT4, functional network IT, considers the degree to which the site uses functional network IT, that is, network IT used to automate processes of delivering services, including, if applicable, delivery of health information exchange IT services to organizational or individual users. This variable was both measurable and showed variation. All the HIENs had a mission to use network IT to deliver health information exchange related IT services of one type or another to participants. Two HIENs had functional network IT platforms and vendors selected, while others did not. Different platforms had different capabilities. NIT4 was assessed as valid, with recommendations for further research on how to measure this attribute because of the rapid evolution of this kind of network IT.

Hypothesis NIT4 was that increased use of functional network IT to deliver services would increase low cost expectancy (LCE) and facilitating conditions (FC). This is because access to and use of network IT to deliver services was believed to lead to lower costs and reduced barriers to participants. Evidence for this was found in all 6 
HIENs. The 2 HIENs which actually had selected functional IT experienced increased LCE and FC. It created a 'bird-in-the-hand is worth two in the bush' effect. It helped make 'real' the opportunity that was being offered to participants. The ones that did not have it found it more difficult to make the case for LCE and FC, because of the unknowns involved. Evidence against it was found in 1 HIEN which selected a functional network IT which was not compatible with some participants, causing reduction in LCE and FC in these cases. No alternate explanations were found. The hypothesis was supported with recommendations for research to better define this attribute and understand its effects.

Variable NIT5, individual network IT, considers the degree to which individual participants have access, either as individuals or through their work, to individual network IT such as cell phones, computers, email service, web-browsers, printers, and so on to support activities related to the whole-network (e.g., none, low, moderate, high, extremely high). This variable appeared assessable and showed variance. For example, some individuals lacked cell phones, while others lacked access to current web browsers to access intranets. It was assessed as valid, with recommendations for further research on how to measure this attribute because of the rapid evolution of this kind of network IT.

Hypothesis NIT5 was that increased use of individual network IT would increase facilitating conditions (FC) - it would make it easier for individuals to participate. Evidence for this was found in all 6 HIENs. Individual network IT was associated with increased FC in all 6 HIENs. Individuals with ready access to computers, websites, cellphones, PDAs, and so on were better able to participate. Individuals lacking access to 
such tools were sometimes unable to participate in important discussions, view information, or other activities. It appears probable that these individuals experienced lower FC. No evidence against it and no alternate explanations were found. The hypothesis was supported with recommendations for research to better define this attribute and understand its effects.

Variable NIT8, network IT openness, considers the openness of the network IT used by this HIEN, where openness refers to the use of open source code, open standards or open application programming interfaces (APIs). Network IT could be totally closed, somewhat closed, in-between, somewhat open, or highly open. This variable appeared assessable through evaluation of the network IT in question. Some HIENs' network IT was more 'open' than others. It was assessed as valid, with recommendations for further research on how to measure this attribute because of the rapid evolution of this kind of network IT.

Hypothesis NIT8 was that increased network IT openness would increase low cost expectancy (LCE). This is because more openness would reduce potential for vendors to engage in rent seeking behavior based on their ability to charge for changes to the network IT. Evidence for this was found in 4 HIENs which used this kind of rationale to justify selection and use of more open network IT. Evidence against it was found in 2 HIENs. One of these, for example, spent over $\$ 12$ million 'improving' and 'customizing' an entirely open-source solution. This ended up being abandoned because it was too expensive to keep modifying it. It was replaced by a vendor-based solution with a proprietary core but open-standards and open APIs. This supports the argument that sometimes some proprietary protection is needed by vendors to support ongoing 
investment by private sector markets in complex software. An alternate explanation was also found. Some HIEN participants questioned the concept of openness as a false premise. The concept of cost/value was used instead. These participants said they didn't care about openness or closedness but about whether the technology worked, how well it was proven in the field and what the cost was for the desired functionality. This suggests more research could be done to consider how to measure cost for value of network IT, and the effects of different cost/value scenarios. The hypothesis was rated unsure with recommendations for research to better define this attribute and understand its effects.

Variable NIT9, network IT innovativeness, considers the degree to which network IT used in the site is innovative, featuring use of new or emerging approaches or designs (low, moderate, high). This variable appeared assessable through evaluation of the types of network IT used. For example, some HIENs mentioned innovativeness as a criterion for selecting network IT. There were also variations in innovation. For example, some HIENs supported novel uses of functional, market and governance network IT, while others used more 'tried and true' network IT. It was assessed as valid, with recommendations for further research on how to measure this attribute because of the rapid evolution of this kind of network IT.

Hypothesis NIT9 was that increased network IT innovation would increase low cost expectancy (LCE). It was believed this would occur because of the rapid evolution of new capabilities in network IT, combined with the reduction in costs of computer processing power. These trends meant that sites with more innovative technology would be able to deliver value at lower costs, thereby increasing LCE. As participants talked about innovation and LCE, it would also affect SI. Evidence for this was found in all 6 
sites. All HIENs had to innovate in many ways over time to succeed. Innovation in network IT was seen as a positive attribute, and did appear to positively affect SI, LCE. Evidence against it was found in $1 \mathrm{HIEN}$, when governance network IT was used that was 'too innovative' leading to confusion, reduced SI and increased LCE for a time until it was modified. One alternate explanation was found. Perhaps the concept of network IT innovation is overly vague. Perhaps the concept of cost/value could replace this concept as well. The hypothesis was rated as unsure, with recommendations for research to better define this attribute and understand its effects.

Variable NIT11, network IT environmental stability, considers the stability of the environment (regulatory, financial, competitive, etc.) in which the network IT of interest to the HIEN operates (e.g., highly unstable, unstable, unsure, stable, highly stable.). Stability of the network IT environment for various products appeared assessable and showed variation. For example, the environment for health information exchange related technology for all HIENs was volatile and rapidly changing; while the environment for email services was quite stable for the HIENs. It was assessed as valid, with recommendations for further research on how to measure this attribute because of the rapid evolution of this kind of network IT.

Hypothesis NIT1 was that increased network IT environmental stability would increase social influence (SI) and facilitating conditions (FC). The argument here is that increased stability should reduce risk. This would result in increased SI (e.g. support by others for participation), and FC (because participants wouldn't have to deal with learning new technology emerging from the environment just to participate). Evidence for this was found in all 6 HIENs. All HIENs experienced decreases in network IT 
environmental stability, generated by announcements of new standards by government and new technologies by large vendors. These decreases correlated with decreases in SI (participants were concerned about risk) and FC (change caused concerns about whether the HIEN had the right FC in place). No evidence against it and no alternate explanations were found. The hypothesis was supported.

Variable NIT12, network IT outsourcing, considers the degree to which network IT used by this site is outsourced versus developed and maintained internally (e.g., none, a little, some, most, all). Outsourcing appeared to be readily assessable by looking at network IT used, and determining how it was purchased and maintained. Some HIENs did try to make, versus buy, their network IT. NIT12 was assessed as valid, but further research is recommended to measure this attribute because of the rapid evolution of this kind of network IT.

Hypothesis NIT12 was that increased use of network IT outsourcing would increase benefit expectancy (BE), low cost expectancy (LCE) and facilitating conditions (FC). This is because HIENs which outsourced would be able to offer increased benefits (faster implementation, more functionality), lower costs (faster start-up, and less start-up investment) and more support for users (through established procedures provided by vendor). Evidence for this was found in 5 of the 6 HIENs. For example, HIENs that planned to outsource, or did outsource their functional network IT experienced increases in participant perceptions regarding BE, LCE and FC. It seemed than having functional network IT 'in hand' was worth 'two in the bush': participants could kick the tires, see the software work, and get a realistic sense that it would in fact work. Conversely, one site which did not outsource failed in maintaining the technology, and had to abandon it, 
leading to a reduction in BE, LCE and FC. No evidence against the hypothesis and no alternate hypotheses were found. The hypothesis was supported, with recommendations for research to better define this attribute and understand its effects.

Variable NIT13, network IT ownership symmetry, considers the symmetry of ownership and/or control of the network IT used by the HIEN (e.g., one participant controls it all, in between, all participants own/control it jointly/equally). This variable appeared assessable and showed variation. For example, in some HIENs, some technologies were owned and controlled by just one of several participants on the board. Other HIENs had policies to ensure that all network IT was contracted directly with the HIEN, and that no participants had asymmetrical control. It was assessed as valid.

Hypothesis NIT13 was that increased network IT ownership symmetry would increase social influence (SI). This is because it would reduce potential for influential others to perceive that one party was 'controlling' or influencing the others to serve its own particular interests. Evidence for this was found in all 6 HIENs. Network IT ownership symmetry was associated with increased SI (reduced conflict and increased trust among participants). Conversely, several asymmetrical ownership scenarios (including two where one party owned the governance network IT and one where one party controlled functional network IT) led to increased conflict and decreased trust among participants. No evidence against it and no alternate explanations were found. The hypothesis was supported, with recommendations for research to better define this attribute.

Variable NIT14, network IT abundance, considers how much network IT is in place and being used by current and potential participants in a site's marketplace (e.g., 
hardly any, a little, some, a lot, a great deal). This variable appeared assessable through questions to site leaders and market surveys. Variation was seen. For example, several HIENs' target markets included physicians. The HIENs conducted surveys to assess physicians' use of different network IT. Most of these surveys found that about 15-20\% of physicians, on average, had electronic medical records, and many did not fully use these. Hardly any physicians used email or the web to communicate with patients. However, most physicians used network IT to handle billing and collections. As this example illustrates, the concept of network IT abundance is a broad-brush. To get an accurate picture of network IT abundance in a given context may require assessment of specific types of network IT which are of interest. It was assessed as valid, with recommendations for further research to measure this attribute because of the rapid evolution of this kind of network IT.

Hypothesis NIT14 was that increased network IT abundance would increase facilitating conditions (FC). This is because HIEN participants would have network IT and support staff in place to support their use of services. Network IT abundance was clearly correlated with increased FC. In each HIEN, potential or current participants lacking network IT found it more difficult to participate. For example, potential participants lacking electronic medical records expressed concerns about the challenges of making a transition to the use of these technologies; participants lacking access to certain types of individual network IT had more difficulty participating in governance processes. No evidence against it and no alternate explanations were found. The hypothesis was supported, with recommendations for research to better define this attribute. 
The need for additional network IT variables was considered. While other network IT related variables are likely to be applicable, no additional network IT attributes were identified at this time.

To summarize, in general, the network IT variables proposed in Set 9 appeared valid and likely to influence predictors as proposed. However, additional research is recommended to refine ways to measure some of the attributes and better understand their effects.

\subsection{Influential Network-Level Variables}

Influential network level (site) variables identified in this analysis are those featuring high levels of evidence for, low levels of evidence against, and no alternative explanations.

In Set 8, influential whole-network variables include: WN2 (learning and education), WN6 (formalization), WN10 (steering network processes), WN9 (accountability management), WN13 (staff coherence), WN12 (management tenure), and WN15a (resource availability).

In set 9, influential network IT variables include NIT11 (network IT environmental stability) NIT5 (individual network IT), NIT13 (network IT ownership symmetry) and NIT14 (network IT abundance).

\subsection{Results Recap}

This completes the review of the results. To recap, results were presented by variable set, beginning with Set 1: Actual Participation, and ending with Set 9: Network 
IT. Most of the variables proposed were found to be valid and most of the hypotheses regarding the effects of the variables on participation were supported. Principal component analysis of the predictor variables led to development of factor variables, formed by combining variables in groups. OLS regression was then done on these factors to identify those with significant influence on intent to participate.

The most influential individual/organization level predictor variables (high to low) were social influence, benefit expectancy, knowledge about HIENs and low cost expectancy.

The most influential network level (site) variables included learning and education, formalization, steering network processes, accountability management, staff coherence, management tenure, and resource availability, network IT environmental stability, individual network IT, network IT ownership symmetry and network IT abundance. 


\section{CHAPTER 6. DISCUSSION}

In Chapter 6, the results from Chapter 5 are discussed and interpreted to answer the five questions posed for the study:

1. What kinds of participation opportunities do the 6 HIENs offer?

2. Which of the proposed DNPT variables are valid for the study of participation in the HIENs?

3. What new variables should be considered and are they valid?

4. Once valid variables are selected, what does the data say about barriers and enablers to participation in the 6 HIENs?

5. What are the implications of the study for theory and research?

\subsection{Participation Opportunities}

The first question was what kinds of participation opportunities the 6 HIENs offer. Ten standardized participation opportunities were identified. These are: 1.) generate idea, 2.) provide funding to explore idea, 3.) participate in meetings to explore idea, 4.) join board/ committees, 5.) invest in plan development, 6.) provide public comment/input, 7.) invest in start-up of operations, 8.) use of services, 9.) use of educational services, and 10.) services provider. Participation opportunities 2-10 appeared to be measurable through surveys or review of HIEN records. 
Participation opportunities differed considerably with respect to the level of commitment required from the participant. For example, participation in meetings to explore an idea involved little or no commitment of funding, but increased commitment

of time. Participation in start-up or operational funding required commitment and approvals from multiple organizational leaders. Participation in using services required participation by both individual employees within a participating organization or group and by leaders of the organization or group.

The 10 stages suggest a developmental sequence similar to those seen in organizational development, e.g., birth, maturation, decline (Vandeven et al. 1995). However, caution should be taken in interpreting this finding. While a general pattern of development through stages is visible, the stages may vary in different contexts. Phelps et al. (2007) for instance, find that organizations do not develop through predictable lifecycle stages, but rather, experience tipping points related to challenges to their survival such as strategy, finance, or people. The same may be true of dual networks.

\subsection{Validity of Variables}

The second question asked about the validity of variables used. The validity of the variables was assessed by considering their measurability and applicability to the subject and/or site being considered. As noted in the results section, all of the proposed variables in the 9 sets studied were found to be valid for the 6 HIENs with the exception of M4, organizational size. However, a number of the variables at both subject and site level were asterisked to indicate recommendations for additional research to develop effective data-capture techniques, refine definitions, and/or develop more robust measures. 
Three validity issues at the subject level bear additional discussion. First, a few participants in the six HIENs did not represent organizations, but rather represented themselves as individuals, professionals or leaders of informal groups or network level collaboratives. For these people, several questions related to their organizational roles were not valid. Second, some participants represented multiple organizations, such as a physician representing both a professional association and a physician practice. This raised questions about how to reflect multiple types of representation for a single subject. Third, M4, organizational size proved challenging to measure because of limitations related to the use of employee size (one firm had a handful of employees but hundreds of millions in revenues). Firm revenue posed similar challenges in instances where a majority of services were outsourced to third party vendors.

Two validity issues found at the site level bear further discussion. The first issue was difficulty in obtaining accurate measurement for some variables. For example, measurement of WN13, staff coherence, may require use of confidential survey questions, and assurance of confidentiality of response, in order to obtain valid measures. Otherwise, respondents may bias their answers to suggest everything is ' $\mathrm{OK}$ ', even if, in fact, they feel it is not. Second, the rapid pace of change in network IT innovations led to concerns about measurement for most variables in set 9 . For example, for network IT variables related to governance, a question arose about whether a survey question referencing use of teleconferencing technologies would still be applicable in 10 years. Might such a question need to be rephrased to reflect the use of computer based videoconferencing? Might such a question need to consider ability to vote using texting versus voice votes? 


\subsection{New Variables}

The third question was whether new variables were needed for the theory. The answer was yes. Several new variables were added. In Set 4: moderators, M6a, subject level, M6b, professional membership, M7a organizational level, and M7b, product/service of organization/group were added. In Set 8: whole-network Attributes, WN15a, resource availability was added. All were found to be valid. In addition, in set 5, the need to develop a variable to assess regulatory compliance costs was identified.

\subsection{Barriers and Enablers of Participation in HIENs}

The fourth question asked was about barriers and enablers of participation in the HIENs of interest. This question contained three parts.

1. How do moderators (organizational leader gender, age; organization size, type) influence intent to participate?

2. How do predictors affect intent to participate?

3. How do dual network attributes affect the predictors? Each is considered in turn.

\subsubsection{How Do Moderators Influence Intent to Participate?}

The dual network participation theory (DNPT) hypothesizes that the four predictors, benefit expectancy (BE), low cost expectancy (LCE), social influence (SI) and facilitating conditions (FC), will influence decision-making for potential participants in a dual network. However, it also recognizes the potential for other factors - moderators of individuals or their organizations - to influence the predicted effect. Moderators with 
potential to influence participation were identified at an individual and organizational level.

At the individual level, the most influential moderator identified was M4, prior experience with dual networks and collaboration. Each of the HIENs included some participants on boards and committees who had low levels of experience with collaboration. These participants tended to behave impatiently or autocratically at times, leading to developmental delays and problems.

Also influential were M6a and M6b. In M6a (subject level of authority), members of the HIEN boards and committees ranged from individuals with no authority at all to people serving as the chair of a board of directors. In M6b (professional membership), HIEN members were also diverse, including accountants, physicians, nurses, union members and elected officials. In both of these categories, increased heterogeneity of participants appeared to reduce likelihood to participate. For example, some senior organizational leaders with advanced professional degrees found it unproductive trying to collaborate with individuals with no professional degrees or little relevant business experience. To paragraph comments from one CEO: 'It's hard to get anything done when you have to work with a bunch of community do-gooders with no experience'.

M1, age, also appeared to have some influence. Here, people who were on the edges of the scale (very young or very old) appeared less likely to participate. M2, gender was not found to have an influence, although it seems probable that it would in other contexts.

At the organizational level, influential moderators were also identified. For M4, organizational experience with dual networks and collaboration, the HIENs included 
some participants who represented organizations with low levels of experience with collaboration. These participants tended to be given a shorter leash by their superiors and peers. They felt pressure from their organizations to achieve faster results; their organizations commented that the planning process was taking too long or seemed cumbersome. This influenced participants to try to speed up or force the planning process, which tended to reduce ability to make decisions supported by others.

For M4, M7a, and M7b, high levels of heterogeneity were also found in the HIENs studied. For M4, organization size, participant attributes ranged from notapplicable (individual doesn't work for employer) to 1 employee to $25,000+$ employees. For M7a, organization level, participants included suppliers (such as a supplier of technology to a hospital), classic organizations (such as a hospital, employer or health plan), trade associations representing many organizations (such as a hospital association), government agencies representing whole sectors (like a state cabinet for health services), and other HIENs representing combinations of levels. For M7b, product/service of organization/group, participants represented as many as 15 different types of product/service, including government oversight, in-patient hospital services, outpatient physician services, laboratory testing, pharmacy, pharmaceuticals, public health services, nursing services, health information technology services, and so on. In each of these cases, increased heterogeneity appeared to increase complexity of communications and decision-making.

The analysis of moderators in HIENs points to two key barriers and possible enablers for participation in HIENS. The first barrier is lack of experience with collaboration at individual and organizational levels. A possible enabler here is increased 
training and education for participants and their organizations about collaboration in dual-network contexts. The second barrier is the high heterogeneity of participants in the several dimensions noted. A possible enabler here is to reduce heterogeneity of participants invited to participate in opportunities such as boards, committees, or planning activities.

\subsubsection{How Do Predictors Affect Intent to Participate in the HIENs?}

The four predictors, benefit expectancy (BE), low cost expectancy (LCE), social influence (SI) and facilitating conditions (FC), were found to have significant effect on intent to participate in the less and more challenging participation opportunities considered. For the more challenging participation opportunity (investing in the HIEN start-up, and lobbying for government recognition), the most influential predictors were social influence (.412), benefit expectancy (.368), knowledge about HIENs (.198), and low cost expectancy (.130). These findings imply the need for HIEN leaders to focus efforts on increasing these influences.

Actions to increase social influence could include increased use of surveys to assess levels of social support, increased use of broadcast or social media, and increased private meetings with networks of people involved in the organizations of interest.

Actions to increase benefit expectancy could include additional research on benefits of interest, a reduction of scope, so that a stronger set of benefits could be developed and offered for a subset of the market. 
Actions to increase knowledge about HIENs could include special training and education on how to lead in collaboratives and on how to understand the unique and evolving characteristics of HIENs.

Actions to increase low cost expectancy could include a focus on simplifying product offerings, simplifying governance processes, and increased use of network IT to automate processes for participation in governance and planning.

\subsubsection{How Do Dual Network Attributes Affect Predictors?}

As expected, the study found that dual network attributes in Sets 8 and 9 influenced the predictors.

In Set 8 (whole-network variables) the most influential variables were WN2 (learning and education), WN6 (formalization), WN10 (steering network processes), WN9 (accountability management), WN13 (staff coherence), WN12 (management tenure), and WN15a (resource availability). A key challenge visible in this list is the need for qualified, competent leadership. Many of these variables, including WN6, WN10, WN9, and WN13 and WN12, are clearly influenced by the behaviors of one or a few leaders. Lack of qualified, competent leadership in the HIENS studied had an adverse influence on success in these dimensions. In addition, lack of HIEN access to resources and lack of provision of learning and education were also important barriers to development. Lack of resources can be thought of as an overarching challenge, since it had an adverse affect both on ability to obtain and maintain strong leadership, and, on ability to provide adequate learning and education. These findings suggest three enablers 
for HIENs: secure ample funding to support planning and implementation; engage or develop well qualified leaders; and provide increased education and training at all levels.

In set 9 (Network IT variables), influential variables include NIT11 (network IT environmental stability) NIT5 (individual network IT), NIT13 (network IT ownership symmetry) and NIT14 (network IT abundance). A key challenge here was lack of access to stable network IT for both individual and organizational participants at all five levels (environment, governance, markets, functional, and individual). Key enablers here could include emphasis of use of stable NIT; increased investment in network IT at all five levels; and requiring participants to have a minimum level of access to network IT at all five levels.

\subsubsection{Summary of Barriers and Enablers for HIENs}

Table 17 summarizes the key barriers and enablers identified through the analysis of the moderators, predictors and site level variables. 
Table 17: Barriers and enablers of participation in HIENs (Summary)

\begin{tabular}{|c|c|}
\hline HIEN Participation Barrier & Possible Enabler \\
\hline \multicolumn{2}{|l|}{ Moderator Related } \\
\hline $\begin{array}{l}\text { Lack of participant experience with } \\
\text { collaboration and dual networks }\end{array}$ & Education/training on collaboration for participants \\
\hline Heterogeneity of subject levels/professions & Reduce heterogeneity of participants \\
\hline \multicolumn{2}{|l|}{ Predictor Related } \\
\hline $\begin{array}{l}\text { Lack of social influence (support from } \\
\text { influential others) }\end{array}$ & $\begin{array}{l}\text { Surveys to measure social influence } \\
\text { Increased use of broadcast and social media } \\
\text { Increased private meetings with influential others }\end{array}$ \\
\hline Low benefit expectancy & $\begin{array}{l}\text { Increase research on benefits of interest } \\
\text { Reduction of scope for initial offerings }\end{array}$ \\
\hline Lack of knowledge & $\begin{array}{l}\text { Increase training and education about network } \\
\text { leadership and HIENs }\end{array}$ \\
\hline Lack of low cost expectancy & $\begin{array}{l}\text { Simplify product offerings and pricing } \\
\text { Simplify governance processes } \\
\text { Increase use of network IT for governance and } \\
\text { planning. }\end{array}$ \\
\hline \multicolumn{2}{|l|}{ HIEN Related } \\
\hline HIEN lack of resources & Secure ample funding to support development \\
\hline HIEN lack of qualified, competent leadership & Engage qualified, competent leadership \\
\hline $\begin{array}{l}\text { HIEN lack of provision of training and } \\
\text { education }\end{array}$ & $\begin{array}{l}\text { Increase training and education for participants about } \\
\text { network leadership and HIENs }\end{array}$ \\
\hline HIEN lack of stable network IT & Select and use stable network IT (as much as possible) \\
\hline $\begin{array}{l}\text { HIEN and participant lack of access to network } \\
\text { IT at each of the } 5 \text { levels. }\end{array}$ & $\begin{array}{l}\text { Invest in network IT at all } 5 \text { levels } \\
\text { Require participants to have a minimum level of access } \\
\text { to network IT at all five levels }\end{array}$ \\
\hline
\end{tabular}

\subsection{Implications for Research and Theory}

The final question asked about the implications of the study for theory and research. Implications include the need to refine the terminology and concepts used to describe the theory; conduct additional research to refine and validate the participation opportunity typology; refine and validate variables; test the theory using larger sample sizes; and, study outcomes. 


\subsubsection{Revised Terminology and Concepts}

The theory constructed for this study was called a network IT dependent wholenetwork, or 'dual network'. In this definition, Provan's term 'whole-network' refers to a network of three or more organizations collaborating to achieve a shared goal. However, more than just organizations participated in the HIENs in the study. Participants also included other individuals, individual networks and network-level collaboratives. This situation implies that the concept of a network IT dependent whole-network is not broad enough to describe the phenomena of interest.

To address this limitation, several new terms are proposed. As illustrated in Figure 11, a general form of network-level endeavor is proposed called a network level collaborative (NLC). This term retains Provan's important concept of 'network level', with its emphasis on a collaborative governance structure operating at a network level. It uses the term collaborative to connote the softer, non-hierarchical decision-making style of a collaborative network.

Network Level
Collaboratives

Organizations

Individuals

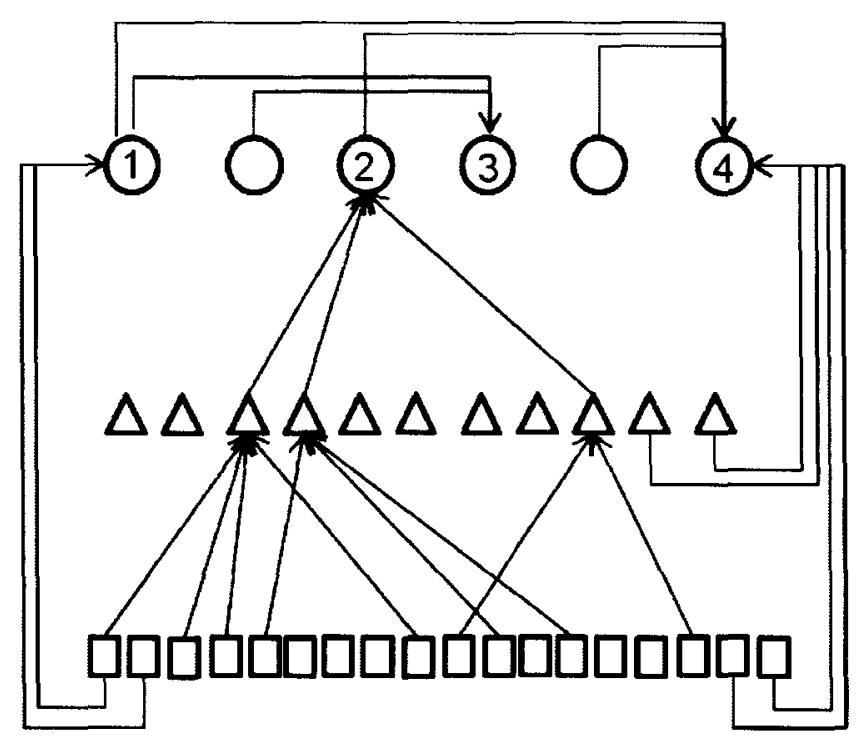

Figure 11: Four Types of Network Level Collaboratives 
Four general types of NLC are proposed. Type 1, an individual network, refers to a collaboration among two or more individuals seeking to achieve a shared goal. For example, a consumer membership association is an individual network. Type 2, a wholenetwork (an inter-organizational network at the network level) refers to a collaboration among two or more organizations seeking to achieve a shared goal. For example, a hospital association is a whole-network. Type 3, a network of $N L C s$ (also called a network of networks) refers to a collaboration among two or more NLCs seeking to achieve a shared goal. For example, a collaboration among multiple HIENs collaborating in a state HIEN planning network is a network of networks. Type 4, a mixed network, refers to a collaboration among two or more individuals, organizations or networks drawn from two or more levels to achieve a shared goal. For example, an HIEN involving participants representing an individual, a consumer association (an individual network), a hospital association (a whole-network), and a state-level network of HIENs (a network of networks) is a mixed network.

The four basic types of NLI will also have additional attributes which increase or decrease their network complexity. Attributes may include network IT dependency, individual attributes, organizational attributes, and network attributes.

Network IT dependency refers to the NLC's level of dependency on the use of network IT for achievement of its stated goal. Five broad types of dependency were identified in this study: dependency on environmental linking, market bridging, governance, functional and individual network IT. As noted, additional, and ongoing research is recommended to define these attributes. 
Individual attributes (drawn from the moderators) may include age, gender, individual's NLC experience, level of authority and professional memberships.

Organizational attributes (drawn from the moderators) may include organization size, level, and product/service.

Network attributes may include network size, vertical heterogeneity (\# of participants), horizontal heterogeneity (\# of different participant types represented), product heterogeneity (\# of different products/services offered), and level of development (e.g. starting-up, providing, transitioning).

The discussion of terminology leads to a recommendation to make two changes to the DNPT. First, the phenomenon of interest should be a network level collaborative (NLC), rather than a network IT dependent whole-network. Second, the theory should be renamed a network level collaborative participation theory or NTP for short.

\subsubsection{Research Participation Opportunity Typology}

A number of different examples and types of participation opportunity were identified in the study. These included opportunities to participate in planning, education, funding, governance, educational services and use of technology services. Are there other participation opportunities offered by NLCs which are not identified here? Are the categories generated optimal for research purposes? Research across larger sample sizes and more diversity of NLCs could lead to improved definitions of this important construct. 


\subsubsection{Refine and Validate Variables}

More than half the variables identified and used in this study were asterisked to denote needs for additional research to understand the best ways to obtain data, and/or to validate the categories developed. In addition, other variables, especially at the site level, may be useful to study. Research using larger sample sizes of sites and participants, in diverse contexts, should be done to refine and validate current and future variables for a network participation theory.

\subsubsection{Test the Theory Using Larger Sample Sizes}

With just 6 network level collaboratives and 109 participants, there was not enough statistical power to generalize findings beyond the sites and participants studied. However, the results of the qualitative study may be promising enough to justify studies with larger sample sizes randomly selected to represent populations of sites/participants. A study designed with enough statistical power to support hypothesis testing at both the site and participant level (e.g., 100-300 sites and 1,000 - 3,000 participants) could lead to ability to quantify affects of the model for larger populations.

\subsubsection{Study Outcomes}

As noted in the methods section, outcomes - effects of network level collaboratives on individuals, organizations and networks in the environment - were not considered in this study. There is little doubt, however, that network level collaboratives can, and will, influence the environment. Do they reduce transaction costs? Do they speed up dissemination of innovations? Do they influence design of network information 
technology? Do they decrease or increase stability of governments? Many questions like

these could be fruitfully researched.

\subsubsection{Summary of Implications for Theory and Research}

Table 18 summarizes the implications of the study for theory and research.

Table 18: Summary of Implications for Theory and Research

\begin{tabular}{|c|c|}
\hline Limitation / Challenge & Proposed Response \\
\hline \multicolumn{2}{|l|}{ Terminology and Concepts } \\
\hline $\begin{array}{l}\text { Concepts of whole-networks and dual networks } \\
\text { only apply to inter-organizational networks. } \\
\text { HIENs also include individuals and other } \\
\text { networks level collaboratives }\end{array}$ & $\begin{array}{l}\text { Replace terms with network level collaborative } \\
(N L C) \text {. NLCs are collaboratives which may } \\
\text { include participants from individual, } \\
\text { organizational and network levels. Whole- } \\
\text { networks are a kind of NLC. NLCs may or may } \\
\text { not be Network IT dependent. }\end{array}$ \\
\hline $\begin{array}{l}\text { Name of theory not adequate to describe } \\
\text { phenomena being researched }\end{array}$ & $\begin{array}{l}\text { Drop 'dual' in dual network participation theory; } \\
\text { call theory a network participation theory (NPT). }\end{array}$ \\
\hline \multicolumn{2}{|l|}{ Typology of Participation Opportunities } \\
\hline $\begin{array}{l}\text { Possible limitations regarding types of participation } \\
\text { opportunity identified }\end{array}$ & $\begin{array}{l}\text { Conduct additional research on types of } \\
\text { participation opportunity offered by NLCs. }\end{array}$ \\
\hline \multicolumn{2}{|l|}{ Variable Validity } \\
\hline $\begin{array}{l}\text { Limitations on validity of variables used in the } \\
\text { (dual) network participation theory }\end{array}$ & $\begin{array}{l}\text { Refine and validate variables used in the network } \\
\text { participation theory. }\end{array}$ \\
\hline \multicolumn{2}{|l|}{ Sample Sizes } \\
\hline $\begin{array}{l}\text { Small sample sizes ( } 6 \text { network level collaboratives, } \\
109 \text { participants) }\end{array}$ & $\begin{array}{l}\text { Conduct studies using larger, randomized samples } \\
\text { to support studies with enough statistical power } \\
\text { for hypothesis testing across populations of } \\
\text { sites/participants (e.g., 100-300 sites; } 1,000- \\
3,000 \text { participants). }\end{array}$ \\
\hline \multicolumn{2}{|l|}{ Outcomes } \\
\hline Lack of study of outcomes & $\begin{array}{l}\text { Conduct studies of outcomes caused by network } \\
\text { level collaboratives. }\end{array}$ \\
\hline
\end{tabular}

\subsection{Limitations}

As a case study of six non-randomly selected HIENs (network level) and key

board and committee members (individual level) and their affiliated organizations

(organizational level), this research has a number of important limitations. First, many of 
the variables have only limited validity. Additional research will need to be done to develop effective ways to obtain data and validate the variables. Second, the data generated on barriers and enablers only applies to the 6 HIENS studied. It may not apply to other HIENs or dual network sites. Third, answers to a number of queries in the subject instrument were estimated by the researchers, based on review of qualitative data about the subjects. Data generated by actual subjects, using survey instruments, could vary significantly from the estimates generated. Given these limitations, caution should be used in extrapolating these findings to other contexts.

\subsection{Summary of Chapter 6}

This concludes Chapter 6 . The discussion provided answers to the five questions asked at the start of the study. The HIENs in the study offered 10 standardized participation opportunities, ranging from generating the idea to using services. Many of these HIENS experienced particular challenges obtaining participation in the financing of start-up of operations. Most of the proposed DNPT variables were found to be valid, although additional research was suggested on how to measure and refine a number of the variables. Several new variables were added, including moderator variables to capture level of individuals and organizations, and types of professionals and organizations. Key barriers to participation in the HIENs included lack of experience with collaboration, low social influence and low benefit expectancy, lack of resources and lack of qualified leadership. A number of enablers were suggested to address these challenges. Implications for theory and research include recommendations to reframe the theory as a network level collaborative participation theory which could work for 4 different types of 
network level collaboratives, and, the development of large studies with statistical power needed for hypothesis testing across large populations of networks, individuals and organizations. Much was learned through this study, but it was only valid for the six HIENS and affiliated individuals and organizations. As a qualitative study of retrospective data, the study supported development of valuable knowledge about the validity of a new theory, and provided insights into challenges faced by the HIENS studied; but additional research will be required to see whether the propositions in the theory are valid in other contexts. 


\section{CONCLUSION}

This study was motivated by the failure, or failure to achieve established goals, of over 200 U.S. health information exchange networks (HIENs) which formed or operated in the U.S. from 2004 to 2010 . As discussed in Chapter 1, the introduction, the study seemed important to do for two reasons. First, there are significant costs including lost time, capital and opportunity to individuals, organizations and society associated with these kinds of systemic network-level failures. Second, no theory driven research appears in the literature which studies the failures of HIENS.

Chapter 2, the literature review, began with a review of the HIEN literature. Three key challenges faced by HIENS from 2004 - 2010 were identified: challenges of wholenetwork, IOS and individual participation. Three theories relevant to understanding the three challenges were then identified: whole-network, IOS adoption and technology acceptance model (TAM) theories. Limitations for each theory were considered. Wholenetwork theory lacked ability to address information technology and IOS aspects of HIENs, while IOS and TAM theories lacked ability to address interorganizational network aspects of HIENs. These limitations pointed to a need for new theory which could account for the affects of both organizational and technological attributes on participation in HIENS and similar collaboratives within an integrated context.

Chapter 3 presented a dual network participation theory (DNPT) formed by combining elements from the three theories. The term dual network, short for a network 
IT dependent whole-network, was formulated. Drawing from Azjen's theory of planned behavior, the DNPT was designed to predict intent to participate and actual participation in dual networks. Four participant level predictors - factors with potential to influence intent to participate - were proposed. These were benefit expectancy, cost expectancy, social influence and facilitating conditions. In addition, two sets of site-level attributes whole-network attributes and network IT attributes - were proposed. Finally, a set of outcome variables was proposed. In final form, the theory consisted of 10 sets of variables - about 85 variables in total. The development of the DNPT led to formulation of five research questions:

1. What kinds of participation opportunities do HIENs offer?

2. Which of the proposed DNPT variables are valid for the study of participation in dual networks like HIEN?

3. What new variables should be considered, and are they valid?

4. Once valid variables are selected, what does the data say about barriers and enablers to participation in the 6 HIENs in this study?

5. What are the implications of the findings for theory and research?

Chapter 4 presented the method used to answer these five questions. A retrospective case study method was developed. A rich set of qualitative data was drawn from a convenience sample of 6 HIEN sites (network level cases) with 109 individuals (individual level cases) and 125 organizations (organizational level cases). Scales and testable hypotheses for each variable were developed. Surveys for each site and subject were created and completed through review of the qualitative data. Two researchers reviewed the qualitative data, developed the coding and discussed interpretations. This 
'triangulated' data was summarized in tabular format. The tabular summaries included evidence which supported, refuted or provided alternate explanations for each variable and hypothesis. Valid variables were then selected and entered into SPSS. A principal component analysis was done to identify common factors. Combined variables were formed and an OLS regression analysis done to explore effects of predictors on intent to participate.

Chapter 5 reviewed results including analysis of validity and affects of the variables in the study, the principal component analysis and OLS regression. In general, most variables were found to be valid and most hypotheses were supported.

In Chapter 6, answers to each of the five questions were discussed. A set of 10 participation opportunities offered by HIENs were identified (question 1), including opportunities to participate in start-up planning, start-up investments, and using services. Valid variables were identified (question 2). Effects of the site-level variables and predictor variables were evaluated for each variable (question 3). Barriers and enablers for participation in HIENs were identified (question 4). Implications for research and theory were considered (question 5).

With respect to barriers and enablers to participation in HIENS at the site level, key barriers identified were heterogeneity of participants, lack of resources, lack of qualified, competent leadership, lack of provision of training and education, lack of stable network IT, and lack of access to network IT. Key enablers recommended were to reduce heterogeneity of participants, secure ample funding to support development, engage qualified, competent leadership, increase training and education for participants about network leadership, select and use stable network IT, and invest more in network IT. 
With respect to barriers and enablers to participation in HIENs at the participant level, key barriers identified were lack of social influence (support from influential others), low benefit expectancy, lack of knowledge, and lack of low cost expectancy. Key enablers recommended were to use surveys to measure social influence, increase use of broadcast and social media to educate markets, increase private meetings with influential others, increase research on benefits of interest to participants, reduce the scope of initial service offerings, simplify product offerings and pricing, simplify governance processes, increase use of network IT to support governance and planning processes, and require participants to have a minimum level of access to network IT in order to participate.

With respect to implications for theory and research, key recommendations include: 1.) drop use of term 'dual network' and replace with the term 'Network Level Collaborative' (NLC), where a NLC is a collaborative which may include participants from individual, organizational and network levels; 2.) drop use of the term 'dual' in the DNPT, and call it a network participation theory (NPT); 3.) conduct additional research on what types of participation opportunity are offered by NLCs; 4.) refine and validate variables used in the NPT; 5.) conduct studies using larger, randomized samples with enough statistical power for hypothesis testing across populations of sites/participants (e.g., 100-300 sites; 1,000 - 3,000 participants); and 5.) conduct studies of NLC outcomes.

While this study was exploratory in nature, it yielded a rich set of insights with implications for both theory and practice. This implies that additional research in this area may be worthwhile to pursue. 


\section{REFERENCES}

Academy of Management "Organization and Management Theory," 2010, p.

Organization and management theory portion of the AofM site.

Adam, F., and Roncevic, B. "Social Capital: Recent Debates and Research Trends," Social Science Information (42:2), June 1, 2003 2003, pp 155-183.

Adler-Milstein, J., Bates, D.W., and Jha, A.K. "Us Regional Health Information Organizations: Progress and Challenges," Health Affairs (28:2), Mar-Apr 2009, pp 483-492.

Adler-Milstein, J., McAfee, A.P., Bates, D.W., and Jha, A.K. "The State of Regional Health Information Organizations: Current Activities and Financing," Health Affairs (27:1), Jan-Feb 2008, pp W60-W69.

Ajzen, I. "The Theory of Planned Behavior," Organizational Behavior and Human Decision Processes (50:2), Dec 1991, pp 179-211.

Ajzen, I. "Behavioral Interventions Base on the Theory of Planned Behavior," Azjen, I, 2011 a.

Ajzen, I. "Constructing a Theory of Planned Behavior Questionnaire," Azjen, I, 2011b.

Al-Natour, S., and Benbasat, I. "The Adoption and Use of It Artifacts: A New Interaction-Centric Model for the Study of User-Artifact Relationships," Journal of the Association for Information Systems (10:9) 2009, pp 661-685.

AMIA "American Medical Informatics Association," 2010.

Ammenwerth, E., Brender, J., Nykanen, P., Prokosch, H.U., Rigby, M., and Talmon, J. "Visions and Strategies to Improve Evaluation of Health Information Systems Reflections and Lessons Based on the His-Eval Workshop in Innsbruck," International Journal of Medical Informatics (73:6) 2004, pp 479-491.

Anderson, J.G. "Social, Ethical and Legal Barriers to E-Health," International Journal of Medical Informatics (76:5-6) 2007, pp 480-483.

Armitage, C., and Conner, M. "Efficacy of the Theory of Planned Behaviour: A MetaAnalytic Review," British Journal of Social Psychology (40:4) 2001, pp 471-499.

Association of Information Systems "Ais Mission Statement ", Association of Information Systems, 2010a, pp. \{Association of Information Systems, 2010 $\# 1471\}$.

Association of Information Systems "Research Resources," Association of Information Systems, 2010b, p. .

Association of Information Systems "Senior Scholars' Basket of Journals," Association of Information Systems, 2010c.

Babbie, E.R. The Practice of Social Research (11th Edition ed.) Thomas Wadsworth, Belmont, CA, 2007.

Bagozzi, R.P. "The Legacy of the Technology Acceptance Model and a Proposal for a Paradigm Shift," Journal of the Association for Information Systems (8:4) 2007, pp 243-254. 
Ball, M.J., and Gold, J.D. "The Health Record Banking Imperative: A Conceptual Model," IBM Systems Journal (Vol 46:No 1) 2007, pp 43-55.

Barrett, S., and Konsynski, B. "Inter-Organization Information Sharing Systems," MIS Quarterly (6) 1982, pp 93-105.

Baskerville, R., and Wood-Harper, A.T. "Diversity in Information Systems Action Research Methods," European Journal of Information Systems (7:2) 1998, pp 90107.

Bazzoli, G.J., Shortell, S.M., Dubbs, N., Chan, C.L., and Kralovec, P. "A Taxonomy of Health Networks and Systems: Bringing Order out of Chaos," Health Services Research (33:6), Feb 1999, pp 1683-1717.

Benbasat, I., and Barki, H. "Quo Vadis, Tam?," Journal of the Association for Information Systems (8:4), Apr 2007, pp 211-218.

Benbasat, I., Goldstein, D.K., and Mead, M. "The Case Research Strategy in Studies of Information-Systems," MIS Quarterly (11:3), Sep 1987, pp 369-386.

Benson, J.K. "Interorganizational Network as a Political-Economy," Administrative Science Quarterly (20:2) 1975, pp 229-249.

Bhattacherjee, A., and Hikmet, N. "Physicians' Resistance toward Healthcare Information Technology: A Theoretical Model and Empirical Test," European Journal of Information Systems (16:6), Dec 2007, pp 725-737.

Boonstra, A., and Govers, M.J.G. "Understanding Erp System Implementation in a Hospital by Analysing Stakeholders," New Technology Work and Employment (24:2) 2009, pp 177-193.

Borgatti, S.P., and Foster, P.C. "The Network Paradigm in Organizational Research: A Review and Typology," Journal of Management (29:6) 2003, pp 991-1013.

Bostrom, R.P., Gupta, S., and Thomas, D. "A Meta-Theory for Understanding Information Systems within Sociotechnical Systems," Journal of Management Information Systems (26:1), Sum 2009, pp 17-47.

Brailer, D. "From Santa Barbara to Washington: A Person's and a Nation's Journey toward Portable Health Information," Health Affairs (26:5) 2007, p w581.

Brass, D.J., Galaskiewicz, J., Greve, H.R., and Tsai, W.P. "Taking Stock of Networks and Organizations: A Multilevel Perspective," Academy of Management Journal (47:6), Dec 2004, pp 795-817.

Bruque, S., Moyano, J., and Eisenberg, J. "Individual Adaptation to It-Induced Change: The Role of Social Networks," Journal of Management Information Systems (25:3) 2008, pp 177-206.

Burt, R.S. Brokerage and Closure: An Introduction to Social Capital Oxford University Press, 2005.

Bush, G.W. "Executive Order 13335 - April 2004," 2005.

Byers, D.H. "Occupational-Health Information Exchange," Public Health Reports (72:12) 1957, pp 1077-1078.

Cargo, M., and Mercer, S. "The Value and Challenges of Participatory Research:

Strengthening Its Practice," Annual Review of Public Health (29) 2008, p 325.

Castells, M. The Rise of the Network Society Wiley-Blackwell, 2000.

Checkland, P. Systems Thinking, Systems Practice John Wiley, Chichester, 1999.

Chester, J.A. "Electronic Data Interchange," Infosystems (33:6), Jun 1986, pp 48-50. 
Cho, S., Mathiassen, L., and Nilsson, A. "Contextual Dynamics During Health Information Systems Implementation: An Event-Based Actor-Network Approach," European Journal of Information Systems (17:6) 2008, pp 614-630.

Christens, B., and Perkins, D. "Transdisciplinary, Multilevel Action Research to Enhance Ecological and Psychopolitical Validity," Journal of Community Psychology (36:2) 2008, p 214.

Coase, R.H. "The Nature of the Firm," Economica, 1937, p. 405.

Cook, K.S. "Exchange and Power in Networks of Interorganizational Relations," Sociological Quarterly (18:1) 1977, pp 62-82.

Cox, B., and Thornewill, J. "The Consumer's View of the Electronic Health Record," Journal of Healthcare Information Management (22:2) 2008, p 43.

Creswell, D.J.W. Research Design: Qualitative, Quantitative, and Mixed Methods Approaches Sage Pubns, 2003.

Davidson, E., and Chiasson, M. "Contextual Influences on Technology Use Mediation: A Comparative Analysis of Electronic Medical Record Systems," European Journal of Information Systems (14:1), Mar 2005, pp 6-18.

Davis, F.D., Bagozzi, R.P., and Warshaw, P.R. "User Acceptance of ComputerTechnology - a Comparison of 2 Theoretical-Models," Management Science (35:8) 1989, pp 982-1003.

Davison, R., Martinsons, M.G., and Kock, N. "Principles of Canonical Action Research," Information Systems Journal (14:1), Jan 2004, pp 65-86.

De Brantes, F., Emery, D., Overhage, J., Glaser, J., and Marchibroda, J. "The Potential of Hies as Infomediaries," Journal of healthcare information management: JHIM (21:1) 2007, p 69.

DeLone, W., and McLean, E. "Information Systems Success: The Quest for the Dependent Variable," Information Systems Research (3:1) 1992, pp 60-95.

Delone, W., and McLean, E. "The Delone and Mclean Model of Information Systems Success: A Ten-Year Update," Journal of Management Information Systems (19:4) 2003, pp 9-30.

Desanctis, G., and Poole, M.S. "Capturing the Complexity in Advanced Technology Use - Adaptive Structuration Theory," Organization Science (5:2) 1994, pp 121-147.

Devaraj, S., Easley, R.E., and Crant, J.M. "How Does Personality Matter? Relating the Five-Factor Model to Technology Acceptance and Use," Information Systems Research (19:1) 2008, pp 93-105.

Devaraj, S., and Kohli, R. "Performance Impacts of Information Technology: Is Actual Usage the Missing Link?," Management Science (49:3) 2003, pp 273-289.

Dierker, L. "The State Connection. State-Level Efforts in Health Information Exchange," J Ahima (79:5) 2008, pp 40-43.

Dimitropoulos, L. "Privacy and Security Solutions for Interoperable Health Information Exchange: Assessment of Variation and Analysis of Solutions."

Dolin, R.H., Alschuler, L., Beebe, C., Biron, P.V., Boyer, S.L., Essin, D., Kimber, E., Lincoln, T., and Mattison, J.E. "The Hl7 Clinical Document Architecture," Journal of the American Medical Informatics Association (8:6) 2001, pp 552-569.

Dolin, R.H., Alschuler, L., Boyer, S., Beebe, C., Behlen, F.M., Biron, P.V., and Shabo, A. "H17 Clinical Document Architecture, Release 2," Journal of the American Medical Informatics Association (13:1) 2006, pp 30-39. 
Donaldson, T., and Preston, L.E. "The Stakeholder Theory of the Corporation - Concepts, Evidence, and Implications," Academy of Management Review (20:1), Jan 1995, pp 65-91.

Dowling, A. "Chins-- the Current State," in: Information Networks for Community Health, Springer-Verlag, 1997, p. 15.

Dowling, A.F., Thornewill, J., Cox, B., and Esterhay, R.J. "Information Infrastructure for Public Health and Health Research: Findings from a Large-Scale HIE Stakeholder Study," in: Hawaii International Conference on Systems Sciences 2010, Hawaii, 2010.

Drazin, R., and Van de Ven, A. "Alternative Forms of Fit in Contingency Theory," Administrative science quarterly) 1985, pp 514-539.

e-Health Initiatives "E Health Initiatives Web Site", $2007 \mathrm{a}$.

e-Health Initiatives "Health Information Exchange: From Start-up to Sustainability ".

eHealth Initiative "Breakthrough Health Information Exchange Research and Sustainability Tools," eHealth Initiative Foundation, 2007.

eHealth Initiative "Ehealth Initiative's Fifth Annual Survey of Health Information Exchange at the State and Local Levels " in: Health Information Exchange Surveys, Washington, DC, 2008.

eHealth Initiative "Migrating toward Meaningful Use: The State of Health Information Exchange," in: Health Information Exchange Surveys, Washington, DC, 2009.

Eischen, K. "Information Technology: History, Practice and Implications for Development," UC Santa Cruz: Center for Global, International and Regional Studies, 2000.

Eisenhardt, K. "Building Theories from Case Study Research," Academy of Management Review) 1989, pp 532-550.

Foster-Fishman, P., Berkowitz, S., Lounsbury, D., Jacobson, S., and Allen, N. "Building Collaborative Capacity in Community Coalitions: A Review and Integrative Framework," American Journal of Community Psychology (29:2) 2001, pp 241261.

Foundation of Research and Education of AHIMA "Advancing Effective State-Level Approaches to Interoperability in the New Federal Context," AHIMA, 2009.

Frisse, M.E. "Health Information Exchange in Memphis: Impact on the Physician-Patient Relationship," Journal of Law Medicine \& Ethics (38:1), Spr 2010, pp 50-57.

Galbraith, J. "Organization Design: An Information Processing View," Interfaces (4:3) 1974, pp 28-36.

Giddens, A. The Constitution of Society: Outline of the Theory of Structuration University of California Press, 1986.

Granovetter, M.S. "Strength of Weak Ties," American Journal of Sociology (78:6) 1973, pp 1360-1380.

Grossman, J., Kushner, K., and November, E. "Creating Sustainable Local Health Information Exchanges: Can Barriers to Stakeholder Participation Be Overcome?," Research briefs: center for studying health system change:2) 2008, $\mathrm{p} 1$.

Grover, V., Lyytinen, K., Srinivasan, A., and Tan, B.C.Y. "Contributing to Rigorous and Forward Thinking Explanatory Theory," Journal of the Association for Information Systems (9:2) 2008, pp 40-47. 
Gulati, R., and Gargiulo, M. "Where Do Interorganizational Networks Come From?," American Journal of Sociology (104:5), Mar 1999, pp 1439-1493.

Halpern, D. Social Capital Cambridge, UK; Malden, MA: Polity, 2005.

Harrison, J.S., and Freeman, R.E. "Stakeholders, Social Responsibility, and Performance: Empirical Evidence and Theoretical Perspectives," Academy of Management Journal (42:5), Oct 1999, pp 479-485.

Hart, P., and Saunders, C. "Power and Trust: Critical Factors in the Adoption and Use of Electronic Data Interchange," Organization Science (8:1) 1997, pp 23-42.

Health Data Management "RHIO Market Growth Small," in: Health Data Management, 2007.

Herranz, J. "Multilevel Performance Indicators for Multisectoral Networks and Management," American Review of Public Administration (40:4), Jul 2010, pp 445-460.

Hessler, B.J., Soper, P., Bondy, J., Hanes, P., and Davidson, A. "Assessing the Relationship between Health Information Exchanges and Public Health Agencies," Journal of Public Health Management and Practice (15:5) 2009, pp 416-424.

Hevner, A., March, S., Park, J., and Ram, S. "Design Science in Information Systems Research," MIS Quarterly) 2004, pp 75-105.

Huang, K., and Provan, K.G. "Resource Tangibility and Patterns of Interaction in a Publicly Funded Health and Human Services Network," Journal of Public Administration Research and Theory (17:3) 2007a, pp 435-454.

Huang, K., and Provan, K.G. "Structural Embeddedness and Organizational Social Outcomes in a Centrally Governed Mental Health Services Network," Public Management Review (9:2), Jun 2007b, pp 169-189.

Imperial, M. "Using Collaboration as a Governance Strategy - Lessons from Six Watershed Management Programs," Administration \& Society (37:3) 2005, pp 281-320.

INFORMS "Institute for Operations Research and the Management Sciences Website," 2010, p. INFORMS website

JAIS "Call for Papers: Special Issue on Health Care It: Process, People and Patients," Journal of the Association for Information Systems) 2009.

Jick, T. "Mixing Qualitative and Quantitative Methods: Triangulation in Action," Administrative Science Quarterly) 1979, pp 602-611.

Johnson, K., and Gadd, C. "Playing Smallball: Approaches to Evaluating Pilot Health Information Exchange Systems," Journal of Biomedical Informatics (40:6S) 2007, pp 21-26.

Johnson, R., and Onwuegbuzie, A. "Mixed Methods Research: A Research Paradigm Whose Time Has Come," Educational Researcher (33:7) 2004, p 14.

Jones, M.R., and Karsten, H. "Giddens's Structuration Theory and Information Systems Research," MIS Quarterly (32:1), Mar 2008, pp 127-157.

Jones, T.M. "Instrumental Stakeholder Theory - a Synthesis of Ethics and Economics," Academy of Management Review (20:2), Apr 1995, pp 404-437.

Kane, G.C., and Alavi, M. "Casting the Net: A Multimodal Network Perspective on UserSystem Interactions," Information Systems Research (19:3), Sep 2008, pp 253272. 
Kaushal, R., Blumenthal, D., Poon, E.G., Jha, A.K., Franz, C., Middleton, B., Glaser, J., Kuperman, G., Christino, M., Fernandopulle, R., Newhouse, J.P., Bates, D.W., and Cost Natl Hlth Info Network Wkng, G. "The Costs of a National Health Information Network," Annals of Internal Medicine (143:3) 2005, pp 165-173.

Kelly, S., Gibson, N., Holland, C.P., and Light, B. "Focus Issue on Legacy Information Systems and Busines Process Engineering: A Business Perspective of Legacy Information Systems," Communications of the AIS (2:1es) 1999, pp 7-es.

Kenis, P., and Provan, K.G. "Towards an Exogenous Theory of Public Network Performance," Public Administration (87:3) 2009, pp 440-456.

Kilduff, M., and Tsai, W. Social Networks and Organizations Sage Publications Ltd, 2003.

King, J., and Lyytinen, K. Information Systems: The State of the Field (John Wiley Series in Information Systems) John Wiley \& Sons, 2006.

Kivisto, P. Social Theory: Roots and Branches Roxbury; Roundhouse, 2004.

Klein, R. "An Empirical Examination of Patient-Physician Portal Acceptance," European Journal of Information Systems (16:6) 2007, pp 751-760.

Krohn, R. "Health Information Exchanges--What's Working?," Journal of healthcare information management: JHIM (22:3) 2008, p 7.

Kuhn, K.A., Giuse, D.A., Lapdo, L., and Wurst, S.H.R. "Expanding the Scope of Health Information Systems - from Hospitals to Regional Networks, to National Infrastructures, and Beyond," Methods of Information in Medicine (46:4) 2007, pp 500-502.

Labkoff, S.E., and Yasnoff, W.A. "A Framework for Systematic Evaluation of Health Information Infrastructure Progress in Communities," Journal of Biomedical Informatics (40:2) 2007, pp 100-105.

Laumann, E., Marsden, P., and Prensky, D. "The Boundary Specification Problem in Network Analysis," Research Methods in Social Network Analysis) 1989, pp 6187.

Law, J. "Notes on the Theory of the Actor Network - Ordering, Strategy, and Heterogeneity," Systems Practice (5:4), Aug 1992, pp 379-393.

Leiner, B., Cerf, V., Clark, D., Kahn, R., Kleinrock, L., Lynch, D., Postel, J., Roberts, L., and Wolff, S. "A Brief History of the Internet," ACM SIGCOMM Computer Communication Review (39:5) 2009, pp 22-31.

Lemert, C.C. Social Theory: The Multicultural and Classic Readings 3rd Ed Westview Press, Boulder, 2004.

Lorenzi, N. "Strategies for Creating Successful Local Health Information Infrastructure Initiatives," US Department of Health and Human Services, Washington, DC, 2003.

Luhmann, N. Social Systems Stanford University Press, 1995.

Mantzana, V., Themistocleous, M., Irani, Z., and Morabito, V. "Identifying Healthcare Actors Involved in the Adoption of Information Systems," European Journal of Information Systems (16:1) 2007, pp 91-102.

Marchibroda, J.M. "Health Information Exchange Policy and Evaluation," Journal of Biomedical Informatics (40:6) 2007, pp S11-S16.

Marshall, D.C., and Rossman, D.G.B. Designing Qualitative Research Sage Publications, 2006. 
Mason, R., and Mitroff, I. "A Program for Research on Management Information Systems," Management Science (19:5) 1973, pp 475-487.

McGraw, D., Dempsey, J., Harris, L., and Goldman, J. "Privacy as an Enabler, Not an Impediment: Building Trust into Health Information Exchange," Health Affairs (28:2) 2009, p 416.

Merriam-Webster "Merriam-Webster Dictionary," 2010.

Middleton, B. "Achieving U.S. Health Information Technology Adoption: The Need for a Third Hand," Health Aff (Millwood.) (24:5) 2005, pp 1269-1272.

Middleton, B. "Evaluating the Value of Healthcare Information Technology: Finding the Diamond in the Rough, and Tumble," AMIA.Annu.Symp.Proc.) 2006, pp 11721173.

Milward, H.B., Provan, K.G., Fish, A., Isett, K.R., and Huang, K. "Governance and Collaboration: An Evolutionary Study of Two Mental Health Networks," Journal of Public Administration Research and Theory (20) 2010, pp I125-I141.

Minkler, M. "Using Participatory Action Research to Build Healthy Communities," Public Health Reports (115:2-3), Mar-Jun 2000, pp 191-197.

Morrissey, J.P., Calloway, M., Bartko, W.T., Ridgely, M.S., Goldman, H.H., and Paulson, R.I. "Local Mental-Health Authorities and Service System Change Evidence from the Robert-Wood-Johnson-Program-on-Chronic-Mental-Illness," Milbank Quarterly (72:1) 1994, pp 49-80.

Mumford, E. "The Story of Socio-Technical Design: Reflections on Its Successes, Failures and Potential," Information Systems Journal (16:4) 2006, pp 317-342.

Nonaka, I. "A Dynamic Theory of Organizational Knowledge Creation," Organization Science (5:1), Feb 1994, pp 14-37.

NORC "Health Information Exchange Economic Sustainability Panel: Final Report," US Cabinet of Health and Human Services, Office of the National Coordinator for Health IT.

North, D. "The New Institutional Economics," Journal of Institutional and Theoretical Economics (142:1) 1986, pp 230-237.

North, D. Understanding the Process of Economic Change Princeton University Press, 2005.

Norusis, M. Spss 14.0 Statistical Procedures Companion Prentice-Hall, Inc. Upper Saddle River, NJ, USA, 2005.

Office of National Coordinator "Definition of Key Health Information Technology Terms," US Health and Human Services, Office of the National Coordinator for Health Information Technology, Washington, DC.

ONC-HIT "Health Information Technology Strategic Framework ", Office of the National Coordinator for Health Information Technology (ONC-HIT) 2004.

ONC-HIT "Definition of Key Health Information Technology Terms," US Health and Human Services, Office of the National Coordinator for Health Information Technology, Washington, DC.

ONC-HIT "State Health Information Exchange Cooperative Agreement Program," Office of the National Coordinator for Health Information Technology, 2009.

Orlikowski, W., and Baroudi, J. "Studying Information Technology in Organizations: Research Approaches and Assumptions," Information Systems Research (2:1) 1991, pp 1-28. 
Orlikowski, W.J. "The Duality of Technology - Rethinking the Concept of Technology in Organizations," Organization Science (3:3), Aug 1992, pp 398-427.

Orlikowski, W.J. "The Sociomateriality of Organisational Life: Considering Technology in Management Research," Cambridge Journal of Economics (34:1), Jan 2010, pp 125-141.

Orlikowski, W.J., and Barley, S.R. "Technology and Institutions: What Can Research on Information Technology and Research on Organizations Learn from Each Other?," MIS Quarterly (25:2), Jun 2001, pp 145-165.

Overhage, J. "Health Information Exchange:'Lex Parsimoniae'," Health Affairs (26:5) 2007, p w595.

Owen-Smith, J., and Powell, W.W. "Knowledge Networks as Channels and Conduits: The Effects of Spillovers in the Boston Biotechnology Community," Organization Science (15:1), Jan-Feb 2004, pp 5-21.

Pavlou, P. "Consumer Acceptance of Electronic Commerce: Integrating Trust and Risk with the Technology Acceptance Model," International Journal of Electronic Commerce (7:3) 2003, pp 101-134.

Perrow, C. "A Society of Organizations," Theory and Society (20:6), Dec 1991, pp 725762.

Phelps, R., Adams, R., and Bessant, J. "Life Cycles of Growing Organizations: A Review with Implications for Knowledge and Learning," International Journal of Management Reviews (9:1), Mar 2007, pp 1-30.

Pipek, V., and Wulf, V. "Infrastructuring: Toward an Integrated Perspective on the Design and Use of Information Technology," Journal of the Association for Information Systems (10:5) 2009, pp 447-473.

Plas, J.V. "Healthcare It: In Wake of Harvard Study, Experts Call for New RHIO Funding Model," in: WTN News, 2007.

Popper, K. Objective Knowledge: An Evolutionary Approach Oxford University Press, USA, 1972.

Powell, W.W. "Neither Market nor Hierarchy - Network Forms of Organization," Research in Organizational Behavior (12) 1990, pp 295-336.

Provan, K.G. "Advances in Health Care Organization Theory," Administrative science quarterly (49:1), Mar 2004, pp 139-141.

Provan, K.G., Fish, A., and Sydow, J. "Interorganizational Networks at the Network Level: A Review of the Empirical Literature on Whole Networks," Journal of Management (33:3) 2007, pp 479-516.

Provan, K.G., Harvey, J., and de Zapien, J.G. "Network Structure and Attitudes toward Collaboration in a Community Partnership for Diabetes Control on the UsMexican Border," J Health Organ Manag (19:6) 2005, pp 504-518.

Provan, K.G., Huang, K., and Milward, H.B. "The Evolution of Structural Embeddedness and Organizational Social Outcomes in a Centrally Governed Health and Human Services Network, "Journal of Public Administration Research and Theory (19:4), Oct 2009, pp 873-893.

Provan, K.G., and Kenis, P. "Modes of Network Governance: Structure, Management, and Effectiveness," Journal of Public Administration Research and Theory (18:2), Apr 2008, pp 229-252. 
Provan, K.G., Lamb, G., and Doyle, M. "Building Legitimacy and the Early Growth of Health Networks for the Uninsured," Health Care Management Review (29:2) 2004, pp 117-128.

Provan, K.G., and Milward, H.B. "A Preliminary Theory of Interorganizational Network Effectiveness - a Comparative-Study of 4 Community Mental-Health Systems," Administrative Science Quarterly (40:1) 1995, pp 1-33.

Provan, K.G., and Milward, H.B. "Do Networks Really Work? A Framework for Evaluating Public-Sector Organizational Networks," Public Administration Review (61:4), Jul-Aug 2001, pp 414-423.

Provan, K.G., and Sebastian, J.G. "Networks within Networks: Service Link Overlap, Organizational Cliques, and Network Effectiveness," Academy of Management Journal (41:4), Aug 1998, pp 453-463.

Raab, J., and Kenis, P. "Heading toward a Society of Networks Empirical Developments and Theoretical Challenges," Journal of Management Inquiry (18:3), Sep 2009, pp 198-210.

Railton, P. "A Deductive-Nomological Model of Probabilistic Explanation," Philosophy of Science (45:2) 1978, pp 206-226.

Ramamurthy, K., and Premkumar, G. "Determinants and Outcomes of Electronic Data Interchange Diffusion," Ieee Transactions on Engineering Management (42:4) 1995, pp 332-351.

Ramsaroop, P., and Ball, M.J. "The "Bank of Health". A Model for More Useful Patient Health Records," MD Comput. (17:4) 2000, pp 45-48.

Ravichandran, T., and Lertwongsatien, C. "Effect of Information Systems Resources and Capabilities on Firm Performance: A Resource-Based Perspective," Journal of Management Information Systems (21:4), Spr 2005, pp 237-276.

Reardon, J.L., and Davidson, E. "An Organizational Learning Perspective on the Assimilation of Electronic Medical Records among Small Physician Practices," European Journal of Information Systems (16:6) 2007, pp 681-694.

Reimers, K., Johnston, R., and Klein, S. "The Difficulty of Studying Inter-Organisational Is Phenomena on Large Scales: Critical Reflections on a Research Journey," Electronic Markets (20:3-4), Dec 2010, pp 229-240.

Reynolds, P.D. A Primer in Theory Construction Pearson Education, Boston, 2007.

Robey, D., Im, G., and Wareham, J.D. "Theoretical Foundations of Empirical Research on Interorganizational Systems: Assessing Past Contributions and Guiding Future Directions," Journal of the Association for Information Systems (9:9) 2008, pp 497-518.

Rogers, E.M. Diffusion of Innovations Free Press, New York, 1995.

Rudin, R.S., Simon, S.R., Volk, L.A., Tripathi, M., and Bates, D. "Understanding the Decisions and Values of Stakeholders in Health Information Exchanges: Experiences from Massachusetts," American Journal of Public Health (99:5), May 2009, pp 950-955.

Sahay, S., Monteiro, E., and Aanestad, M. "Configurable Politics and Asymmetric Integration: Health E-Infrastructures in India," Journal of the Association for Information Systems (10:5) 2009, pp 399-414.

Science Watch "Journals Ranked by Impact: Management," Thompson Reuters, 2010. 
Shabo, A. "A Global Socio-Economic-Medico-Legal Model for the Sustainability of Longitudinal Electronic Health Records - Part 2," Methods Inf.Med. (45:5) 2006, pp 498-505.

Shapiro, J.S., Genes, N., Kuperman, G., Chason, K., Richardson, L.D., and New York Clinical Information, E. "Health Information Exchange, Biosurveillance Efforts, and Emergency Department Crowding During the Spring 2009 H1n1 Outbreak in New York City," Annals of Emergency Medicine (55:3) 2010, pp 274-279.

Simon, S.R., Evans, J.S., Benjamin, A., Delano, D., and Bates, D.W. "Patients' Attitudes toward Electronic Health Information Exchange: Qualitative Study," Journal of Medical Internet Research (11:3), Jul-Sep 2009.

SLHIE, A.-. "Advancing Effective State-Level Approaches to Interoperability in the New Federal Context," AHIMA.

Sprivulis, P., Walker, J., Johnston, D., Pan, E., Adler-Milstein, J., Middleton, B., and Bates, D.W. "The Economic Benefits of Health Information Exchange Interoperability for Australia," Australian Health Review (31:4) 2007, pp 531539.

Stacey, R.D. Complex Responsive Processes in Organizations Learning and Knowledge Creation Routledge, London, 2001.

Starr, P. "Smart Technology, Stunted Policy: Developing Health Information Networks," Health Affairs (16:3) 1997, p 91.

Straub, D., Limayem, M., and Karahannaevaristo, E. "Measuring System Usage Implications for Is Theory Testing," Management Science (41:8), Aug 1995, pp 1328-1342.

Sydow, J., and Windeler, A. "Organizing and Evaluating Interfirm Networks: A Structurationist Perspective on Network Processes and Effectiveness," Organization Science (9:3), May-Jun 1998, pp 265-284.

Sykes, T.A., Venkatesh, V., and Gosain, S. "Model of Acceptance with Peer Support: A Social Network Perspective to Understand Employees' System Use," MIS Quarterly (33:2) 2009, pp 371-393.

Taylor, F. The Principles of Scientific Management 1st World Library, 2005.

Teo, H.H., Wei, K.K., and Benbasat, I. "Predicting Intention to Adopt Interorganizational Linkages: An Institutional Perspective," Mis Quarterly (27:1) 2003, pp 19-49.

Thompson, T., and Brailer, D. "The Decade of Health Information Technology: Delivering Consumer-Centric and Information-Rich Health Care," US Department of Health and Human Services, Washington, DC:, 2004.

Thornewill, J., Dowling, A., Cox, B., and Esterhay, R. "Information Infrastructure for Consumer Health: Findings from a Large-Scale HIE Stakeholder Study," American Journal of Preventive Medicine: June, 2011) 2011.

Thornewill, J., and Esterhay, R.J. "Capitalizing the NHIN: A Strategy for Funding an Integrated Nationwide Network of Community Hies," Journal of Healthcare Information Management (21:3), August 2007 2007, pp 18-24.

Tripathi, M., Delano, D., Lund, B., and Rudolph, L. "Engaging Patients for Health Information Exchange," Health Affairs (28:2), Mar-Apr 2009, pp 435-443.

Turrini, A., Cristofoli, D., Frosini, F., and Nasi, G. "Networking Literature About Determinants of Network Effectiveness," Public Administration (88:2) 2010, pp 528-550. 
University of Massachusetts Medical School "Public Governance Models for a Sustainable Health Information Exchange Industry," National Governors Association, State Alliance for e-Health, 2008.

University of Massachusetts Medical School "Public Governance Models for a Sustainable Health Information Exchange Industry ", National Governors Association, State Alliance for e-Health

University of North Carolina at Charlotte "Organizational Science," 2010.

Ure, J., Procter, R., Lin, Y.W., Hartswood, M., Anderson, S., Lloyd, S., Wardlaw, J., Gonzalez-Velez, H., and Ho, K. "The Development of Data Infrastructures for Ehealth: A Socio-Technical Perspective," Journal of the Association for Information Systems (10:5) 2009, pp 415-429.

Vaast, E. "Danger Is in the Eye of the Beholders: Social Representations of Information Systems Security in Healthcare," Journal of Strategic Information Systems (16) 2007, pp 130-152.

van Raak, A., and Paulus, A. "A Sociological Systems Theory of Interorganizational Network Development in Health and Social Care," Systems Research and Behavioral Science (18:3), May-Jun 2001, pp 207-224.

Vandeven, A.H., and Poole, M.S. "Explaining Development and Change in Organizations," Academy of Management Review (20:3), Jul 1995, pp 510-540.

Venkatesh, V., and Bala, H. "Technology Acceptance Model 3 and a Research Agenda on Interventions," Decision Sciences (39:2) 2008, pp 273-315.

Venkatesh, V., and Davis, F.D. "A Theoretical Extension of the Technology Acceptance Model: Four Longitudinal Field Studies," Management Science (46:2), Feb 2000, pp 186-204.

Venkatesh, V., Morris, M.G., Davis, G.B., and Davis, F.D. "User Acceptance of Information Technology: Toward a Unified View," MIS Quarterly (27:3), Sep 2003, pp 425-478.

Venkatesh, V., and Zhang, X.J. "Unified Theory of Acceptance and Use of Technology: Us Vs. China," Journal of Global Information Technology Management (13:1) 2010, pp 5-27.

Venkatraman, N., and Lee, C.H. "Preferential Linkage and Network Evolution: A Conceptual Model and Empirical Test in the Us Video Game Sector," Academy of Management Journal (47:6), Dec 2004, pp 876-892.

Vest, J.R., and Gamm, L.D. "Health Information Exchange: Persistent Challenges and New Strategies," Journal of the American Medical Informatics Association (17:3), May 2010a, pp 288-294.

Vest, J.R., and Jasperson, J. "What Should We Measure? Conceptualizing Usage in Health Information Exchange," Journal of the American Medical Informatics Association (17:3), May 2010b, pp 302-307.

Walker, J., Pan, E., Johnston, D., Adler-Milstein, J., Bates, D., and Middleton, B. "The Value of Health Care Information Exchange and Interoperability," Health Affairs (19) 2005, pp W5-10W15.

Walsham, G. "Interpretive Case-Studies in Is Research - Nature and Method," European Journal of Information Systems (4:2) 1995, pp 74-81.

Wasserman, S., and Faust, K. Social Network Analysis Methods and Applications Cambridge University Press, Cambridge, 1994. 
Weber, E.P., Lovrich, N.P., and Gaffney, M.J. "Assessing Collaborative Capacity in a Multidimensional World," Administration \& Society (39:2) 2007, pp 194-220.

Wernerfelt, B. "A Resource-Based View of the Firm," Strategic Management Journal (5:2) 1984, pp 171-180.

Whetten, D.A. "What Constitutes a Theoretical Contribution," Academy of Management Review (14:4), Oct 1989, pp 490-495.

Whetten, D.A., Felin, T., and King, B.G. "The Practice of Theory Borrowing in Organizational Studies: Current Issues and Future Directions," Journal of Management (35:3), Jun 2009, pp 537-563.

Whyte, W.F. "Advancing Scientific Knowledge through Participatory Action Research," Springer, 1989, pp. 367-385.

Wikipedia "History of Computers," Wikipedia, 2010.

Williams, M. A History of Computing Technology IEEE Computer Society Press Los Alamitos, CA, USA, 1997.

Williamson, O.E. "The Economics of Organization - the Transaction Cost Approach," American Journal of Sociology (87:3) 1981, pp 548-577.

Yasnoff, W., Humphreys, B., Marc Overhage, J., Detmer, D., Flatley Brennan, P., Morris, R., Middleton, B., Bates, D., and Fanning, J. "A Consensus Action Agenda for Achieving the National Health Information Infrastructure," Journal of the American Medical Informatics Association (11:4) 2004, pp 332-338.

Yin, R. Case Study Research: Design and Methods Sage publications, Inc., 2008.

Zaheer, A., Gozubuyuk, R., and Milanov, H. "It's the Connections: The Network Perspective in Interorganizational Research," Academy of Management Perspectives (24:1), Feb 2010, pp 62-77. 


\section{APPENDIX 1: GLOSSARY OF TERMS}

Dual Network Participation Theory (DNPT). A theory developed in this study designed to predict factors which affect participation in dual networks like HIENs

EHR. See Electronic Health Record.

Electronic Health Record (EHR). An electronic record of health-related information on an individual that conforms to nationally recognized interoperability standards and that can be created, managed, and consulted by authorized clinicians and staff across more than one health care organization (e.g., Office of National Coordinator 2008)."

Electronic Medical Record (EMR). An electronic record of health-related information on an individual that conforms to nationally recognized interoperability standards and that can be created, gathered, managed, and consulted by authorized clinicians and staff within one health care organization (Office of National Coordinator 2008).

EMR. See Electronic Medical Record.

Health Information Exchange (HIE). The electronic movement of health-related information among organizations according to nationally recognized standards (Office of National Coordinator 2008)."

Health Information Exchange Network (HIEN). An umbrella term referring to the combination of a health information organization (a whole-network) and the health information exchange (a network IT) which it provides or supports.

Health Information Organization (HIO). "An organization that oversees and governs the exchange of health related information among organizations according to nationally recognized standards (Office of National Coordinator 2008)."

HIE. See Health Information Exchange.

HIEN. See Health Information Exchange Network.

HIO. See Health Information Organizations.

Information System (IS). "Information systems or the more common legacy information systems include people, procedures, data, software, and hardware (by degree) that are used to gather and analyze digital information" (from Kelly et al. 1999).

Interorganizational Network at the Network Level (Whole-Network). A formal network of three or more organizations collaborating to achieve a shared goal (Provan et al. 2007).

Interorganizational System (IOS). An information system (IS) used by two or more organizations to gather or exchange electronic information.

IOS. See Interorganizational System.

Mixed Network. A network level collaborative involving participants drawn from two or more levels, such as an individual, organizational and network level.

Nationwide Health Information Network (NHIN) - A standardized, secure and confidential way to link information systems together for authorized users to 
share reliable health-related information.

Network Information Technology. Properties of electronic information systems connected to an electronic communications network (Orlikowski 1992).

Network IT. See Network Information Technology

Network Level Collaborative (NLC). A general form of network-level endeavor in which two or more individuals, organizations or NLIs collaborate in order to achieve a shared goal.

Network Participation Theory (NPT). An updated version of the dual network participation theory proposed at the end of this study, which focuses on factors affecting participation in network level collaboratives, rather than dual networks.

NHIN. See Nationwide Health Information Network.

NIT. See Network Information Technology.

NLC. See Network Level Collaborative.

Personal Health Record. "An electronic record of health-related information on an individual that conforms to nationally recognized interoperability standards and that can be drawn from multiple sources while being managed, shared and controlled by the individual" (Office of National Coordinator 2008).

PHR. See Personal Health Record

Predictors. The DNPT variables including Effort Expectancy, Performance Expectancy, Social Influence and Facilitating Conditions.

Regional Health Information Organization (RHIO). A health information organization that brings together health care stakeholders within a defined geographic area and governs health information exchange among them for the purpose of improving health and care in that community" (Office of National Coordinator 2008).

RHIO. See Regional Health Information Organization.

SLHIO. See State Level Health Information Organization

State Level Health Information Organization (SLHIO). A state level HIO operating with state government involvement and/or oversight.

TAM. See technology acceptance model.

TBP. See Theory of Planned Behavior.

Technology acceptance Model (TAM). A theory which studies and model which predicts the adoption of information technology by individuals in organizational settings.

Theory of Planned Behavior (TPB). A theory, developed in the field of social psychology, which proposes that individual behavior is determined by three factors: individual attitudes towards the behavior, subjective norms shaping the behavior, and perceived ability to control the behavior (Ajzen 1991).

Whole-Network. See interorganizational network at the network level. 


\section{APPENDIX 2: THE HIEN LITERATURE}

\section{HIEN Literature Search Criteria}

A HIEN literature search was completed in July 2010 using the ISI Web of Knowledge, Google Scholar, and Google on combinations of the terms health, healthcare, medical, information, exchange, system, technology, platform, network, and organization. Table 19 highlights papers of interest in the HIEN Literature. These include academic papers published in top ranked academic journals in the areas of 1.) organizational sciences; 2.) information systems; and 3.) health informatics and health policy; as well as papers and reports found in 4.) professional healthcare journals; and, 5.) U.S. federal and state government websites. 
Table 19: Selected HIEN Literature

\begin{tabular}{|c|c|c|}
\hline Area & Key Journals Included in Search & Key Papers and Reports Found \\
\hline $\begin{array}{l}\text { Information } \\
\text { Systems }\end{array}$ & $\begin{array}{l}\text { MIS Quarterly (MISQ) } \\
\text { Journal of Association of Information } \\
\text { Systems (JAIS) } \\
\text { European Journal of Information } \\
\text { Systems (EJIS) } \\
\text { Information Systems Research (ISR) } \\
\text { Journal of Management Information } \\
\text { Systems (JMIS) } \\
\text { Information Systems Journal (ISJ) } \\
\text { Journal of Information Technology (JIT) }\end{array}$ & $\begin{array}{l}\text { Studies of HIEN-like collaboratives in other } \\
\text { countries (Mantzana et al. 2007; Sahay et al. } \\
\text { 2009; Ure et al. 2009). } \\
\text { Studies of electronic medical record adoption } \\
\text { (Cox et al. 2008; Davidson et al. 2005; } \\
\text { Reardon et al. 2007) } \\
\text { Other (Cho et al. 2008; Ravichandran et al. } \\
\text { 2005; Vaast 2007) }\end{array}$ \\
\hline $\begin{array}{l}\text { Organization } \\
\text { al Sciences }\end{array}$ & $\begin{array}{l}\text { MIS Quarterly(MISQ) } \\
\text { Academy of Management Journal (AMJ) } \\
\text { Academy of Management Review (AMR) } \\
\text { Organization Science (OS) } \\
\text { Administrative Science Quarterly (ASQ) } \\
\text { Strategic Management Journal (SMJ). } \\
\text { International Journal of Business } \\
\quad \text { Studies (IJBS). } \\
\text { Administration and Society (A\&S) } \\
\text { Business Ethics Quarterly } \\
\text { American Journal of Sociology (AJS) }\end{array}$ & $\begin{array}{l}\text { Studies of health sector organizations at the } \\
\text { organizational or network level (Huang et al. } \\
\text { 2007a; Huang et al. 2007b; Milward et al. } \\
\text { 2010; Provan 2004; Provan et al. 2005; } \\
\text { Provan et al. 2009) }\end{array}$ \\
\hline $\begin{array}{l}\text { Health } \\
\text { Policy and } \\
\text { Health } \\
\text { Informatics }\end{array}$ & $\begin{array}{l}\text { Journal of Health Affairs } \\
\text { American Journal of Public Health } \\
\text { (AJPH) } \\
\text { Journal of the American Medical } \\
\text { Informatics Association (JAMIA) } \\
\text { Journal of Biomedical Informatics } \\
\text { International Journal of Medical } \\
\text { Informatics } \\
\text { New England Journal of Medicine }\end{array}$ & $\begin{array}{l}\text { HIEN assessment f(Johnson et al. 2007; Labkoff } \\
\text { et al. 2007) } \\
\text { Governance and Policy (Marchibroda 2007) } \\
\text { Costs and outcomes (Middleton 2006) } \\
\text { Privacy/security (McGraw et al. 2009; Simon et } \\
\text { al. 2009) } \\
\text { Technical design (Ramsaroop et al. 2000; Shabo } \\
\text { 2006) } \\
\text { Adoption (Vest et al. 2010b) } \\
\text { Strategy (Overhage 2007; Vest et al. 2010a; } \\
\text { Yasnoff et al. 2004). }\end{array}$ \\
\hline $\begin{array}{l}\text { Professional } \\
\text { Journals in } \\
\text { Healthcare }\end{array}$ & $\begin{array}{l}\text { Journal of Healthcare Information } \\
\text { Management } \\
\text { Journal of the American Health } \\
\text { Information Management Association }\end{array}$ & $\begin{array}{l}\text { (De Brantes et al. 2007; Krohn 2008; Thornewill } \\
\text { et al. 2007) }\end{array}$ \\
\hline $\begin{array}{l}\text { US } \\
\text { Government } \\
\text { Sponsored } \\
\text { Studies and } \\
\text { Documents }\end{array}$ & $\begin{array}{l}\text { US Health and Human Services (HHS) } \\
\text { HHS Office of the National Coordinator } \\
\text { of Health Information Technology } \\
\text { Centers for Disease Control (CDC) } \\
\text { HHS Centers for Medicare and } \\
\text { Medicaid Services }\end{array}$ & $\begin{array}{l}\text { HIEN Related Studies (eHealth Initiative 2007; } \\
\text { eHealth Initiative 2008; eHealth Initiative } \\
\text { 2009; Foundation of Research and Education } \\
\text { of AHIMA 2009; NORC 2009; Office of } \\
\text { National Coordinator 2008; ONC-HIT 2004; } \\
\text { e.g. SLHIE 2009; University of Massachusetts } \\
\text { Medical School 2009) }\end{array}$ \\
\hline
\end{tabular}


The field of organizational sciences, also called organizational studies, has been developing since early in the $20^{\text {th }}$ century. Webster defines an organization as "an administrative and functional structure (such as a business or a political party)" (Merriam-Webster 2010). Organizational sciences have been described as:

... an interdisciplinary field of inquiry focusing on employee and organizational health, well-being, and effectiveness. Organizational Science is both a science and a practice, founded on the notion that enhanced understanding leads to applications and interventions that benefit the individual, work groups, the organization, the customer, the community, and the larger society in which the organization operates. (University of North Carolina at Charlotte 2010).

Research on formal organizations becomes increasingly prevalent as the $20^{\text {th }}$ century progresses (Perrow 1991). Top journals in this field include MIS Quarterly (MISQ), Academy of Management Journal (AMJ), Academy of Management Review (AMR), Organization Science (OS), Administrative Science Quarterly (ASQ), Strategic Management Journal (SMJ), International Journal of Business Studies (IJBS) and Administration and Society (A\&S) (Science Watch 2010). Major accomplishments in the field include scientific management theory (Taylor 2005), contingency theories of the firm (Drazin et al. 1985), transaction cost economic theory (Coase 1937; Williamson 1981), new institutional theory (North 1986; North 2005), and, more recently, organizational network studies (Borgatti et al. 2003; Granovetter 1973). In this field, no papers were found on U.S. HIENs. However, relevant studies of other health sector organizations and health networks were identified (e.g., Huang et al. 2007a; Huang et al. 2007b; Milward et al. 2010; Provan 2004; Provan et al. 2005; Provan et al. 2009).

The field of information systems (IS) research begins developing in the 1960s, initially focusing on use of management information systems (MIS) in organizations (Mason et al. 1973). It has grown substantially since its start to become widely 
recognized as an important sub-discipline in business schools (King et al. 2006). As reflected in the mission statement of the leading association in the field, IS researchers seek "to advance knowledge in the use of information technology to improve organizational performance and individual quality of work life" (Association of Information Systems 2010a). Top journals in the IS field include MIS Quarterly (MISQ), Journal of Association of Information Systems (JAIS), European Journal of Information Systems (EJIS), Information Systems Research (ISR), Journal of Management Information Systems (JMIS), Information Systems.Journal (ISJ) and the Journal of Information Technology (JIT) (Association of Information Systems 2010c). A key accomplishment in the field are the technology acceptance models (TAM) used to predict individuals' adoption of IS in organizational contexts (Venkatesh et al. 2003). In recent years, IS researchers have shown increasing interest in interorganizational systems, defined as "automated information systems shared by two or more organizations, and designed to link business processes" (Robey et al. 2008), in infrastructure IS (Pipek et al. 2009) and network factor affects on IS (Bruque et al. 2008; Kane et al. 2008). No studies of U.S. HIENs were found in this field. However, the search did find studies of HIENlike collaboratives in other countries (Mantzana et al. 2007; Sahay et al. 2009; Ure et al. 2009), studies of electronic medical record adoption (Cox et al. 2008; Davidson et al. 2005; Reardon et al. 2007), and some related topics (e.g., Ravichandran et al. 2005; Vaast 2007)

The fields of health informatics and health policy have grown up through the $20^{\text {th }}$ century alongside healthcare itself. These fields tend to be healthcare specific, showing little overlap with research in non-healthcare domains, although efforts are being made to 
bridge these divides (e.g., JAIS 2009). Researchers in the field of health informatics focus on "the effective organization, analysis, management, and use of information in health care in support of patient care, public health, teaching, research, administration, and related policy" (AMIA 2010). Informaticians focus on understanding and use of large, specialized, rapidly evolving medical vocabularies involving hundreds of thousands of unique terms, many of which are used or interpreted in different ways in different care settings by different types of professionals (Dolin et al. 2001). Top journals in this area include the Journal of the American Medical Informatics Association (JAMIA), Journal of Biomedical Informatics and International Journal of Medical Informatics. Researchers in health policy provide advice and guidance to international, national and state policy makers administering Medicare, Medicaid and other government funded healthcare programs. Key journals in this area include Health Affairs, medically focused journals, such as the New England Journal of Medicine and specialty journals, such as the American Journal of Public Health. Researchers in both areas - health informatics and health policy - are focusing increased attention on the development and use of health information technology to increase quality and efficiency of healthcare processes (Kuhn et al. 2007; Starr 1997). HIEN related papers in these two areas focus on topics such as HIEN assessment (Johnson et al. 2007; Labkoff et al. 2007), governance and policy (Marchibroda 2007), costs and outcomes (Middleton 2006), privacy/security (McGraw et al. 2009; Simon et al. 2009), technical design (Ramsaroop et al. 2000; Shabo 2006), adoption (Vest et al. 2010b), and strategy (Overhage 2007; Vest et al. 2010a; Yasnoff et al. 2004). 
Professional and trade journals in the healthcare domain are a source of information about HIENs. These include the Journal of Healthcare Information Management (De Brantes et al. 2007; Krohn 2008; Thornewill et al. 2007), Journal of the American Health Information Management Association (Dierker 2008), and a variety of specialty journals (e.g., Frisse 2010; Hessler et al. 2009; Kuhn et al. 2007; Shapiro et al. 2010). Papers in these journals tend to be written for lay audiences rather than academics. Lastly, U.S. Federal and state government groups sponsor a number of HIEN related reports and assessments from 2005 - 2010. Most prominent among these is non-profit organization, eHealth Initiatives, which produced a series of reports over several years assessing HIEN development in the U.S. (e-Health Initiatives 2007a; e-Health Initiatives 2007b; eHealth Initiative 2007; eHealth Initiative 2008; eHealth Initiative 2009). In addition, studies of state level health information exchange (Foundation of Research and Education of AHIMA 2009; University of Massachusetts Medical School 2009), and the economics of HIEN (Kaushal et al. 2005; NORC 2009) were identified. In addition, the U.S. Government Office of the National Coordinator for Health IT publishes selected plans and reports directly (ONC-HIT 2004; ONC-HIT 2008; ONC-HIT 2009; Thompson et al. 2004) 


\section{APPENDIX 3: THEORIES CONSIDERED}

Table 20: Partial List of Theories Considered for HIEN Research

\begin{tabular}{|c|c|c|}
\hline Area & $\begin{array}{l}\text { Theories Considered } \\
*=\text { Selected }\end{array}$ & Reason for Selection/ Rejection \\
\hline \multirow{6}{*}{$\begin{array}{l}\text { Information Systems } \\
\text { (Association of } \\
\text { Information } \\
\text { Systems 2010b) }\end{array}$} & Actor Network Theory (Law 1992) & $\begin{array}{l}\text { Tends to focus at individual level; concerns } \\
\text { about how to distinguish between social } \\
\text { and material. }\end{array}$ \\
\hline & $\begin{array}{l}\text { Socio-Technical Theory (Mumford } \\
2006 \text { ) }\end{array}$ & $\begin{array}{l}\text { Includes a normative ethics which limits its } \\
\text { utility as a meta-theory. }\end{array}$ \\
\hline & $\begin{array}{l}\text { *Diffusion of Innovations Theory } \\
\text { Applied to IOS Adoption (Robey } \\
\text { et al. 2008) }\end{array}$ & HIENs are IOS; adoption is a challenge \\
\hline & $\begin{array}{l}\text { *Individual Technology acceptance } \\
\text { (Venkatesh et al. 2003) }\end{array}$ & Individual adoption of HIEN is a challenge \\
\hline & $\begin{array}{l}\text { Structuration of Technology } \\
\text { (Orlikowski et al. 1991) }\end{array}$ & $\begin{array}{l}\text { HIEN development seems to exhibit } \\
\text { complex structurational dynamics; but } \\
\text { theory limited in for developing } \\
\text { predictive theory. }\end{array}$ \\
\hline & $\begin{array}{l}\text { Adaptive Structuration Theory } \\
\text { (Desanctis et al. 1994) }\end{array}$ & $\begin{array}{l}\text { A variation on Orlikowski's model; some } \\
\text { concerns about distance from original } \\
\text { theory (Bostrom et al. 2009) }\end{array}$ \\
\hline \multirow{9}{*}{$\begin{array}{l}\text { Organizational } \\
\text { Sciences } \\
\text { (Academy of } \\
\text { Management } \\
\text { 2010; INFORMS } \\
\text { 2010) }\end{array}$} & $\begin{array}{l}\text { Stakeholder Theory (Donaldson et al. } \\
\text { 1995; Harrison et al. 1999; Jones } \\
\text { 1995) }\end{array}$ & $\begin{array}{l}\text { Organization focused; normative focus } \\
\text { (stakeholders ought to be included). }\end{array}$ \\
\hline & $\begin{array}{l}\text { Collaborative Capacity Theory } \\
\text { (Foster-Fishman et al. 2001; } \\
\text { Imperial 2005; Weber et al. 2007) }\end{array}$ & $\begin{array}{l}\text { Only one of several measures of potential } \\
\text { value in assessing HIENs }\end{array}$ \\
\hline & $\begin{array}{l}\text { New Institutional Economics (North } \\
\text { 1986; North 2005) }\end{array}$ & One of several ways of looking at HIENs \\
\hline & Transaction Cost Economics & $\begin{array}{l}\text { One of several ways of looking at HIENs; } \\
\text { assumes rational basis for decision- } \\
\text { making. }\end{array}$ \\
\hline & $\begin{array}{l}\text { Resource Based View of the Firm } \\
\text { (Wernerfelt 1984) }\end{array}$ & One of several ways of looking at HIENs \\
\hline & $\begin{array}{l}\text { Information Processing Theory of the } \\
\text { Firm (Galbraith 1974) }\end{array}$ & One of several ways of looking at HIENs \\
\hline & $\begin{array}{l}\text { Knowledge Based Theory of the } \\
\text { Firm (Nonaka 1994) }\end{array}$ & One of several ways of looking at HIENs \\
\hline & $\begin{array}{l}\text { Systems Theory (Checkland 1999; } \\
\text { Luhmann 1995) }\end{array}$ & $\begin{array}{c}\text { One of several ways of looking at HIENs; } \\
\text { problems with causality (Stacey 2001) }\end{array}$ \\
\hline & $\begin{array}{l}\text { Whole-Network Theory* (Provan et } \\
\text { al. 2007; Raab et al. 2009) }\end{array}$ & $\begin{array}{l}\text { HIENs are whole-networks; whole- } \\
\text { network theory is essentially multi- } \\
\text { theoretic }\end{array}$ \\
\hline \multirow{3}{*}{$\begin{array}{l}\text { Social Theory } \\
\text { (Kivisto 2004; } \\
\text { Lemert 2004) }\end{array}$} & $\begin{array}{l}\text { Network Theory (Borgatti et al. } \\
2003 \text { ) }\end{array}$ & $\begin{array}{l}\text { One of several ways of looking at HIENs; } \\
\text { important paradigm. }\end{array}$ \\
\hline & $\begin{array}{l}\text { Social Capital Theory (Adam et al. } \\
\text { 2003; Burt 2005; Halpern 2005) }\end{array}$ & One of several ways of looking at HIENs; \\
\hline & $\begin{array}{l}\text { Structuration Theory * (Giddens } \\
\text { 1986; Jones et al. 2008) }\end{array}$ & A reasonable model of causality for HIENs \\
\hline $\begin{array}{l}\text { Health Policy and } \\
\text { Health Informatics }\end{array}$ & $\begin{array}{l}\text { HIENs as Infomediaries (De Brantes } \\
\text { et al. 2007) }\end{array}$ & $\begin{array}{l}\text { Non-academic journal; professional focus; } \\
\text { transaction cost economics based } \\
\text { paradigm. }\end{array}$ \\
\hline
\end{tabular}




\section{APPENDIX 4: INSTRUMENTS}

Instrument 1: Participation Opportunity Types

Instrument 1a: Actual Participation Opportunity Types - Non-Standardized

\begin{tabular}{|l|l||l|l|}
\hline Participation Opportunity & Months & Participation Opportunity & Months \\
\hline Site 1 & & Site 4 & \\
\hline & & & \\
\hline & & & \\
\hline & & & \\
\hline & & & \\
\hline & & & \\
\hline & & Site 5 & \\
\hline Site 2 & & & \\
\hline & & & \\
\hline & & & \\
\hline & & & \\
\hline & & & \\
\hline & & & \\
\hline$\underline{\text { Site 3 }}$ & & & \\
\hline & & Site 6 & \\
\hline & & & \\
\hline & & & \\
\hline & & & \\
\hline & & & \\
\hline
\end{tabular}


Instrument 1b. Actual Participation Opportunity Types - Standardized

\begin{tabular}{|l|l|l||l|l|}
\hline $\begin{array}{l}\text { Participation } \\
\text { opportunity }\end{array}$ & Prompt & $\begin{array}{l}\text { Is Intent to } \\
\text { participate } \\
\text { measurable? } \\
\text { If so, how? }\end{array}$ & Prompt & $\begin{array}{l}\text { Is actual } \\
\text { participation } \\
\text { measurable? }\end{array}$ \\
If so, how?
\end{tabular}




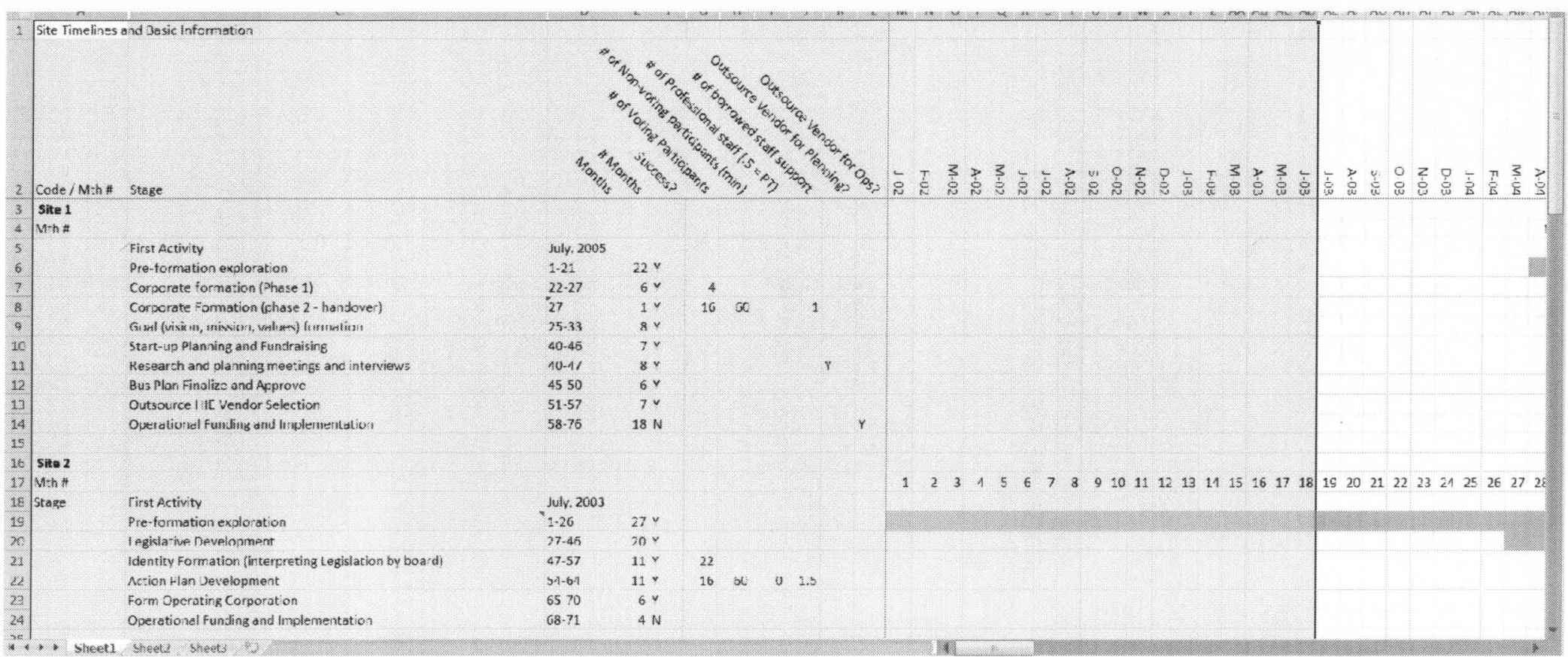




\section{Instrument 2: Subject Profile}

Instrument 2 was developed in Excel. The development was iterative. As questions were refined, additional variables added, or variables defined, the instrument was updated. The example below is the final version used. In some cases, the order and coding of variables may be slightly different from the actual data presented in the summary tables. This example includes actual answers developed for one subject. For each variable, categories were developed and entered in the Code and Description fields. For example, for variable M1, the age selected was 1 (45-54 years old). In general, comment fields were left blank if no information was found. For example, the alternative explanation (AE) field was left blank in this survey because AEs were either not applicable or not identified for this subject. Data generated from each subject profile was rolled up to generate the results presented in Appendix 4. 
Table 21: Instrument 2: Subject Profile

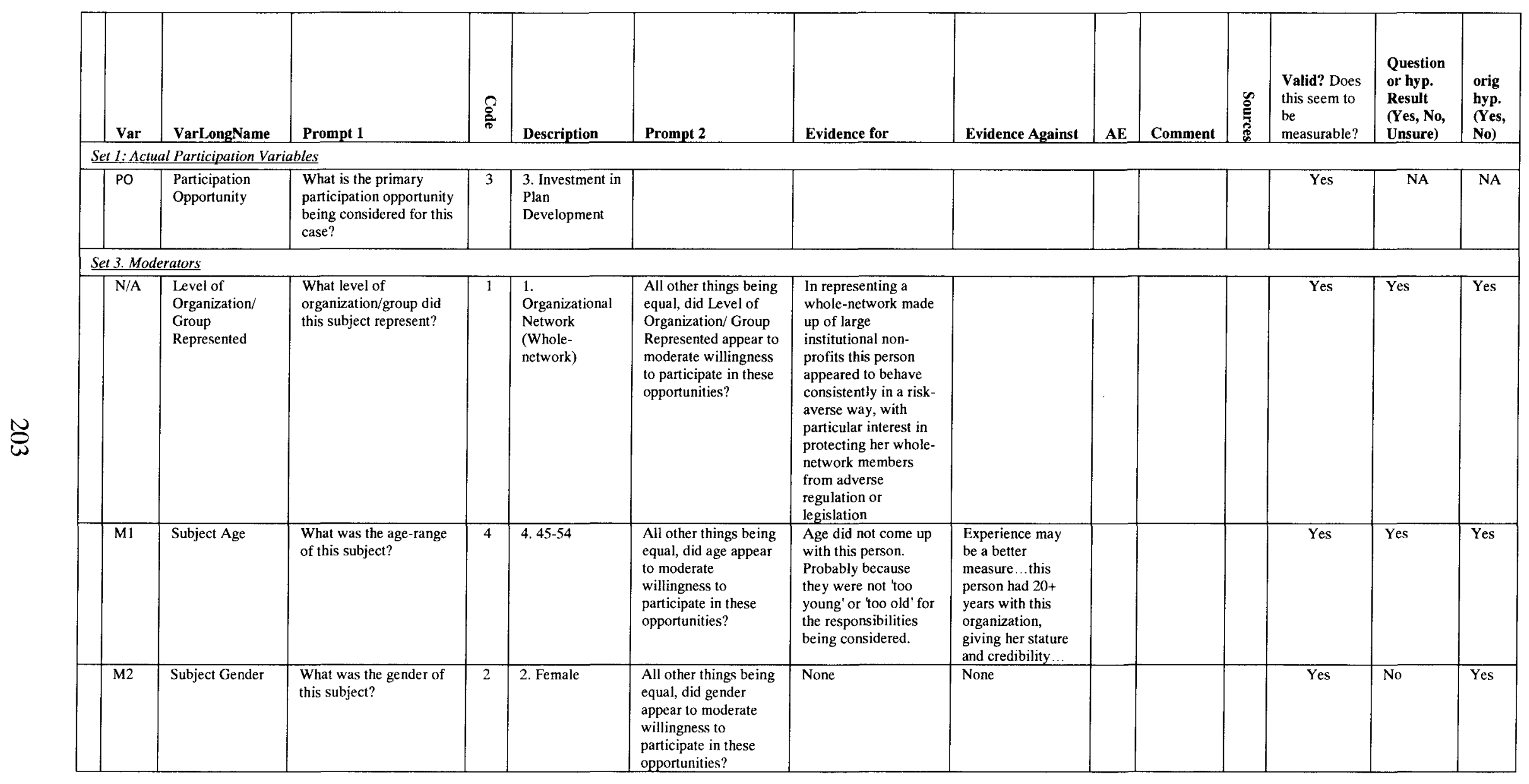




\begin{tabular}{|c|c|c|c|c|c|c|c|c|c|c|c|c|c|}
\hline \multirow{8}{*}{$\stackrel{尺}{\Phi}$} & VarLongName & Prompt 1 & 气ิ & Description & Prompt 2 & Evidence for & Evidence Against & $\mathbf{A E}$ & Comment & $\stackrel{\mathscr{E}}{\mathscr{B}}$ & $\begin{array}{l}\text { Valid? Does } \\
\text { this seem to } \\
\text { be } \\
\text { measurable? }\end{array}$ & $\begin{array}{l}\text { Question } \\
\text { or hyp. } \\
\text { Result } \\
\text { (Yes, No, } \\
\text { Unsure) }\end{array}$ & $\begin{array}{l}\text { orig } \\
\text { hyp. } \\
\text { (Yes, } \\
\text { No) } \\
\end{array}$ \\
\hline & Subject Level & $\begin{array}{l}\text { What was the level in } \\
\text { the organization/group } \\
\text { of this subject? }\end{array}$ & 2 & $\begin{array}{l}\text { 2. } \mathrm{CxO} \text { (CFO, } \\
\mathrm{COO}, \mathrm{CMO} \text {, } \\
\text { etc.) }\end{array}$ & $\begin{array}{l}\text { All other things being } \\
\text { equal, did subject } \\
\text { level appear to } \\
\text { moderate willingness } \\
\text { to participate in these } \\
\text { opportunities? }\end{array}$ & $\begin{array}{l}\text { This level seemed } \\
\text { adequate to support } \\
\text { participation }\end{array}$ & & & & & Yes & Yes & Yes \\
\hline & $\begin{array}{l}\text { Subject DN } \\
\text { Experience }\end{array}$ & $\begin{array}{l}\text { What level of experience } \\
\text { with dual networks and } \\
\text { collaboration did this } \\
\text { subject have? }\end{array}$ & 3 & $\begin{array}{l}\text { 3. Moderate } \\
\text { DN experience }\end{array}$ & $\begin{array}{l}\text { All other things being } \\
\text { equal, did subject } \\
\text { experience with } \\
\text { collaboration and } \\
\text { dual networks appear } \\
\text { to moderate } \\
\text { willingness to } \\
\text { participate in these } \\
\text { opportunities? }\end{array}$ & $\begin{array}{l}\text { Experience in } \\
\text { collaboration allowed } \\
\text { this person to rise to a } \\
\text { leadership position in } \\
\text { the DN; }\end{array}$ & & & & & Yes & Yes & Yes \\
\hline & $\begin{array}{l}\text { Organization } \\
\text { size }\end{array}$ & $\begin{array}{l}\text { What was the size of this } \\
\text { organization/group? }\end{array}$ & 3 & $\begin{array}{l}\text { 3. Medium } \\
\text { (500-4999 } \\
\text { employees) }\end{array}$ & $\begin{array}{l}\text { All other things being } \\
\text { equal, did } \\
\text { organization/group } \\
\text { size appear to } \\
\text { moderate willingness } \\
\text { to participate in these } \\
\text { opportunities? }\end{array}$ & $\begin{array}{l}\text { Larger organization } \\
\text { more risk averse? }\end{array}$ & $\begin{array}{l}\text { More general asset } \\
\text { specificity factors } \\
\text { may better explain } \\
\text { this affect. }\end{array}$ & & & & Yes & Yes & Yes \\
\hline & & & & & & & & & & & & & \\
\hline & $\begin{array}{l}\text { Organization DN } \\
\text { experience }\end{array}$ & $\begin{array}{l}\text { What level of experience } \\
\text { with dual networks and } \\
\text { collaboration did this } \\
\text { organization have? }\end{array}$ & 3 & $\begin{array}{l}\text { 3. Moderate } \\
\text { DN experience }\end{array}$ & $\begin{array}{l}\text { All other things being } \\
\text { equal, did } \\
\text { organization/group } \\
\text { experience with } \\
\text { collaboration and } \\
\text { dual networks appear } \\
\text { to moderate } \\
\text { willingness to } \\
\text { participate in these } \\
\text { opportunities? }\end{array}$ & $\begin{array}{l}\text { Experience in } \\
\text { collaboration allowed } \\
\text { this organization to } \\
\text { provide support for } \\
\text { the leader, in } \\
\text { representing her } \\
\text { organization in the } \\
\text { DN }\end{array}$ & & & & & Yes & Yes & Yes \\
\hline & $\begin{array}{l}\text { Other Individual } \\
\text { Factors }\end{array}$ & $\begin{array}{l}\text { Are additional individual } \\
\text { moderators needed for } \\
\text { the model? If so, what? }\end{array}$ & & & $\begin{array}{l}\text { What effects did they } \\
\text { have? }\end{array}$ & & & & & & & No & $\mathrm{NA}$ \\
\hline & $\begin{array}{l}\text { Other } \\
\text { Organizational } \\
\text { Factors }\end{array}$ & $\begin{array}{l}\text { Are additional } \\
\text { organizational/group } \\
\text { moderators needed for } \\
\text { the model? If so, what? }\end{array}$ & & & $\begin{array}{l}\text { What effects did they } \\
\text { have? }\end{array}$ & & & & & & & No & $\mathrm{NA}$ \\
\hline
\end{tabular}




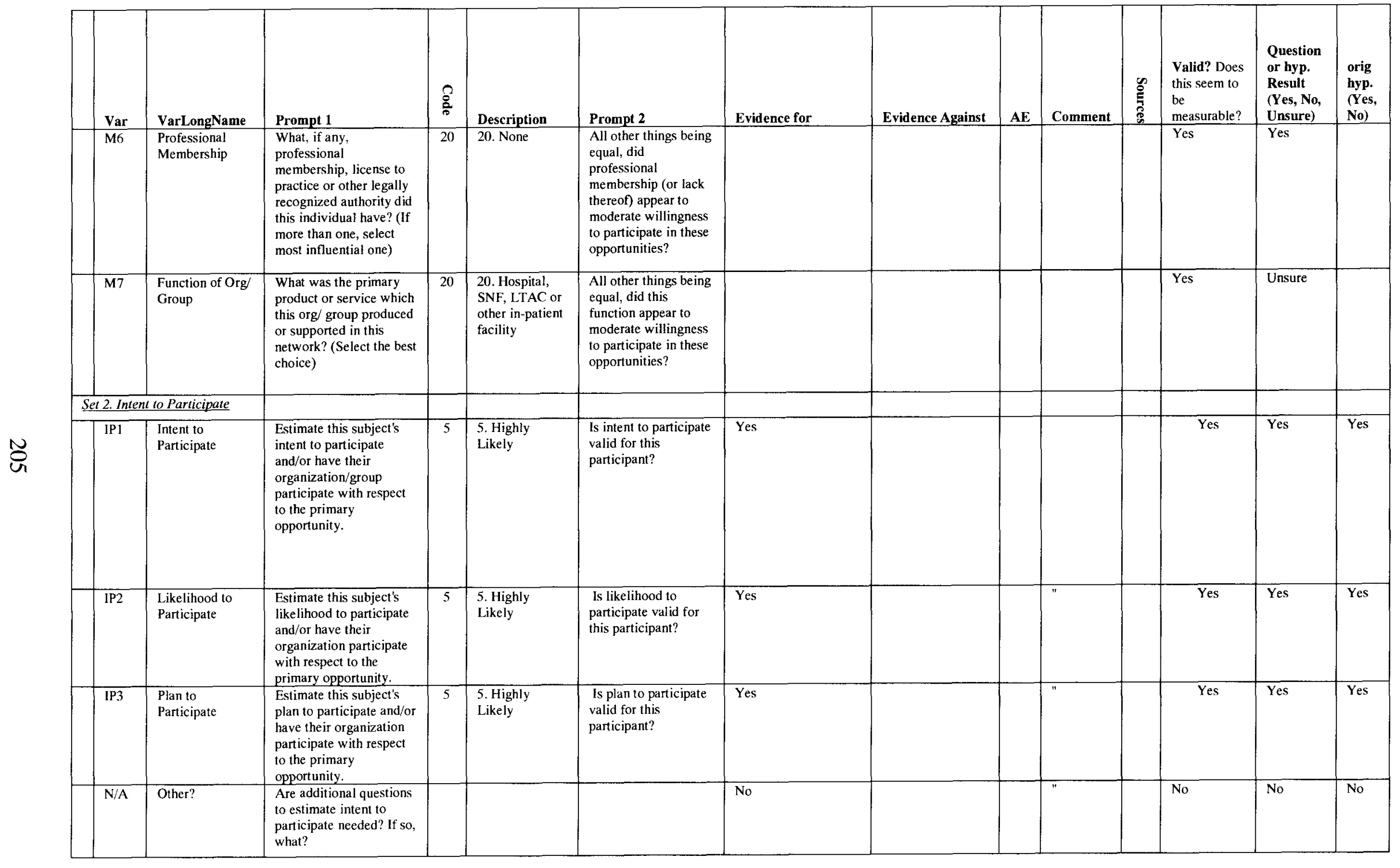




\begin{tabular}{|c|c|c|c|c|c|c|c|c|c|c|c|c|c|}
\hline Var & VarLongName & Prompt 1 & $\frac{2}{2}$ & Description & Prompt 2 & Evidence for & Evidence Against & $\mathbf{A E}$ & Comment & 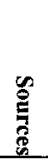 & $\begin{array}{l}\text { Valid? Does } \\
\text { this seem to } \\
\text { be } \\
\text { measurable? }\end{array}$ & $\begin{array}{l}\text { Question } \\
\text { or hyp. } \\
\text { Result } \\
\text { (Yes, No, } \\
\text { Unsure) } \\
\end{array}$ & $\begin{array}{l}\text { orig } \\
\text { hyp. } \\
\text { (Yes, } \\
\text { No) } \\
\end{array}$ \\
\hline \multicolumn{14}{|c|}{ Set 4. Benefit Expectancy } \\
\hline $\mathrm{BE} 1$ & Ability to do Job & $\begin{array}{l}\text { Estimate the potential } \\
\text { for the HIEN to increase } \\
\text { the subject's ability to do } \\
\text { his/her job for the } \\
\text { organization/group s/he } \\
\text { is representing. }\end{array}$ & 3 & $\begin{array}{l}\text { 3. Moderate } \\
\text { potential } \\
\text { increase in } \\
\text { ability to do job }\end{array}$ & $\begin{array}{l}\text { All other things being } \\
\text { equal, does increase } \\
\text { in this rating correlate } \\
\text { positively with intent } \\
\text { to have organization } \\
\text { participate? }\end{array}$ & $\begin{array}{l}\text { This person's 'job is } \\
\text { to support policy and } \\
\text { strategy that benefits } \\
\text { the sector; } \\
\text { participation is useful } \\
\text { to her in her job; her } \\
\text { intent to recommend } \\
\text { that her } \\
\text { organization(s) } \\
\text { participate is } \\
\text { influenced by this } \\
\text { usefulness }\end{array}$ & $\begin{array}{l}\text { This depends on } \\
\text { the type of } \\
\text { participation being } \\
\text { discussed. If it is } \\
\text { participation in } \\
\text { funding; or } \\
\text { participation in } \\
\text { using the HIE } \\
\text { technolology, it is } \\
\text { not applicable. } \\
\text { Her decisions are } \\
\text { based on whether } \\
\text { those org's she } \\
\text { represents feel } \\
\text { this. }\end{array}$ & & & & Yes & Yes & Yes \\
\hline BE2 & Task Completion & $\begin{array}{l}\text { Estimate the potential } \\
\text { for the HIEN to increase } \\
\text { the subject's ability to } \\
\text { complete tasks for the } \\
\text { organization/group s/he } \\
\text { is representing. }\end{array}$ & 3 & $\begin{array}{l}\text { 3. Moderate } \\
\text { potential } \\
\text { increase }\end{array}$ & $\begin{array}{l}\text { All other things being } \\
\text { equal, does increase } \\
\text { in this rating correlate } \\
\text { positively with intent } \\
\text { to have organization } \\
\text { participate? }\end{array}$ & $\begin{array}{l}\text { Yes. Creating } \\
\text { efficiency for her } \\
\text { organization and } \\
\text { members }\end{array}$ & & & & & Yes & Yes & Yes \\
\hline $\mathrm{BE} 3$ & Productivity & $\begin{array}{l}\text { Estimate the potential } \\
\text { for the HIEN to increase } \\
\text { the subject's productivity } \\
\text { when he/she is working } \\
\text { for the } \\
\text { organization/group being } \\
\text { represented. }\end{array}$ & 3 & $\begin{array}{l}\text { 3. Moderate } \\
\text { potential } \\
\text { increase }\end{array}$ & $\begin{array}{l}\text { All other things being } \\
\text { equal, does increase } \\
\text { in this rating correlate } \\
\text { positively with intent } \\
\text { to have organization } \\
\text { participate? }\end{array}$ & & & & & & Yes & Yes & Yes \\
\hline $\mathrm{BE4}$ & $\begin{array}{l}\text { Financial } \\
\text { Performance }\end{array}$ & $\begin{array}{l}\text { Estimate the potential } \\
\text { for the HIEN to improve } \\
\text { the financial } \\
\text { performance of the } \\
\text { organization/group } \\
\text { which this subject } \\
\text { represents. }\end{array}$ & 3 & $\begin{array}{l}\text { 3. Moderate } \\
\text { potential } \\
\text { improvement }\end{array}$ & $\begin{array}{l}\text { All other things being } \\
\text { equal, does increase } \\
\text { in this rating correlate } \\
\text { positively with intent } \\
\text { to have organization } \\
\text { participate? }\end{array}$ & & & & & & Yes & Yes & Yes \\
\hline
\end{tabular}




\begin{tabular}{|c|c|c|c|c|c|c|c|c|c|c|c|c|c|}
\hline Var & VarLongName & Prompt 1 & @ి & Description & Prompt 2 & Evidence for & Evidence Against & $\mathbf{A E}$ & Comment & 里 & $\begin{array}{l}\text { Valid? Does } \\
\text { this seem to } \\
\text { be } \\
\text { measurable? }\end{array}$ & $\begin{array}{l}\text { Question } \\
\text { or hyp. } \\
\text { Result } \\
\text { (Yes, No, } \\
\text { Unsure) }\end{array}$ & $\begin{array}{l}\text { orig } \\
\text { hyp. } \\
\text { (Yes, } \\
\text { No) }\end{array}$ \\
\hline BE5 & $\begin{array}{l}\text { Value of } \\
\text { Decision }\end{array}$ & $\begin{array}{l}\text { Estimate this subject's } \\
\text { belief that his/her } \\
\text { superiors and peers will } \\
\text { see participation as a } \\
\text { positive contribution to } \\
\text { the organization/group } \\
\text { s/he represents. }\end{array}$ & 4 & $\begin{array}{l}\text { 4. High } \\
\text { potential for } \\
\text { being seen as } \\
\text { positive } \\
\text { contribution }\end{array}$ & $\begin{array}{l}\text { All other things being } \\
\text { equal, does increase } \\
\text { in this rating correlate } \\
\text { positively with intent } \\
\text { to have organization } \\
\text { participate? }\end{array}$ & & & & & & Yes & Yes & Yes \\
\hline BE6 & \begin{tabular}{|l} 
Other Value \\
\end{tabular} & $\begin{array}{l}\text { Are additional questions } \\
\text { to estimate benefit } \\
\text { expectancy needed? If } \\
\text { so, what? }\end{array}$ & & & & & & & & & No & No & No \\
\hline \multicolumn{14}{|c|}{ Set 5. Cost Expectancy } \\
\hline CE1 & $\begin{array}{l}\text { Leader Time and } \\
\text { Effort } \\
\text { (Reversed) }\end{array}$ & $\begin{array}{l}\text { Estimate the level of } \\
\text { time and effort that this } \\
\text { subject will require to } \\
\text { participate. }\end{array}$ & 3 & $\begin{array}{l}\text { 3. Moderate } \\
\text { time and effort }\end{array}$ & $\begin{array}{l}\text { All other things being } \\
\text { equal, does increase } \\
\text { in this rating correlate } \\
\text { positively with intent } \\
\text { to have organization } \\
\text { participate? }\end{array}$ & & & & & & Yes & Yes & Yes \\
\hline CE2 & $\begin{array}{l}\text { Organization } \\
\text { Time and Effort } \\
\text { (Reversed) }\end{array}$ & $\begin{array}{l}\text { Estimate the level of } \\
\text { time and effort that will } \\
\text { be required from the } \\
\text { organization/group } \\
\text { which this subject } \\
\text { represents in order for } \\
\text { the organization/group to } \\
\text { participate. }\end{array}$ & 4 & $\begin{array}{l}\text { 4. Low } \\
\text { organizational } \\
\text { time and effort }\end{array}$ & $\begin{array}{l}\text { All other things being } \\
\text { equal, does increase } \\
\text { in this rating correlate } \\
\text { positively with intent } \\
\text { to have organization } \\
\text { participate? }\end{array}$ & & & & & & Yes & Yes & Yes \\
\hline CE3 & $\begin{array}{l}\text { Financial } \\
\text { Commitment } \\
\text { (Reversed) }\end{array}$ & $\begin{array}{l}\text { Estimate the level of } \\
\text { financial commitment } \\
\text { that this subject's } \\
\text { organization/group will } \\
\text { need to make in order to } \\
\text { participate. }\end{array}$ & 4 & $\begin{array}{l}\text { 4. Low } \\
\text { financial } \\
\text { commitment }\end{array}$ & $\begin{array}{l}\text { All other things being } \\
\text { equal, does increase } \\
\text { in this rating correlate } \\
\text { positively with intent } \\
\text { to have organization } \\
\text { participate? }\end{array}$ & & & & & & Yes & Yes & Yes \\
\hline $\mathrm{CE} 4$ & $\begin{array}{l}\text { Subject's Social } \\
\text { Capital Risk } \\
\text { (Reversed) }\end{array}$ & $\begin{array}{l}\text { Estimate the level of } \\
\text { subject's social capital } \\
\text { (personal reputation) that } \\
\text { this subject will be } \\
\text { putting at risk in } \\
\text { participating. }\end{array}$ & 4 & $\begin{array}{l}\text { 4. Low level of } \\
\text { subject's social } \\
\text { capital at risk }\end{array}$ & $\begin{array}{l}\text { All other things being } \\
\text { equal, does increase } \\
\text { in this rating correlate } \\
\text { positively with intent } \\
\text { to have organization } \\
\text { participate? }\end{array}$ & & & & & & Yes & Yes & Yes \\
\hline
\end{tabular}




\begin{tabular}{|c|c|c|c|c|c|c|c|c|c|c|c|c|c|}
\hline Var & VarLongName & Prompt 1 & ڤ్ & Description & Prompt 2 & Evidence for & Evidence Against & $\mathbf{A E}$ & Comment & 点 & $\begin{array}{l}\text { Valid? Does } \\
\text { this seem to } \\
\text { be } \\
\text { measurable? }\end{array}$ & $\begin{array}{l}\text { Question } \\
\text { or hyp. } \\
\text { Result } \\
\text { (Yes, No, } \\
\text { Unsure) } \\
\end{array}$ & $\begin{array}{l}\text { orig } \\
\text { hyp. } \\
\text { (Yes, } \\
\text { No) }\end{array}$ \\
\hline CES & \begin{tabular}{|l|} 
Organization's's \\
Social Capital \\
Risk (Reversed)
\end{tabular} & $\begin{array}{l}\text { Estimate the level of } \\
\text { organizational social } \\
\text { capital (organizational } \\
\text { reputation) that this } \\
\text { subect will be putting at } \\
\text { risk in participating }\end{array}$ & 4 & $\begin{array}{l}\text { 4. Low level of } \\
\text { organization's } \\
\text { social capital at } \\
\text { risk }\end{array}$ & $\begin{array}{l}\text { All other things being } \\
\text { equal, does increase } \\
\text { in this rating correlate } \\
\text { positively with intent } \\
\text { to have organization } \\
\text { participate? }\end{array}$ & & & & & & Yes & Yes & Yes \\
\hline $\mathrm{N} / \mathrm{A}$ & Other? & $\begin{array}{l}\text { Arc additional questions } \\
\text { to estimate cost } \\
\text { expectancy needed? If } \\
\text { so, what? }\end{array}$ & & & & & & & & & No & No & No \\
\hline \multicolumn{14}{|c|}{ Set 6. Social Influence } \\
\hline S11 & $\begin{array}{l}\text { Support by } \\
\text { Influential } \\
\text { People }\end{array}$ & $\begin{array}{l}\text { Estimate this subject's } \\
\text { level of support by } \\
\text { influential people with } \\
\text { respect to participation } \\
\text { in the site }\end{array}$ & 4 & $\begin{array}{l}\text { 4. Influential } \\
\text { people } \\
\text { supportive } \\
\text { about } \\
\text { participation }\end{array}$ & $\begin{array}{l}\text { All other things being } \\
\text { equal, does increase } \\
\text { in this rating correlate } \\
\text { positively with intent } \\
\text { to have organization } \\
\text { participate? }\end{array}$ & & & & & & Yes & Yes & Yes \\
\hline SI2 & $\begin{array}{l}\text { Support by } \\
\text { Important People }\end{array}$ & $\begin{array}{l}\text { Estimate this subject's } \\
\text { level of support by } \\
\text { important people respect } \\
\text { to participation in the } \\
\text { site }\end{array}$ & 4 & $\begin{array}{l}\text { 4. Important } \\
\text { people } \\
\text { supportive } \\
\text { about } \\
\text { participation }\end{array}$ & $\begin{array}{l}\text { All other things being } \\
\text { equal, does increase } \\
\text { in this rating correlate } \\
\text { positively with intent } \\
\text { to have organization } \\
\text { participate? }\end{array}$ & & & & & & Yes & Yes & Yes \\
\hline S13 & $\begin{array}{l}\text { Support by } \\
\text { Superiors }\end{array}$ & $\begin{array}{l}\text { Estimate this subject's } \\
\text { level of support by } \\
\text { superiors respect to } \\
\text { participation in the site }\end{array}$ & 4 & $\begin{array}{l}\text { 4. Superiors } \\
\text { supportive } \\
\text { about } \\
\text { participation }\end{array}$ & $\begin{array}{l}\text { All other things being } \\
\text { equal, does increase } \\
\text { in this rating correlate } \\
\text { positively with intent } \\
\text { to have organization } \\
\text { participate? }\end{array}$ & & & & & & Yes & Yes & Yes \\
\hline $\mathrm{N} / \mathrm{A}$ & Other & $\begin{array}{l}\text { Are additional questions } \\
\text { to estimate social } \\
\text { influence needed? If so, } \\
\text { what? }\end{array}$ & & & & & & & & & No & No & No \\
\hline
\end{tabular}




\begin{tabular}{|c|c|c|c|c|c|c|c|c|c|c|c|c|c|}
\hline Var & VarLongName & Prompt 1 & $\stackrel{2}{\varrho}$ & Description & Prompt 2 & Evidence for & Evidence Against & $\mathbf{A E}$ & Comment & 象 & $\begin{array}{l}\text { Valid? Does } \\
\text { this seem to } \\
\text { be } \\
\text { measurable? }\end{array}$ & $\begin{array}{l}\text { Question } \\
\text { or hyp. } \\
\text { Result } \\
\text { (Yes, No, } \\
\text { Unsure) } \\
\end{array}$ & $\begin{array}{l}\text { orig } \\
\text { hyp. } \\
\text { (Yes, } \\
\text { No) } \\
\end{array}$ \\
\hline FC1 & $\begin{array}{l}\text { Relevant } \\
\text { Resources } \\
\text { Available to } \\
\text { Subject }\end{array}$ & $\begin{array}{l}\text { Estimatet this subject's } \\
\text { perception about the } \\
\text { level or felevant } \\
\text { resources available to } \\
\text { the subject to support the } \\
\text { subject's particippation in } \\
\text { the site. }\end{array}$ & 4 & $\begin{array}{l}\text { 4. High level of } \\
\text { resources } \\
\text { available to } \\
\text { subject }\end{array}$ & $\begin{array}{l}\text { All other things being } \\
\text { equal, does increase } \\
\text { in this rating correlate } \\
\text { positively with intent } \\
\text { to have organization } \\
\text { participate? }\end{array}$ & Drome tor & 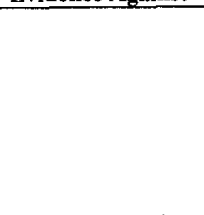 & & & & Yes & Yes & Yes \\
\hline $\mathrm{FC} 2$ & $\begin{array}{l}\text { Relevant } \\
\text { Resources } \\
\text { Available to } \\
\text { Organization }\end{array}$ & $\begin{array}{l}\text { Estimate this subject's } \\
\text { perception about the } \\
\text { level of organizational } \\
\text { resources available to } \\
\text { the organization to } \\
\text { support the } \\
\text { organization's } \\
\text { participation in the site. }\end{array}$ & 4 & $\begin{array}{l}\text { 4. High level of } \\
\text { resources } \\
\text { available to } \\
\text { organization }\end{array}$ & $\begin{array}{l}\text { All other things being } \\
\text { equal, does increase } \\
\text { in this rating correlate } \\
\text { positively with intent } \\
\text { to have organization } \\
\text { participate? }\end{array}$ & & & & & & Yes & Yes & Yes \\
\hline FC3 & $\begin{array}{l}\text { Relevant } \\
\text { Resources } \\
\text { Available to the } \\
\text { Site/HIE }\end{array}$ & $\begin{array}{l}\text { Estimate this subject's } \\
\text { perception about the } \\
\text { level of IIEN resources } \\
\text { which are available to } \\
\text { support participation by } \\
\text { the subject and his/her } \\
\text { organization/group. }\end{array}$ & 4 & $\begin{array}{l}\text { 4. High level of } \\
\text { resources } \\
\text { available to } \\
\text { HIEN }\end{array}$ & $\begin{array}{l}\text { All other things being } \\
\text { equal, does increase } \\
\text { in this rating correlate } \\
\text { positively with intent } \\
\text { to have organization } \\
\text { participate? }\end{array}$ & & & & & & Yes & Yes & Yes \\
\hline $\mathrm{FC4}$ & $\begin{array}{l}\text { Relevant } \\
\text { Knowledge of } \\
\text { Subject }\end{array}$ & $\begin{array}{l}\text { Estimate this subject's } \\
\text { level of knowledge } \\
\text { about the HIE domain }\end{array}$ & 3 & $\begin{array}{l}\text { 3. Subject has } \\
\text { moderate level } \\
\text { of knowledge } \\
\text { needed }\end{array}$ & $\begin{array}{l}\text { All other things being } \\
\text { equal, does increase } \\
\text { in this rating correlate } \\
\text { positively with intent } \\
\text { to have organization } \\
\text { participate? }\end{array}$ & $\begin{array}{l}\text { Analysis paralysis - } \\
\text { too much knowledge } \\
\text { can be a burden, and } \\
\text { slow down decision- } \\
\text { makingin; However, } \\
\text { this didn't seem to } \\
\text { apply to this subject. }\end{array}$ & & & & & Yes & Yes & Yes \\
\hline FC5 & $\begin{array}{l}\text { Relevant } \\
\text { Knowledge of } \\
\text { Organization/ } \\
\text { Group }\end{array}$ & $\begin{array}{l}\text { Estimate this } \\
\text { organization/group's } \\
\text { level of knowledge } \\
\text { about the HIE domain. }\end{array}$ & 3 & $\begin{array}{l}\text { 3. Organization } \\
\text { has moderate } \\
\text { level of } \\
\text { knowledge } \\
\text { needed }\end{array}$ & $\begin{array}{l}\text { All other things being } \\
\text { equal, does increase } \\
\text { in this rating correlate } \\
\text { positively with intent } \\
\text { to have organization } \\
\text { participate? }\end{array}$ & $\begin{array}{l}\text { Analysis paralysis - } \\
\text { too much knowledge } \\
\text { can be a burden and } \\
\text { slow down decision- } \\
\text { making; However, } \\
\text { this didn't seem to } \\
\text { apply to this subject. }\end{array}$ & & & & & Yes & Yes & Yes \\
\hline
\end{tabular}




\begin{tabular}{|c|c|c|c|c|c|c|c|c|c|c|c|c|c|}
\hline Var & VarLongName & Prompt 1 & $\frac{8}{0}$ & Description & Prompt 2 & Evidence for & Evidence Against & $\mathbf{A E}$ & Comment & 号 & $\begin{array}{l}\text { Valid? Does } \\
\text { this seem to } \\
\text { be } \\
\text { measurable? }\end{array}$ & $\begin{array}{l}\text { Question } \\
\text { or hyp. } \\
\text { Result } \\
\text { (Yes, No, } \\
\text { Unsure) }\end{array}$ & $\begin{array}{l}\text { orig } \\
\text { hyp. } \\
\text { (Yes, } \\
\text { No) } \\
\end{array}$ \\
\hline FC6 & $\begin{array}{l}\text { Relevant } \\
\text { Knowledge of } \\
\text { the Site/HIE }\end{array}$ & $\begin{array}{l}\text { Estimate the HIEN's } \\
\text { level of knowledge } \\
\text { about the HIE domain as } \\
\text { it applies to this } \\
\text { organization/group. }\end{array}$ & 3 & $\begin{array}{l}\text { 3. Site/HIE has } \\
\text { moderate level } \\
\text { of knowledge } \\
\text { needed }\end{array}$ & $\begin{array}{l}\text { All other things being } \\
\text { equal, does increase } \\
\text { in this rating correlate } \\
\text { positively with intent } \\
\text { to have organization } \\
\text { participate? }\end{array}$ & $\begin{array}{l}\text { Analysis paralysis- } \\
\text { too much knowledge } \\
\text { can be a burden, and } \\
\text { slow down decision- } \\
\text { making; However, } \\
\text { this didn't seem to } \\
\text { apply to this subject. }\end{array}$ & & & & & Yes & Yes & Yes \\
\hline FC7 & $\begin{array}{l}\text { Relevant } \\
\text { network IT tools } \\
\text { and technologies } \\
\text { Available to } \\
\text { Subject }\end{array}$ & $\begin{array}{l}\text { Estimate the level of } \\
\text { network IT tools and } \\
\text { technologies available to } \\
\text { this subject which this } \\
\text { subject needs in order to } \\
\text { participate. }\end{array}$ & 4 & $\begin{array}{l}\text { 4. Subject has } \\
\text { high level of } \\
\text { network IT } \\
\text { tools and } \\
\text { technologies } \\
\text { needed }\end{array}$ & $\begin{array}{l}\text { All other things being } \\
\text { equal, does increase } \\
\text { in this rating correlate } \\
\text { positively with intent } \\
\text { to have organization } \\
\text { participate? }\end{array}$ & $\begin{array}{l}\text { teleconferencing, } \\
\text { websites access, and } \\
\text { email were essential }\end{array}$ & & & & & Yes & Yes & Yes \\
\hline FC8 & $\begin{array}{l}\text { Relevant } \\
\text { network IT tools } \\
\text { and technologies } \\
\text { Available to } \\
\text { Organization/ } \\
\text { Group }\end{array}$ & $\begin{array}{l}\text { Estimate the level of } \\
\text { network IT tools and } \\
\text { technologies available to } \\
\text { this subject's } \\
\text { organization/group } \\
\text { which this } \\
\text { organization/group } \\
\text { needs in order to } \\
\text { participate. }\end{array}$ & 4 & $\begin{array}{l}\text { 4. Organization } \\
\text { has high level } \\
\text { of network IT } \\
\text { tools and } \\
\text { technologies } \\
\text { needed }\end{array}$ & $\begin{array}{l}\text { All other things being } \\
\text { equal, does increase } \\
\text { in this rating correlate } \\
\text { positively with intent } \\
\text { to have organization } \\
\text { participate? }\end{array}$ & $\begin{array}{l}\text { teleconferencing, } \\
\text { websites access, and } \\
\text { email were essential }\end{array}$ & & & & & Yes & Yes & Yes \\
\hline FC9 & $\begin{array}{l}\text { Relevant } \\
\text { network IT tools } \\
\text { and technologies } \\
\text { Available to } \\
\text { Site/HIE }\end{array}$ & $\begin{array}{l}\text { Estimate the level of } \\
\text { network IT tools and } \\
\text { technologies available to } \\
\text { the HIEN which are } \\
\text { needed to support } \\
\text { participation by this } \\
\text { subject and his/her } \\
\text { organization. }\end{array}$ & 1 & $\begin{array}{l}\text { 1. Site/HIE has } \\
\text { hardly any of } \\
\text { the network IT } \\
\text { tools and } \\
\text { technologies } \\
\text { needed }\end{array}$ & $\begin{array}{l}\text { All other things being } \\
\text { equal, does increase } \\
\text { in this rating correlate } \\
\text { positively with intent } \\
\text { to have organization } \\
\text { participate? }\end{array}$ & $\begin{array}{l}\text { teleconferencing, } \\
\text { websites access, and } \\
\text { email were essential }\end{array}$ & & & & & Yes & Yes & Yes \\
\hline FC10 & $\begin{array}{l}\text { Subject's Staff } \\
\text { Support }\end{array}$ & $\begin{array}{l}\text { Estimate the level of } \\
\text { staff support available to } \\
\text { this subject which this } \\
\text { subject needs to } \\
\text { participate. }\end{array}$ & 4 & $\begin{array}{l}\text { 4. Subject has } \\
\text { high level of } \\
\text { personal staff } \\
\text { support needed }\end{array}$ & $\begin{array}{l}\text { All other things being } \\
\text { equal, does increase } \\
\text { in this rating correlate } \\
\text { positively with intent } \\
\text { to have organization } \\
\text { participate? }\end{array}$ & $\begin{array}{l}\text { This person had a FT } \\
\text { staff support, which } \\
\text { was highly beneficial } \\
\text { in getting stuff done } \\
\text { for the DN }\end{array}$ & & & & & Yes & Yes & Yes \\
\hline
\end{tabular}




\begin{tabular}{|c|c|c|c|c|c|c|c|c|c|c|c|c|c|c|}
\hline \multirow{7}{*}{$\stackrel{N}{\ominus}$} & Var & VarLongName & Prompt 1 & @) & Description & Prompt 2 & Evidence for & Evidence Against & $\mathbf{A E}$ & Comment & 象 & $\begin{array}{l}\text { Valid? Does } \\
\text { this seem to } \\
\text { be } \\
\text { measurable? }\end{array}$ & $\begin{array}{l}\text { Question } \\
\text { or hyp. } \\
\text { Result } \\
\text { (Yes, No, } \\
\text { Unsure) } \\
\end{array}$ & $\begin{array}{l}\text { orig } \\
\text { hyp. } \\
\text { (Yes, } \\
\text { No) }\end{array}$ \\
\hline & $\mathrm{FC11}$ & $\begin{array}{l}\text { Relevant Staff } \\
\text { Support } \\
\text { Available to } \\
\text { Organization/ } \\
\text { Group }\end{array}$ & $\begin{array}{l}\text { Estimate the level of } \\
\text { staff support available to } \\
\text { this organization/group } \\
\text { which is needed in order } \\
\text { for the } \\
\text { organization/group to } \\
\text { participate. }\end{array}$ & 4 & $\begin{array}{l}\text { 4. Organization } \\
\text { has high level } \\
\text { of staff support } \\
\text { needed }\end{array}$ & $\begin{array}{l}\text { All other things being } \\
\text { equal, does increase } \\
\text { in this rating correlate } \\
\text { positively with intent } \\
\text { to have organization } \\
\text { participate? }\end{array}$ & $\begin{array}{l}\text { This person had a FT } \\
\text { staff support, which } \\
\text { was highly beneficial } \\
\text { in getting stuff done } \\
\text { for the DN }\end{array}$ & & & & & Yes & Yes & Yes \\
\hline & FC12 & $\begin{array}{l}\text { Relevant Staff } \\
\text { Support } \\
\text { Available to } \\
\text { Site/HIE }\end{array}$ & $\begin{array}{l}\text { Estimate the level of } \\
\text { staff support available to } \\
\text { this HIEN which is } \\
\text { needed to support } \\
\text { participation by this } \\
\text { subject and his/her } \\
\text { organization/group. }\end{array}$ & 3 & $\begin{array}{l}\text { 3. Dual network } \\
\text { has moderate } \\
\text { level of staff } \\
\text { support needed }\end{array}$ & $\begin{array}{l}\text { All other things being } \\
\text { equal, does increase } \\
\text { in this rating correlate } \\
\text { positively with intent } \\
\text { to have organization } \\
\text { participate? }\end{array}$ & $\begin{array}{l}\text { Some staff support } \\
\text { was provided by the } \\
\text { DN - and was } \\
\text { valuable; more was } \\
\text { needed for } \\
\text { administering this. }\end{array}$ & & & & & Yes & Yes & Yes \\
\hline & FC13 & $\begin{array}{l}\text { Environmental } \\
\text { Stability }\end{array}$ & $\begin{array}{l}\text { Estimate how this } \\
\text { subject would perceive } \\
\text { the level of } \\
\text { environmental stability } \\
\text { as it applies to this } \\
\text { participation } \\
\text { opportunity. }\end{array}$ & 2 & $\begin{array}{l}\text { 2. Unstable } \\
\text { environment }\end{array}$ & $\begin{array}{l}\text { All other things being } \\
\text { equal, does increase } \\
\text { in this rating correlate } \\
\text { positively with intent } \\
\text { to have organization } \\
\text { participate? }\end{array}$ & & & & & & Yes & Yes & Yes \\
\hline & FC14 & $\begin{array}{l}\text { Resource } \\
\text { Munificence }\end{array}$ & $\begin{array}{l}\text { Estimate how this } \\
\text { subject would perceive } \\
\text { the level of 'resource } \\
\text { munificence' (the general } \\
\text { availability of resources } \\
\text { such as money, space, } \\
\text { and equipment) available } \\
\text { to the } \\
\text { organizations/groups } \\
\text { who the HIEN seeks to } \\
\text { serve. }\end{array}$ & 3 & $\begin{array}{l}\text { 3. Moderate } \\
\text { level of } \\
\text { resources } \\
\text { available in the } \\
\text { environment }\end{array}$ & $\begin{array}{l}\text { All other things being } \\
\text { equal, does increase } \\
\text { in this rating correlate } \\
\text { positively with intent } \\
\text { to have organization } \\
\text { participate? }\end{array}$ & $\begin{array}{l}\text { Depends on the type } \\
\text { of resources floating } \\
\text { around... but in } \\
\text { general, yes... for this } \\
\text { person. During times } \\
\text { of increased funding } \\
\text { from the gov't there } \\
\text { was increased interest } \\
\text { in participating... }\end{array}$ & & & & & Yes & yes & Yes \\
\hline & $\mathrm{N} / \mathrm{A}$ & Other? & $\begin{array}{l}\text { Are additional questions } \\
\text { to estimate 'facilitating } \\
\text { conditions' needed? If } \\
\text { so, what? }\end{array}$ & & & & & & & & & No & No & No \\
\hline & $\mathrm{N} / \mathrm{A}$ & & $\begin{array}{l}\text { Is there potential } \\
\text { duplication or overlay of } \\
\text { factors? If so, what? }\end{array}$ & & & & & & & & & Yes & Yes & Yes \\
\hline
\end{tabular}


Instrument 3: Site Profile

Instrument 3 contained a section for each variable in sets 8-9 in the form show below.

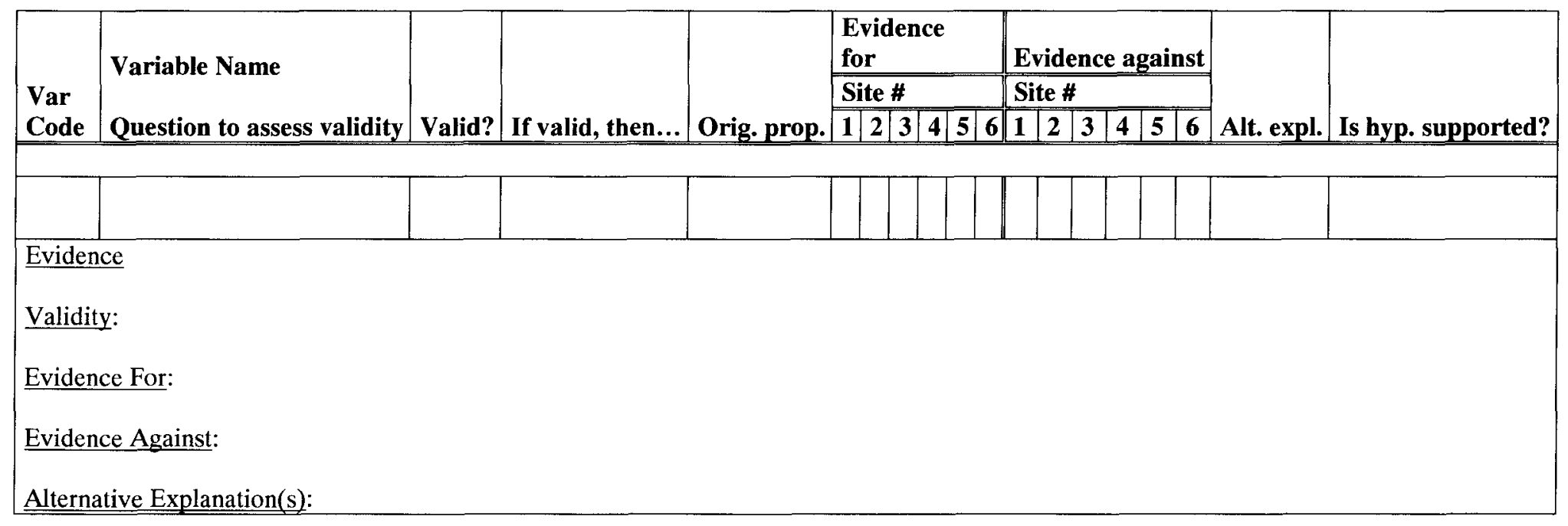




\section{APPENDIX 5: RESULTS TABLES}

Appendix 5 contains tables of results for variable sets 1-9. Tables of data for sets 2-7 are presented in aggregate form as the original data would require about 1100 pages to print, and contains some potentially identifiable information. To protect confidentiality identifiable information including comments about individual subjects are not published in accordance with the approved IRB protocol. 
Table 22: Set 1: Actual Participation Opportunity Types - Non-Standardized, by Site

\begin{tabular}{|c|c|c|c|}
\hline Participation Opportunity & Months & Participation Opportunity & Months \\
\hline \multicolumn{4}{|l|}{ Site 1} \\
\hline Pre-formation exploration & $1-21$ & $\begin{array}{l}\text { Goal formation phase } 1 \text { (HIE } \\
\text { planning and education for state) }\end{array}$ & $17-27$ \\
\hline Corporate formation (phase 1) & $22-27$ & $\begin{array}{l}\text { Business Plan for planning and } \\
\text { education services (refined yearly) }\end{array}$ & $25-59$ \\
\hline Corporate formation (phase 2 - handover) & 27 & Fundraising & $25-59$ \\
\hline Goal formation (vision, mission, values) & $25-33$ & $\begin{array}{l}\text { Participate in educational } \\
\text { events/tradeshows }\end{array}$ & $25-59$ \\
\hline Start-up planning and fundraising & $40-46$ & $\begin{array}{l}\text { Planning phase 2: planning for } \\
\text { growth opportunities (including } \\
\text { providing HIE services) }\end{array}$ & $47-59$ \\
\hline $\begin{array}{l}\text { Research and planning meetings and } \\
\text { interviews }\end{array}$ & $40-47$ & $\begin{array}{l}\text { Lobby state government for } \\
\text { recognition as state designated entity } \\
\text { for HIE }\end{array}$ & $47-59$ \\
\hline $\begin{array}{l}\text { Lobby state government for formal } \\
\text { recognition as 'exclusive' HIE for metro } \\
\text { area. }\end{array}$ & $35-60$ & $\begin{array}{l}\text { Operational funding and } \\
\text { implementation (phase } 2-\text { EMR } \\
\text { education) }\end{array}$ & $55-65$ \\
\hline $\begin{array}{l}\text { Business plan (develop, finalize and } \\
\text { approve) }\end{array}$ & $45-50$ & Site 5 & \\
\hline Outsource HIE vendor selection & $51-57$ & Pre-formation exploration & $1-63$ \\
\hline Operational funding and implementation & $58-76$ & Goal formation (4 organizations) & $11-19$ \\
\hline Site 2 & & Start-up planning, fundraising & 16-19 \\
\hline Pre-formation exploration & $1-26$ & Select planning vendor & $20-25$ \\
\hline Legislative development & $27-46$ & $\begin{array}{l}\text { Participate in research and planning } \\
\text { process }\end{array}$ & $26-60$ \\
\hline $\begin{array}{l}\text { Identity formation (interpreting legislation } \\
\text { by board) }\end{array}$ & $47-57$ & $\begin{array}{l}\text { Business plan Version } 1 \text { (develop, } \\
\text { finalize and approve) }\end{array}$ & $46-54$ \\
\hline Action plan (develop, finalize, approve) & $54-64$ & Outsource HIE vendor selection & $55-64$ \\
\hline $\begin{array}{l}\text { Conduct annual trade-shows and } \\
\text { educational event }\end{array}$ & $56-71$ & Corporation formation & $64-66$ \\
\hline Form operating corporation & $65-70$ & $\begin{array}{l}\text { Business plan Version } 2 \text { (develop, } \\
\text { finalize and approve) }\end{array}$ & $65-75$ \\
\hline Operational funding and implementation & $68-71$ & $\begin{array}{l}\text { Operational funding and } \\
\text { implementation }\end{array}$ & $69-76$ \\
\hline Site 3 & & Site 6 & \\
\hline Pre-formation exploration & $1-4$ & $\begin{array}{l}\text { Pre-formation exploration (each party } \\
\text { contributed staff) }\end{array}$ & $1-10$ \\
\hline Corporation formation & $5-8$ & Corporate formation & 9-11 \\
\hline Goal formation & 6-8 & Goal formation & $10-13$ \\
\hline Select/engage third party administrative org & $6-8$ & Start-up planning and fundraising & $12-15$ \\
\hline Participate in research and planning & $6-8$ & $\begin{array}{l}\text { Business plan (develop, finalize and } \\
\text { approve) }\end{array}$ & $15-17$ \\
\hline $\begin{array}{l}\text { Business plan (develop, finalize and } \\
\text { approve) }\end{array}$ & $9-16$ & $\begin{array}{l}\text { Outsource HIE vendor selection } \\
\text { (from merger partner) }\end{array}$ & $16-20$ \\
\hline Site 4 & & $\begin{array}{l}\text { Operational funding and } \\
\text { implementation }\end{array}$ & $21-$ \\
\hline $\begin{array}{l}\text { Pre-formation exploration (governor gives } \\
\text { executive order for call to action summit } \\
\text { with follow-up) }\end{array}$ & $1-15$ & & \\
\hline $\begin{array}{l}\text { Corporate formation (board and non-profit } \\
\text { form) }\end{array}$ & $15-18$ & & \\
\hline
\end{tabular}


Table 23: Set 1: Actual Participation Opportunity Types - Standardized and Ranked

\begin{tabular}{|c|c|c|c|c|}
\hline $\begin{array}{l}\text { Participation } \\
\text { opportunity }\end{array}$ & Prompt & $\begin{array}{l}\text { Is Intent to } \\
\text { participate } \\
\text { measurable? } \\
\text { If so, how? }\end{array}$ & Prompt & $\begin{array}{l}\text { Is actual } \\
\text { participation } \\
\text { measurable? } \\
\text { If so, how? }\end{array}$ \\
\hline 12. Generate idea & $\begin{array}{l}\text { Were } 1 \text { or more } \\
\text { people involved in } \\
\text { coming up with } \\
\text { ideas? }\end{array}$ & No & & No \\
\hline $\begin{array}{l}\text { 13. Provide } \\
\text { funding to } \\
\text { explore idea }\end{array}$ & $\begin{array}{l}\text { Were one or more } \\
\text { funders invited to } \\
\text { participate in pre- } \\
\text { formation funding? }\end{array}$ & $\begin{array}{l}\text { By network } \\
\text { entrepreneur(s) }\end{array}$ & $\begin{array}{l}\text { Did the subject } \\
\text { provide } \\
\text { funding? }\end{array}$ & $\begin{array}{l}\text { Yes } \\
\text { Based on funding } \\
\text { records }\end{array}$ \\
\hline $\begin{array}{l}\text { 14. Participate in } \\
\text { Meetings to } \\
\text { Explore Idea }\end{array}$ & $\begin{array}{l}\text { Was the subject } \\
\text { invited to participate } \\
\text { in pre-formation } \\
\text { exploration? }\end{array}$ & $\begin{array}{l}\text { By network } \\
\text { entrepreneur(s) }\end{array}$ & $\begin{array}{l}\text { Did the subject } \\
\text { attend } \\
\text { meetings? }\end{array}$ & $\begin{array}{l}\text { Yes } \\
\text { Based on attendance } \\
\text { at meetings }\end{array}$ \\
\hline $\begin{array}{r}\text { 15.Join board/ } \\
\text { committees }\end{array}$ & $\begin{array}{l}\text { Was the subject } \\
\text { invited to participate } \\
\text { as a member of a } \\
\text { board or committee? }\end{array}$ & $\begin{array}{l}\text { Yes } \\
\text { Based on response } \\
\text { to invitations to } \\
\text { attend or renew }\end{array}$ & $\begin{array}{l}\text { Did the subject } \\
\text { attend } \\
\text { meetings? How } \\
\text { did the subject } \\
\text { vote? } \\
\end{array}$ & $\begin{array}{l}\text { Yes } \\
\text { Based on attendance } \\
\text { at meetings and } \\
\text { voting record. }\end{array}$ \\
\hline $\begin{array}{l}\text { 16. Invest in plan } \\
\text { development }\end{array}$ & $\begin{array}{l}\text { Was the subject } \\
\text { invited to invest in } \\
\text { plan development? }\end{array}$ & $\begin{array}{l}\text { Yes } \\
\text { Based on pre- } \\
\text { funding survey }\end{array}$ & & $\begin{array}{l}\text { Yes } \\
\text { Based on actual } \\
\text { investment made }\end{array}$ \\
\hline $\begin{array}{l}\text { 17. Provide } \\
\text { public } \\
\text { comment/ } \\
\text { input }\end{array}$ & $\begin{array}{l}\text { Was the subject } \\
\text { invited to provide } \\
\text { comment as a } \\
\text { potential member of } \\
\text { the network? }\end{array}$ & $\begin{array}{l}\text { Yes } \\
\text { Based on response } \\
\text { to invitations }\end{array}$ & $\begin{array}{l}\text { Did the subject } \\
\text { make comments } \\
\text { or attend } \\
\text { comment } \\
\text { meetings? }\end{array}$ & $\begin{array}{l}\text { Yes } \\
\text { Based on record of } \\
\text { comments or } \\
\text { attendance at } \\
\text { meetings. }\end{array}$ \\
\hline $\begin{array}{l}\text { 18. Invest in } \\
\text { start-up of } \\
\text { operations }\end{array}$ & & $\begin{array}{l}\text { Yes } \\
\text { Based on pre- } \\
\text { funding survey }\end{array}$ & & $\begin{array}{l}\text { Yes } \\
\text { Based on actual } \\
\text { investment made }\end{array}$ \\
\hline 19. Use services & $\begin{array}{l}\text { Was the subject } \\
\text { invited to use } \\
\text { technology services } \\
\text { offered by network? }\end{array}$ & $\begin{array}{l}\text { Yes } \\
\begin{array}{l}\text { Based on records } \\
\text { of invitation }\end{array}\end{array}$ & $\begin{array}{l}\text { Did subject use } \\
\text { technology } \\
\text { services offered } \\
\text { by network? } \\
\end{array}$ & $\begin{array}{l}\text { Yes } \\
\text { Based on actual use } \\
\text { of services }\end{array}$ \\
\hline $\begin{array}{l}\text { 20. Lobby } \\
\text { Government } \\
\text { for Protected } \\
\text { Status } \\
\end{array}$ & $\begin{array}{l}\text { Was the subject } \\
\text { invited to lobby } \\
\text { government for } \\
\text { protected status? }\end{array}$ & \begin{tabular}{|l|} 
Yes \\
$\begin{array}{l}\text { Based on records } \\
\text { of request(s) }\end{array}$ \\
\end{tabular} & $\begin{array}{l}\text { Did subject } \\
\text { lobby for } \\
\text { protected } \\
\text { status? }\end{array}$ & $\begin{array}{l}\text { Yes } \\
\text { Requires reporting } \\
\text { back by subject. }\end{array}$ \\
\hline $\begin{array}{l}\text { 21. Use of } \\
\text { Educational } \\
\text { Services }\end{array}$ & $\begin{array}{l}\text { Was the subject } \\
\text { invited to use } \\
\text { educational services } \\
\text { offered by network? }\end{array}$ & \begin{tabular}{|l|} 
Yes \\
Based on records \\
of invitation
\end{tabular} & $\begin{array}{l}\text { Did subject use } \\
\text { educational } \\
\text { services offered } \\
\text { by network? } \\
\end{array}$ & $\begin{array}{l}\text { Yes } \\
\text { Based on actual use } \\
\text { of services }\end{array}$ \\
\hline $\begin{array}{r}\text { 22. Services } \\
\text { provider }\end{array}$ & $\begin{array}{l}\text { Was the subject } \\
\text { invited to provide } \\
\text { services to the } \\
\text { network? }\end{array}$ & $\begin{array}{l}\text { Yes } \\
\text { Based on records } \\
\text { of invitation }\end{array}$ & $\begin{array}{l}\text { Did subject } \\
\text { actually provide } \\
\text { services to the } \\
\text { network? }\end{array}$ & $\begin{array}{l}\text { Yes } \\
\text { Based on records of } \\
\text { actual provision of } \\
\text { services. }\end{array}$ \\
\hline
\end{tabular}


Table 24: Set 1: Actual Participation Opportunity Types - Validity Test Results

\begin{tabular}{|c|c|c|c|c|c|}
\hline \multicolumn{6}{|l|}{ Variable } \\
\hline $\begin{array}{l}\text { Name } \\
\text { Prompt }\end{array}$ & \multicolumn{2}{|l|}{ Choices Count } & $\mathbf{N}$ & 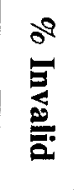 & 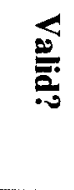 \\
\hline \multicolumn{6}{|l|}{ Participation Opportunities } \\
\hline $\begin{array}{l}\text { Participation Opportunity (Mixture) } \\
\text { What is the participation opportunity being considered for this subject? }\end{array}$ & $\begin{array}{l}\text { 1. Board/Committees } \\
\text { 2. Public Comment/Input } \\
\text { 3. Investment in Plan Development } \\
\text { 4. Investment in Start-up } \\
\text { 5. Use of Technology Services } \\
\text { 6. Use of Educational Services } \\
\text { 7. Services Provider } \\
\text { 8. Lobby Gov't for Protected Status } \\
\text { 98. Data not available } \\
\text { 99. Attribute not valid for this subject }\end{array}$ & $\begin{array}{r}73 \\
7 \\
5 \\
20 \\
0 \\
0 \\
4 \\
0 \\
0 \\
0\end{array}$ & 109 & $0 \%$ & Yes \\
\hline $\begin{array}{l}\text { Participation Opportunity (Greatest Challenge) } \\
\text { What is the participation opportunity being considered for this subject? }\end{array}$ & $\begin{array}{l}\text { 1. Board/Committees } \\
\text { 2. Public Comment/Input } \\
\text { 3. Investment in Plan Development } \\
\text { 4. Investment in Start-up } \\
\text { 5. Use of Technology Services } \\
\text { 6. Use of Educational Services } \\
\text { 7. Services Provider } \\
\text { 8. Lobby Gov't for Protected Status } \\
\text { 98. Data not available } \\
\text { 99. Attribute not valid for this subject }\end{array}$ & $\begin{array}{r}0 \\
0 \\
0 \\
79 \\
0 \\
0 \\
0 \\
21 \\
0 \\
0\end{array}$ & 109 & $0 \%$ & Yes \\
\hline
\end{tabular}


Table 25: Set 2: Intent to Participate Variables - Validity Test Results

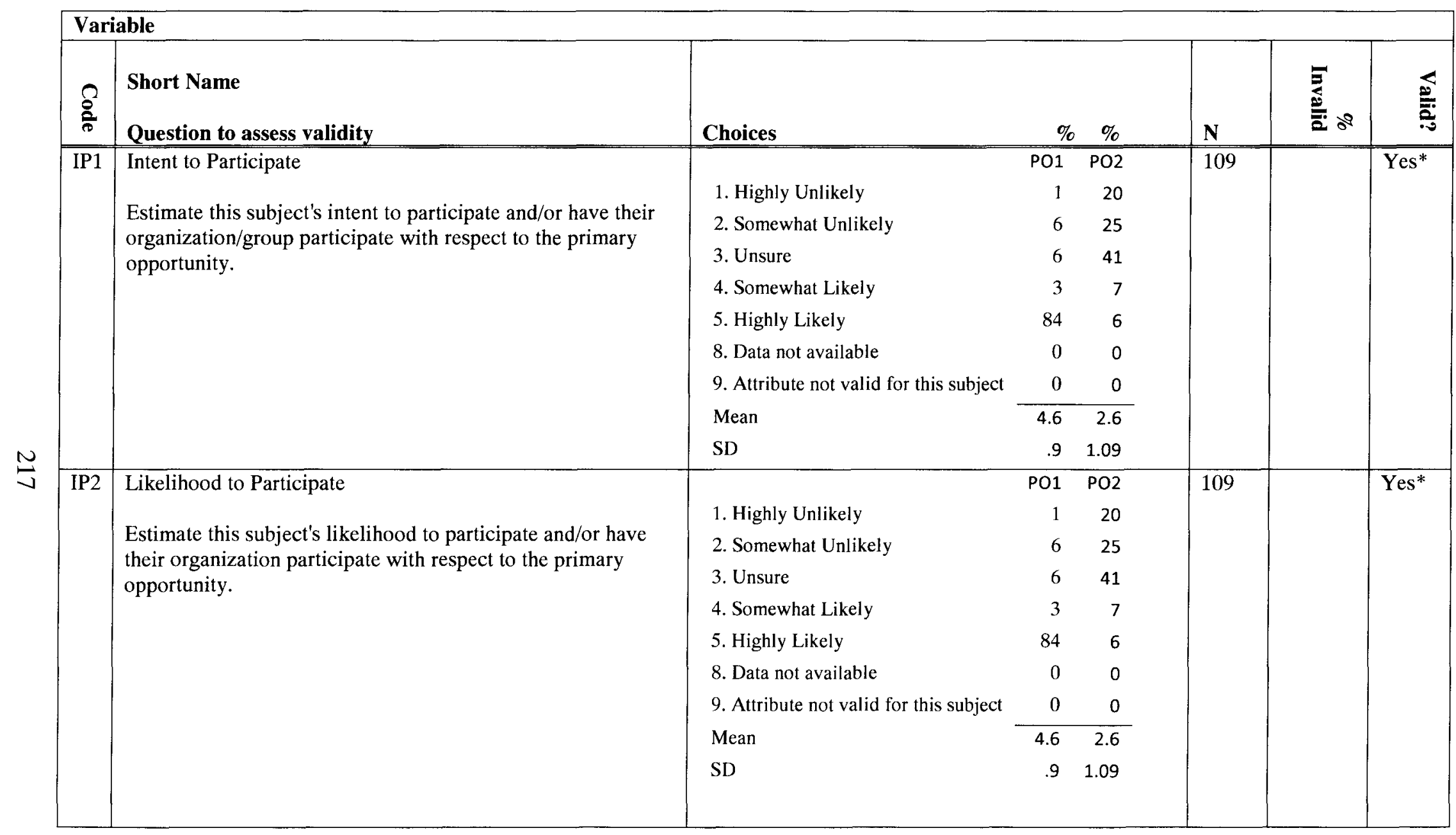




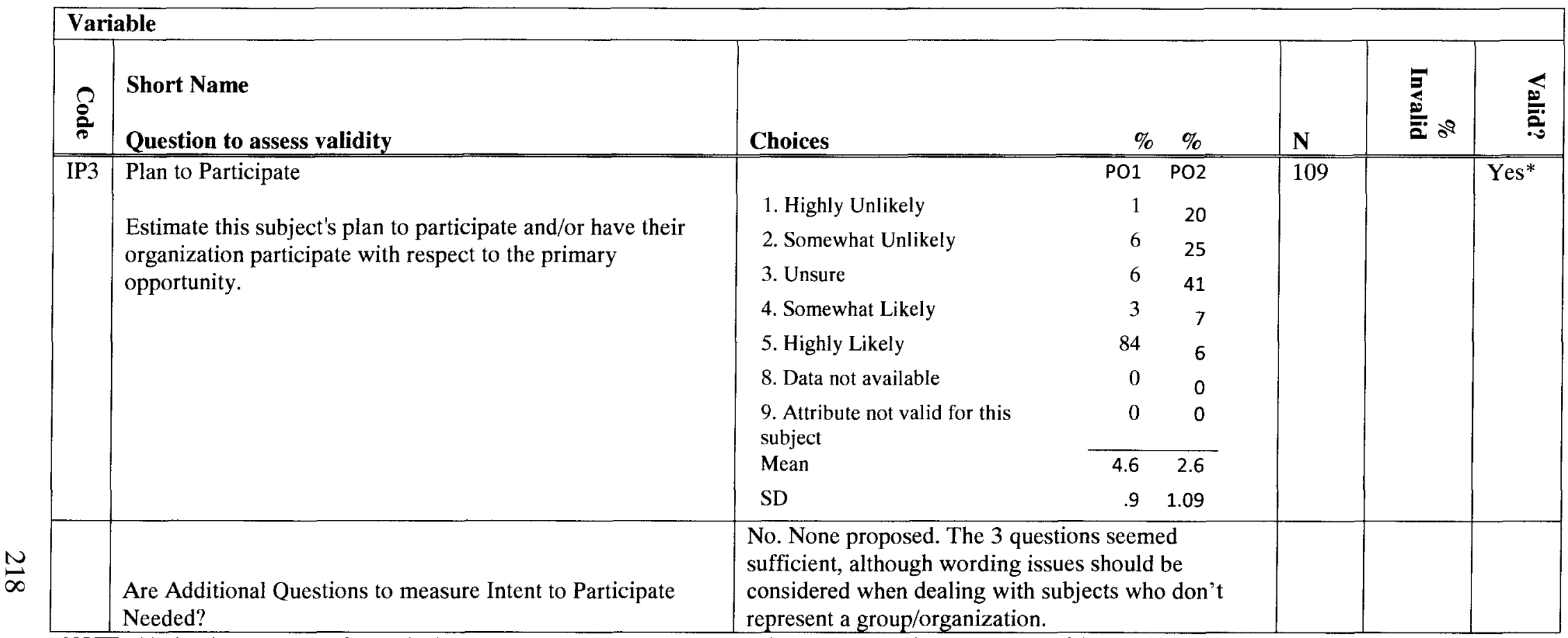

NOTE: this data is a summary of a qualitative assessment done on a case by case base for the 109 individuals and 125 organizations in the study. The assessment was done by completing the Subject Profile instrument for each subject. For each subject, qualitative evidence was considered by two researchers, sitting together, to refine the variable description and coding, and determine variable validity for that subject. In addition, where appropriate, evidence was considered which supported and refuted hypotheses, or provided alternative explanations for the phenomena. The researchers sat together to evaluate evidence for each case, answer the questions noted, and determine whether the hypothesis was supported for that case.

* Means additional research is recommended to further develop/validate this variable.

** Means additional research is recommended to evaluate the evidence supporting, refuting or providing alternative explanations for the hypothesis. 
Table 26: Set 3: Moderator Variables - Test Results for Validity and Effect

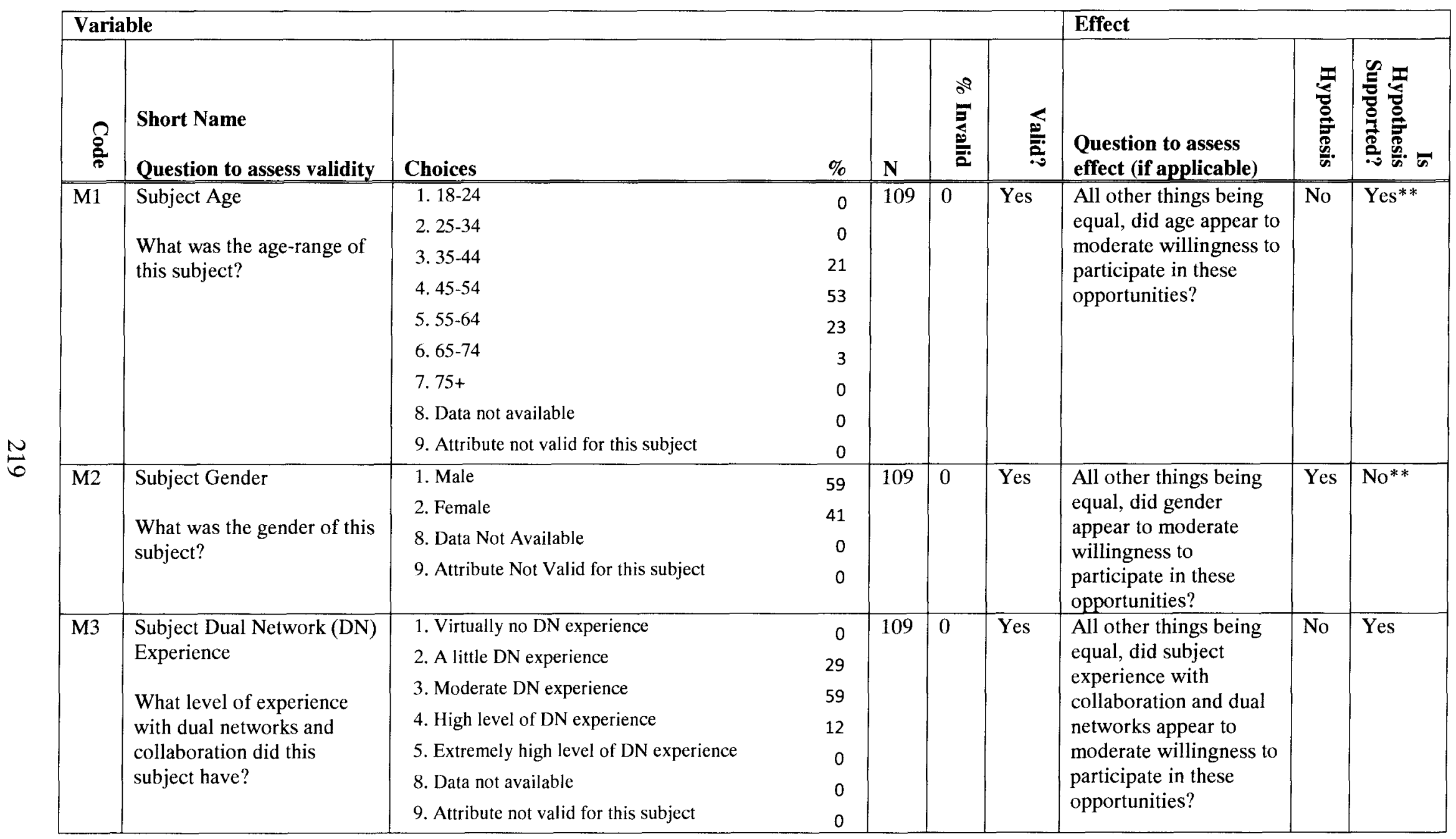




\begin{tabular}{|c|c|c|c|c|c|c|c|c|c|}
\hline \multicolumn{7}{|c|}{ Variable } & \multicolumn{3}{|l|}{ Effect } \\
\hline$\frac{2}{2}$ & $\begin{array}{l}\text { Short Name } \\
\text { Question to assess validity }\end{array}$ & Choices & $\%$ & $\mathbf{N}$ & $\frac{a 9}{3}$ & : & $\begin{array}{l}\text { Question to assess } \\
\text { effect (if applicable) }\end{array}$ & 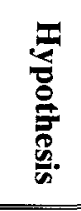 & 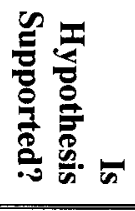 \\
\hline M4 & $\begin{array}{l}\text { Organization size } \\
\text { What was the size of this } \\
\text { organization/group }\end{array}$ & $\begin{array}{l}\text { 1. Small (0-10 Employees) } \\
\text { 2. Somewhat Small (11-499 employees) } \\
\text { 3. Medium (500-4999 employees) } \\
\text { 4. Large ( } 5000-24999 \text { employees) } \\
\text { 5. Very Large ( } 25000+\text { employees) } \\
\text { 8. Data not available } \\
\text { 9. Attribute not valid for this subject }\end{array}$ & $\begin{array}{r}11 \\
24 \\
16 \\
22 \\
24 \\
0 \\
4\end{array}$ & 109 & 4 & $\begin{array}{l}\text { Un } \\
\text { sure* }\end{array}$ & $\begin{array}{l}\text { All other things being } \\
\text { equal, did size appear } \\
\text { to moderate willingness } \\
\text { to participate in these } \\
\text { opportunities (mixed } \\
\text { affects)? }\end{array}$ & Yes & $\begin{array}{l}\text { Un } \\
\text { sure** }\end{array}$ \\
\hline M5 & $\begin{array}{l}\text { Organization/ Group Dual } \\
\text { Network (DN) experience } \\
\\
\text { What level of experience } \\
\text { with dual networks and } \\
\text { collaboration did this } \\
\text { organization/group have? }\end{array}$ & $\begin{array}{l}\text { 1. Virtually no DN experience } \\
\text { 2. A little DN experience } \\
\text { 3. Moderate DN experience } \\
\text { 4. High level of DN experience } \\
\text { 5. Extremely high level of DN experience } \\
\text { 8. Data not available } \\
\text { 9. Attribute not valid for this subject }\end{array}$ & $\begin{array}{r}0 \\
13 \\
72 \\
12 \\
0 \\
0 \\
3\end{array}$ & 109 & 4 & Yes* & $\begin{array}{l}\text { All other things being } \\
\text { equal, did organization/ } \\
\text { group experience with } \\
\text { collaboration and dual } \\
\text { networks appear to } \\
\text { moderate willingness to } \\
\text { participate in these } \\
\text { opportunities (higher } \\
\text { level, higher intent)? }\end{array}$ & Yes & Yes** \\
\hline M6 & $\begin{array}{l}\text { Other Individual } \\
\text { Moderators }\end{array}$ & $\begin{array}{l}\text { Question: Are additional individual moderators } \\
\text { needed for the model? If so, what? } \\
\text { Answer: yes. See below. }\end{array}$ & & & & & & & \\
\hline M6a & $\begin{array}{l}\text { Subject Level } \\
\text { What was the level in the } \\
\text { organization/group of this } \\
\text { subject? }\end{array}$ & $\begin{array}{l}\text { A. Member, Board of Directors } \\
\text { B. Committee Member, Board of Directors } \\
\text { C. Chair, Board of Directors } \\
\text { D. Member (Dues Paying) } \\
\text { E. Elected Official (Legislator) } \\
\text { 1. President/CEO/Executive Director }\end{array}$ & $\begin{array}{r}4 \\
0 \\
3 \\
6 \\
4 \\
22\end{array}$ & 109 & 0 & Yes & $\begin{array}{l}\text { All other things being } \\
\text { equal, did subject level } \\
\text { appear to moderate } \\
\text { willingness to } \\
\text { participate in these } \\
\text { opportunities (higher } \\
\text { level, higher intent) }\end{array}$ & Yes & $\mathrm{No}^{* *}$ \\
\hline
\end{tabular}




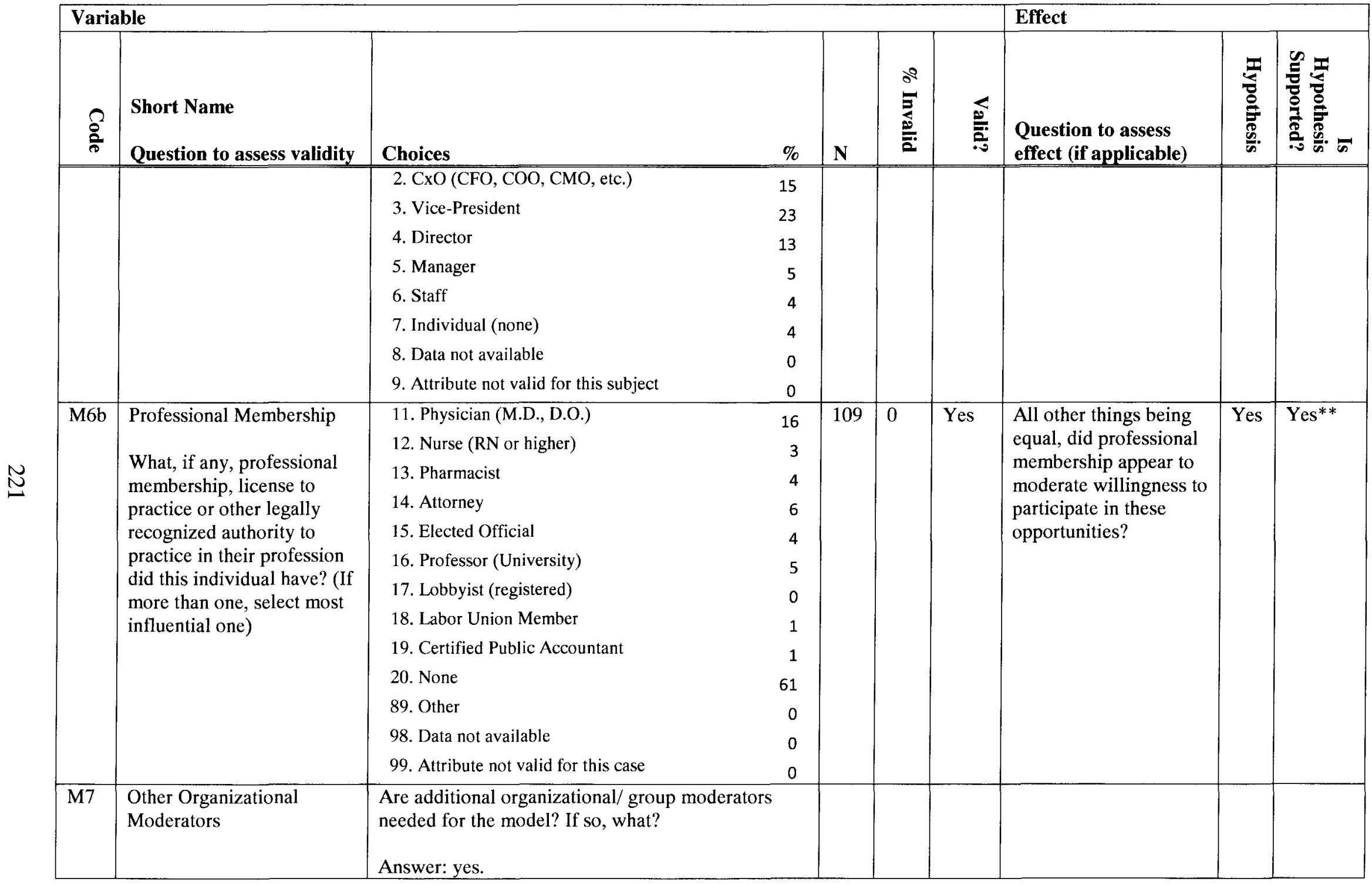




\begin{tabular}{|c|c|c|c|c|c|c|c|c|c|}
\hline \multicolumn{7}{|c|}{ Variable } & \multicolumn{3}{|l|}{ Effect } \\
\hline 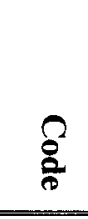 & $\begin{array}{l}\text { Short Name } \\
\text { Question to assess validity }\end{array}$ & Choices & $\%$ & $\mathbf{N}$ & 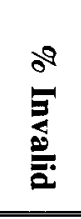 & : & $\begin{array}{l}\text { Question to assess } \\
\text { effect (if applicable) }\end{array}$ & 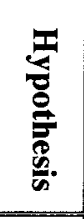 & 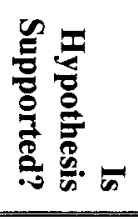 \\
\hline M7a & $\begin{array}{l}\text { Organizational } \\
\text { Level } \\
\text { At what level in the } \\
\text { network did this } \\
\text { organization/group } \\
\text { operate? }\end{array}$ & $\begin{array}{l}\text { 1. Mixed Network (Other) } \\
\text { 2.Mixed Network (Policy Network, represented } \\
\text { by a leader of the network) } \\
\text { 3. Mixed Network (Legislative Network, } \\
\text { represented by an elected official) } \\
\text { 4. Organizational Network (Whole-network) } \\
\text { 5. Organization } \\
\text { 6. Professional Network (Network of Licensed } \\
\text { or Specialized Professionals) } \\
\text { 7. Professional } \\
\text { 8. Individual Network (network of individuals) } \\
\text { 9. Individual } \\
\text { 98. Data not available } \\
\text { 99. Attribute not valid for this subject }\end{array}$ & $\begin{array}{r}3 \\
4 \\
14 \\
64 \\
8 \\
0 \\
1 \\
4 \\
0 \\
0\end{array}$ & 109 & $\overline{0}$ & Yes* & $\begin{array}{l}\text { All other things being } \\
\text { equal, did level of } \\
\text { organization/group } \\
\text { represented appear to } \\
\text { moderate willingness to } \\
\text { participate in these } \\
\text { opportunities? }\end{array}$ & Yes & Yes** \\
\hline
\end{tabular}




\begin{tabular}{|c|c|c|c|c|c|c|c|c|c|}
\hline \multicolumn{7}{|c|}{ Variable } & \multicolumn{3}{|l|}{ Effect } \\
\hline$\frac{2}{8}$ & $\begin{array}{l}\text { Short Name } \\
\text { Question to assess validity }\end{array}$ & Choices & $\%$ & $\mathbf{N}$ & 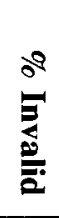 & 悉 & $\begin{array}{l}\text { Question to assess } \\
\text { effect (if applicable) }\end{array}$ & 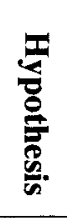 & 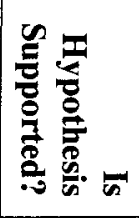 \\
\hline & & $\begin{array}{l}\text { 21. Pharmacy, medical supply store, or other } \\
\text { healthcare retailer } \\
\text { 22. Public health department or group } \\
\text { 23. Physician Office, DO, or out-patient fac. } \\
\text { 24. Nursing, or Allied Health Professional/ } \\
\text { facility } \\
\text { 25. HIE vendor (Consulting / Business Services) } \\
\text { 26. Healthcare Industry Advocacy/Network } \\
\text { 27. Government Oversight/Reg./Support } \\
\text { 28. Other } 1 \\
\text { 29. Other } 2 \\
\text { 98. Data not available } \\
\text { 99. Attribute not valid for this case }\end{array}$ & $\begin{array}{r}1 \\
4 \\
3 \\
16 \\
1 \\
0 \\
0 \\
4\end{array}$ & & & & & & \\
\hline
\end{tabular}

administrator; SNF, skilled nursing facility; LTAC, long term acute care; DO, doctor of osteopathy.

NOTE: this data is a summary of a qualitative assessment done on a case by case base for the 109 individuals and 125 organizations in the study. The assessment was done by completing the Subject Profile instrument for each subject. For each subject, qualitative evidence was considered by two researchers, sitting together, to refine the variable description and coding, and determine variable validity for that subject. In addition, where appropriate, evidence was considered which supported and refuted hypotheses, or provided alternative explanations for the phenomena. The researchers sat together to evaluate evidence for each case, answer the questions noted, and determine whether the hypothesis was supported for that case.

* Means additional research is recommended to further develop/validate this variable.

** Means additional research is recommended to evaluate the evidence supporting, refuting or providing alternative explanations for the hypothesis. 
Table 27: Set 4: Benefit Expectancy - Test Results for Validity and Effect

\begin{tabular}{|c|c|c|c|c|c|c|c|c|c|c|}
\hline \multicolumn{8}{|c|}{ Variable } & \multicolumn{3}{|l|}{ Effect } \\
\hline BE1 & $\begin{array}{l}\text { Ability to do Job } \\
\text { Estimate the potential for } \\
\text { the HIEN to increase the } \\
\text { subject's ability to do } \\
\text { his/her job for the } \\
\text { organization/group s/he is } \\
\text { representing }\end{array}$ & $\begin{array}{l}\text { 1. No potential increase in ability to do job } \\
\text { 2. Low potential increase in ability to do job } \\
\text { 3. Moderate potential increase in ability to do } \\
\text { job } \\
\text { 4. High potential increase in ability to do job } \\
\text { 5. Extremely high potential increase in ability to } \\
\text { do job } \\
\text { 8. Data not available } \\
\text { 9. Attribute not valid for this subject } \\
\text { Mean } \\
\text { SD }\end{array}$ & $\begin{array}{r}1 \\
101 \\
30 \\
46 \\
12 \\
0 \\
\\
0 \\
11 \\
2.7 \\
.69\end{array}$ & $\begin{array}{r}\mathrm{PO} 2 \\
4 \\
52 \\
30 \\
3 \\
0 \\
\\
0 \\
11 \\
2.4 \\
.62\end{array}$ & 109 & $1 / 11 / 11$ & Yes* & $\begin{array}{l}\text { All other things } \\
\text { being equal, does } \\
\text { increase in this } \\
\text { rating correlate } \\
\text { positively with intent } \\
\text { to participate? }\end{array}$ & Yes & Yes** \\
\hline BE2 & $\begin{array}{l}\text { Task Completion } \\
\text { Estimate the potential for } \\
\text { the HIEN to increase the } \\
\text { subject's ability to } \\
\text { complete tasks for the } \\
\text { organization/group s/he is } \\
\text { representing }\end{array}$ & $\begin{array}{l}\text { 1. No potential increase } \\
\text { 2. Low potential increase } \\
\text { 3. Moderate potential increase } \\
\text { 4. High potential increase } \\
\text { 5. Extremely high potential increase } \\
\text { 8. Data not available } \\
\text { 9. Attribute not valid for this subject } \\
\text { Mean } \\
\text { SD }\end{array}$ & $\begin{array}{r}\mathrm{PO1} \\
1 \\
30 \\
51 \\
6 \\
0 \\
0 \\
11 \\
2.7 \\
.61\end{array}$ & $\begin{array}{r}\mathrm{PO2} \\
3 \\
54 \\
31 \\
1 \\
0 \\
0 \\
11 \\
2.3 \\
.56\end{array}$ & 109 & 11 & Yes* & $\begin{array}{l}\text { All other things } \\
\text { being equal, does } \\
\text { increase in this } \\
\text { rating correlate } \\
\text { positively with intent } \\
\text { to participate? }\end{array}$ & Yes & Yes** \\
\hline
\end{tabular}




\begin{tabular}{|c|c|c|c|c|c|c|c|c|c|c|}
\hline \multicolumn{8}{|c|}{ Variable } & \multicolumn{3}{|l|}{ Effect } \\
\hline BE3 & $\begin{array}{l}\text { Productivity } \\
\text { Estimate the potential for } \\
\text { the HIEN to increase the } \\
\text { subject's productivity when } \\
\text { he/she is working for the } \\
\text { organization/group being } \\
\text { represented }\end{array}$ & $\begin{array}{l}\text { 1. No potential increase } \\
\text { 2. Low potential increase } \\
\text { 3. Moderate potential increase } \\
\text { 4. High potential increase } \\
\text { 5. Extremely high potential increase } \\
\text { 8. Data not available } \\
\text { 9. Attribute not valid for this subject } \\
\text { Mean } \\
\text { SD }\end{array}$ & $\begin{array}{r}\text { PO1 } \\
4 \\
28 \\
55 \\
3 \\
0 \\
0 \\
11 \\
2.6 \\
.62\end{array}$ & $\begin{array}{r}\mathrm{PO2} \\
5 \\
55 \\
28 \\
1 \\
0 \\
0 \\
11 \\
2.3 \\
.58\end{array}$ & 109 & 11 & Yes* & $\begin{array}{l}\text { All other things } \\
\text { being equal, does } \\
\text { increase in this } \\
\text { rating correlate } \\
\text { positively with intent } \\
\text { to participate? }\end{array}$ & Yes & Yes** \\
\hline BE5 & $\begin{array}{l}\text { Value of Decision } \\
\text { Estimate this subject's } \\
\text { belief that his/her superiors }\end{array}$ & $\begin{array}{l}\text { 1. No potential value } \\
\text { 2. Low potential value }\end{array}$ & $\begin{array}{r}\mathrm{PO} 1 \\
0 \\
8\end{array}$ & $\begin{array}{r}\mathrm{PO} 2 \\
0 \\
39\end{array}$ & 109 & 6 & Yes & $\begin{array}{l}\text { All other things } \\
\text { being equal, does } \\
\text { increase in this } \\
\text { rating correlate } \\
\end{array}$ & Yes & Yes** \\
\hline
\end{tabular}




\begin{tabular}{|c|c|c|c|c|c|c|c|c|c|c|}
\hline \multicolumn{8}{|c|}{ Variable } & \multicolumn{3}{|l|}{ Effect } \\
\hline & $\begin{array}{l}\text { and peers will see } \\
\text { participation as a positive } \\
\text { contribution to the } \\
\text { organization/group s/he } \\
\text { represents }\end{array}$ & $\begin{array}{l}\text { 3. Moderate potential value } \\
\text { 4. High potential value } \\
\text { 5. Extremely high potential value } \\
\text { 8. Data not available } \\
\text { 9. Attribute not valid for this subject } \\
\text { Mean } \\
\text { SD }\end{array}$ & $\begin{array}{r}35 \\
51 \\
0 \\
0 \\
6 \\
3.5 \\
.65\end{array}$ & $\begin{array}{r}42 \\
14 \\
0 \\
0 \\
6 \\
2.7 \\
.70\end{array}$ & & & & $\begin{array}{l}\text { positively with intent } \\
\text { to participate? }\end{array}$ & & \\
\hline BE6 & $\begin{array}{l}\text { Other Value } \\
\text { Are additional questions to } \\
\text { estimate benefit } \\
\text { expectancy needed? } \\
\text { If so, what? }\end{array}$ & No. None proposed. & & & & & & & & \\
\hline
\end{tabular}

NOTE: this data is a summary of a qualitative assessment done on a case by case base for the 109 individuals and 125 organizations in the study. The assessment was done by completing the Subject Profile instrument for each subject. For each subject, qualitative evidence was considered by two researchers, sitting together, to refine the variable description and coding, and determine variable validity for that subject. In addition, where appropriate, evidence was considered which supported and refuted hypotheses, or provided alternative explanations for the phenomena. The researchers sat together to evaluate evidence for each case, answer the questions noted, and determine whether the hypothesis was supported for that case.

* Means additional research is recommended to further develop/validate this variable.

** Means additional research is recommended to evaluate the evidence supporting, refuting or providing alternative explanations for the hypothesis. 
Table 28: Set 5: Cost Expectancy - Test Results for Validity and Effect

\begin{tabular}{|c|c|c|c|c|c|c|c|c|c|c|}
\hline \multicolumn{8}{|c|}{ Variable } & \multicolumn{3}{|l|}{ Effect } \\
\hline$\hat{\varrho}$ & $\begin{array}{l}\text { Short Name } \\
\text { Question to assess } \\
\text { validity }\end{array}$ & Choices & $\%$ & $\%$ & $\mathbf{N}$ & 递 & 产 & $\begin{array}{l}\text { Question to assess } \\
\text { effect (if } \\
\text { applicable) }\end{array}$ & 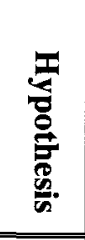 & 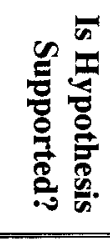 \\
\hline CE1 & $\begin{array}{l}\text { Subject Time and Effort } \\
\text { (Reversed) } \\
\text { Estimate the level of time } \\
\text { and effort that this } \\
\text { subject will require to } \\
\text { participate }\end{array}$ & $\begin{array}{l}\text { 1. Extremely high time and effort } \\
\text { 2. High time and effort } \\
\text { 3. Moderate time and effort } \\
\text { 4. Low time and effort } \\
\text { 5. No time and effort } \\
\text { 8. Data not available } \\
\text { 9. Attribute not valid for this subject } \\
\text { Mean } \\
\text { SD }\end{array}$ & $\begin{array}{r}P 01 \\
0 \\
7 \\
45 \\
48 \\
0 \\
0 \\
0 \\
3.4 \\
.63\end{array}$ & $\begin{array}{r}P O 2 \\
0 \\
7 \\
70 \\
23 \\
0 \\
0 \\
0 \\
3.2 \\
.53\end{array}$ & 109 & 0 & Yes & $\begin{array}{l}\text { All other things } \\
\text { being equal, does } \\
\text { increase in this } \\
\text { rating correlate } \\
\text { positively with } \\
\text { intent to } \\
\text { participate? }\end{array}$ & Yes & Yes \\
\hline CE2 & $\begin{array}{l}\text { Organization/Group Time } \\
\text { and Effort (Reversed) } \\
\text { Estimate the level of time } \\
\text { and effort that will be } \\
\text { required from the } \\
\text { organization/group which } \\
\text { this subject represents in } \\
\text { order for the } \\
\text { organization/group to } \\
\text { participate }\end{array}$ & $\begin{array}{l}\text { 1. Extremely high time and effort } \\
\text { 2. High time and effort } \\
\text { 3. Moderate time and effort } \\
\text { 4. Low time and effort } \\
\text { 5. No time and effort } \\
\text { 8. Data not available } \\
\text { 9. Attribute not valid for this subject } \\
\text { Mean } \\
\text { SD }\end{array}$ & $\begin{array}{r}\mathrm{PO} \\
0 \\
0 \\
47 \\
49 \\
1 \\
0 \\
4 \\
3.5 \\
.52\end{array}$ & $\begin{array}{r}\mathrm{PO} 2 \\
0 \\
4 \\
73 \\
17 \\
0 \\
0 \\
6 \\
3.2 \\
.45\end{array}$ & 109 & 4 & Yes & $\begin{array}{l}\text { All other things } \\
\text { being equal, does } \\
\text { increase in this } \\
\text { rating correlate } \\
\text { positively with } \\
\text { intent to } \\
\text { participate? }\end{array}$ & Yes & Yes \\
\hline
\end{tabular}




\begin{tabular}{|c|c|c|c|c|c|c|c|c|c|c|}
\hline \multicolumn{8}{|c|}{ Variable } & \multicolumn{3}{|l|}{ Effect } \\
\hline 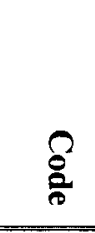 & $\begin{array}{l}\text { Short Name } \\
\text { Question to assess } \\
\text { validity }\end{array}$ & Choices & $\%$ & $\%$ & $\mathbf{N}$ & 胥 & 产 & $\begin{array}{l}\text { Question to assess } \\
\text { effect (if } \\
\text { applicable) } \\
\end{array}$ & 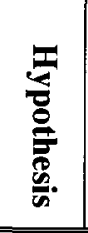 & 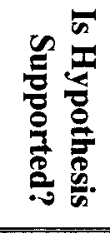 \\
\hline CE3 & $\begin{array}{l}\text { Financial Commitment } \\
\text { (Reversed) } \\
\text { Estimate the level of } \\
\text { financial commitment } \\
\text { that this subject's } \\
\text { organization/group will } \\
\text { need to make in order to } \\
\text { participate }\end{array}$ & $\begin{array}{l}\text { 1. Extremely high financial commitment } \\
\text { 2. High financial commitment } \\
\text { 3. Moderate financial commitment } \\
\text { 4. Low financial commitment } \\
\text { 5. No financial commitment } \\
\text { 8. Data not available } \\
\text { 9. Attribute not valid for this subject } \\
\text { SD } \\
\text { Mean }\end{array}$ & $\begin{array}{r}01 \\
0 \\
0 \\
35 \\
45 \\
17 \\
0 \\
4 \\
3.8 \\
.71\end{array}$ & $\begin{array}{r}\mathrm{PO2} \\
0 \\
25 \\
57 \\
13 \\
0 \\
0 \\
6 \\
2.9 \\
.62\end{array}$ & 109 & 4 & Yes & $\begin{array}{l}\text { All other things } \\
\text { being equal, does } \\
\text { increase in this } \\
\text { rating correlate } \\
\text { positively with } \\
\text { intent to } \\
\text { participate? }\end{array}$ & Yes & Yes \\
\hline CE5 & $\begin{array}{l}\text { Organization/Group } \\
\text { Social Capital Risk } \\
\text { (Reversed) }\end{array}$ & $\begin{array}{l}\text { 1. Extremely high level of risk } \\
\text { 2. High level of risk }\end{array}$ & $\begin{array}{r}\mathrm{PO1} \\
0 \\
1 \\
\end{array}$ & $\begin{array}{r}\mathrm{PO2} \\
0 \\
3\end{array}$ & 109 & 6 & Yes* & $\begin{array}{l}\text { All other things } \\
\text { being equal, does } \\
\text { increase in this } \\
\text { rating correlate }\end{array}$ & Yes & Yes \\
\hline
\end{tabular}




\begin{tabular}{|c|c|c|c|c|c|c|c|c|c|c|}
\hline \multicolumn{8}{|c|}{ Variable } & \multicolumn{3}{|l|}{ Effect } \\
\hline \multirow[t]{2}{*}{$\stackrel{8}{8}$} & $\begin{array}{l}\text { Short Name } \\
\text { Question to assess } \\
\text { validity }\end{array}$ & Choices & $\%$ & $\%$ & $\mathbf{N}$ & $\frac{\partial^{9}}{3}$ & 产. & $\begin{array}{l}\text { Question to assess } \\
\text { effect (if } \\
\text { applicable) }\end{array}$ & 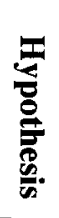 & 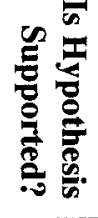 \\
\hline & $\begin{array}{l}\text { Estimate the level of } \\
\text { organization/group } \\
\text { reputation that this } \\
\text { subject will be putting at } \\
\text { risk in participating }\end{array}$ & $\begin{array}{l}\text { 3. Moderate level of risk } \\
\text { 4. Low level of risk } \\
\text { 5. Virtually no risk } \\
\text { 8. Data not available } \\
\text { 9. Attribute not valid for this subject } \\
\text { Mean } \\
\text { SD }\end{array}$ & $\begin{array}{r}33 \\
36 \\
27 \\
0 \\
4 \\
3.9 \\
.81\end{array}$ & $\begin{array}{r}71 \\
19 \\
2 \\
0 \\
6 \\
3.2 \\
.52\end{array}$ & & & & $\begin{array}{l}\text { positively with } \\
\text { intent to } \\
\text { participate? }\end{array}$ & & \\
\hline CE6 & $\begin{array}{l}\text { Other? } \\
\text { Are additional questions } \\
\text { to estimate cost } \\
\text { expectancy needed? If so, } \\
\text { what? }\end{array}$ & $\begin{array}{l}\text { Yes. An additional issue - regulat } \\
\text { identified for some participants. F } \\
\text { highly sensitive to regulatory issue } \\
\text { architecture and affect. Regulatory } \\
\text { added in this study. But it should } \\
\text { studies of costs for participants inf } \\
\text { potential legislation or regulation } \\
\text { opportunity. }\end{array}$ & $\begin{array}{l}\text { Ost - } \\
\text { itals } \\
\text { HIEN } \\
\text { r wa: } \\
\text { futurs } \\
\text { ent or } \\
\text { work }\end{array}$ & & & & & & & \\
\hline
\end{tabular}

* Means additional research is recommended to further develop/validate this variable.

** Means additional research is recommended to evaluate the evidence supporting, refuting or providing alternative explanations for the hypothesis. 
Table 29: Set 6: Social Influence - Test Results for Validity and Effect

\begin{tabular}{|c|c|c|c|c|c|c|c|c|c|c|}
\hline \multicolumn{8}{|c|}{ Variable } & \multicolumn{3}{|l|}{ Effect } \\
\hline 8 & $\begin{array}{l}\text { Short Name } \\
\text { Question to assess } \\
\text { validity }\end{array}$ & Choices & $\%$ & $\%$ & $\mathbf{N}$ & $\begin{array}{l}\text { 象 } \\
\frac{0}{2}\end{array}$ & 产 & $\begin{array}{l}\text { Question to assess } \\
\text { effect (if } \\
\text { applicable) }\end{array}$ & 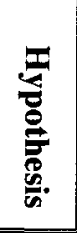 & 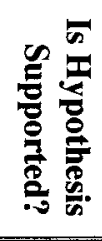 \\
\hline \multirow[t]{10}{*}{ SI1 } & \multirow{10}{*}{$\begin{array}{l}\text { Support by Influential } \\
\text { People } \\
\text { Estimate this subject's } \\
\text { level of support by } \\
\text { influential people with } \\
\text { respect to participation } \\
\text { in the site }\end{array}$} & & PO1 & $\mathrm{PO2}$ & \multirow[t]{10}{*}{109} & \multirow[t]{10}{*}{ 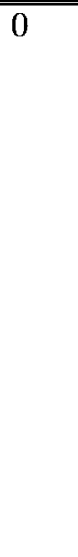 } & \multirow[t]{10}{*}{ Yes } & \multirow{10}{*}{$\begin{array}{l}\text { All other things } \\
\text { being equal, does } \\
\text { increase in this } \\
\text { rating correlate } \\
\text { positively with } \\
\text { intent to } \\
\text { participate? }\end{array}$} & \multirow[t]{10}{*}{ Yes } & \multirow[t]{10}{*}{ Yes } \\
\hline & & 1. Influential people strongly against participation & 0 & & & & & & & \\
\hline & & $\begin{array}{l}\text { 2. Influential people somewhat against } \\
\text { participation }\end{array}$ & 6 & & & & & & & \\
\hline & & 3. Influential people neutral about participation & 8 & 60 & & & & & & \\
\hline & & 4. Influential people supportive about participation & 84 & 14 & & & & & & \\
\hline & & $\begin{array}{l}\text { 5. Influential people highly supportive about } \\
\text { participation }\end{array}$ & 1 & 1 & & & & & & \\
\hline & & 8. Data not available & 0 & 0 & & & & & & \\
\hline & & 9. Attribute not valid for this subject & 0 & 0 & & & & & & \\
\hline & & Mean & 3.8 & & & & & & & \\
\hline & & SD & .56 & .71 & & & & & & \\
\hline \multirow[t]{10}{*}{ SI2 } & \multirow{10}{*}{$\begin{array}{l}\text { Support by Important } \\
\text { People } \\
\text { Estimate this subject's } \\
\text { level of support by } \\
\text { important people } \\
\text { respect to participation } \\
\text { in the site }\end{array}$} & & $\mathrm{PO1}$ & $\mathrm{PO2}$ & \multirow[t]{10}{*}{109} & \multirow[t]{10}{*}{5} & \multirow[t]{10}{*}{ Yes } & \multirow{10}{*}{$\begin{array}{l}\text { All other things } \\
\text { being equal, does } \\
\text { increase in this } \\
\text { rating correlate } \\
\text { positively with } \\
\text { intent to } \\
\text { participate? }\end{array}$} & \multirow[t]{10}{*}{ Yes } & \multirow[t]{10}{*}{ Yes } \\
\hline & & 1. Important people strongly against participation & 0 & & & & & & & \\
\hline & & 2. Important people somewhat against participation & 6 & & & & & & & \\
\hline & & 3. Important people neutral about participation & 8 & 60 & & & & & & \\
\hline & & 4. Important people supportive about participation & 84 & 14 & & & & & & \\
\hline & & $\begin{array}{l}\text { 5. Important people highly supportive about } \\
\text { participation }\end{array}$ & 1 & 1 & & & & & & \\
\hline & & 8. Data not available & 0 & 0 & & & & & & \\
\hline & & 9. Attribute not valid for this subject & 0 & 0 & & & & & & \\
\hline & & Mean & 3.8 & 2.9 & & & & & & \\
\hline & & SD & .56 & .71 & & & & & & \\
\hline
\end{tabular}




\begin{tabular}{|c|c|c|c|c|c|c|c|c|c|c|}
\hline \multicolumn{8}{|c|}{ Variable } & \multicolumn{3}{|l|}{ Effect } \\
\hline SI3 & $\begin{array}{l}\text { Support by Superiors } \\
\text { Estimate this subject's } \\
\text { level of support by } \\
\text { superiors respect to } \\
\text { participation in the site }\end{array}$ & $\begin{array}{l}\text { 1. Superiors strongly against participation } \\
\text { 2. Superiors somewhat against participation } \\
\text { 3. Superiors neutral about participation } \\
\text { 4. Superiors supportive about participation } \\
\text { 5. Superiors highly supportive about participation } \\
\text { 8. Data not available } \\
\text { 9. Attribute not valid for this subject } \\
\text { Mean } \\
\text { SD }\end{array}$ & $\begin{array}{r}P O 1 \\
0 \\
6 \\
7 \\
80 \\
0 \\
0 \\
6 \\
3.8 \\
.56\end{array}$ & $\begin{array}{r}\mathrm{PO2} \\
3 \\
22 \\
57 \\
14 \\
0 \\
0 \\
5 \\
2.9 \\
.69\end{array}$ & 109 & $6 \%$ & Yes* & & Yes & Yes** \\
\hline
\end{tabular}

NOTE: this data is a summary of a qualitative assessment done on a case by case base for the 109 individuals and 125 organizations in the study. The assessment was done by completing the Subject Profile instrument for each subject. For each subject, qualitative evidence was considered by two researchers, sitting together, to refine the variable description and coding, and determine variable validity for that subject. In addition, where appropriate, evidence was considered which supported and refuted hypotheses, or provided alternative explanations for the phenomena. The researchers sat together to evaluate evidence for each case, answer the questions noted, and determine whether the hypothesis was supported for that case.

*Means additional research is recommended to further develop/validate this variable.

** Means additional research is recommended to evaluate the evidence supporting, refuting or providing alternative explanations for the hypothesis. 
Table 30: Set 7: Facilitating Conditions - Test Results for Validity and Effect

\begin{tabular}{|c|c|c|c|c|c|c|c|c|c|c|}
\hline \multicolumn{8}{|c|}{ Variable } & \multicolumn{3}{|l|}{ Effect } \\
\hline$\stackrel{8}{8}$ & $\begin{array}{l}\text { Short Name } \\
\text { Question to assess } \\
\text { validity }\end{array}$ & Choices & $\%$ & $\%$ & $\mathbf{N}$ & $\frac{a^{9}}{3}$ & 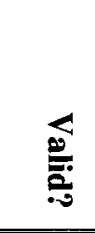 & $\begin{array}{l}\text { Question to assess } \\
\text { effect (if applicable) }\end{array}$ & 这 & 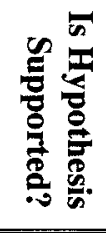 \\
\hline FC1 & $\begin{array}{l}\text { Subject Resources } \\
\text { Estimate this } \\
\text { subject's perception } \\
\text { about the level of } \\
\text { relevant resources } \\
\text { available to the } \\
\text { subject to support the } \\
\text { subject's participation } \\
\text { in the site }\end{array}$ & $\begin{array}{l}\text { 1. Hardly any resources available to subject } \\
\text { 2. Few resources available to subject } \\
\text { 3. Moderate level of resources available to subject } \\
\text { 4. High level of resources available to subject } \\
\text { 5. Extremely high level of resources available to } \\
\text { subject } \\
\text { 8. Data not available } \\
\text { 9. Attribute not valid for this subject } \\
\text { Mean } \\
\text { SD }\end{array}$ & $\begin{array}{r}P 01 \\
0 \\
4 \\
77 \\
19 \\
0 \\
\\
0 \\
0 \\
3.2 \\
.46\end{array}$ & $\begin{array}{r}\mathrm{PO} \\
0 \\
4 \\
77 \\
19 \\
0 \\
\\
0 \\
0 \\
3.2 \\
.46\end{array}$ & 109 & 0 & Yes & $\begin{array}{l}\text { All other things being } \\
\text { equal, does increase } \\
\text { in this rating correlate } \\
\text { positively with intent } \\
\text { to participate? }\end{array}$ & Yes & Yes \\
\hline $\mathrm{FC} 2$ & $\begin{array}{l}\text { Organizational } \\
\text { Resources } \\
\text { Estimate this } \\
\text { subject's perception } \\
\text { about the level of } \\
\text { organizational } \\
\text { resources available to } \\
\text { the organization to } \\
\text { support the } \\
\text { organization's } \\
\text { participation in the } \\
\text { site }\end{array}$ & $\begin{array}{l}\text { 1. Hardly any resources available to organization } \\
\text { 2. Few resources available to organization } \\
\text { 3. Moderate level of resources available to } \\
\text { organization } \\
\text { 4. High level of resources available to organization } \\
\text { 5. Extremely high level of resources available to } \\
\text { organization } \\
\text { 8. Data not available } \\
\text { 9. Attribute not valid for this subject } \\
\text { Mean }\end{array}$ & $\begin{array}{r}01 \\
0 \\
3 \\
75 \\
\\
18 \\
0 \\
\\
0 \\
4 \\
3.2\end{array}$ & 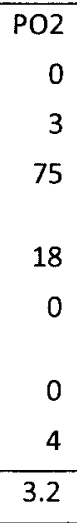 & 109 & 4 & Yes* & $\begin{array}{l}\text { All other things being } \\
\text { equal, does increase } \\
\text { in this rating correlate } \\
\text { positively with intent } \\
\text { to participate? }\end{array}$ & Yes & Yes \\
\hline
\end{tabular}




\begin{tabular}{|c|c|c|c|c|c|c|c|c|c|c|}
\hline \multicolumn{8}{|c|}{ Variable } & \multicolumn{3}{|l|}{ Effect } \\
\hline$\frac{8}{8}$ & $\begin{array}{l}\text { Short Name } \\
\text { Question to assess } \\
\text { validity }\end{array}$ & Choices & $\%$ & $\%$ & $\mathbf{N}$ & $\frac{j}{a}$ & $\frac{\widehat{0}}{\frac{0}{0: 5}}$ & $\begin{array}{l}\text { Question to assess } \\
\text { effect (if applicable) }\end{array}$ & 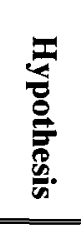 & 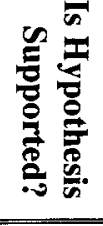 \\
\hline & & $\mathrm{SD}$ & .44 & .44 & & & & & & \\
\hline FC3 & $\begin{array}{l}\text { Dual Network } \\
\text { Resources } \\
\text { Estimate this } \\
\text { subject's perception } \\
\text { about the level of } \\
\text { HIEN resources } \\
\text { which are available to } \\
\text { support participation } \\
\text { by the subject and } \\
\text { his/her organization/ } \\
\text { group }\end{array}$ & $\begin{array}{l}\text { 1. Hardly any resources available to Site/HIE } \\
\text { 2. Few resources available to HIEN } \\
\text { 3. Moderate level of resources available to HIEN } \\
\text { 4. High level of resources available to HIEN } \\
\text { 5. Extremely high level of resources available to } \\
\text { HIEN } \\
\text { 8. Data not available } \\
\text { 9. Attribute not valid for this subject } \\
\text { Mean } \\
\text { SD }\end{array}$ & $\begin{array}{r}\mathrm{PO1} \\
0 \\
2 \\
91 \\
7 \\
0 \\
\\
0 \\
0 \\
3.1 \\
.30\end{array}$ & $\begin{array}{r}\mathrm{PO2} \\
0 \\
2 \\
91 \\
7 \\
0 \\
\\
0 \\
0 \\
3.1 \\
.30\end{array}$ & 109 & 0 & Yes & $\begin{array}{l}\text { All other things being } \\
\text { equal, does increase } \\
\text { in this rating correlate } \\
\text { positively with intent } \\
\text { to participate? }\end{array}$ & Yes & Yes \\
\hline FC4 & $\begin{array}{l}\text { Subject Knowledge } \\
\text { Estimate this } \\
\text { subject's level of } \\
\text { knowledge about the } \\
\text { Health Information } \\
\text { Exchange or HIE } \\
\text { domain }\end{array}$ & $\begin{array}{l}\text { 1. Subject has hardly any of the knowledge needed } \\
\text { 2. Subject has little of the knowledge needed } \\
\text { 3. Subject has moderate level of knowledge needed } \\
\text { 4. Subject has high level of knowledge needed } \\
\text { 5. Subject has extremely high level of knowledge } \\
\text { needed } \\
\text { 8. Data not available } \\
\text { 9. Attribute not valid for this subject } \\
\text { Mean } \\
\text { SD }\end{array}$ & $\begin{array}{r}\mathrm{PO1} \\
1 \\
31 \\
61 \\
6 \\
0 \\
0 \\
0 \\
2.7 \\
.59\end{array}$ & $\begin{array}{r}\mathrm{PO2} \\
1 \\
31 \\
61 \\
6 \\
0 \\
\\
0 \\
0 \\
2.7 \\
.59\end{array}$ & 109 & 0 & Yes & $\begin{array}{l}\text { All other things being } \\
\text { equal, does increase } \\
\text { in this rating correlate } \\
\text { positively with intent } \\
\text { to participate? }\end{array}$ & Yes & Yes** \\
\hline
\end{tabular}




\begin{tabular}{|c|c|c|c|c|c|c|c|c|c|c|}
\hline \multicolumn{8}{|c|}{ Variable } & \multicolumn{3}{|c|}{ Effect } \\
\hline ڤิ & $\begin{array}{l}\text { Short Name } \\
\text { Question to assess } \\
\text { validity }\end{array}$ & Choices & $\%$ & $\%$ & $\mathbf{N}$ & $\begin{array}{l}39 \\
\vdots \\
\vdots \\
\end{array}$ & 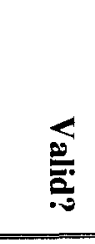 & $\begin{array}{l}\text { Question to assess } \\
\text { effect (if applicable) }\end{array}$ & 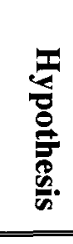 & 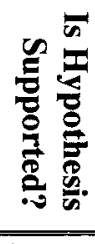 \\
\hline FC5 & $\begin{array}{l}\text { Organizational } \\
\text { Knowledge } \\
\text { Estimate this } \\
\text { organization/group's } \\
\text { level of knowledge } \\
\text { about the HIE } \\
\text { domain }\end{array}$ & $\begin{array}{l}\text { 1. Organization has hardly any of the knowledge } \\
\text { needed } \\
\text { 2. Organization has little of the knowledge needed } \\
\text { 3. Organization has moderate level of knowledge } \\
\text { needed } \\
\text { 4. Organization has high level of knowledge } \\
\text { needed } \\
\text { 5. Organization has extremely high level of } \\
\text { knowledge needed } \\
\text { 8. Data not available } \\
\text { 9. Attribute not valid for this subject } \\
\text { Mean } \\
\text { SD }\end{array}$ & $\begin{array}{r}\mathrm{PO1} \\
0 \\
32 \\
62 \\
2 \\
0 \\
0 \\
4 \\
2.7 \\
.51\end{array}$ & $\begin{array}{r}\mathrm{PO2} \\
0 \\
32 \\
62 \\
2 \\
0 \\
0 \\
4 \\
2.7 \\
.51\end{array}$ & 109 & 4 & Yes* & $\begin{array}{l}\text { All other things being } \\
\text { equal, does increase } \\
\text { in this rating correlate } \\
\text { positively with intent } \\
\text { to participate? }\end{array}$ & Yes & Yes \\
\hline FC6 & $\begin{array}{l}\text { Dual Network } \\
\text { Knowledge } * * * \\
\text { Estimate the HIEN's } \\
\text { level of knowledge } \\
\text { about the HIE } \\
\text { domain as it applies } \\
\text { to this organization/ } \\
\text { group }\end{array}$ & $\begin{array}{l}\text { 1. Site/HIE has hardly any of the knowledge } \\
\text { needed } \\
\text { 2. Site/HIE has little of the knowledge needed } \\
\text { 3. Site/HIE has moderate level of knowledge } \\
\text { needed } \\
\text { 4. Site/HIE has high level of knowledge needed } \\
\text { 5. Site/HIE has extremely high level of knowledge } \\
\text { needed } \\
\text { 8. Data not available } \\
\text { 9. Attribute not valid for this subject } \\
\text { Mean }\end{array}$ & $\begin{array}{r}\mathrm{PO} 1 \\
0 \\
47 \\
53 \\
0 \\
0 \\
0 \\
0 \\
2.5\end{array}$ & $\begin{array}{r}\text { PO2 } \\
0 \\
47 \\
53 \\
0 \\
0 \\
0 \\
0 \\
2.5\end{array}$ & 109 & 0 & Yes & $\begin{array}{l}\text { All other things being } \\
\text { equal, does increase } \\
\text { in this rating correlate } \\
\text { positively with intent } \\
\text { to participate? }\end{array}$ & Yes & Yes \\
\hline
\end{tabular}




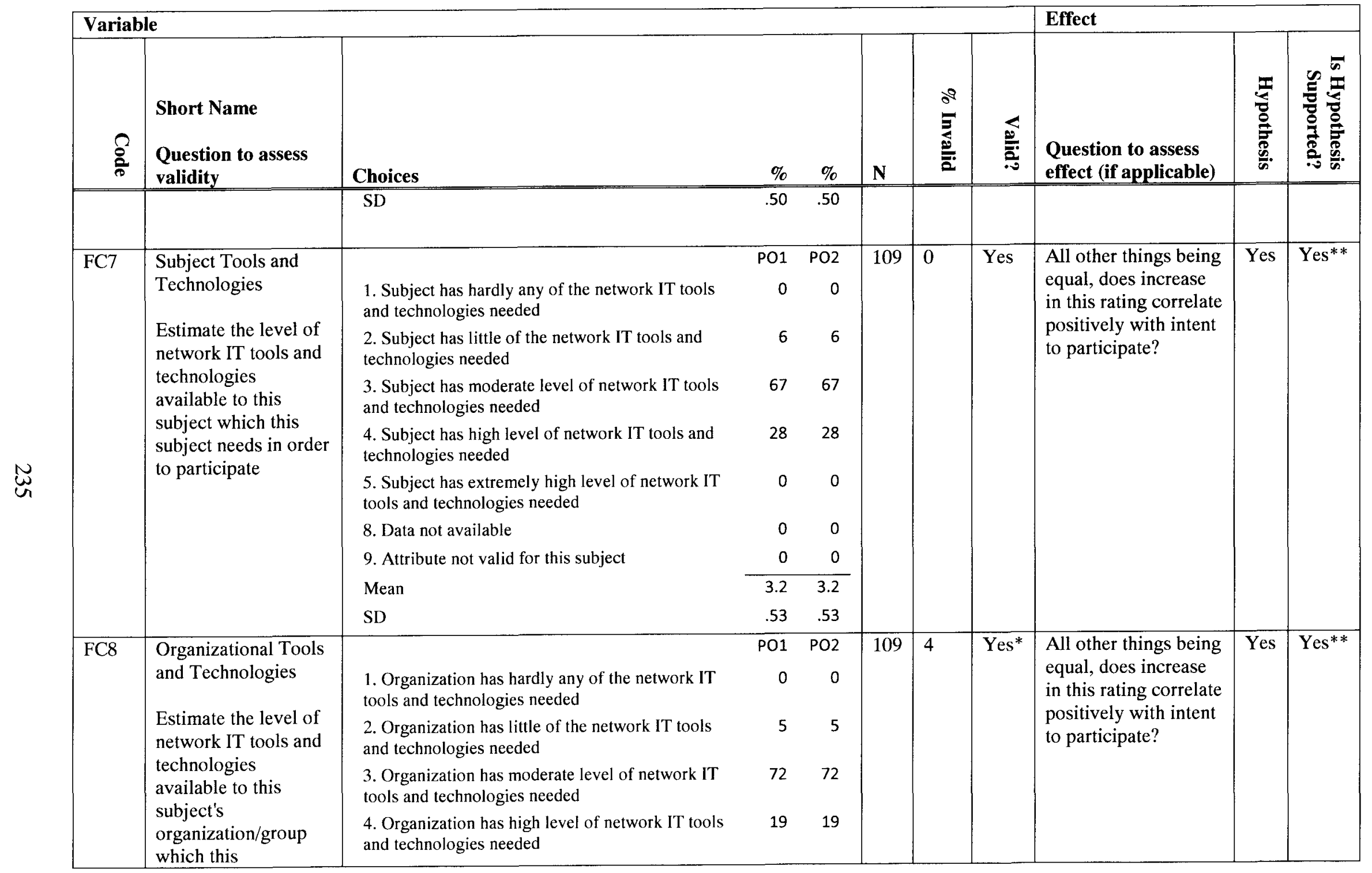




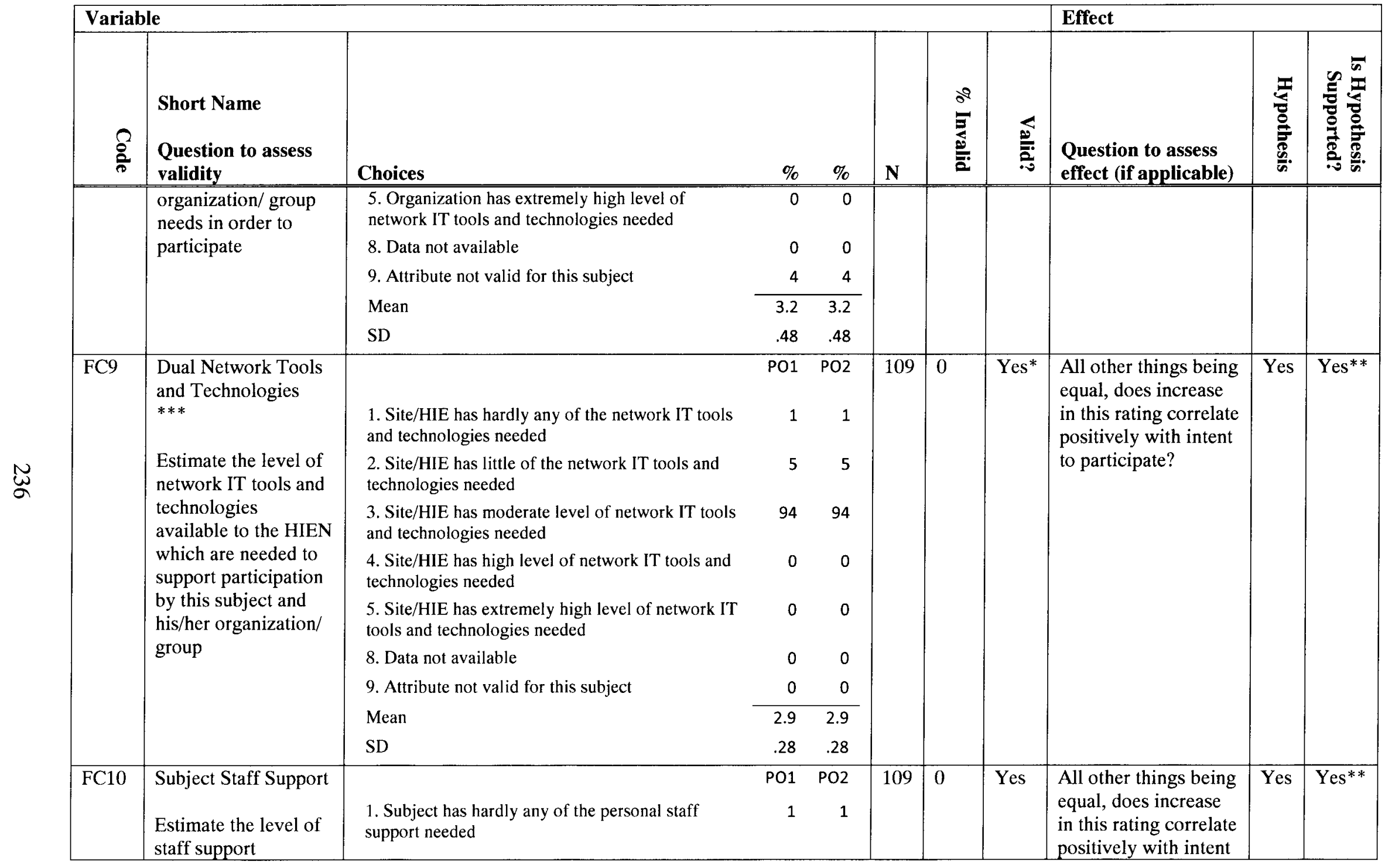




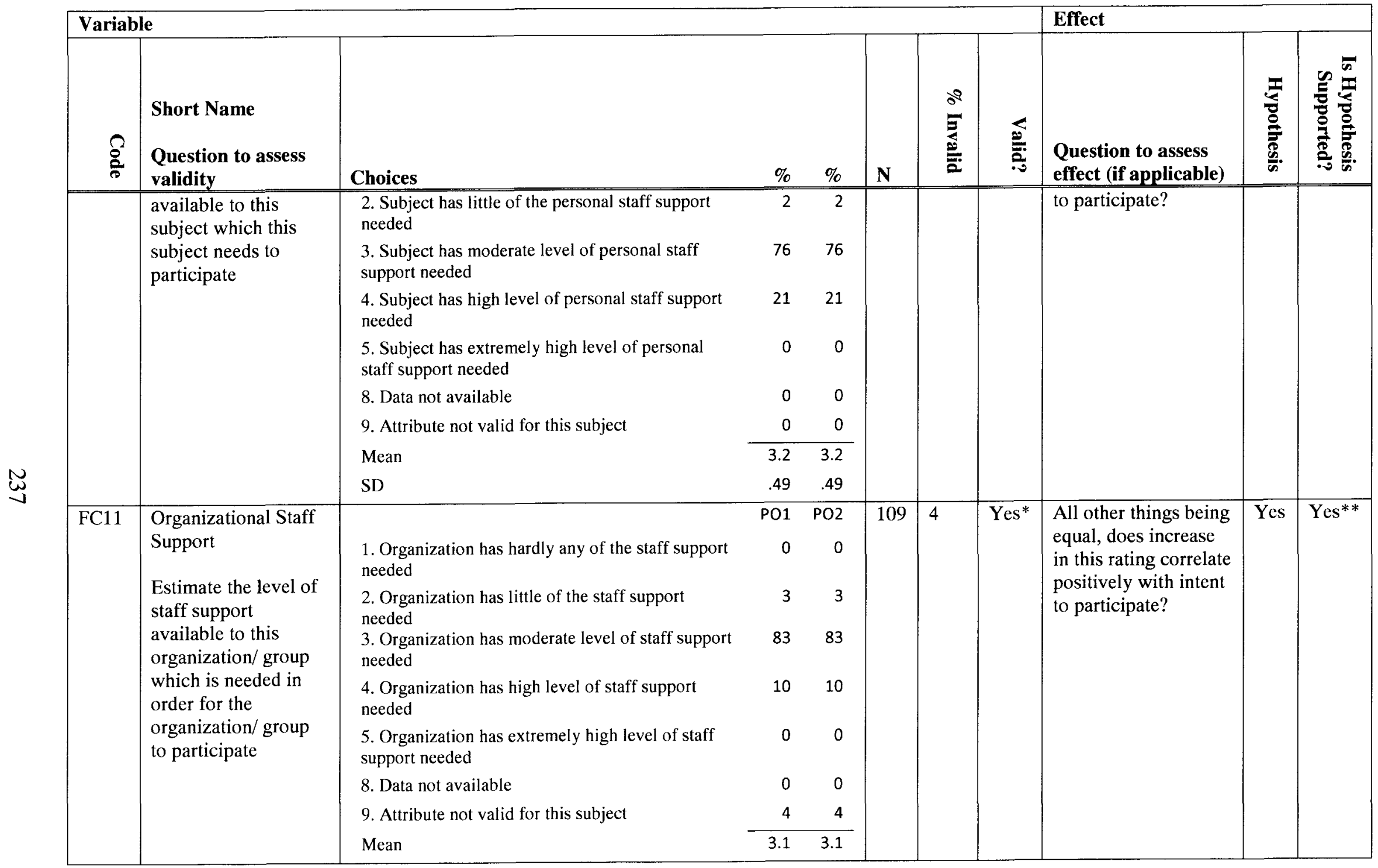




\begin{tabular}{|c|c|c|c|c|c|c|c|c|c|c|}
\hline \multicolumn{8}{|c|}{ Variable } & \multicolumn{3}{|l|}{ Effect } \\
\hline$\stackrel{\varrho}{\partial}$ & $\begin{array}{l}\text { Short Name } \\
\text { Question to assess } \\
\text { validity }\end{array}$ & Choices & $\%$ & $\%$ & $\mathbf{N}$ & 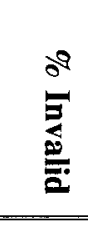 & & $\begin{array}{l}\text { Question to assess } \\
\text { effect (if applicable) }\end{array}$ & 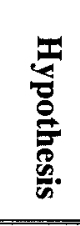 & 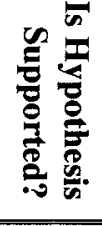 \\
\hline & & SD & .36 & .36 & & & & & & \\
\hline FC12 & $\begin{array}{l}\text { Dual Network Staff } \\
\text { Support *** } \\
\text { Estimate the level of } \\
\text { staff support } \\
\text { available to this } \\
\text { HIEN which is } \\
\text { needed to support } \\
\text { participation by this } \\
\text { subject and his/her } \\
\text { organization/group }\end{array}$ & $\begin{array}{l}\text { 1. Site/HIE has hardly any of the staff support } \\
\text { needed } \\
\text { 2. Site/HIE has little of the staff support needed } \\
\text { 3. Site/HIE has moderate level of staff support } \\
\text { needed } \\
\text { 4. Site/HIE has high level of staff support needed } \\
\text { 5. Site/HIE has extremely high level of staff } \\
\text { support needed } \\
\text { 8. Data not available } \\
\text { 9. Attribute not valid for this subject } \\
\text { Mean } \\
\text { SD }\end{array}$ & $\begin{array}{r}P 01 \\
0 \\
5 \\
95 \\
0 \\
0 \\
0 \\
0 \\
3.0 \\
.21\end{array}$ & $\begin{array}{r}\text { PO2 } \\
0 \\
5 \\
95 \\
0 \\
0 \\
0 \\
0 \\
3.0 \\
.21\end{array}$ & 109 & 0 & Yes* & $\begin{array}{l}\text { All other things being } \\
\text { equal, does increase } \\
\text { in this rating correlate } \\
\text { positively with intent } \\
\text { to participate? }\end{array}$ & Yes & Yes \\
\hline FC13 & $\begin{array}{l}\text { Environmental } \\
\text { Stability } \\
\text { Estimate how this } \\
\text { subject would } \\
\text { perceive the level of } \\
\text { environmental } \\
\text { stability - including } \\
\text { the financial, } \\
\text { regulatory and } \\
\text { competitive }\end{array}$ & $\begin{array}{l}\text { 1. Highly unstable environment } \\
\text { 2. Unstable environment } \\
\text { 3 Neither stable nor unstable environment } \\
\text { 4. Stable environment } \\
\text { 5. Highly stable environment } \\
\text { 8. Data not available } \\
\text { 9. Attribute not valid for this subject }\end{array}$ & $\begin{array}{r}\mathrm{PO1} \\
0 \\
57 \\
43 \\
0 \\
0 \\
0 \\
0\end{array}$ & $\begin{array}{r}\mathrm{PO2} \\
0 \\
57 \\
43 \\
0 \\
0 \\
0 \\
0\end{array}$ & 109 & 0 & Yes & $\begin{array}{l}\text { All other things being } \\
\text { equal, does increase } \\
\text { in this rating correlate } \\
\text { positively with intent } \\
\text { to participate? }\end{array}$ & Yes & Yes \\
\hline
\end{tabular}




\begin{tabular}{|c|c|c|c|c|c|c|c|c|c|c|}
\hline Variab & & & & & & & & Effect & & \\
\hline$\frac{8}{8}$ & $\begin{array}{l}\text { Short Name } \\
\text { Question to assess } \\
\text { validity }\end{array}$ & Choices & $\%$ & $\%$ & $\mathbf{N}$ & $\frac{29}{3}$ & 苛 & $\begin{array}{l}\text { Question to assess } \\
\text { effect (if applicable) }\end{array}$ & 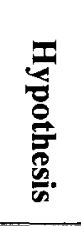 & 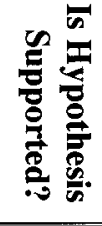 \\
\hline & $\begin{array}{l}\text { environment - as it } \\
\text { applies to this } \\
\text { participation } \\
\text { opportunity } \\
\end{array}$ & $\begin{array}{l}\text { Mean } \\
\text { SD }\end{array}$ & $\begin{array}{l}2.4 \\
.50\end{array}$ & $\begin{array}{l}2.4 \\
.50\end{array}$ & & & & & & \\
\hline$\overline{\mathrm{FC} 14}$ & Resource & & PO1 & PO2 & 109 & 0 & Yes & All other things being & Yes & Yes \\
\hline & Munificence & $\begin{array}{l}\text { 1. Hardly any resources available in the } \\
\text { environment }\end{array}$ & 0 & 0 & & & & & & \\
\hline & Estimate how this & 2. Few resources available in the environment & 5 & 5 & & & & positively with intent & & \\
\hline & $\begin{array}{l}\text { subject would } \\
\text { perceive the level of }\end{array}$ & $\begin{array}{l}\text { 3. Moderate level of resources available in the } \\
\text { environment }\end{array}$ & 94 & 94 & & & & to participate? & & \\
\hline & $\begin{array}{l}\text { 'resource } \\
\text { munificence' the }\end{array}$ & $\begin{array}{l}\text { 4. High level of resources available in the } \\
\text { environment }\end{array}$ & 1 & 1 & & & & & & \\
\hline & $\begin{array}{l}\text { general availability of } \\
\text { resources such as }\end{array}$ & $\begin{array}{l}\text { 5. Extremely high level of resources available in } \\
\text { the environment }\end{array}$ & 0 & 0 & & & & & & \\
\hline & $\begin{array}{l}\text { money, space, and } \\
\text { equipment available }\end{array}$ & 8. Data not available & 0 & 0 & & & & & & \\
\hline & $\begin{array}{l}\text { to the } \\
\text { the }\end{array}$ & 9. Attribute not valid for this subject & 0 & 0 & & & & & & \\
\hline & organizations/groups & Mean & 3.0 & 3.0 & & & & & & \\
\hline & $\begin{array}{l}\text { who the HIEN seeks } \\
\text { to serve }\end{array}$ & SD & .23 & .23 & & & & & & \\
\hline FC15 & $\begin{array}{l}\text { Additional Questions } \\
\text { Needed? } \\
\text { Are additional } \\
\text { questions to estimate } \\
\text { 'facilitating } \\
\text { conditions' needed? } \\
\text { If so, what? }\end{array}$ & No. None added. & & & & & & & & \\
\hline
\end{tabular}


NOTE: this data is a summary of a qualitative assessment done on a case by case base for the 109 individuals and 125 organizations in the study. The assessment was done by completing the Subject Profile instrument for each subject. For each subject, qualitative evidence was considered by two researchers, sitting together, to refine the variable description and coding, and determine variable validity for that subject. In addition, where appropriate, evidence was considered which supported and refuted hypotheses, or provided alternative explanations for the phenomena. The researchers sat together to evaluate evidence for each case, answer the questions noted, and determine whether the hypothesis was supported for that case.

* Means additional research is recommended to further develop/validate this variable.

* Means additional research is recommended to evaluate the evidence supporting, refuting or providing alternative explanations for the hypothesis.

*** A potential overlap of variables was identified for FC6, FC9 and FC12. Are knowledge or resources provided at the HIEN (network) level network level resources, which overlap with sets 8-9 (Dual Network Attributes)? Validity of each of these variables was asterisked to denote recommendation for more research on this question. 
Table 31: Predictors - Principle Component Analysis

Rotated Component Matrix ${ }^{\mathrm{a}}$

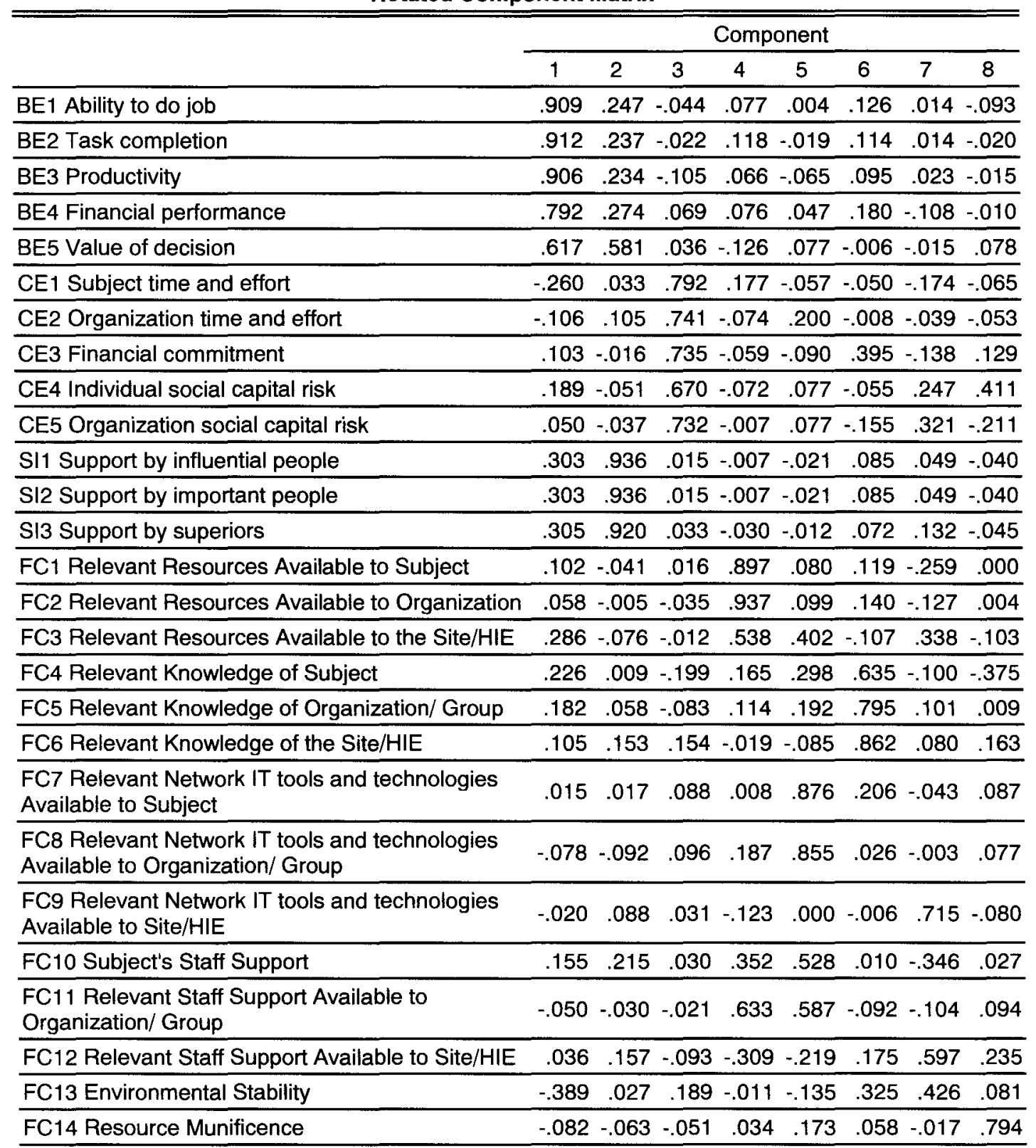

Extraction Method: Principal Component Analysis.

Rotation Method: Varimax with Kaiser Normalization.

a. Rotation converged in 7 iterations. 
Component Transformation Matrix

\begin{tabular}{llllllllr}
\hline \hline $\begin{array}{l}\text { Compo } \\
\text { nent }\end{array}$ & 1 & 2 & 3 & 4 & 5 & 6 & 7 & 8 \\
\hline 1 & .756 & .575 & -.023 & .146 & .108 & .251 & .004 & -.040 \\
\hline 2 & -.039 & -.265 & .018 & .686 & .607 & .070 & -.290 & .000 \\
\hline 3 & -.123 & .123 & .927 & -.077 & .168 & .166 & .172 & .137 \\
\hline 4 & -.160 & -.164 & -.246 & -.104 & .061 & .888 & .253 & .143 \\
\hline 5 & -.307 & .446 & -.274 & -.232 & .626 & -.237 & .321 & .163 \\
\hline 6 & .537 & -.591 & .015 & -.273 & .279 & -.196 & .361 & .202 \\
\hline 7 & -.062 & .017 & -.014 & .542 & -.229 & -.116 & .767 & -.216 \\
\hline 8 & -.002 & .088 & -.059 & .262 & -.256 & -.095 & -.021 & .919 \\
\hline Extraction Method: Principal Component Analysis. & & & & &
\end{tabular}


Table 32: Set 8: Whole-network Attributes

\begin{tabular}{|c|c|c|c|c|c|c|c|c|c|c|c|c|}
\hline \multirow[b]{3}{*}{ Code } & \multirow{3}{*}{$\begin{array}{l}\text { Name } \\
\text { Question to assess validity }\end{array}$} & \multirow[b]{3}{*}{ Valid? } & \multirow[b]{3}{*}{ If valid, then... } & \multirow{3}{*}{$\begin{array}{l}\text { Orig. } \\
\text { prop. }\end{array}$} & \multirow{2}{*}{\multicolumn{4}{|c|}{\begin{tabular}{|l|}
$\begin{array}{l}\text { Evidence } \\
\text { for }\end{array}$ \\
Site \# \\
\end{tabular}}} & \multirow{2}{*}{\multicolumn{2}{|c|}{\begin{tabular}{|l|}
$\begin{array}{l}\text { Evidence } \\
\text { against }\end{array}$ \\
Site \#
\end{tabular}}} & \multirow{3}{*}{$\begin{array}{l}\text { Alt. } \\
\text { expl. }\end{array}$} & \multirow{3}{*}{$\begin{array}{l}\text { Is hyp. } \\
\text { supported? }\end{array}$} \\
\hline & & & & & & & & & & & & \\
\hline & & & & & \begin{tabular}{l|l|}
1 & 2 \\
\end{tabular} & \begin{tabular}{|l|l|}
3 & 4 \\
\end{tabular} & & & \begin{tabular}{l|l|l}
1 & 2 & 3 \\
\end{tabular} & \begin{tabular}{ll|l|l|l}
3 & 4 & 5 \\
\end{tabular} & & \\
\hline \multicolumn{13}{|c|}{ 8. Whole-network Attribute } \\
\hline WN1 & $\begin{array}{l}\text { Rules and Norms (as steering mechanisms) } \\
\text { To what degree are formalized rules and norms } \\
\text { established and used to steer decision-making in } \\
\text { this site? (e.g., low, moderate, high) }\end{array}$ & Yes* & $\begin{array}{l}\text { Do increased rules } \\
\text { and norms increase } \\
\text { SI? }\end{array}$ & Yes & \begin{tabular}{l|l|}
$x$ & $x$ \\
\end{tabular} & \begin{tabular}{|l|l}
$x$ & $x$ \\
\end{tabular} & & $\mathrm{x}$ & $\mathbf{x}$ & $\mathbf{x}$ & No & Yes \\
\hline \multicolumn{13}{|c|}{$\begin{array}{l}\text { Validity: This variable seemed valid for these sites. For each site, the level of development of formalized rules and norm appeared to be assessable } \\
\text { through review of organizational records, documents, bylaws, procedural documents, and websites. Variations were observable (e.g., site } 3=\text { low, site } \\
\text { 4=moderate). } \\
\text { Evidence For: each of the } 6 \text { sites worked hard to develop rules and norms to guide development and assure good decision-making. This was reflected, for } \\
\text { example, in formalized business and strategic planning processes for each site. Adverse affects on social influence (SI) were seen for sites lacking rules } \\
\text { and norms in some areas For example, a lack of rules related to managing conflicts of interest on some boards was associated with widespread } \\
\text { speculation about hidden motives and lack of good faith by parties with conflicts and by breakdowns in communication with key stakeholders. In sites } \\
\text { with better procedures for disclosure and management of conflicts less of this behavior and fewer problems with conflicts were visible. } \\
\text { Evidence Against: None was found in the private sector groups. For a state government led group, complex state rules regarding procurement and } \\
\text { compliance could be interpreted as rules and norms creating barriers. However, further analysis suggests these are better interpreted as rules and norms } \\
\text { associated with one of the stakeholders in the network, e.g., state government, rather than rules and norms of the network itself. } \\
\text { Alternative Explanation: None found. }\end{array}$} \\
\hline$\overline{\mathrm{WN} 2}$ & $\begin{array}{l}\text { Learning and Education } \\
\text { What is the frequency and intensity of activities } \\
\text { related to learning and education for this site? } \\
\text { (e.g., low, moderate, high) }\end{array}$ & Yes & $\begin{array}{l}\text { Does increased } \\
\text { Learning and } \\
\text { Education increase } \\
\text { SI? }\end{array}$ & Yes & \begin{tabular}{l|l|}
$x$ & $x$ \\
\end{tabular} & & & $\mathrm{x}$ & & & No & Yes \\
\hline \multicolumn{13}{|c|}{$\begin{array}{l}\text { Validity: This variable seemed valid for these sites. Records of educational events and activities were found in board meetings, on websites and in press } \\
\text { releases. Variations in frequency and intensity of educational activities were visible. For example, site } 4 \text { exhibited significantly higher frequency and } \\
\text { intensity of educational activity than the others. } \\
\text { Evidence For: Five of the } 6 \text { sites featured periodic activities focused on learning and education for board leaders and the community. These presented } \\
\text { important opportunities for building social connections, strengthening relationships and gaining support for the concept and approach. Participants saw } \\
\text { them as valuable. } \\
\text { Evidence Against: None found. }\end{array}$} \\
\hline
\end{tabular}




\begin{tabular}{|c|c|c|c|c|c|c|c|c|c|c|c|c|c|c|c|}
\hline \multirow[b]{3}{*}{ Code } & \multirow{3}{*}{$\begin{array}{l}\text { Name } \\
\text { Question to assess validity }\end{array}$} & \multirow[b]{3}{*}{ Valid? } & \multirow[b]{3}{*}{ If valid, then... } & \multirow{3}{*}{$\begin{array}{l}\text { Orig. } \\
\text { prop. }\end{array}$} & \multicolumn{5}{|c|}{$\begin{array}{l}\text { Evidence } \\
\text { for }\end{array}$} & \multicolumn{4}{|c|}{$\begin{array}{l}\text { Evidence } \\
\text { against }\end{array}$} & \multirow{3}{*}{ Alt. } & \multirow{3}{*}{$\begin{array}{l}\text { Is hyp. } \\
\text { supported? }\end{array}$} \\
\hline & & & & & \multicolumn{5}{|c|}{ Site \# } & \multicolumn{4}{|c|}{ Site \# } & & \\
\hline & & & & & $\mathbf{1}$ & 2 & 3 & 4 & & 6 & \begin{tabular}{l|l|l|}
1 & 2 & 3 \\
\end{tabular} & 4 & 5 & & \\
\hline WN3 & $\begin{array}{l}\text { Dominant Core } \\
\text { To what degree is there a dominant core of leaders } \\
\text { driving development and making decisions for the } \\
\text { network? (E.g., no core, somewhat dominant core, } \\
\text { highly dominant core.) }\end{array}$ & Yes* & $\begin{array}{l}\text { Does increased } \\
\text { Dominant Core } \\
\text { increase BE, LCE, } \\
\text { SI, FC? }\end{array}$ & Yes & $\mathrm{x}$ & $\mathbf{x}$ & $\mathbf{x}$ & & $\mathrm{x}$ & $\mathrm{x}$ & $\mathbf{x}$ & $\mathbf{x}$ & & No & Yes** \\
\hline
\end{tabular}

Validity: This variable seemed valid for all sites. In each site, a dominant core of leaders such as board chairs, hospital leaders, or government leaders, were visible. Some sites' leadership core showed more dominance than others.

Evidence For: In each site, a dominant core helped pushed the site forward through development stages, resulting in increased BE, LCE, SI and FC supporting participation. In sites with less dominant cores, decisions were postponed, and progress seemed slower. The influence was notable in several situations where influential leaders left sites and the result was a reduction in the speed of progress by the remaining group

Evidence Against: There were instances where leaders comprising a dominant core disagreed, creating a conflict which dominated the situation and reduced progress. However, on further consideration, it can be argued that the disagreement represented a reduction in the influence of a dominant core, and isn't really evidence against the hypothesis.

Alternative Explanation: None found.

WN4 $\quad$ Embedded Relationships

To what degree are there embedded relationships pre-existing social or organizational connections among participants in this network? How many of the participants have successfully worked together with other participants on projects outside of this context? (e.g., none, some, most, all).

\begin{tabular}{|c|c|c|c|c|c|c|c|c|c|c|c|c|}
\hline Yes* & $\begin{array}{l}\text { Does increased } \\
\text { Embedded } \\
\text { Relationships } \\
\text { increase BE, LCE, } \\
\text { SI, FC? }\end{array}$ & Yes & $\mathbf{x}$ & $\mathrm{x}$ & $\mathrm{x}$ & $\mathrm{x}$ & $\mathbf{x}$ & $\mathbf{x}$ & $\mathrm{x}$ & $\mathrm{x}$ & No & Yes** \\
\hline
\end{tabular}

Validity: This variable seemed valid for all sites. It would have been straightforward to have each participant complete a survey to identify their

embedded relationships with other participants on boards and committees. Some sites (e.g., site 6) had more embedded relationships than others (e.g., site 2).

Evidence For: All sites contained evidence that embedded relationships facilitated decision-making and improved confidence in participation. Increased BE, LCE, SI and FC appeared to correlate positively with this factor.

Evidence Against: There were two instances of embedded relationships having a harmful affect on participation. In these cases, embedded relationships between state Medicaid leaders and major hospitals and health plans appeared to reduce BE, LCE, SI and FC. State Medicaid was perceived as holding the sites hostage so they could control services to meet their needs. However, this embedded relationship was a positive in site 6 , which developed an 


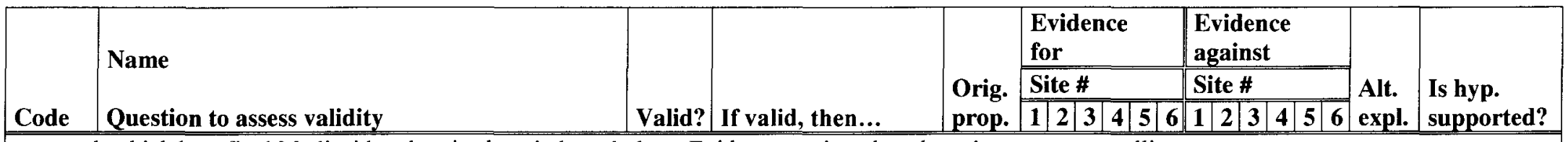

approach which benefited Medicaid and major hospitals and plans. Evidence against thus doesn't appear compelling.

Alternative Explanation: None found.

Recommended Research: Develop, validate and analyze effect of a variable such as 'negative embedded relationships' or 'collusionary relationships'.

WN5 Right Type of Governance?

To what degree is right type of governance in

place (select one)?

1. Wrong governance

2. Mixture of right and wrong governance

3. Right governance: they either:

a. Use shared governance for less than 8 participants/simple project).

b. Use lead organization governance for 9-15 participants and simple to moderate complexity.

c. Use a network administrative organization for more than 15 participants or high complexity.

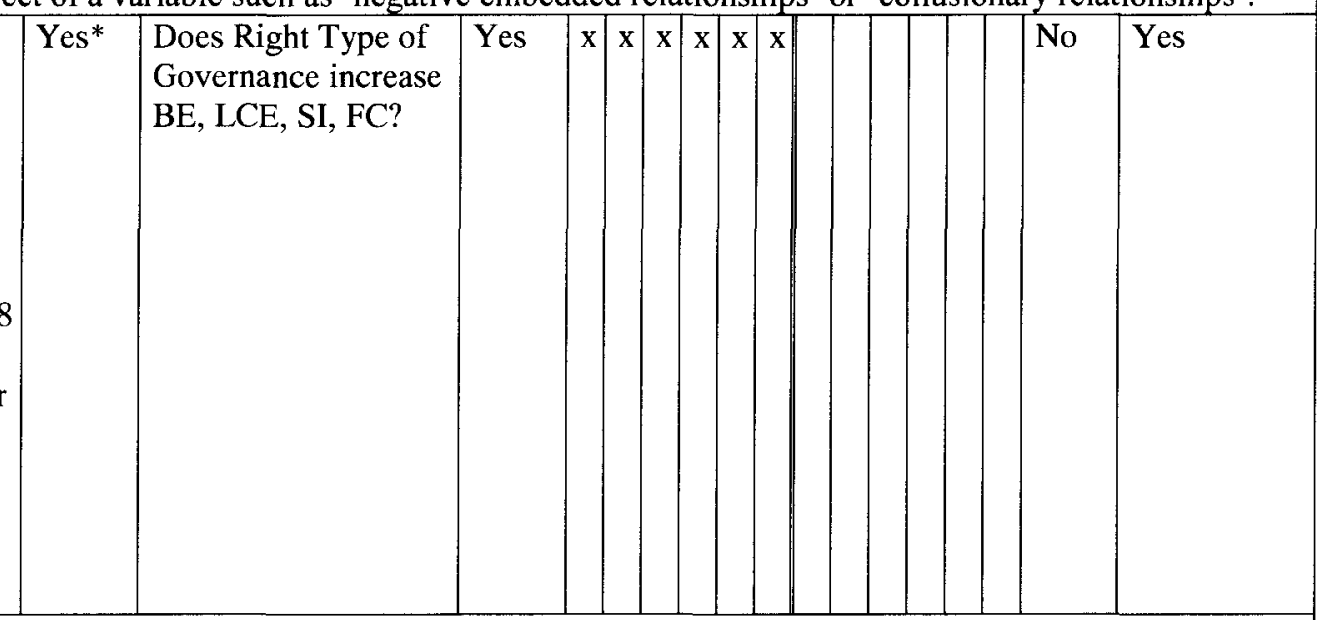

Validity: This variable seemed valid for all sites. Based on criteria, all sites should have been type 3, but were in fact type 4 . Sites 2 and 5 came closer to type 3.

Evidence For: For all 6 sites, significant time and effort was spent debating what type of governance to use and dealing with challenges related to the governance structure(s) selected. None of the sites considered the concept of an NAO. 5 of the 6 sites engaged outside vendors to do market assessment and business and technology planning. However, these vendors, in some cases, had embedded relationships with some participants, creating concerns about collusion or conflicts. One of the 6 sites used a local university as a quasi-NAO, but concerns about conflicts also caused difficulties with this relationship. The evidence clearly suggests that wrong governance reduced BE, LCE, SI and FC, and that increased right governance had a positive effect on these factors.

Evidence Against: None.

Alternative Explanation: None.

\begin{tabular}{|l|l|l|l|l|l|l|l|l|l|l|l|l|l|l|l|l|l|l|l|}
\hline WN6 & Formalization & Yes & $\begin{array}{l}\text { Does increased } \\
\text { Formalization } \\
\text { increase BE, LCE, } \\
\text { SI, FC? }\end{array}$ & $\begin{array}{l}\text { Yo what degree does the site use formalized rules, } \\
\text { written agendas and well defined decision-making }\end{array}$ & $\mathrm{x}$ & $\mathrm{x}$ & $\mathrm{x}$ & $\mathrm{x}$ & $\mathrm{x}$ & $\mathrm{x}$ & &
\end{tabular}




\begin{tabular}{|c|c|c|c|c|c|c|c|c|c|c|c|c|c|}
\hline \multirow[b]{3}{*}{ Code } & \multirow{3}{*}{$\begin{array}{l}\text { Name } \\
\text { Question to assess validity }\end{array}$} & \multirow[b]{3}{*}{ Valid? } & \multirow[b]{3}{*}{ If valid, then... } & \multirow{3}{*}{$\begin{array}{l}\text { Orig. } \\
\text { prop. }\end{array}$} & \multirow{2}{*}{\multicolumn{3}{|c|}{$\begin{array}{l}\begin{array}{l}\text { Evidence } \\
\text { for }\end{array} \\
\text { Site \# }\end{array}$}} & \multirow{2}{*}{\multicolumn{4}{|c|}{\begin{tabular}{|l|}
$\begin{array}{l}\text { Evidence } \\
\text { against }\end{array}$ \\
Site \# \\
\end{tabular}}} & \multirow{3}{*}{$\begin{array}{l}\text { Alt. } \\
\text { expl. }\end{array}$} & \multirow{3}{*}{$\begin{array}{l}\text { Is hyp. } \\
\text { supported? }\end{array}$} \\
\hline & & & & & & & & & & & & & \\
\hline & & & & & \begin{tabular}{|l|l|l}
1 & 2 & 3 \\
\end{tabular} & \begin{tabular}{|l|l|}
4 & 5 \\
\end{tabular} & 6 & \begin{tabular}{|l|l|}
1 & 2 \\
\end{tabular} & \begin{tabular}{l|l}
3 & 4 \\
\end{tabular} & $\begin{array}{l}45 \\
\end{array}$ & 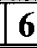 & & \\
\hline
\end{tabular}

Validity: This variable seemed valid for all sites. Review of board minutes, site documents like bylaws and ethics policies and documentation of policies and procedures provided a basis for determining levels of formalization in place. Variations in levels of formalization were visible across sites.

Evidence For: For all 6 sites, significant effort was made to formalize governance and management policies and procedures. Formalization was seen as a good and necessary activity. Sites which developed more formalization, especially around governance related activities, and communications with participants and the public, seemed to have increased success in developing and maintaining participation. Some sites lacking formalization in some areas, such as ways to handle conflicts of interest, experienced problems which reduced participation. This indicates a positive relationship between Formalization and BE, LCE, SI and FC.

Evidence Against: None.

Alternative Explanation: None.

What is the degree to which trust, reciprocity and

norms of cooperation exist among the participants

in this site? (E.g., very low, low, moderate, high,

very high).

\begin{tabular}{l|l|} 
Yes* & $\begin{array}{l}\text { Does increased } \\
\text { Network Inner } \\
\text { Stability increase } \\
\text { BE, LCE, SI, FC? }\end{array}$ \\
\end{tabular}
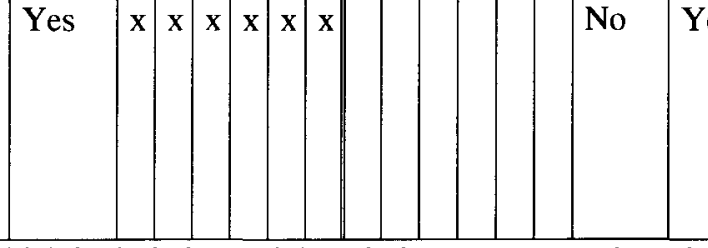

Validity: This variable seemed valid for all sites. A formal 'collaborative capacity' survey which included a social capital measure was done for subjects in three of the sites, and valid answers were able to be developed. Variations were visible in all 6 sites, from lowest (site 3) to highest (site 4).

Evidence For: For all 6 sites, network inner stability was discussed at board meetings, and actively developed as a site asset. Ability to make progress through steps of development was clearly dependent on this factor, with participant trust being the most commonly discussed concept. BE, LCE, SI and

FC all appeared to increase with increases in network inner stability.

Evidence Against: None.

Alternative Explanation: None.

WN8 $\quad$ Stability Management

To what degree does leadership buffer instability

or nurture stability in the network? (E.g., low,

moderate, high).

\begin{tabular}{|c|c|c|c|c|c|c|c|c|c|c|}
\hline Yes* & $\begin{array}{l}\text { Does increase in } \\
\text { Stability } \\
\text { Management } \\
\text { increase BE, LCE, } \\
\text { SI, FC? }\end{array}$ & Yes & $x$ & $x$ & \begin{tabular}{l|l|}
$x$ & $x$ \\
\end{tabular} & \begin{tabular}{|l|l|}
$x$ & $x$ \\
\end{tabular} & $x$ & $\mathbf{x}$ & $\mathrm{Y}$ & Yes** \\
\hline
\end{tabular}

Validity: This variable seemed valid for all sites. Leadership statements in board meetings for each site touched on this issue. The records suggested that some site leaders (sites $1,4,5$ ) spent more time than others (site 2 ) on stability management.

Evidence For: All 6 sites engaged in some efforts to manage stability, and the record suggests that private meetings between leaders and participants usually resulted in increased BE, LCE, SI and FC. For 4 of the 6 sites, instances are seen where leadership did not engage in stability management, 


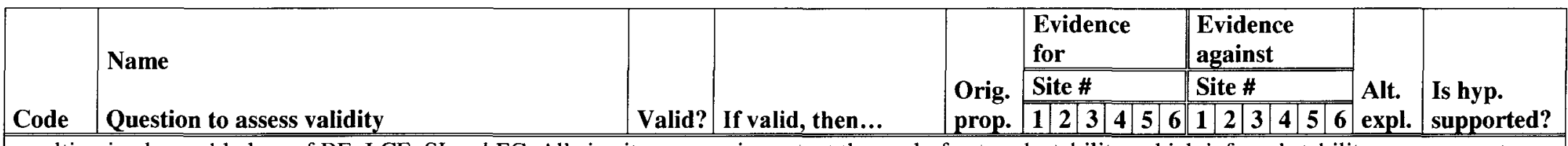

resulting in observable loss of BE, LCE, SI and FC. All six sites saw as important the goal of network stability, which inferred stability management.

Evidence Against: Some site leaders attempted to use power as a mechanism to achieve stability. For example, states (sites 2 and 4) attempted to leverage the state's regulatory or purchasing power to create stability by requiring major participants to adhere to an approach supported by the state. These approaches were less effective, in some cases backfiring to create loss of BE, LCE, SI and FC for a majority of participants.

Alternative Explanation: An alternative explanation for the evidence against the hypothesis appears: that the problem here was a participant (the state) attempting to exert its interests against other interests. This may be better explained through looking at attributes related to collusion, conflict of interest management, and so on.

Recommended Research: How should challenges of collusion or coercion by participants be measured? What are the effects?

\begin{tabular}{|l|l|l|l|}
\hline WN9 & Accountability Management & Yes & $\begin{array}{l}\text { Does increase in } \\
\text { Accountability } \\
\text { Management } \\
\text { increase BE, LCE, } \\
\text { To what degree are managers assigned } \\
\text { accountability for performance and results for } \\
\text { network? (E.g., low, moderate, high.) }\end{array}$ \\
\hline
\end{tabular}

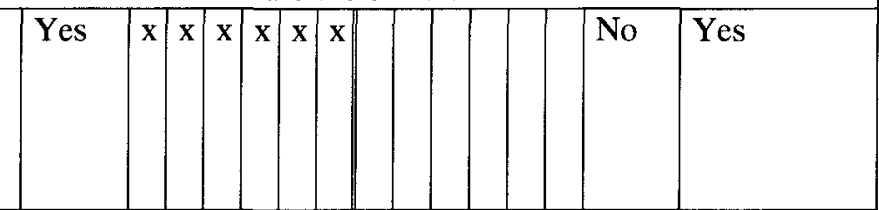

Validity: This variable seemed valid for all sites. Leadership accountability was assessable by considering factors such as type of contract, existence of written job contracts and performance goals, and power of a board to censure or remove managers for non-performance. The records showed that some sites had full time managers with stronger accountability (sites 4,5) while others had part time managers with less accountability (sites $1,2,3,6)$.

Evidence For: All 6 sites engaged in some efforts to set goals and hold managers accountable for achieving those goals. Several sites encountered problems controlling managers who had first loyalties to a primary employer. This led to reductions in BE, LCE, SI, and FC. Other sites which held managers more accountable for performance achieved better results.

Evidence Against: None.

Alternative Explanation: None.

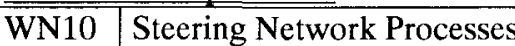

To what degree are processes in place to support

ethical decision-making, and facilitate

centralization of control? (E.g., low, moderate, high.)

\begin{tabular}{|c|c|c|c|c|c|c|c|c|}
\hline Yes* & $\begin{array}{l}\text { Does increase in } \\
\text { Steering Network } \\
\text { Processes increase } \\
\text { BE, LCE, SI, FC? }\end{array}$ & Yes & \begin{tabular}{l|l}
$x$ & $x$
\end{tabular} & $\mathbf{x}$ & \begin{tabular}{|l|l}
$\mathrm{x}$ & $\mathrm{x}$ \\
\end{tabular} & \begin{tabular}{|l|l|}
$x$ & \\
\end{tabular} & No & Yes \\
\hline
\end{tabular}

Validity: This variable seemed valid for all sites. All sites developed and used formal decision-making processes and somewhat centralized controls, and most had some type of written conflict of interest policy. Some sites had more developed processes and controls than others.

Evidence For: Efforts to develop and administer steering network processes occupied significant time and effort of all sites, suggesting this was seen as an important area to develop in order to progress. Sites with better developed processes seemed to engender more BE, LCE, SI and FC. Conversely, several sites experienced loss of $\mathrm{BE}, \mathrm{LCE}, \mathrm{SI}, \mathrm{FC}$ as a result of conflict of interest problems caused by weak or non-existent policies, or as a result of 


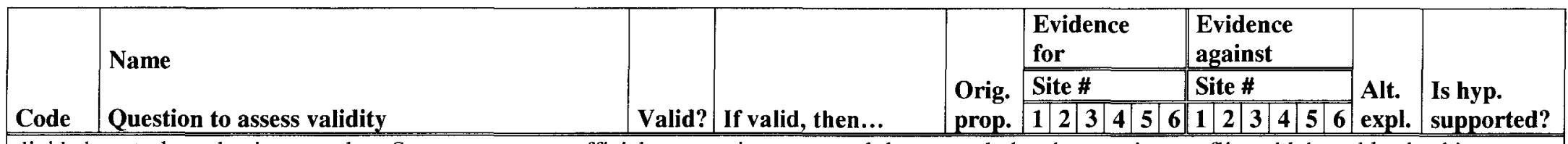

divided control-mechanisms, such as State government officials attempting to control the network thereby creating conflict with board leadership.

Evidence Against: None.

Alternative Explanation: None

WN11 Generic Networking

How much time is spent interacting with network

constituencies to identify tensions, and blend

participant interests to achieve whole-network

goals? (E.g., little to none, some, a lot.)

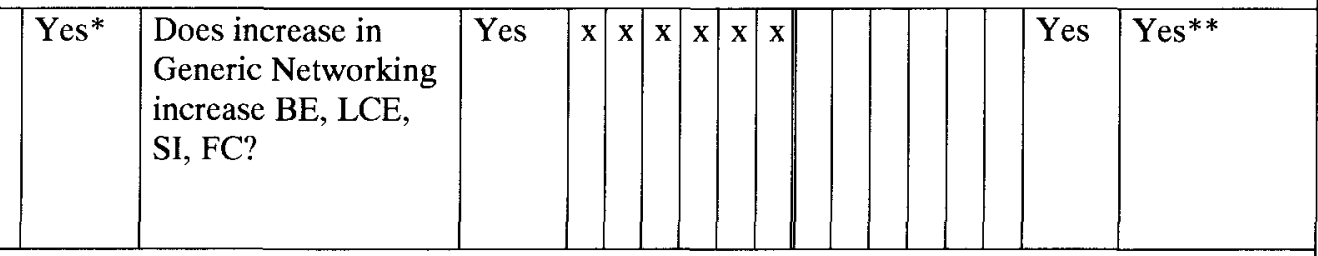

Validity: This variable seemed valid for all sites. Each site involved leaders who spent significant time and effort doing generic networking. Some sites showed more time and effort than others in this area. This could present some measurement challenges, since it is possible that a leader thinks s/he is doing this, but may not be, or vice versa.

Evidence For: Generic networking appears highly influential in developing BE, LCE, SI, FC. Tensions and conflicting interests abounded in these sites.

In some cases, leaders failed to put significant time and effort into addressing these conflicts effectively, resulting in serious challenges and problems.

Conversely, some of the greatest accomplishments for many of these sites - development and approval of consensus plans - occurred as a result of

extensive time and effort in this area.

Evidence Against: None.

Alternative Explanation: WN8, stability management, appears to be similar to this factor. Perhaps the two overlap or are the same?

WN12 Management Tenure

What is the tenure of the whole-network

management team in months? (E.g., 1-11, 12-35,

$36-59,60+)$

Yes Does increase in

Management Tenure

increase $\mathrm{BE}, \mathrm{LCE}$,

SI, FC?

Validity: This variable seemed valid for all sites. Tenure was readily measurable through site records. Different sites had leaders with different tenures, the longest being over 6 years ( 72 months).

Evidence For: Management Tenure is associated with increased BE, LCE, SI and FC in all 6 sites. Given other challenges already noted, including leadership, network stability, steering network processes, generic networking and so forth, it makes sense that increased management tenure would have a positive effect. Supporting this, several sites lost leaders to turnover, causing significant problems which adversely affected BE, LCE, SI and FC.

Evidence Against: None.

Alternative Explanation: None.

\begin{tabular}{|l|l|l|l|l|l|l|l|l|l|l|l|l|l|l|l|l|l|l|l|l|}
\hline WN13 & Staff Coherence & Yes* & $\begin{array}{l}\text { Does increase in } \\
\text { Staff Coherence }\end{array}$ & Yes & $\mathbf{x}$ & $\mathrm{x}$ & $\mathrm{x}$ & $\mathrm{x}$ & $\mathrm{x}$ & $\mathrm{x}$ & & & & & & No & Yes &
\end{tabular}




\begin{tabular}{|c|c|c|c|c|c|c|c|c|c|c|c|c|c|c|c|}
\hline \multirow[b]{3}{*}{ Code } & \multirow{3}{*}{$\begin{array}{l}\text { Name } \\
\text { Question to assess validity }\end{array}$} & \multirow[b]{3}{*}{ Valid? } & \multirow[b]{3}{*}{ If valid, then... } & \multirow{3}{*}{$\begin{array}{l}\text { Orig. } \\
\text { prop. }\end{array}$} & \multirow{2}{*}{\multicolumn{4}{|c|}{$\begin{array}{l}\text { Evidence } \\
\text { for } \\
\end{array}$}} & \multirow{2}{*}{\multicolumn{5}{|c|}{\begin{tabular}{|l|}
$\begin{array}{l}\text { Evidence } \\
\text { against }\end{array}$ \\
Site \#
\end{tabular}}} & & \multirow{3}{*}{$\begin{array}{l}\text { Is hyp. } \\
\text { supported? }\end{array}$} \\
\hline & & & & & Sit & & & & & & & & & & \\
\hline & & & & & 12 & 3 & 4 & \begin{tabular}{l|l}
5 & 6 \\
\end{tabular} & 1 & \begin{tabular}{l|l}
2 & 3 \\
\end{tabular} & 4 & & & & \\
\hline & $\begin{array}{l}\text { Is the staff for this site a highly competitive with } \\
\text { one another, or more coherent and cooperative? } \\
\text { (E.g., highly competitive, somewhat competitive, } \\
\text { in between, somewhat coherent, highly coherent.) }\end{array}$ & & $\begin{array}{l}\text { increase BE, LCE, } \\
\text { SI, FC? }\end{array}$ & & & & & & & & & & & & \\
\hline
\end{tabular}

Validity: This variable seemed valid for all sites. Staff coherence could pose some measurement difficulties when actual observation is not possible.

Confidential surveys by multiple staff could be needed to accurately measure this. Otherwise subordinate staff could say things are coherent, in order not to displease their boss. Different sites varied on this dimension (e.g., site 4 staff was highly coherent, while site 2 staff was somewhat competitive).

Evidence For: Staff coherence is associated with increased BE, LCE, SI and FC in all 6 sites. Given other challenges already noted, including leadership, network stability, steering network processes, generic networking and so forth, it makes sense that increased staff coherence would have a positive effect. Supporting this, several sites with competitive staff encountered serious problems making progress.

Evidence Against: None. However, it is plausible that in a more mature network with more professional staff, competitiveness among staff could be beneficial.

Alternative Explanation: None.

WN14 Services Capability

To what degree is the site capable of providing services desired to participants?

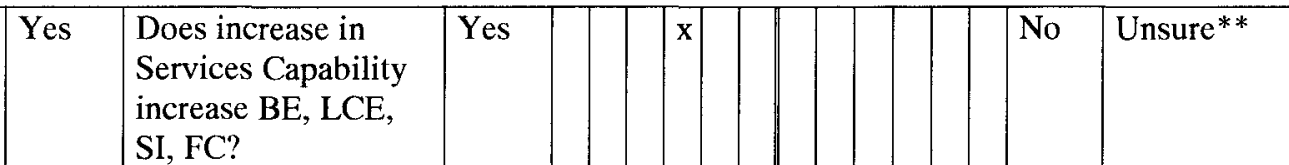

Validity: This variable was not able to be measured for 5 of the 6 sites because they were not offering services yet - only planning/developing. However, in principle it seems it would be measurable when services-oriented participation opportunities are involved.

Evidence For: Unsure.

Evidence Against: None.

Alternative Explanation: None.

\begin{tabular}{|l|l|l|l|}
\hline WN15 & Other & $\begin{array}{l}\text { Do other important } \\
\text { whole-network } \\
\text { attribute variables } \\
\text { affect BE, LCE, SI, } \\
\text { FC? If so, what? }\end{array}$ \\
\hline
\end{tabular}

While there are, undoubtedly, many more whole-network factors which may affect the predictors, one in particular is identified: the 'Resource Availability' for the network.

\begin{tabular}{|c|c|c|c|c|c|c|c|c|c|}
\hline WN15a & Resource Availability & Yes* & $\begin{array}{l}\text { Do other important } \\
\text { whole-network }\end{array}$ & & & & $\mathrm{x}$ & No & Yes \\
\hline
\end{tabular}




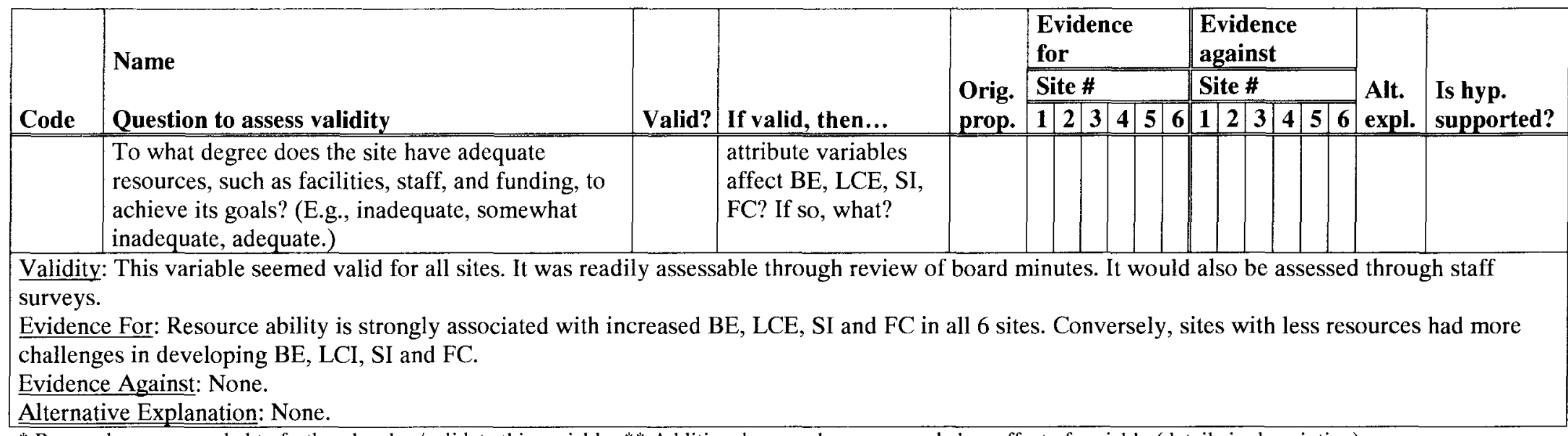

* Research recommended to further develop/validate this variable; ** Additional research recommended on effect of variable (details in description)

BE, Benefit Expectancy; LCE, Low Cost Expectancy; SI, Social Influence; FC, Facilitating Conditions. 
Table 33: Set 9: Network IT Attributes

\begin{tabular}{|c|c|c|c|c|c|c|c|c|c|c|c|c|c|c|c|c|}
\hline \multirow[t]{3}{*}{ Code } & \multirow{3}{*}{$\begin{array}{l}\text { Name } \\
\text { Question to assess validity }\end{array}$} & \multirow[t]{3}{*}{ Valid? } & \multirow[t]{3}{*}{ If valid, then... } & \multirow[t]{3}{*}{$\begin{array}{l}\text { Orig. } \\
\text { Prop. }\end{array}$} & \multicolumn{5}{|c|}{$\begin{array}{l}\text { Evidence } \\
\text { For } \\
\end{array}$} & \multicolumn{5}{|c|}{\begin{tabular}{|l} 
Evidence \\
against
\end{tabular}} & \multirow[t]{3}{*}{$\begin{array}{l}\text { Alt. } \\
\text { Exp. }\end{array}$} & \multirow[t]{3}{*}{$\begin{array}{l}\text { Is prop. } \\
\text { supported? }\end{array}$} \\
\hline & & & & & \multicolumn{5}{|c|}{ Site \# } & \multicolumn{5}{|c|}{ Site \# } & & \\
\hline & & & & & & 2 & 3 & 5 & $\overline{6}$ & $\mathbf{1}$ & \begin{tabular}{l|l}
2 & 3 \\
\end{tabular} & 3 & 45 & 6 & & \\
\hline \multicolumn{17}{|c|}{ 9. Network IT (NIT) Attributes } \\
\hline NIT1 & $\begin{array}{l}\text { Environmental Linking Network IT } \\
\text { To what degree was network IT used to connect } \\
\text { site leaders with information about financial, } \\
\text { regulatory, political and other changes occurring in } \\
\text { the environment? For example, were e-newsletters } \\
\text { or web-site subscriptions used? (E.g., little or no } \\
\text { use, some use, extensive use). }\end{array}$ & Yes* & \begin{tabular}{|l|} 
Does increased \\
Environmental Linking \\
Network IT improve \\
BE, SI?
\end{tabular} & Yes & $\mathbf{x}$ & $\mathrm{x}$ & $\mathrm{x}$ & $x$ & $\mathrm{x}$ & $x$ & $x$ & $\mathbf{x}$ & & & No & Yes** \\
\hline
\end{tabular}

Validity: This variable seemed valid for all sites. It was readily assessable through questions to site leaders regarding how they gather information about changes in the environment. Some sites had different, or better, environmental linking IT tools than others.

Evidence For: Environmental linking Network IT is strongly associated with increased BE and SI in all 6 sites. Site leaders used online services such as the iHealthBeat service to maintain current intelligence about the environment. Conversely, site leaders who at times did not access or use such tools seemed to have less ability to anticipate and manage changes in the environment which might then be brought by participants

Evidence Against: In two cases, situations were found where board members accessed information that created increased complexity of decision-making. This is an argument for too much information being a bad thing. However, further analysis suggests such information, if it were to have a substantive impact on the site, would need to be identified and addressed anyway. Given this, if site leaders had more timely access to such information, through network IT, it would in fact be helpful, rather than harmful to the goal of increasing participation. Information overkill may be more likely to be a problem if the environment is fairly stable. But in this case, the environment was changing rapidly. Therefore, access to current information was important.

Alternative Explanation: None

\begin{tabular}{|c|c|c|c|c|c|c|c|c|c|c|c|c|c|}
\hline NIT2 & $\begin{array}{l}\text { Market Bridging Network IT } \\
\text { To what degree was network IT used to connect } \\
\text { site leaders with current and potential participants } \\
\text { in their markets - organizations and individuals. } \\
\text { For example, were e-newsletters or web-site } \\
\text { communications, or customer relationship } \\
\text { management software used (e.g., little or no use, } \\
\text { some use, extensive use)? }\end{array}$ & Yes* & $\begin{array}{l}\text { Does increased Market } \\
\text { Bridging Network IT } \\
\text { improve BE, SI? }\end{array}$ & Yes & $x$ & $x$ & $\mathbf{x}$ & $\mathrm{x}$ & $\mathbf{x}$ & $\mathrm{x} x$ & $\mathbf{x}$ & & Yes \\
\hline
\end{tabular}




\begin{tabular}{|c|c|c|c|c|c|c|c|c|}
\hline \multirow[t]{3}{*}{ Code } & \multirow{3}{*}{$\begin{array}{l}\text { Name } \\
\text { Question to assess validity }\end{array}$} & \multirow[t]{3}{*}{ Valid? } & \multirow[t]{3}{*}{ If valid, then... } & \multirow[t]{3}{*}{$\begin{array}{l}\text { Orig. } \\
\text { Prop. }\end{array}$} & $\begin{array}{l}\text { Evidence } \\
\text { For } \\
\end{array}$ & \begin{tabular}{|l}
$\begin{array}{l}\text { Evidence } \\
\text { against }\end{array}$ \\
\end{tabular} & \multirow[t]{3}{*}{$\begin{array}{l}\text { Alt. } \\
\text { Exp. }\end{array}$} & \multirow[t]{3}{*}{$\begin{array}{l}\text { Is prop. } \\
\text { supported? }\end{array}$} \\
\hline & & & & & Site \# & Site \# & & \\
\hline & & & & & \begin{tabular}{|l|l|l|l|l}
1 & 2 & 3 & 4 & 5 \\
\end{tabular} & \begin{tabular}{|l|l|l|l|l|l|}
1 & 2 & 3 & 4 & 5 & 6 \\
\end{tabular} & & \\
\hline
\end{tabular}

Validity: This variable seemed valid for all sites. It was readily assessable through questions to site leaders regarding how they gather information about the interests of their markets - the organizations and individuals they seek to serve. Some sites had different, or better, market bridging IT tools than others. Tools included use of email, websites, online surveys, webinars and teleconferences to communicate with market actors.

Evidence For: Market Bridging Network IT is strongly associated with increased BE, LCE, SI and FC in all 6 sites. Conversely, site leaders who at times did not access or use such tools experienced problems with alienating markets by not fully understanding their wants and needs and not communicating effectively with them.

Evidence Against: In a few cases, situations were found where information was posted on websites or sent via email which created confusion in the markets, rather than helping. However, on further reflection this seems attributable to problems with leadership decision-making, rather than the use of network IT as such.

Alternative Explanation: None.

\begin{tabular}{|l|l|l|l|l|l|l|l|l|l|l|l|l|l|l|l|}
\hline NIT3 & $\begin{array}{l}\text { Governance Network IT } \\
\begin{array}{l}\text { To what degree did this site use Governance } \\
\text { network IT to automate processes of governance? } \\
\text { (E.g., little or no use, some use, extensive use.) }\end{array}\end{array}$ & Yes* & $\begin{array}{l}\text { Does increased } \\
\text { Governance Network } \\
\text { IT improve SI, FC? }\end{array}$ & Yes & x & $\mathrm{x}$ & $\mathrm{x}$ & $\mathrm{x}$ & $\mathrm{x}$ & $\mathrm{x}$ & $\mathbf{x}$ & $\mathrm{x}$ & $\mathrm{x}$ & No & Yes** \\
\hline
\end{tabular}

Validity: This variable seemed valid for all sites. It was readily assessable through questions to site leaders and/or review of board minutes to identify what kinds of network IT were used to automate Governance processes. The most common network IT used was teleconferencing (to support remote attendance of meetings), public and private websites for storing and disseminating governance documents such as minutes, procedures and bylaws. Some sites had different, or better, governance network IT tools than others.

Evidence For: Governance Network IT was associated with increased SI and FC in all 6 sites. Participants and site leaders viewed used of teleconferencing meeting facilities, and online document storage and access, as useful and helpful. Conversely, lack of such tools was often viewed as a barrier and hindrance. An example which came up in multiple sites was limitations of teleconferencing technology to support virtual board and committee meetings. Problems included difficult hearing, not knowing who was on the phone or in the meeting, and concerns about confidentiality since someone could be on the phone who is not identified. A more sophisticated web-based meeting software, such as WebX, could address these concerns, by improving quality of sound, and showing who is actually in the meeting. However, many sites and/or their members did not have this kind of technology available.

Evidence Against: In two cases, situations were found where board members accessed information that created increased complexity of decision-making. This is an argument for too much information being a bad thing. However, further analysis suggests such information, if it were to have a substantive impact on the site, would need to be identified and addressed anyway. Given this, if site leaders had more timely access to such information, through network IT, it would in fact be helpful, rather than harmful to the goal of increasing participation.

Alternative Explanation: None.

\begin{tabular}{|l|l|l|l|l|l|l|l|l|l|l|l|l|l|l|l|l|}
\hline NIT4 & Functional Network IT & Yes* & Does increased & Yes & $\mathbf{x}$ & $\mathbf{x}$ & $\mathbf{x}$ & $\mathbf{x}$ & $\mathbf{x}$ & $\mathbf{x}$ & & $\mathbf{x}$ & & No & Yes** \\
\hline
\end{tabular}




\begin{tabular}{|c|c|c|c|c|c|c|c|c|c|c|c|c|c|c|}
\hline \multirow[t]{3}{*}{ Code } & \multirow{3}{*}{$\begin{array}{l}\text { Name } \\
\text { Question to assess validity }\end{array}$} & \multirow[t]{3}{*}{ Valid? } & \multirow[t]{3}{*}{ If valid, then... } & \multirow[t]{3}{*}{$\begin{array}{l}\text { Orig. } \\
\text { Prop. }\end{array}$} & \multicolumn{5}{|c|}{\begin{tabular}{|l|} 
Evidence \\
For \\
\end{tabular}} & \multicolumn{3}{|c|}{\begin{tabular}{|l} 
Evidence \\
against
\end{tabular}} & \multirow[t]{3}{*}{$\begin{array}{l}\text { Alt. } \\
\text { Exp. }\end{array}$} & \multirow[t]{3}{*}{$\begin{array}{l}\text { Is prop. } \\
\text { supported? }\end{array}$} \\
\hline & & & & & \multicolumn{5}{|c|}{ Site \# } & \multicolumn{3}{|c|}{ Site \# } & & \\
\hline & & & & & 112 & & 34 & 5 & 6 & \begin{tabular}{|l|l|}
1 & 2 \\
\end{tabular} & \begin{tabular}{|l|l|}
3 & 4 \\
\end{tabular} & \begin{tabular}{|l|l|}
5 & 6 \\
\end{tabular} & & \\
\hline & $\begin{array}{l}\text { To what degree did the site use functional Network } \\
\text { IT to automate processes of delivering services, } \\
\text { including, if applicable, delivery of health } \\
\text { information exchange IT services to organizational } \\
\text { or individual users }\end{array}$ & & $\begin{array}{l}\text { Functional Network IT } \\
\text { improve LCE, FC? }\end{array}$ & & & & & & & & & & & \\
\hline \multicolumn{15}{|c|}{$\begin{array}{l}\text { Validity: This variable seemed valid for all sites. This is because all the sites had a mission to use network IT to deliver health information exchange } \\
\text { related IT services of one type or another to participants. Two sites had functional network IT platforms and vendors selected, while others did not. } \\
\text { Evidence For: Functional network IT - actually having it selected - was associated with increased LCE and FC in the } 2 \text { sites that had it. It created a } \\
\text { 'bird-in-the-hand is worth } 2 \text { in the bush' effect. It helped made 'real' the hypothesis that was being offered to participants. It thereby reduced opportunity } \\
\text { costs. } \\
\text { Evidence Against: In one case, a site selected a functional network IT which was not compatible with some participants, causing reduction in LCE and } \\
\text { FC in these cases } \\
\text { Alternative Explanation: None. }\end{array}$} \\
\hline NIT5 & $\begin{array}{l}\text { Individual Network IT } \\
\text { To what degree did individual participants have } \\
\text { access, either as individuals or through their work, } \\
\text { to individual network IT such as cell phones, } \\
\text { computers, email service, web-browsers, printers, } \\
\text { and so on to support activities related to the whole- } \\
\text { network? (E.g., none, low, moderate, high, } \\
\text { extremely high). }\end{array}$ & Yes* & $\begin{array}{l}\text { Does increased } \\
\text { Individual Network IT } \\
\text { improve FC? }\end{array}$ & Yes & $\mathrm{x}$ & & $x$ & $\mathrm{x}$ & $\mathrm{x}$ & & & & Yes & Yes $^{* *}$ \\
\hline
\end{tabular}

Validity: This variable seemed valid for all sites. It would, potentially, require surveys of individuals to assess the level of individual network IT in place by individual.

Evidence For: Individual Network IT is associated with increased FC in all 6 sites. Individuals with ready access to computers, websites, cell-phones, PDAs, and so on were better able to participate. Individuals lacking access to such tools were sometimes unable to participate in important discussions, view information, or other activities. It appears probable that these individuals would have had lower FC. In all cases, had the service itself become operational, concerns were raised about how people on the losing side of the 'digital divide' may lack access to the services to be offered.

Evidence Against: None

Alternative Explanation: It appears that this attribute is more like an individual attribute than a site attribute. It may overlay with factors like resource munificence, and individual access to resources. At the same time, it seems important for the site to understand the level of individual network IT in 


\begin{tabular}{|c|c|c|c|c|c|c|c|c|c|c|c|c|c|c|}
\hline \multirow[t]{3}{*}{ Code } & \multirow{3}{*}{$\begin{array}{l}\text { Name } \\
\text { Question to assess validity }\end{array}$} & \multirow[t]{3}{*}{ Valid? } & \multirow[t]{3}{*}{ If valid, then... } & \multirow[t]{3}{*}{$\begin{array}{l}\text { Orig. } \\
\text { Prop. }\end{array}$} & \multirow{2}{*}{\multicolumn{4}{|c|}{$\begin{array}{l}\text { Evidence } \\
\text { For } \\
\text { Site \# }\end{array}$}} & \multicolumn{4}{|c|}{\begin{tabular}{|l}
$\begin{array}{l}\text { Evidence } \\
\text { against }\end{array}$ \\
\end{tabular}} & \multirow[t]{3}{*}{$\begin{array}{l}\text { Alt. } \\
\text { Exp. }\end{array}$} & \multirow[t]{3}{*}{$\begin{array}{l}\text { Is prop. } \\
\text { supported? }\end{array}$} \\
\hline & & & & & & & & & \multicolumn{4}{|c|}{ Site \# } & & \\
\hline & & & & & & \begin{tabular}{l|l}
2 & 3 \\
\end{tabular} & \begin{tabular}{l|l}
4 & 5 \\
\end{tabular} & \begin{tabular}{|l|l}
5 & 6 \\
\end{tabular} & \begin{tabular}{|l|l|}
1 & 2 \\
\end{tabular} & \begin{tabular}{|l|l}
3 & 4 \\
\end{tabular} & 5 & 6 & & \\
\hline \multicolumn{15}{|c|}{ place, in order to understand barriers to participation. } \\
\hline NIT8 & $\begin{array}{l}\text { Network IT Openness } \\
\text { How 'open' (e.g., how much did it use open } \\
\text { source, open standards or open APIs) was the } \\
\text { network IT used by this site? (E.g., Totally closed, } \\
\text { somewhat closed, in-between, somewhat open, } \\
\text { highly open). }\end{array}$ & Yes* & $\begin{array}{l}\text { Does increased } \\
\text { Network IT Openness } \\
\text { improve LCE? }\end{array}$ & Yes * & $\mathbf{x}$ & $\mathrm{x}$ & $\mathrm{x}$ & $x$ & $\mathrm{x}$ & & & $x$ & Yes & Unsure** \\
\hline
\end{tabular}

Validity: This variable seemed valid for all sites. Two kinds of 'openness' were identified. First, was openness of source code - was it 'open-source' or 'proprietary'. For open-source based network IT, gradations of open source existed based on different types of open source licenses used. For proprietary network IT, gradations of openness existed from network IT which was entirely proprietary (meaning all changes or connections had to be customized by the vendor) to network IT which used open standards and open APIs and had high ability to 'plug-and-play' with other systems.

Evidence For: Rationales about the value of higher levels of openness was used in four sites to justify selection of both functional network IT and governance network IT. Data about high costs of building custom interfaces between site and clients when using proprietary network IT also supported the claims regarding superiority of openness. Two sites which attempted to use proprietary governance software encountered significant challenges from participants about the lack of openness, and whether this would lock the site into a higher-cost relationship with a vendor.

Evidence Against: One site spent over $\$ 12$ million 'improving' and 'customizing' an entirely open-source solution. This ended up being abandoned because it was too expensive to keep modifying it. It was replaced by a vendor-based solution with a proprietary core but open-standards and open APIs. This supports the argument that sometimes some proprietary protection is needed by vendors to support ongoing investment by private sector markets in complex software.

Alternative Explanation: The concept of openness was questioned by many people as a false premise. The concept of cost-value - does it work? Does it do what we need it to do for a low cost? - was often used. This suggests more research could be done to consider how to measure cost-value attributes of network IT and its subsequent effects. However, when selecting a highly complex technology for an emerging, technical market, cost and value may not be knowable in advance. In this case, openness still appears be beneficial to reduce high rent costs as vendors charge for changes to proprietary code. Additional research: Recommended to advance knowledge of how to measure this attribute at the site level, and how to assess low cost functionality.

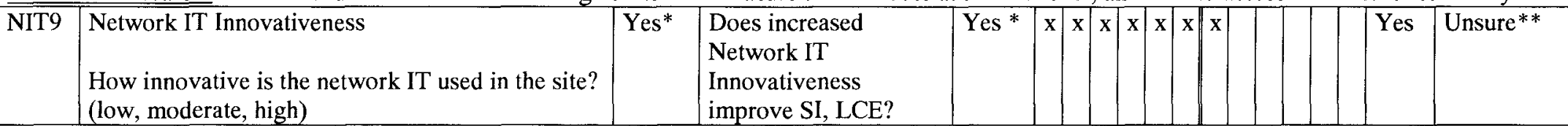

Validity: This variable seemed valid for all sites. Innovativeness was often mentioned as a rationale for selecting network IT used. In addition, some sites attempted novel uses of functional, market and governance network IT, while others used more 'tried and true' network IT. Thus, innovation with 


\begin{tabular}{|c|c|c|c|c|c|c|c|c|c|c|c|}
\hline \multirow[t]{3}{*}{ Code } & \multirow{3}{*}{$\begin{array}{l}\text { Name } \\
\text { Question to assess validity }\end{array}$} & \multirow[t]{3}{*}{ Valid? } & \multirow[t]{3}{*}{ If valid, then... } & \multirow[t]{3}{*}{$\begin{array}{l}\text { Orig. } \\
\text { Prop. }\end{array}$} & \multirow{2}{*}{\multicolumn{3}{|c|}{\begin{tabular}{|l|}
$\begin{array}{l}\text { Evidence } \\
\text { For }\end{array}$ \\
Site \# \\
\end{tabular}}} & \multirow{2}{*}{\multicolumn{2}{|c|}{\begin{tabular}{|l|}
$\begin{array}{l}\text { Evidence } \\
\text { against }\end{array}$ \\
Site \# \\
\end{tabular}}} & \multirow[t]{3}{*}{$\begin{array}{l}\text { Alt. } \\
\text { Exp. }\end{array}$} & \multirow[t]{3}{*}{$\begin{array}{l}\text { Is prop. } \\
\text { supported? }\end{array}$} \\
\hline & & & & & & & & & & & \\
\hline & & & & & \begin{tabular}{|l|l|}
1 & 2 \\
\end{tabular} & 34 & \begin{tabular}{|l|l|}
45 \\
\end{tabular} & 1 & \begin{tabular}{|l|l|l|l|l|l|}
1 & 2 & 3 & 4 & 5 & 6 \\
\end{tabular} & & \\
\hline \multicolumn{12}{|c|}{$\begin{array}{l}\text { network IT was possible to assess. } \\
\text { Evidence For: These sites all had to innovate in many ways over time to succeed. Thus, innovation did appear to positively affect SI, LCE. } \\
\text { Evidence Against: In one case, governance network IT was used that was 'too innovative' leading to confusion, reduced SI and increased LCE for a time, } \\
\text { until it was modified. Thereafter, it is uncertain whether the modified network IT was viewed as an innovative asset. } \\
\text { Alternative Explanation: The concept of network IT innovation could also be a false premise. Again, the concept of cost/value - does it work? Does it do } \\
\text { what we need it to do for a low cost? - could replace this concept. } \\
\text { Additional research: Recommended to advance knowledge of how to measure this attribute at the site level, and how to assess low cost functionality. }\end{array}$} \\
\hline NIT11 & $\begin{array}{l}\text { Network IT Environmental Stability } \\
\text { With respect to the network IT of interest to the } \\
\text { site, how stable was the network IT environment? } \\
\text { (E.g., highly unstable, unstable, unsure, stable, } \\
\text { highly stable.) }\end{array}$ & Yes* & $\begin{array}{l}\text { Does increased } \\
\text { Network IT } \\
\text { Environmental } \\
\text { Stability improve SI, } \\
\text { FC? }\end{array}$ & Yes & & & & & & \begin{tabular}{|l|} 
No \\
\end{tabular} & Yes \\
\hline
\end{tabular}

Validity: This variable seemed valid for all sites. Stability of network IT environment for various products was readily understandable. For example, the environment for health information exchange related technology for all sites was volatile and rapidly changing; while the environment for email services was stable. Since the environment was primarily influenced by national or international firms, most sites had fairly similar experiences with respect to this factor.

Evidence For: All sites experienced decreases in network IT environmental stability (generated by announcements of new standards by government and new technologies by large vendors) that correlated with decreases in SI (participants were concerned about risk), FC (change caused concerns about whether the site had the right FC in place). LCE was not included in this hypothesis. This is because effects on LCE were mixed: new technologies seemed to have potential to lower costs long term, even if they increased costs for new planning, or obsoleted existing technologies, in the short term. Evidence Against: None.

Alternative Explanation: None.

Additional research: Recommended to advance knowledge of how to measure this attribute in different contexts.

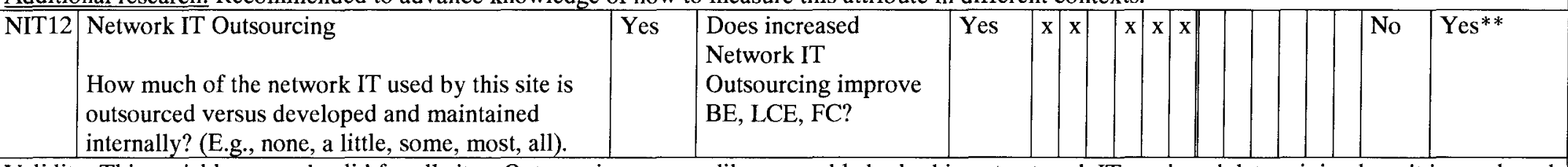

Validity: This variable seemed valid for all sites. Outsourcing was readily assessable by looking at network IT used, and determining how it is purchased and maintained. Some sites did try to make, versus buy, their network IT.

Evidence For: The sites that outsourced their functional network IT experienced increases in participant perceptions regarding BE, LCE and FC. It 


\begin{tabular}{|c|c|c|c|c|c|c|c|c|c|c|c|c|c|c|c|}
\hline \multirow[t]{3}{*}{ Code } & \multirow{3}{*}{$\begin{array}{l}\text { Name } \\
\text { Question to assess validity }\end{array}$} & \multirow[t]{3}{*}{ Valid? } & \multirow[t]{3}{*}{ If valid, then... } & \multirow[t]{3}{*}{$\begin{array}{l}\text { Orig. } \\
\text { Prop. }\end{array}$} & \multicolumn{5}{|c|}{\begin{tabular}{|l} 
Evidence \\
For \\
\end{tabular}} & \multirow{2}{*}{\multicolumn{4}{|c|}{$\begin{array}{l}\text { Evidence } \\
\text { against } \\
\end{array}$}} & \multirow[t]{3}{*}{$\begin{array}{l}\text { Alt. } \\
\text { Exp. }\end{array}$} & \multirow[t]{3}{*}{$\begin{array}{l}\text { Is prop. } \\
\text { supported? }\end{array}$} \\
\hline & & & & & \multicolumn{5}{|c|}{ Site \# } & & & & & & \\
\hline & & & & & 1 & \begin{tabular}{|l|l|}
$\mathbf{2}$ & $\mathbf{3}$ \\
\end{tabular} & \begin{tabular}{|l|l|}
3 & 4 \\
\end{tabular} & 5 & 6 & \begin{tabular}{|l|l|}
1 & 2 \\
\end{tabular} & \begin{tabular}{l|l}
3 & 4 \\
\end{tabular} & 5 & 6 & & \\
\hline
\end{tabular}

seemed than having functional network IT 'in hand' was worth 'two in the bush': participants could kick the tires, see the software work, and get a realistic sense that it would in fact work. One site which did not outsource failed in maintaining the technology, and had to abandon it. Vendors serving multiple sites in national markets were also perceived as having increased ability to invest in, innovate and improve the technology.

Evidence Against:

Alternative Explanation:

Additional research: Recommended to advance knowledge of how to measure this attribute in different contexts.

NIT13 Network IT Ownership Symmetry

How asymmetrical is the ownership and/or control

of network IT used by the site? (E.g., one

participant controls it all, in between, all

participants own/control it jointly/equally.)

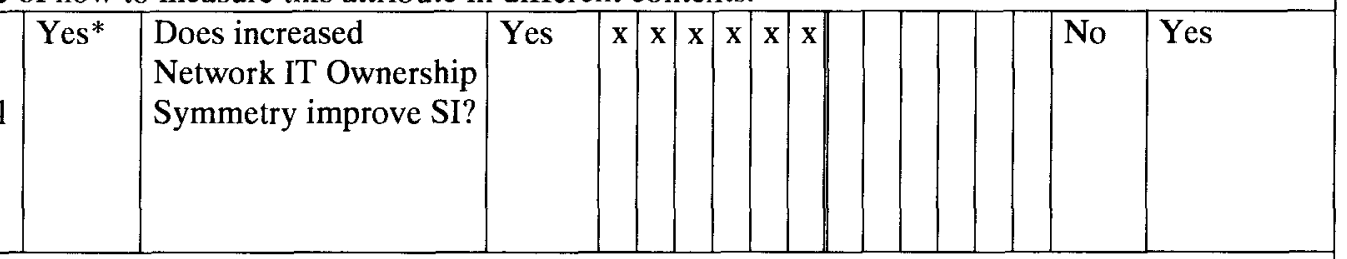

Validity: This variable seemed valid for all sites. For some sites, some technologies were owned and controlled by just one of several participants on the board. Other sites had policies to ensure that all network IT was contracted directly with the site, and that no participants had asymmetrical control.

Evidence For: Network IT Ownership Symmetry was associated with increased SI (reduced conflict and increased trust among participants). Conversely, several asymmetrical ownership scenarios (including 2 where one party owned the governance network IT, and 1 where one party controlled functional network IT) increased conflict and decreased trust among participants.

Evidence Against: None.

Alternative Explanation: None.

Additional research: Recommended to advance knowledge of how to measure this attribute in different contexts. \begin{tabular}{l|l}
\hline NIT14 & Network IT Abundance
\end{tabular}

How much network IT is in place and being used by current and potential participants in this site's marketplace? (E.g., hardly any, a little, some, a lot, a great deal.)

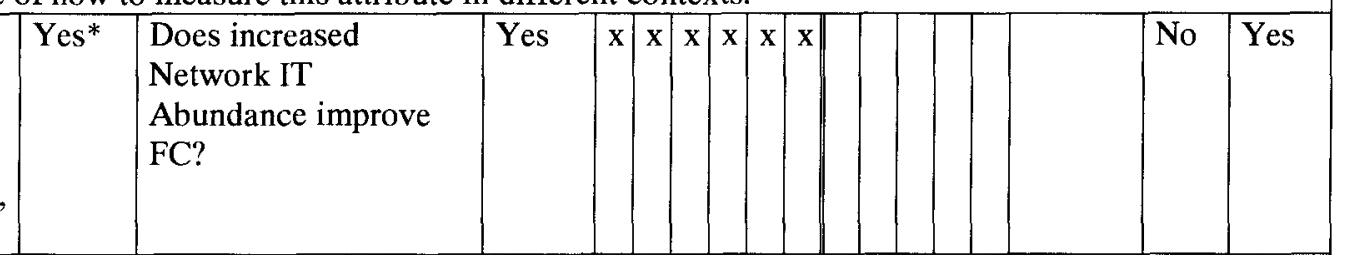

Validity: This variable seemed valid for all sites. To illustrate, one site's addressable market was a metropolitan area. Physicians were one segment of potential participants in the market. Physicians in this market, on average, appeared to have "a little" network IT in place and in use. About $15 \%$ had electronic medical records, and many did not fully use these. A lot had network IT in place to handle billing and collections. However, hardly any used email or the web to communicate with patients. As this example illustrates, the concept of Network IT Abundance is a broad-brush. To get an accurate picture of network IT abundance in a given context may require listing a number of specific types of network IT which are of interest. Thus, additional research is recommended to develop valid measures of this attribute. 


\begin{tabular}{|c|c|c|c|c|c|c|c|c|c|c|c|c|c|c|}
\hline \multirow[t]{3}{*}{ Code } & \multirow{3}{*}{$\begin{array}{l}\text { Name } \\
\text { Question to assess validity }\end{array}$} & \multirow[t]{3}{*}{ Valid? } & \multirow[t]{3}{*}{ If valid, then... } & \multirow[t]{3}{*}{$\begin{array}{l}\text { Orig. } \\
\text { Prop. }\end{array}$} & \multirow{2}{*}{\multicolumn{4}{|c|}{$\begin{array}{l}\text { Evidence } \\
\text { For } \\
\end{array}$}} & \multicolumn{4}{|c|}{\begin{tabular}{|l} 
Evidence \\
against \\
\end{tabular}} & \multirow[t]{3}{*}{$\begin{array}{l}\text { Alt. } \\
\text { Exp. }\end{array}$} & \multirow[t]{3}{*}{$\begin{array}{l}\text { Is prop. } \\
\text { supported? }\end{array}$} \\
\hline & & & & & & & & & Sit & te \# & & & & \\
\hline & & & & & \begin{tabular}{|l|l|l|}
1 & 2 & 3 \\
\end{tabular} & $3 \sqrt{4}$ & 45 & 6 & 1 & \begin{tabular}{l|l}
2 & 3 \\
\end{tabular} & 4 & \begin{tabular}{c|c|c}
5 & 6
\end{tabular} & & \\
\hline
\end{tabular}

Evidence For: Network IT Abundance was clearly correlated with increased FC. In each site, potential or current participants lacking network IT found it more difficult to participate. For example, potential participants lacking electronic medical records expressed concerns about the challenges of making a transition to the use of these technologies; participants lacking access to certain types of individual network IT had more difficulty participating in governance processes.

Evidence Against: None.

Alternative Explanation: None.

Additional research: Recommended to advance knowledge of how to measure this attribute in different contexts.

\begin{tabular}{|l|l|l|l|l|}
\hline NIT15 & Other & NA & Are there other
\end{tabular}

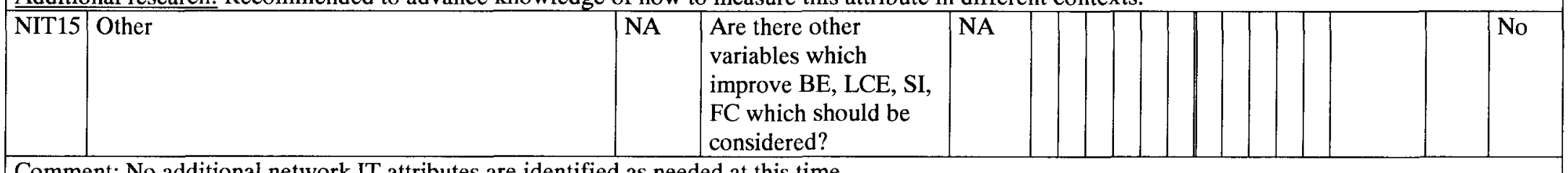

Comment: No additional network IT attributes are identified as needed at this time.

* Research recommended to further develop/validate this variable; ** Additional research recommended on effect of variable (details in description)

BE, Benefit Expectancy; LCE, Low Cost Expectancy; SI, Social Influence; FC, Facilitating Conditions. 


\section{APPENDIX 6: OLS REGRESSION DATA}

\section{SYNTAX}

/DESCRIPTIVES MEAN STDDEV CORR SIG N

/MISSING LISTWISE

/STATISTICS COEFF OUTS CI(95) R ANOVA COLLIN TOL CHANGE ZPP

/CRITERIA=PIN(.05) POUT(.10)

/NOORIGIN

/DEPENDENT IPCombined

/METHOD=ENTER BECombined SICombined LCECombined FCResources FCNetworkIT FCKnowledge FCSiteSupport FCenvironment.

$\stackrel{\sim}{\infty}$

\begin{tabular}{|c|c|c|c|}
\hline \multicolumn{4}{|c|}{ Variables Entered/Removed } \\
\hline Model & $\begin{array}{l}\text { Variables } \\
\text { Entered }\end{array}$ & $\begin{array}{l}\text { Variables } \\
\text { Removed }\end{array}$ & Method \\
\hline 1 & $\begin{array}{l}\text { FCenvironment, } \\
\text { FCNetworkIT, } \\
\text { SICombined, } \\
\text { LCECombined, } \\
\text { FCSiteSupport, } \\
\text { FCKnowledge, } \\
\text { FCResources, } \\
\text { BECombined }\end{array}$ & & Enter \\
\hline
\end{tabular}

a. All requested variables entered. 


\begin{tabular}{|c|c|c|c|c|c|c|c|c|c|}
\hline \multirow[b]{2}{*}{ Model } & \multirow[b]{2}{*}{$\mathbf{R}$} & \multirow[b]{2}{*}{ R Square } & \multirow[b]{2}{*}{$\begin{array}{l}\text { Adjusted R } \\
\text { Square }\end{array}$} & \multirow[b]{2}{*}{$\begin{array}{l}\text { Std. Error of } \\
\text { the Estimate }\end{array}$} & \multicolumn{5}{|c|}{ Change Statistics } \\
\hline & & & & & $\begin{array}{l}\text { R Square } \\
\text { Change }\end{array}$ & F Change & $\mathrm{df} 1$ & $\mathrm{df} 2$ & $\begin{array}{c}\text { Sig. F } \\
\text { Change }\end{array}$ \\
\hline 1 & $.781^{\mathrm{a}}$ & .611 & .575 & .68415 & .611 & 17.247 & 8 & 88 & .000 \\
\hline
\end{tabular}

a. Predictors: (Constant), FCenvironment, FCNetworkIT, SICombined, LCECombined, FCSiteSupport, FCKnowledge, FCResources, BECombined

\section{ANOVA $^{b}$}

\begin{tabular}{|c|c|c|c|c|c|c|}
\hline Model & & Sum of Squares & $\mathrm{df}$ & Mean Square & $\mathrm{F}$ & Sig. \\
\hline \multirow[t]{3}{*}{1} & Regression & 64.583 & 8 & 8.073 & 17.247 & $.000^{\mathrm{a}}$ \\
\hline & Residual & 41.190 & 88 & .468 & & \\
\hline & Total & 105.773 & 96 & & & \\
\hline
\end{tabular}

a. Predictors: (Constant), FCenvironment, FCNetworkIT, SICombined, LCECombined,

FCSiteSupport, FCKnowledge, FCResources, BECombined

b. Dependent Variable: IPCombined

\section{Coefficients $^{\mathrm{a}}$}




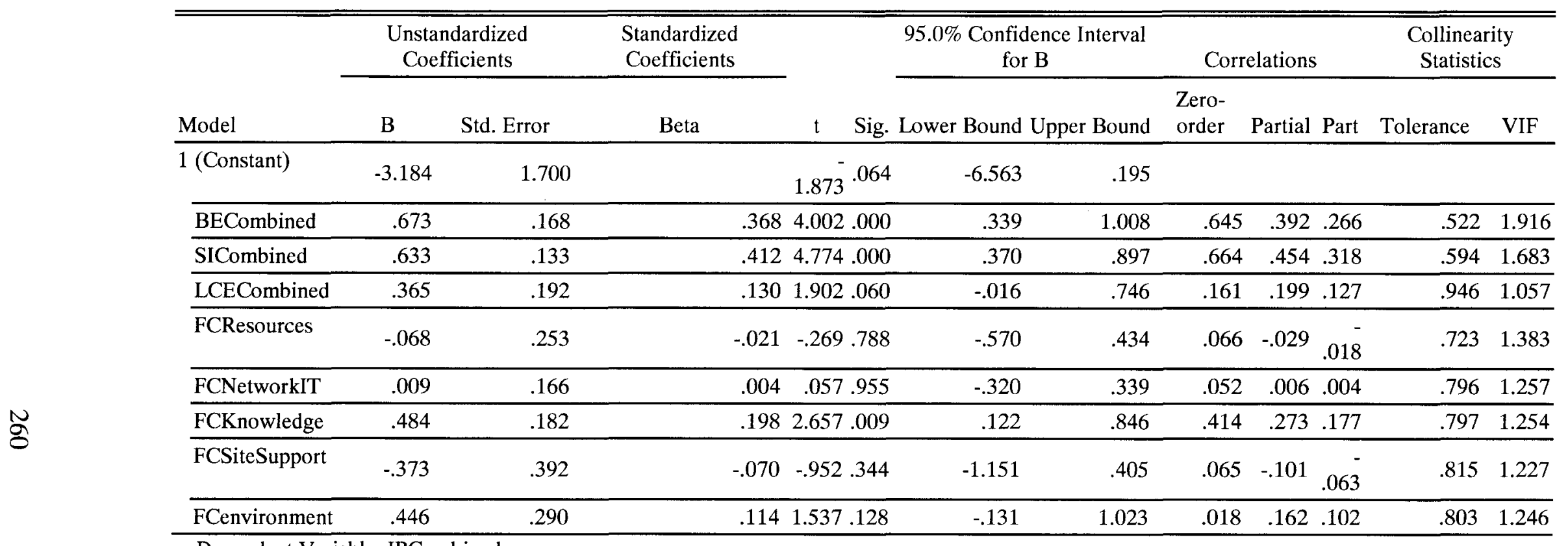

a. Dependent Variable: IPCombined 


\section{CURRICULUM VITAE}

NAME: John-Mark Judah Thornewill

ADDRESS: 2208 Bell Tavern Court

Louisville, KY 40207

D.O.B. Bradford, England - November 3, 1961

\section{EDUCATION AND TRAINING:}

Liberal Arts Studies

University of Louisville, Louisville, KY

1986-1988

B.A., Literature

Maharishi International University, Fairfield, IA

$1979-1988$

Ph.D., Interdisciplinary Studies

University of Louisville

2004- 2011

POSITIONS, ROLES AND HONORS:

Positions

2010 - Chief Executive Officer, GroupPlus LLC

2003 - 2009 Research Manager, University of Louisville, School of Public Health and Information Sciences, Department of Health Management and Systems Sciences (DHMSS)

$2000-2006$ President, Four-Leaf Clover Corporation, a developer of knowledge exchange methods and technologies

$1995-2000$ Consultant and Chief Operating Officer, Network Direct, Inc., a callcenter services and direct-marketing consulting firm

1988 - 1995 President, Integrated Customer Services, Inc., a call-center services and direct marketing firm 
$\underline{\text { Roles }}$

2007 - 2009 Director, Collaborative Communities Research Program (DHMSS)

2006 - 2008 Acting Executive Director, the Louisville Health Information Exchange, Inc.

2007 - 2008 Chair, Communities Committee, Health Record Banking Alliance

$2005-2007$ Director, Center for Complexity and Health (DHMSS)

$2004-2006$ Executive Director, VisPlex Association, Inc. a non-profit membership based knowledge-exchange services provider

$\underline{\text { Honors }}$

May 2005 University of Louisville Faculty of Excellence Award, for "significant contribution to research and industry."

April 2006 University of Louisville Faculty of Excellence Award, for "significant contribution to research and industry."

\section{PUBLISHED INTELLECTUAL CONTRIBUTIONS:}

1. Thornewill J, Dowling A, Cox B, Esterhay R. (2011). Information Infrastructure for Consumer Health: Findings from a Large-Scale HIE Stakeholder Study. American Journal of Preventive Medicine.

2. Dowling, A. F., Thornewill, J., Cox, B., \& Esterhay, R. J. (2010). Information Infrastructure for Public Health and Health Research: Findings from a Large-Scale HIE Stakeholder Study. Paper presented at the Hawaii International Conference on Systems Sciences 2010.

3. Cox, B., Thornewill, J. J. (2008). The Consumer's View of the Electronic Health Record. Journal of Healthcare Information Management, 22(2)(43).

4. Mills, M., Esterhay, R. J., Thornewill, J. J. (2007). Using a Tetradic Network Method and a Transaction Cost Economic Analysis to Illustrate an Economic Model for an Open-Access Medical Journal. First Monday, Volume 12 - 1((Number 10)).

5. Thornewill, J. J., Esterhay, R. J. (2007). A Strategy for Funding an Integrated Nationwide Network of Community HIEs. Journal of Healthcare Information Management, 21(3), 18-24.

CONTRACTS, GRANTS AND SPONSORED RESEARCH:

\section{$\underline{\text { Contracts }}$}

Thornewill, John-Mark J (Co-Principal Investigator through GroupPlus, LLC), Esterhay, Robert J (Principal), "Developing a Near-Real-Time Syndromic Surveillance System in 
Kentucky Schools: A Feasibility Study," Sponsored by Kentucky Institute for Hometown Security, State, \$475,000.00. (September 9, 2010 - March 30, 2011).

Thornewill John-Mark J, "Arizona Health Information Exchange Governance and Collaborative Capacity Assessment", St. Luke's Health Initiatives, 2010.

Thornewill, John-Mark J (Co-Principal), Esterhay, Robert J (Principal), "Developing a Near-Real-Time Syndromic Surveillance System in Kentucky Schools: A Feasibility Study," Sponsored by Kentucky Institute for Hometown Security, State, $\$ 475,000.00$. (March 9, 2009 - September 8, 2010).

Thornewill, John-Mark J (Co-Principal), Esterhay, Robert J (Principal), "Louisville and Kentucky e-Health Research 2007," Sponsored by Kentucky Cabinet for Health and Family Services, State, $\$ 25,000.00$. (August 2007 - December 2007).

Thornewill, John-Mark J (Co-Principal), Esterhay, Robert J (Principal), Gabbard, Laura A (Supporting), LaJoie, Andrew S (Supporting), McCabe, Steven J (Supporting), Walton, Peter L (Supporting), "Developing a Bioterrorism Preparedness Assessment Dashboard for a Health Event Network," Sponsored by Kentucky Hospital Association and the Kentucky Department of Public Health, State, $\$ 150,000.00$. (June 1, 2005 - August 31, 2007).

Thornewill, John-Mark J (Co-Principal), Esterhay, Robert J (Principal), "Evaluation of Prescription Drug Monitoring Information Technology," Sponsored by Kentucky Commonwealth Office of Technology, State, \$50,000.00. (October 1, 2004 - June 30, 2005).

\section{$\underline{\text { Grants }}$}

Thornewill, John-Mark J (Co-Principal), Esterhay, Robert J (Principal), "Kentucky eHealth research, service and support funding.," Sponsored by Kentucky Cabinet for Health and Family Services, State, \$150,000.00. (August 2006 - July 2009).

Thornewill, John-Mark J (Co-Principal), Esterhay, Robert J (Principal), Walton, Peter (Co-Principal), "Advancing the Knowledge of Managing Electronic Health Information Network Organizations," Sponsored by Kentucky Science and Engineering Foundation, State, \$98,945.00. (June 1, 2004 - May 31, 2006).

\section{SPEECHES AND PRESENTATIONS:}

Sep 16, 2008 Thornewill, J. J. (Presenter \& Author), Howard L. Bost Memorial Health Policy Forum, "IT Solutions to People Care Problems: technology advances that promote a person centered health system," 
Foundation for a Healthy Kentucky, Lexington, KY.

Aug 6, 2008. Thornewill, J. J. (Presenter \& Author), Esterhay, R. J. (Author Only), Kentucky e-Health Network Board meeting, "Board Results of the Kentucky e-Health Network Strategic Planning Retreat July, 2008," Kentucky e-Health Network Board, Frankfort, KY.

Jul 22, 2008 Thornewill, J. J. (Presenter \& Author), Yasnoff, W. (Presenter \& Author), The Third Annual World Congress Leadership Summit: The Road to Interoperability, "Health Record Banking: Expanding on the Growing Demand for Immediately Accessible and Secure Data," World Congress, Boston, MA.

Jul 14, 2008 Thornewill, J. J. (Presenter \& Author), AHIMA Assembly on Education, "Charlotte Johnston Memorial Keynote Address: When Health Information Shifts from Organizations to Communities... Will the Workforce be Ready?" American Health Information Management Association, Louisville, KY.

Jun 12, 2008 Thornewill, J. J. (Presenter \& Author), The 4th Annual Government Health IT Conference \& Exhibition, "Overcoming Barriers to Health Information Exchange," 1105 Government Information Group, Washington, DC.

Mar 5, 2008 Thornewill, J. J. (Presenter \& Author), Esterhay, R. J. (Author Only), Kentucky e-Health Network Board meeting, "Results of the Greater Louisville e-Health Survey 2007, and Kentucky e-Health Survey 2007," Kentucky e-Health Network Board, Frankfort, KY.

Dec 7, 2007 Thornewill, J. J. (Presenter \& Author), Esterhay, R. J. (Author Only), Kentucky e-Health Network 2nd Annual Summit, "Results of the Greater Louisville e-Health Survey 2007," Kentucky e-Health Network Board, Louisville, KY.

Nov 5, 2007 Thornewill, J. J. (Presenter \& Author), 53rd Annual Employee Benefits Conference, "Strategies for Organizing Community E-Health Initiatives," International Foundation of Employee Benefit Plans, San Diego, CA.

Jul 22, 2007 Thornewill, J. J. (Presenter \& Author), Yasnoff, W. (Presenter \& Author), The Second Annual World Congress Leadership Summit: The Road to Interoperability, "Day Two Keynote Address: Strategies for Funding a National Health Information Network," World Congress, Boston, MA.

Feb 28, 2007 Thornewill, J. J. (Presenter \& Author), Esterhay, R. J. (Presenter \& Author), HIMSS 2007 Annual Conference and Exhibition, "Capitalizing Nationwide Health Information Infrastructure," The Healthcare Information and Management Systems Society (HIMSS), New Orleans, LA.

Nov 10, 2006 Thornewill, J. J. (Presenter \& Author), Open Health Information 
Infrastructure Forum 2006, "Opening Presentation," California Healthcare Foundation and University of Louisville, Washington, DC.

Sep 26, 2006 Thornewill, J. J. (Presenter \& Author), Esterhay, R. J. (Author Only), Public Health Information Networks 2006, "A Web-Based Knowledge Management Dashboard and Collaboration System for Aligning Public Health Partners at Local, District, State and National Levels," Centers for Disease Control, Atlanta, GA.

Aug 11, 2006 Thornewill, J. J. (Presenter \& Author), Yasnoff, W. (Presenter \& Author), World Congress Leadership Summit on RHIOs, EMRs and Patient Portals, "Case Study: Building an e-Health Trust," World Congress, Boston, MA.

May 12, 2005 Thornewill, J. J. (Presenter \& Author), Public Health Information Networks 2005, "A Web-Based Knowledge Management Dashboard supporting a "Fourth Level of Interoperability" - Interoperable Exchange of Context - for Kentucky Public Health Partners at Local, Regional and State levels," Centers for Disease Control, Atlanta, GA.

INVENTIONS AND APPLICATIONS:

$\underline{\text { Inventions }}$

2000 - 2005 Tetradic Network Technique (TNT), a tool for modeling knowledge exchange across organizational types; supports social network analysis and can be computerized.

Role: Inventor, with inputs from approximately 35 collaborators.

$2004-$ TNT Visual Content Management System. Software allows users to organize and view information in tetradic fractal patterns.

Role: Co-Inventor with Robert Esterhay.

Applications

2005 - 2007 VisPlex Collaboration Technology: a Web-Based "open-services" technology for collaborative communities. Includes single-sign-on, privacy protection, membership, document library, WIKI, public/private spaces, meeting management and other collaboration services. Codeveloper with Robert Esterhay.

2005 - 2007 Web-Based Knowledge Management Dashboard and Collaboration System for Aligning Public Health Partners. 